\title{
What works to improve student success
}

\author{
Citation for published version (APA):
}

Sneyers, E. (2017). What works to improve student success: the effects of academic dismissal policies, student grants and institutional mergers on student outcomes. [Doctoral Thesis, Maastricht University]. Maastricht University. https://doi.org/10.26481/dis.20171213es

\section{Document status and date:}

Published: 01/01/2017

DOI:

10.26481/dis.20171213es

Document Version:

Publisher's PDF, also known as Version of record

\section{Please check the document version of this publication:}

- A submitted manuscript is the version of the article upon submission and before peer-review. There can be important differences between the submitted version and the official published version of record.

People interested in the research are advised to contact the author for the final version of the publication, or visit the DOI to the publisher's website.

- The final author version and the galley proof are versions of the publication after peer review.

- The final published version features the final layout of the paper including the volume, issue and page numbers.

Link to publication

\footnotetext{
General rights rights.

- You may freely distribute the URL identifying the publication in the public portal. please follow below link for the End User Agreement:

www.umlib.nl/taverne-license

Take down policy

If you believe that this document breaches copyright please contact us at:

repository@maastrichtuniversity.nl

providing details and we will investigate your claim.
}

Copyright and moral rights for the publications made accessible in the public portal are retained by the authors and/or other copyright owners and it is a condition of accessing publications that users recognise and abide by the legal requirements associated with these

- Users may download and print one copy of any publication from the public portal for the purpose of private study or research.

- You may not further distribute the material or use it for any profit-making activity or commercial gain

If the publication is distributed under the terms of Article $25 \mathrm{fa}$ of the Dutch Copyright Act, indicated by the "Taverne" license above, 


\section{WHAT WORKS TO IMPROVE STUDENT SUCCESS}

The effects of academic dismissal policies, student grants and institutional mergers on student outcomes 
(c) Eline Sneyers, Amsterdam 2017

All rights reserved. No part of this publication may be reproduced, stored in a retrieval system or transmitted in any form, or by any means, electronic, mechanical, photocopying, recording, or otherwise, without the prior permission in writing, from the author.

ISBN 978-94-003-0134-4

Cover design: Raadhuis voor creatieve communicatie, Alkmaar

This book is no. XI of the TIER Research Series, a PhD thesis series published by TIER. 


\section{WHAT WORKS TO IMPROVE STUDENT SUCCESS}

The effects of academic dismissal policies, student grants and institutional mergers on student outcomes

\section{DISSERTATION}

to obtain the degree of Doctor at the Maastricht University,

on the authority of the Rector Magnificus Prof. dr. R.M. Letschert, in accordance with the decision of the Board of Deans, to be defended in public on Wednesday 13 December 2017, at 16.00 hours by

Eline Sneyers 


\section{Supervisor}

Prof. dr. H. Maasen van den Brink

Prof. dr. W. Groot

Prof dr. K. De Witte

\section{Assessment Committee}

Prof. dr. I. De Wolf (Chairman)

Prof. dr. J. Johnes (University of Huddersfield)

Prof. dr. Ir. J. Ritzen

Prof. dr. D. Santín (Universidad Complutense de Madrid)

Prof. dr. L. Soete 


\section{Acknowledgments}

Five years, 179 days, 18 hours and 20 minutes ago I took my first step in academia. This comes down to $173,213,577$ seconds. It seems like an eternity. However, it is not. Five years have never passed so fast. Unfortunately, speed and easiness are not always positively correlated. During my PhD, there have been highs as well as lows. Through the good, the bad and the ugly, I have never been alone and I had the support of many people. Without these supporters, I would have never gotten to where I am today, at least not sanely.

I’d like to give special thanks to my promotors prof. Dr. Henriëtte Maassen van den Brink and Prof. Dr. Wim Groot. They gave me the opportunity to start my PhD research and to deepen my knowledge in education economics. Wim and Henriette pushed me when needed, sometimes with gentle encouragement, sometimes with a critical view. They were the ones that have me put the dots on the i's. Due to the endless confidence they had in me and ours great working relationship, they did not only enable me to finish my $\mathrm{PhD}$ but also to attend to life.

I am very grateful to Dr. Prof. Kristof de Witte. I could not have gotten a promotor that complemented my character and my quirks more than Kristof. He’s been motivating, encouraging and enlightening. When I was in stress mode, which I was every now and then, he calmed me down and convinced me that everything was going to be okay. Kristof never stopped being a fan. For this, I cannot thank him enough. I am forever grateful. 
I would also give thanks to my colleagues at TIER. Inne, thank you for being my hall buddy, for all the coffee lovers moments and for the lack of drama. I consider you not only a colleague but also a friend. Carla L. and Astrid, thanks for the open-door-policy and the coffee breaks at the office (yes, I drink a lot of coffee). Ours talks often cleared my mind for a couple of minutes, leading to more inspiration. Dimona, even though you did not work at TIER during my final $\mathrm{PhD}$ years, I still believe you belong to this list. From the beginning there was a click between us, whether it was our love for sushi or our comparable view to life, nobody will know. You were a great support during the first two years of my PhD. I also want to thank Carla $\mathrm{H}$. She has always been available for a good talk, personal or work related. Joris, Iryna, Sofie, Melline, Paulien and Hans, I want to thank you for all the good times we had, and hopefully, will have.

Thank you to my lovely friends. Specifically, I want to thank Evelien, Dorien and Nele for all the talks, for the 'Wilderen Brouwerij' visits, for the Marvel movie nights and for the 'opkikkertjes'. The last years would not have been the same without any of you.

Family is also an important aspect of my life. Hence, they cannot be skipped in this list. I want to mention Lief, Jef, Willem, Evi, Karen and Stijn. Thank you for all the help and for the support. You are the best family-in-law a girl could wish for. I also want to thank my grandparents for everything they did for me. Opa and Bobonne, I still think back to the trips to the Panne with a smile. Opa, your sole is and will remain the best I ever tasted. Thank you for the moral support during all of this. Oma and Opa, thank you for all the lunches, for all the 'polly pockets' and most of all, for all those years of support. You have formed me to who I am today. Thank you for everything.

Mama and papa, if someone needs to be thanked, it are both of you. You have teached me to go for what I want, you have pushed me, you have supported me and you have loved me unconditionally. I look up to you both and to the way you embrace life. You are my superheroes. I could have never done it without you. Love you. 
And last, but definitely not least, I want to thank the two loves of my life. Pieter, thank you for being there for me. Your support and your faith has been vital for me. When I could not see the wood for the threes, you could. You were always ready for a talk, a hug or a glass of wine. I consider this accomplishment as much yours as it is mine! Gus, although you cannot read (yet), you also deserve special thanks. Gus, you have showed me what's really important in life. Even after a bad day, your smile lights up my word. Love you both, now and always. 


\section{Contents}

Chapter 1: General introduction .................................................................................................1

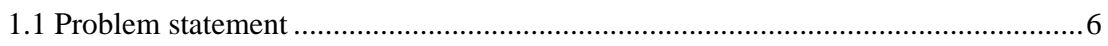

1.2 Theoretical approach ......................................................................................

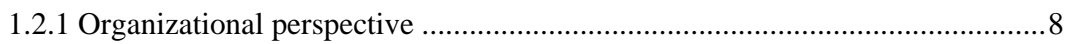

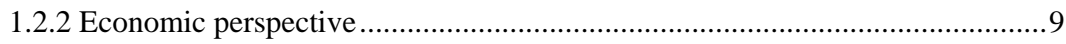

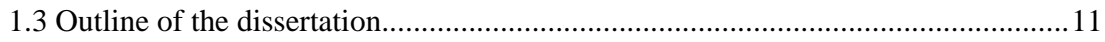

Chapter 2: Interventions in higher education and their effect on student success: A

meta-analysis .......................................................................................................................................21

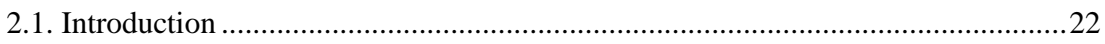

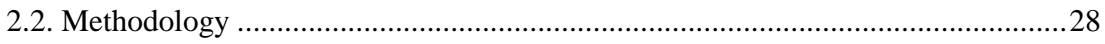

2.2.1 Criteria for inclusion of studies in the review ..............................................28

2.2.2. Search strategies for identification of relevant studies...................................30

2.2.3. Keyword strategies for bibliographic databases...........................................32

2.2.4. Criteria for handling statistical dependencies ...............................................33

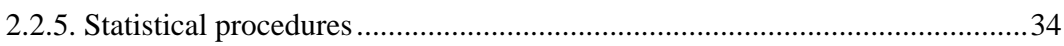

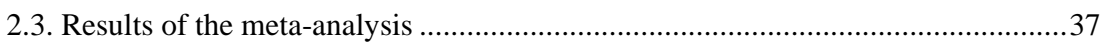

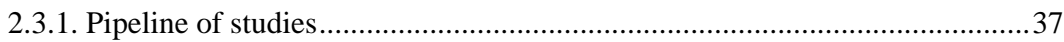


2.3.3. Meta-analysis

2.3.4. Publication bias. 55

2.4. Conclusion 57

Chapter 3: Efficiency in higher education. 65

3.1. Introduction 66

3.2. Literature Review .70

3.2.1. Graduation rates and quality ratings .70

3.2.2 Applied methodologies for measuring efficiency in higher education .74

3.3. A non-parametric technique to estimate the interaction. .76

3.4. The Dutch setting and variables 79

3.4.1. Dutch setting. 79

3.4.2 The data .80

3.4.3 Descriptive statistics of the interaction between dropout and quality adjusted graduation rates

3.5. Results of the efficiency analysis. 88

3.5.1 Relationship between the input and the output variables 88

3.5.2 Student graduation rates and program quality ratings for given dropout rates 89

3.6. Self-selection of students and a robustness test .94

3.7. Conclusions, policy implications and further research 97

Chapter 4: Academic dismissal policy in Dutch higher education 101 
4.1. Introduction 102

4.2. Literature Review of student indicators 105

4.2.1 Student performance indicators. 105

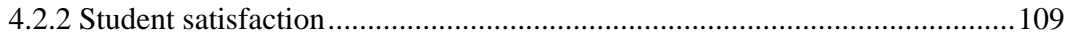

4.3. Dutch Setting

4.3.1 The Dutch higher education system

4.3.2 Academic dismissal policy

4.4 Data and descriptive statistics

4.4.1 Data

4.4.2 Descriptive statistics .....

4.5. Identification strategy and assumptions.

4.5.1 Identification strategy 125

4.5.2 Assumptions behind the identification strategy 128

4.6. Results

4.6.1 Trend analysis

4.6.2 Difference-in-Differences type of estimator

4.7. Robustness tests.

4.7.1 Propensity score matching 143

4.7.2 Different subsamples 145

4.8. Conclusions, further research and policy implications 146

Chapter 5: Need-based grants in Italian tertiary education .155 
5.1. Introduction

5.2. Literature Review

5.3. Setting: student subsidies in the Italian higher education system

5.3.1 The need-based grant.

5.3.2 Underlying mechanisms for need-based grants to be effective

5.4. Methodology

5.5. Data

5.6. Results

5.6.1 The effect of the scholarship.

5.6.2 The heterogeneous impact of the scholarship

5.7. Robustness tests.

5.8. Discussion and concluding remarks 190

Chapter 6: Mergers of higher vocational institutions and their influence on student success: the case of the Netherlands.

6.1. Introduction

6.2. Literature on mergers in higher education

6.2.1 Drivers for mergers in higher education

6.2.2 Possible effects of mergers on student success

6.3. The setting in the Netherlands 201

6.3.1 Higher education in the Netherlands 201

6.3.2 Mergers in higher vocational education. 201 
6.5.1 Spatial analysis

6.5.2 Differentiation ................................................................................208

6.5.3 Difference-in-Differences estimator ..................................................210

6.6. Results .

6.6.2 Results of the spatial lag analysis

6.6.3. Results of the diversification analysis

6.6.4. Results of DiD analyses ..............................................................216

6.7. Conclusions, further research and policy implications ..................................219

Chapter 7: Conclusions and Discussion.

7.1. Introduction 224

7.2 General conclusions 225

7.3 Valorization of the research findings

7.4 Study limitations.

7.5 Further research

References

Appendix A

Appendix B 
Contents

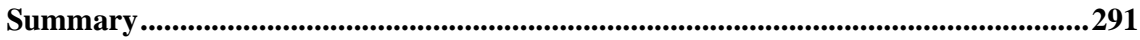

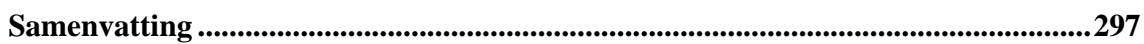

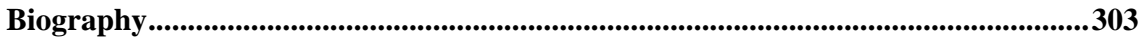




\section{List of Tables}

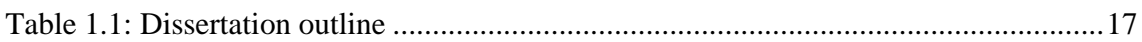

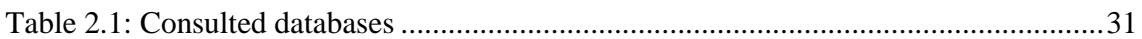

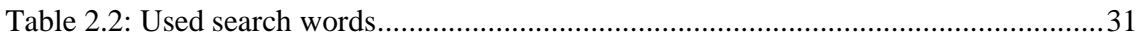

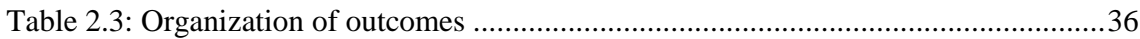

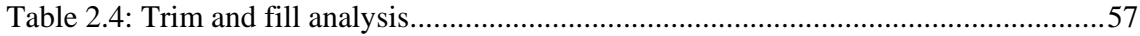

Table 2.5: Summary of average effect sizes for overall intervention effects ....................58

Table 3.1: Overview of the definition of the variables ....................................................83

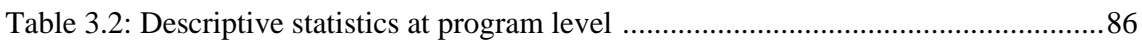

Table 3.3: Correlation of the input variable (dropout) on the output variables (graduation rates and quality ratings).

Table 3.4: Efficiency scores which exclude (unconditional) and include (conditional) the program and institutional characteristics

Table 3.5: Influence and significance of program and institutional characteristics that influence the relationship between dropout, graduation rates and quality ratings

Table 3.6: Efficiency scores which exclude (unconditional) and include (conditional) the program and institutional characteristics .95 
List of Tables

Table 3.7: Influence and significance of program and institutional characteristics that influence the relationship between dropout, graduation rates and quality ratings .96

Table 4.1: Descriptive statistics of student characteristics and equality of means between control and treatment group 121

Table 4.2: Descriptive statistics of the outcome variables, and equality of means between control and treatment group 124

Table 4.3: Schematic presentation of the identification strategy 127

Table 4.4: Institution fixed effect model with the variable "AD policy” as outcome variable

Table 4.5: Regression outcomes of Equation (4.3)

Table 4.6: Regression outcomes for the DiD type of estimation with covariates for the outcome variables

Table 4.7: Robustness check of the five outcome variables using propensity score matching

Table 4.8: Regression outcomes for Equation (4.3) using observations from the years 2003-04 and 2004-05

Table 4.9: Regression outcomes for Equation (4.3) using observations from the years 2005-06 and 2006-07

Table 4.10: Regression outcomes for Equation (4.3) using observations from higher educational institutes in urban areas

Table 5.1: Typology of the analyzed universities 171

Table 5.2: Descriptive statistics of the unmatched sample 174 
Table 5.3: Summary of the distribution of the Absolute Standard Bias (ASB) before and after matching 177

Table 5.4: Impact of receiving the need-based grant on students' performance 178

Table 5.5: Heterogeneity of the impact of receiving the scholarship: Native Italian students versus immigrants

Table 5.6: Heterogeneity of the impact of receiving the scholarship: Near-home students versus students from other regions 184

Table 5.7: Heterogeneity of the impact of receiving the scholarship: Different departments

Table 5.8: The impact of receiving scholarships while not keeping the income level into account

Table 6.1.: Descriptive statistics at campus level

Table 6.2: Results of the spatial lag model of Equation (6.1)

Table 6.3: Results of the robustness test of Equation (6.2) 215

Table 6.4: Regression outcomes of Equation (6.3) 218

Table 7.1: input data for and results of extra meta-analyses 226

Table 7.2: input data for and results of extra meta-analyses 230 


\section{List of Figures}

Figure 1.1: The number of students enrolled in higher education of EU-28 members ........3

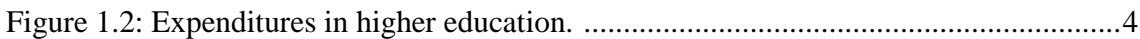

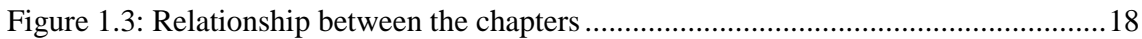

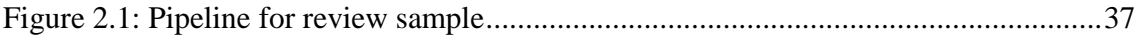

Figure 2.2: Number of included studies by year of publication..........................................39

Figure 2.3: Main effects of AD policy on retention rates. ..............................................45

Figure 2.4: Main effects of AD policy on graduation within the nominal time.................46

Figure 2.5: Main effects of AD policy on graduation within 6 years ................................47

Figure 2.6: Main effects of mentoring on retention..........................................................49

Figure 2.7: Main effects of mentoring on completion....................................................50

Figure 2.8: Main effects of need-based grants on enrollment............................................52

Figure 2.9: Main effects of need-based grants on retention.............................................53

Figure 2.10: Main effects of need-based grants on graduation..........................................54

Figure 2.11: Funnel plot of Standard error by effect size. ..................................................56

Figure 3.1: Influence of program and institutional characteristics on student graduation rates and program quality ratings observed in previous literature .................................73 
Figure 4.1: Percentage of academic programs with an AD policy per year.

Figure 4.2: The number of programs per credit threshold per year

Figure 4.3: Visual representation of the identification strategy

Figure 4.4: Trend of student dropout before (negative numbers) and after (positive numbers) the introduction of an $\mathrm{AD}$ policy.

Figure 4.5: Trend of student graduation before (negative numbers) and after (positive numbers) the introduction of an AD policy

Figure 4.6: Trend of overall student satisfaction of Bachelor's students before (negative numbers) and after (positive numbers) the introduction of an AD policy

Figure 4.7: Trend of average NSE score of Bachelor's students before (negative numbers) and after (positive numbers) the introduction of an AD policy

Figure 4.8: Trend of feasibility of the program perceived by Bachelor's students before (negative numbers) and after (positive numbers) the introduction of an AD policy........134

Figure 5.1: Entry rates into tertiary-type A and B education (2000, 2012). 157

Figure 6.1: Heat map of the location of the different Dutch higher vocational institutions at the start of the academic year 2002-03. .205 
Chapter 1

General introduction 
This dissertation contributes to the knowledge and insight on student success. It does so by investigating the relationship between different interventions and student success indicators. Student success is a complex concept that relates to students' academic achievement and psychological experience. Student success is frequently measured by quantifiable student attainment indicators such as enrollment, credits, time to degree, and graduation (e.g. Hoffer, 2010; Kot, 2014). Students’ impressions of institutional quality, their willingness to recommend the institution to upcoming students, and their overall satisfaction with the institution are all precursors of the psychological dimension of student success (e.g. Strauss \& Volkwein, 2002). Other measurable indicators of success in higher education are employment and income. Moreover, student success enhances the total experience in higher education. It focuses not only on academic outcomes (i.e. graduation) but also on the socioemotional and labor aspects of student life (Kuh, Kinzie, Buckley, Bridges and Hayek, 2007).

The general trend for study success is one of improvement. In OECD countries, on average, graduation rates have increased from 28\% to 38\% between 2000 and 2012 (OECD, 2014). This indicator represents the percentage of young adults (30-35 years) who are expected to complete higher education over their lifetime. Different influential student experience and engagement surveys observe a positive trend in student satisfaction. The National Student Survey in the UK (NSS) finds that in 2013 85.4\% of the students were satisfied with the quality of their course compared with 80.2\% in 2005 (HEFCE, n.d.). This is in line with the findings of the National Student Survey in the Netherlands (NSE, 2016) which shows that the satisfaction of higher education students increased slightly between 2010 and 2016. During the academic year 2015-16, Norwegian students were the most satisfied with their education. Italy and the Netherlands were in the $17^{\text {th }}$ and the $18^{\text {th }}$ place, respectively (Studyportals, 2016). 
Despite this positive trend in student satisfaction, we observe that $31 \%$ of the students who enter tertiary education fail to graduate (OECD, 2013). Student success is of importance for many stakeholders and should be promoted as much as possible. Students are the first group who benefit from entering and graduating from higher education. A tertiary diploma leads to, for example, a higher wage, more and better job opportunities and, a healthier lifestyle (Baum, Ma \& Payea, 2013). Youngsters also realize that a higher education degree increases job mobility and leads to a wage premium for any given job (Autor \& Dorn, 2013; Autor \& Handel, 2013). Higher education protects workers against the consequences of job polarization (Goos, Salomons \& Vandeweyer, 2013). Job polarization implies a shift from middle-skilled (i.e. manufacturing and routine office jobs) towards high-skilled (i.e. professional and managerial) and low-skilled (i.e. personal services) jobs (Goos \& Manning, 2007). Furthermore, higher education has a positive influence on different social outcomes (i.e. identity development, personal confidence and, social justice; Astin, 1993; Chickering \& Reisser, 1993).

\section{Students in tertairy education of EU-28 members (in} 1000)

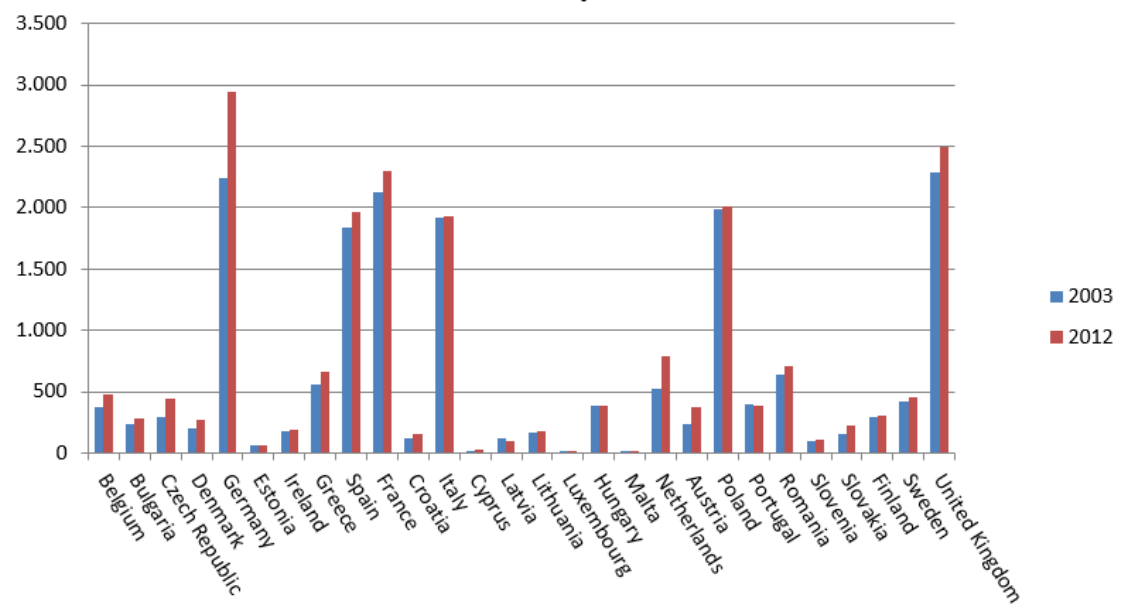

Figure 1.1: The number of students enrolled in higher education in the EU-28 Member. Note: On the horizontal axes the blue bars represent the average number of students enrolled during 2003 of in each country and the red bars represent the average number of students enrolled in 2012 in each country (Eurostat, 2016a). 
Given the increased awareness of the importance of higher education, we observe a steep increase in higher education enrollments. Figure 1 indicates that between 2003 and 2012 the number of students enrolled in higher education increased from 17.90 million students to 24.25 million students (Eurostat, 2016a, see Figure 1.1). Because of the massification of higher education, traditional underserved populations have started to enter higher education. These students tend to be less well-prepared for higher education, and support programs are needed to guide them during their studies. It is necessary for universities and higher vocational institutions to provide new services to address the needs of a more diverse student population. Not surprisingly, public expenditure on higher education in the EU-28 Countries have risen by 41.7\% from €113,125.2 million in 2002 to €160,329.2 million in 2011 (Eurostat, 2016b; see Figure 1.2, left vertical axis). However, this increase is not in line with the rise in the number of students, as public expenditure per student have risen at a slower pace (see Figure 1.2, right axes). Expenditures on tertiary institutions as a percentage of GDP have also remained fairly constant for all EU-28

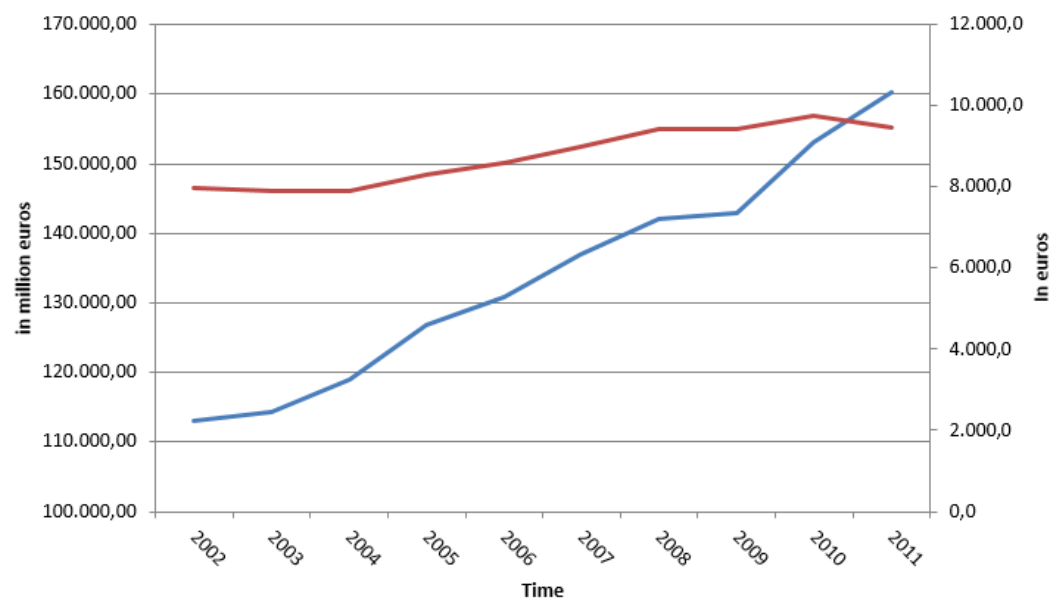

_ Total public expenditures at tertairy education (see left axis) _ _ Total expenditures per student (see right axis)

Figure 1.2: Expenditure in higher education. Note: The yearly total public expenditure for higher education of the EU-28 members is represented by the blue line (right axis). The total expenditure per student of EU-members are represented by the red axis (left axis). Source: Eurostat, 2016b, 2016c. 
countries between 2000 and 2011 (OECD, 2014). Due to the increase in student enrollment and the stabilization of public expenditures per student, higher education institutions are experiencing budget pressures. This has led to cost sharing arrangements, whereby higher education institutions shift some of the cost burden from the taxpayers, or governments, to parents and/or students (Johnstone, 2004). In line with this trend, some institutions have raised their tuition fees. Hence, students benefit if they graduate within the nominal study time since this saves them money

Given the increased spending, governments want to ensure that institutions make optimal use of public resources. Parents and students have also been challenging the presumed quality of higher education since the introduction of cost-sharing and the increase in tuition fees (Johnstone, 2004). They want to get value for money. Because of the need for the documentation of the efficiency and effectiveness of higher education institutions, national performance and excellence targets have been set. Some governments even opted for performance-based funding (PBF) models which combine the need for accountability and the limit on public spending (e.g. the Netherlands, Denmark, Portugal and Norway) (Hicks, 2012). The systems of these countries are based on formula funding for teaching and/or research (based on performance indicators such as the number of students enrolled, number of graduates, patents or number of publications), enabling a degree of transparency with regard to allocations from the state to the higher education institutions (Frølich, Schmidt \& Rosa, 2010).

Governments and tax payers benefit from student success because higher education strengthens a country's competitive position. In a world dominated by knowledge-intensive technology, human capital needs to be developed. Higher education produces a highly educated and skilled workforce, and is associated with: the accumulation of productive 
skills and capabilities; the generation of new knowledge through innovation; and the quicker adoption of existing cutting-edge technologies (Holmes, 2013; Özsoy, 2008).

\subsection{Problem statement}

Improving student success is on the agenda of all EU-28 Member States. In particular, student success is part of the European 2020 strategy which aims to move beyond the crisis while creating conditions for a more competitive economy with higher employment (European Commission, 2015). The Europe 2020 strategy wants to deliver smart, inclusive, and sustainable growth by focusing on interrelated targets concerning employment, R\&D, sustainable energy, education and poverty and social exclusion. Student success is an important aspect in these international agreements, since EU members have agreed to reach a tertiary education attainment of $40 \%$ of the $30-34$ year-olds by 2020 . This indicator represents the percentage of an age group (in this context the 30-34 year-olds) who complete higher education (European Commission, 2015). From 2008 to 2015, the proportion of persons aged 30 to 34 with a tertiary degree steadily increased from $31.2 \%$ to 38.7\% (Eurostat, 2016d). Therefore, the EU-28 Member States seem on track to meet their target.

The European Commission has proposed three broad types of measures to increase attainment levels: (I) remove financial barriers to broaden participation; (II) improve guidance and counseling and help students choose an appropriate course; and (III) develop skills profiles relevant to the world of work (European Commission, 2015). However, the above initiatives are not very specific, and it remains unclear how the EU Member States can reach the above goals in practice. Also, there is little evidence to show that the proposed initiatives influence the social dimension of student success (e.g. student satisfaction). Additionally, as Tinto (2006, p. 5) states: “ most institutions have not yet been able to 
translate what we know about student retention into forms of action that have led to substantial gains in student persistence and graduation” .

In this dissertation, we contribute to the existing literature by investigating the impact of different interventions on student success using: (I) a systematic review; and (II) evidence-based research. Furthermore, we focus on three of the proposed initiatives by the European Commission: student grants; student-faculty mentoring; and an academic dismissal policy (or "bindend studieadvies" in Dutch) which is a student selection mechanism after the gate. The use of need-based grants is investigated in Italy while the implementation of an AD policy is explored in the Netherlands (see further).

\subsection{Theoretical approach}

Previous research has focused on study success by investigating different determinants. Kot (2014), for example, used the grade point average (GPA) and first-tosecond year retention as a proxy of student success. Hoffer (2010) opted for GPA, course completion, and status of the students in the second year as proxies for academic success. Williamson (2002) determined student success in terms of the completion of 12 credit hours of coursework at a 2.0 GPA or higher. Kuh, Cruce, Shoup, Kinzie and Gonyea (2008) used first-year GPA and first-to-second year persistence as dimensions of student success. Braxton (2006), on the other hand, states that there are eight student success domains: academic attainment; acquisition of general education; development of academic competence; development of cognitive skills and intellectual dispositions; occupational attainment; preparation for adulthood and citizenship; personal accomplishments; and personal development. Kuh et al. (2007) proposed the following determinants as proxies of student success: academic achievement; engagement in educationally purposeful activities; 
satisfaction, acquisition of desired knowledge; skills and competencies; persistence; attainment of educational objectives; and postcollege performance.

In line with Braxton (2006) and Kuh et al. (2007), we apply a broad definition whereby student success refers not only to whether a student graduates from higher education but also to whether a student is satisfied with his or her line of study. Moreover, this dissertation studies quantifiable and psychological student success indicators.

As student success is determined by the interplay of many aspects (Kuh et al., 2007), it is not surprising that there is no theoretical point of view that is sufficiently comprehensive to account for the student success puzzle (Kuh et al., 2007). Kuh et al. (2007) describe student success as the result of the interplay of five perspectives (i.e. the organizational, economic, sociological, psychological and cultural perspective), which incorporate different student success theories. Most of the studies in sociology of education focus on the inequality in education, socialization and identity formation. The psychological perspective emphasizes the importance of student characteristics to success in college. The cultural perspective focuses on the challenges of traditionally underrepresented students and the influence of these challenges on student success. In this dissertation the focus is on the organizational and economic perspectives of student success.

\subsubsection{Organizational perspective}

The organizational perspective emphasizes the institutional processes and structures that are expected to influence student success. Understanding the organizational perspective is important, given the fact that it can improve the success of all students and not just of specific student populations (Lenning \& Ebbers, 1999). There is evidence that institutions differ in their effectiveness in helping students graduate, since graduation rates differ significantly even after controlling for student characteristics (Bailey, Calcagno, Jenkins, Leinbach \& Kienzl, 2006). 
The organizational perspective consists of two components: the actions of organizational agents (i.e. faculty administrators and teachers), and structural demographics. Structural demographics consist of institutional characteristics such as institutional selectivity, institutional size and the composition of the student population. Research concerning the former component has shown that the bureaucratic functioning of an institution is related to lower undergraduate degree attainment (Astin and Scherrei, 1980). It is also shown that the relationship between students and faculty is important. When students feel appreciated and respected, they are able to take problems to faculty and resolve them. Unresolved academic difficulties may lead to withdrawal (Thomas, 2002). In this dissertation, we will not focus on the actions of the organizational agents. We will, however, study the effect of two structural demographics of the institution on student success. First, we evaluate the effect of academic dismissal policies on first-year dropout, graduation and student success (see Chapter 3). Academic dismissal policies are a form of selection after the gate, and enable institutions to remove students who do not make satisfactory progress during the first year (in the next section the possible directions of the effects are discussed). Second, we investigate the effect of institutional mergers on student success (see Chapter 5). A merger consists of the integration of two or more institutions into one entity. While the effects of mergers in higher education on faculty or economic outcomes have been investigated extensively, the effect on student outcomes has been ignored.

\subsubsection{Economic perspective}

The economic perspective is also incorporated in this dissertation. This perspective focuses on the economic aspect of student success. The effects of multiple interventions on student outcomes are investigated in this dissertation. However, it is not only the impact of an intervention that is of importance. The costs and benefits of the interventions also need to be taken into consideration. Based on the effect of the academic dismissal policies 
(Chapter 3) and need-based grants (Chapter 4) we evaluate the costs and the benefits from the standpoint of the students and the governments. In particular, we take the costs of the implementation of the intervention into account. The benefits consist of the net present earning for both individuals and society.

Earlier research has found that, for students, the benefits consist of future earnings and less tangible outcomes such as knowledge, skills, and quality of life (Goldin, Katz \& Kuziemko, 2006). For governments, the benefits are associated with the social benefits of a higher education degree. In particular, Marcotte, Bailey, Borkoski and Kienzl (2005) showed that the rates of unemployment were lower in those areas where inhabitants had earned higher numbers of college credits. Moretti (2002) suggested that society benefits because: (I) the share of educated workers raise productivity of uneducated workers; and (II) the presence of human capital spill overs. Higher education also leads to increased income tax revenue from graduates, even in times of economic downturn. Further, there are civic participation benefits and intergenerational benefits.

This dissertation also looks at the effect of need-based grants on student success (see Chapter 4). The provision of public support and subsidies fits in the economic perspective of student success. Many governments and/or institutions provide financial aid for students and their families. This financial aid is supplied in many forms such as income-based and merit-based aid, loans and tax allowances. Because of this aid, the costs of going to college or university are reduced. This may lead to more student enrollment. Because of the financial aid, students may have a positive incentive to remain in higher education. They need to work less to cover living costs, and have more time for studying (Avdic \& Gartell, 2015). These students may also be more motivated, since they feel that they have a more opportunity to study than others who do not receive such aid (Bettinger, 2004). Consequently, student success improves. However, negative incentives can also result from the intervention. Because of the decreased costs, students may be motivated to enter higher 
education even though their chances of graduating are low. Moreover, because an extra year of studying costs less, some students take extra time to finish their degree. It is also not certain that the reduced work hours are used to study.

\subsection{Outline of the dissertation}

This dissertation contributes to our knowledge and insight on student success. It does so by investigating the relationship between different student success indicators. As discussed in the problem statement, EU countries want to increase tertiary attainment. An improvement of student success indicators such as student retention and graduation can contribute to this goal. While the European Commission has proposed multiple general interventions to increase tertiary attainment, individual Member States need to take action. This dissertation focuses on interventions in two EU countries: the Netherlands and Italy. The Netherlands makes an interesting case study as it has already reached the $40 \%$ attainment target of the 2020 Strategy. However, the progress of the attainment rates is only modest (European Commission, 2016). It is interesting to study the effect of two recent policy changes in the Netherlands (i.e. academic dismissal policy and mergers) on student success, since student outcomes can positively influence the progress of the attainment rates (see above). Italy, on the other hand, has a tertiary education attainment below $40 \%$ but attainment is increasing rapidly (European Commission, 2016). In order to further stimulate the attainment rate, good educational policy interventions are needed. One of the proposed Italian initiatives is the provision of public scholarships to targeted groups based on family income. However, evidence on the long-term and heterogeneous effect on student success is lacking.

We have structured the dissertation in four parts covering a total of seven chapters (See Table 1.1). Part I consists of a meta-analysis on three interventions (i.e. need-based grants; 
academic dismissal policy; and faculty mentoring) and their effect on three traditional student success indicators. The research question of this part is:

(I) What are the effects of an academic dismissal policy, need-based grants, and student-faculty mentoring on student enrollment, dropout and student graduation?

Academic dismissal policies are a way to remove students who do not make satisfactory progress during the first year. Student-faculty mentoring is the guidance of students by faculty. This can be individual or group mentoring. Need-based grants are grants assigned to students based on their family income or socioeconomic status. We have opted for the above interventions for two reasons. First, the interventions are in line with the recommendations of the European Commission. Second, two of these interventions (i.e. the academic dismissal policy and need-based grants) are increasingly popular in the Dutch and Italian higher education context.

The meta-analysis will also contribute to the organizational and economic perspective. It will give us a first idea about the effect on student success of an academic dismissal policy, which is being implemented by higher institutional policymakers. We will also evaluate the costs and benefits of all three interventions.

Part II deals with an investigation of student success at study program level. This part starts by evaluating the interplay between three indicators of student success. The research questions of Chapter 3 are:

(II) Do study programs maximize their student graduation rates and quality ratings given the first-year student dropout rates? 

efficiency of study programs?

In this chapter, we study the efficiency of universities in the Netherlands concerning student success, and exploit the ability of institutional and study program characteristics to positively influence quality adjusted graduation rates. We use the following definition for graduation rates: the share of re-enrolled full-time Bachelor students that obtain a degree at the institution within one year after the nominal study time. It is generally assumed that low dropout rates are combined with high graduation rates and quality ratings. We observe that, while this is true for some study programs, others combine high dropout rates with high graduation rates and/or quality ratings. Other programs fail to obtain high graduation rates and/or quality ratings independently of the level of dropout. We want to show that study programs can reach high graduation rates and quality ratings given any level of first-year dropout rates. We also identify program and institutional characteristics which lead to high graduation and quality ratings for given levels of dropout. We make use of a conditional efficiency model which allows us to account for heterogeneity in performance assessment by evaluating the impact of environmental variables and to test their significance on the programs’ performance.

In the next chapter, we evaluate the effect of academic dismissal policies on student dropout, graduation, and satisfaction. The research question of chapter $\mathbf{4}$ is:

(IV) Does the introduction of an academic dismissal (AD) policy result in lower dropout levels, higher graduation rates, and lower student satisfaction?

In the Netherlands the use of academic dismissal (AD) policies is becoming increasingly popular. In the US and Canada, academic dismissal (or academic probation) is 
a long-standing practice. Consequently, most empirical research considering academic dismissal policies is of Canadian or American origin (e.g. Lindo, Sanders \& Oreopoulos, 2010). The implementation of an AD policy has two goals: (1) students need to learn at an early stage whether the program fits them; and (2) study programs are able to select and continue with the most motivated and talented students after the first year (De Koning, Loyens, Rikers, Smeets, \& van der Molen, 2014). This chapter contributes to the organizational perspective of student success by investigating the effect of an organizational intervention on various student outcomes. We also focus on the economic perspective by studying the costs and benefits of an academic dismissal policy. We investigate the above research question with a difference-in-differences approach.

Part III of this dissertation evaluates two interventions at the institutional level. In Chapter 5, we investigate the heterogeneous influence of need-based grants on student outcomes. The research question of Chapter $\mathbf{5}$ is:

(V) Is there a heterogeneous influence of grants on the number of formative credits, dropout, and graduation between and within universities?

Income-based subsidies, such as grants or scholarships, are a common practice to assure equal access to higher education. Need-based subsidies remove some of the economic barriers for poor students to enter tertiary education. We expect that grants can have an impact on the number of credits, dropout, and graduation. Furthermore, a different influence for different populations of students is anticipated. We expect, for example, that the influence of the grants are higher for immigrants compared to native students. The same holds for near-home students and students from other regions. This chapter also contributes 
to the economic perspective. In this chapter, we apply a propensity score matching technique to data of five universities in Italy.

Chapter 6 focuses on the evaluation of mergers and their influence on student outcomes. Mergers are a common practice in higher education. The research question of this chapter is:

(VI) Do mergers occur between diversified or comparable higher education institutions, does distance between these institutions play a role and what is their influence on student dropout and student graduation?

At the beginning of the $20^{\text {th }}$ century, various mergers occurred in the Dutch educational landscape. These mergers were initiated by individual institutions which wanted to strengthen their position in the higher education hierarchy, diversify their programs, remove duplicate programs and/or achieve cost efficiencies. Based on these mergers, this chapter examines the institutional and campus characteristics that increase the changes of merging. We also investigate whether spatial competition (i.e. the competition for students between higher education institutions that are located close to each other) plays a role in these mergers. We do this by taking the distance between institutions into account. Mergers also influence the organization of higher education institutions and, consequently, can affect student success. Investigating the potential effect of mergers on student outcomes is important as in 2011 the Ministry of Education, Culture and Science (OCW) introduced a law for merger control (“fusietoets”) in education. Since mergers lead to an organizational change, this chapter contributes to the organizational perspective. In order to investigate above issues, we use a spatial lag analysis and a difference-in-differences approach to exploit the higher vocational data of the Netherlands. 
Chapter 1

Finally, Chapter 7 contains the conclusions of this dissertation. An overall conclusion is presented by combining the concluding statements of each individual chapter. During this dissertation, multiple interventions are investigated that are in line with the recommendations of the European Commission. The overall conclusion summarizes these results, and relates the findings to the organizational and economic perspective of student success. We close with a section containing future research directions. Figure 1.3 shows the relationship between each chapter in this dissertation. 
Table 1.1: Dissertation outline

\begin{tabular}{|c|c|c|c|c|}
\hline & Chapter & $\begin{array}{l}\text { Research } \\
\text { questions }\end{array}$ & Method & Target groups \\
\hline & Chapter 1 & $\begin{array}{c}\text { General } \\
\text { introduction }\end{array}$ & & \\
\hline $\begin{array}{l}\text { Part I } \\
\text { Overview of } \\
\text { literature }\end{array}$ & Chapter 2 & $\begin{array}{l}\text { Effect of AD } \\
\text { policy, grants and } \\
\text { mentoring on } \\
\text { student outcomes }\end{array}$ & $\begin{array}{l}\text { Meta-analysis: random } \\
\text { effect model }\end{array}$ & $\begin{array}{l}\text { Empirical } \\
\text { studies }\end{array}$ \\
\hline Part II & Chapter 3 & $\begin{array}{l}\text { Exploring the } \\
\text { relationship of } \\
\text { student dropout, } \\
\text { graduation and } \\
\text { quality ratings }\end{array}$ & $\begin{array}{c}\text { Conditional efficiency } \\
\text { model }\end{array}$ & $\begin{array}{l}\text { Academic } \\
\text { programs of } \\
\text { Dutch } \\
\text { universities }\end{array}$ \\
\hline $\begin{array}{l}\text { Study } \\
\text { program } \\
\text { level }\end{array}$ & Chapter 4 & $\begin{array}{l}\text { What is the effect } \\
\text { of AD policies } \\
\text { on student } \\
\text { outcomes? }\end{array}$ & $\begin{array}{c}\text { Difference-in- } \\
\text { differences estimator }\end{array}$ & $\begin{array}{l}\text { Study programs } \\
\text { of universities } \\
\text { and higher } \\
\text { vocational } \\
\text { institutions in } \\
\text { the Netherlands }\end{array}$ \\
\hline \multirow{3}{*}{$\begin{array}{l}\text { Part III } \\
\text { Institutional } \\
\text { level }\end{array}$} & Chapter 5 & $\begin{array}{l}\text { What is the effect } \\
\text { of need-based } \\
\text { grants on student } \\
\text { outcomes } \\
\text { between and } \\
\text { within } \\
\text { universities? }\end{array}$ & $\begin{array}{l}\text { Propensity score } \\
\text { matching }\end{array}$ & $\begin{array}{c}\text { Italian } \\
\text { universities }\end{array}$ \\
\hline & Chapter 6 & $\begin{array}{l}\text { What type of } \\
\text { mergers occurs } \\
\text { and what is their } \\
\text { effect on student } \\
\text { outcomes? }\end{array}$ & $\begin{array}{l}\text { Spatial lag analysis and } \\
\text { Difference-in- } \\
\text { differences approach }\end{array}$ & $\begin{array}{l}\text { Dutch higher } \\
\text { vocational } \\
\text { institutions }\end{array}$ \\
\hline & Chapter 7 & $\begin{array}{c}\text { General } \\
\text { conclusion }\end{array}$ & & \\
\hline
\end{tabular}




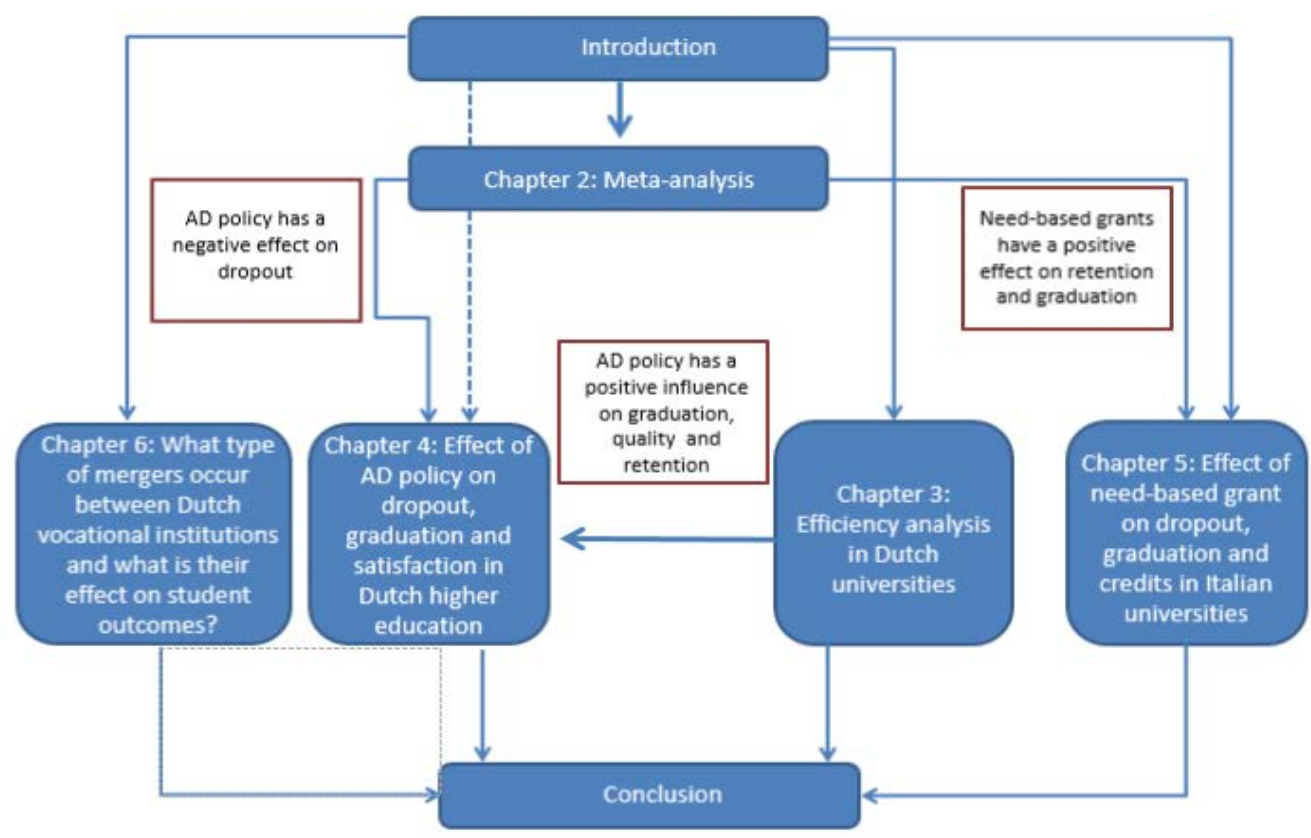

Figure 1.3: Relationship between the chapters. Note: Blue boxes represent the chapters in the dissertation. Blue lines indicate the link between the chapters. Red boxes represent the conclusion from a chapter which led to new research. For example, from chapter 2 we learned that need based grants have a positive effect on retention and graduation. This is the reason why we investigated the effect of need-based grants on various student outcomes in the Italian higher education context (Chapter 5) 


\section{Part I}

Interventions to increase student success 
Interventions in higher education and their effect on student success: a meta-analysis

\section{Chapter 2}

\section{Interventions in higher education and their effect on}

\section{student success: A meta-analysis}

This chapter is based on: Sneyers, E and De Witte, K (2017). Interventions in higher education and their effect on student success: A meta-analysis. Educational Review, Accepted February 2017. 


\subsection{Introduction}

This chapter focuses on summarizing the effect of academic-dismissal policies, needbased grants and student-faculty mentoring. We focus on these interventions for two reasons. First, they are in line with the recommendations of the European Commission (see chapter 1). Second, there are some interesting trends in the Dutch and Italian higher education context concerning these interventions. In the Netherlands, the use of an academic dismissal policy is becoming increasingly popular. Policymakers are even considering implementing a comparable system in the second year of study. In Italy, the use of grants to support students is very common. Due to the Italian university reform that established a national merit-fund, the provision of grants will further increase. This metaanalysis is a first step to get an idea of the effects we can expect of the academic-dismissal policy in the Netherlands and the need-based grants in Italy.

Increasing higher educational attainment and student success is high on the agenda of the EU-28 Member States. Universities and higher vocational institutions are trying to reach this goal by implementing various interventions. Common practices are: pre-enrollment orientation; individual career counseling services; tutoring programs; residence hall programs; programs for racial/ethnic minority students; freshman seminars; selection practices; financial aid and learning communities (Habley \& McClanahan, 2004). A significant part of the research has already focused on evaluating the effectiveness of these interventions. Taster days, for example, increase the intention of students to enroll in higher education (Austin \& Hatt, 2005). Intake interviews are controversial, given the mixed results on student success found in the literature (e.g. Morris, 1999). Scrivener and Au (2007) found that career counseling for students at risk increased first-year credits and firstto-second year retention. A study of Angris, Lang, and Oreopoulos (2009) showed that financial aid in combination with peer mentoring leads to more credits, higher grade point average (GPA), and lower levels of academic probation for female students. Student 
Interventions in higher education and their effect on student success: a meta-analysis

advising also has a significant positive impact on retention (Seidman, 1991). First-year experience programs lead to an increase in student success (Schnell, Louis \& Doetkott, 2003). The tracking of students' motivation also seems to be effective. Stratil, Schreiner and Noel (2001) have indicated that, after controlling for GPA, a motivation questionnaire can make a distinction between persisters and non-persisters. The selection of first-year students for the second year based on the number of acquired credits stimulates student success as well. Indeed, Calcagno, Crosta, Bailey and Jenkins (2007) have found a positive relation between first-year credits and the likelihood of graduation. It is clear that there are many options to stimulate student success and educational attainment.

The European Commission has formulated three broad types of measures to increase retention and student success: (I) remove financial barriers to broaden participation; (II) improve guidance and counseling, and help students to choose an appropriate course; and (III) develop skills profiles relevant to the world of work (European Commission, 2015). In this chapter, we focus on three student success interventions that are in line with these recommendations, i.e. grants, academic dismissal (AD) policies, and student mentoring. Moreover, the introduction of grants leads to the removal of financial barriers for students. Mentoring and AD policies, on the other hand, improve the match between students and study programs and/or lead to an increase in guidance and counseling. The above interventions often focus on first-year students as the first year is seen as the most critical period for the connection between students and the academic programs (Yorke \& Longden, 2004).

Academic dismissal policy ${ }^{1}$. An academic dismissal (AD) policy (or academic probation) is a form of selection 'after the gate'. It is a performance-based selection

1 We also use the term 'academic dismissal policy' and 'academic probation' interchangeably. 


\section{Chapter 2}

mechanism to remove students who are making unsatisfactory academic progress from the institution. Performance-based selection systems have a general structure. If a student's performance falls below the minimum standards of the enrolled institution, the student gets a warning which serves as a wake-up call and can lead to escalating penalties. In the US and Canada, academic probation is implemented in most higher education institutions. It is a generally accepted intervention, and is introduced to ensure that enrolled students make satisfactory progress. It is based on students' GPA. When students do not reach the GPA norm, they are placed on academic probation. If their grades do not improve by the following evaluation, they face suspension (Lindo et al., 2010). In the Netherlands, a comparable system is used in many universities and vocational institutes, i.e. the AD policy (in Dutch "Bindend Studie Advies”) (Van Heerden, 2013). The main difference between the Dutch AD policy and academic probation relates to the threshold unit. While institutions in the US and Canada base their passing norms on an average performance measure called the GPA, institutions in the Netherlands use norms based on credits. Every course that students follow is linked to a number of credits, and, when students pass the course, they earn the corresponding credits. Students who do not earn enough credits to reach the threshold, and thus make substandard progress after the first year, are dismissed.

Academic probation is in line with the paradox of institutional commitment (Tinto, 1987). It states that institutions that are willing to encourage students to leave are the intuitions where students are more likely to stay. Tinto (1987) has argued that institutions which are more committed to the education of students are prepared to tell them when it is in their best interest to leave. Those institutions are also more likely to have students more committed to them and are therefore, more likely to persist until graduation (Tinto, 1987). On the basis of the above considerations, we can assume that an $\mathrm{AD}$ policy strengthens the selective function of the first year. Students who are not likely to finish the study program can be detected and be dismissed early in the program, allowing programs to select and continue with the most talented and motivated students after the first year (De Koning et 
al., 2014). By eliminating those students who do not master the necessary knowledge and capacities to complete their studies, the learning environment should improve for the remaining students and for teachers. In line with the above statements, we can conclude that the effect of academic probation on dropout can go both ways. Indeed, students who are not likely to finish their studies are dismissed and cause more dropout. Another option is that the most committed students themselves choose which subjects to study ${ }^{2}$. As a result, the dropout rate decreases. In each case, an AD policy should lead to higher graduation rates. There are, however, also a number of disadvantages connected to the use of an $\mathrm{AD}$ policy. These can interfere with the mechanism behind academic probation. First of all, Bénabou and Tirole (2003) have argued that the impact of performance standards on students differs by the type of students. Setting performance standards can motivate some students to improve their performance, while others are discouraged from making any attempt at all. The possibility exists that some suitable students do not even enroll in the academic program of their choice due to the AD policy. Next, it is possible that teachers increase the required achievement level for the selected group of students. Based on "grading on a curve", teachers dismiss a fixed number of students, independently of their performance (Sadler, 2005). Finally, the effectiveness of an AD policy as a selection instrument is uncertain. The relationship between first-year progress and graduation is clear (e.g. Gijbels, Van der Rijt \& Van der Watering, 2004; Pascarella \& Terenzini, 1991). However, when the first year is too difficult and no help is provided (e.g. by tutoring), academic probation can lead to the dismissal of capable students.

\footnotetext{
${ }^{2}$ However, it is important to note that, from the early literature concerning the $\mathrm{AD}$ policy in the Netherlands, it has become clear that students are indifferent to studying at an institution with an AD policy, and do not see it as a threat (Felsö, van Leeuwen \& Zijl, 2000).
} 
Mentoring. Mentoring ${ }^{3}$ can be seen as a situation in which a more-experienced member of a higher education institution maintains a relationship with a less-experienced, new member and provides information and guidance. In this context, we refer to the mentor as a faculty member or a professional. The less-experienced individual, or the mentee, is the student. Undergraduate student-faculty mentoring is implemented in various forms in colleges and universities. Some mentoring programs only provide academic help, while others also focus on study skills and social needs (Bettinger \& Baker, 2014). Mentors and mentees are recruited by administrative offices and are matched based on criteria such as academic specialty or ethnicity. Often these programs are enhanced with other support services (such as financial aid) with the intention to create a learning and campus environment that stimulates retention and student success (Pascarella \& Terenzini, 2005). Not surprisingly, the costs of student-faculty mentoring nationwide may be many millions of euros.

Mentoring addresses the problem of student success in multiple dimensions. First of all, student success and retention can be adversely affected by a lack of information. Indeed, research has shown that many students have little information concerning the course requirements (Goldrick-Rab, 2010). Student mentoring can help close this gap by providing students with the necessary information. Besides academic information, students can be informed about institutional resources. It can be expected that first-generation students and students with a low socioeconomic status especially benefit from this structured advising (Deil-Amen \& Rosenbaum, 2003). Next, academic preparation is key for student retention. However, many students do not master the required academic knowledge and are not academically prepared. Mentors can help to bridge this gap. Finally, as Tinto (1975) has stated, feelings of academic or social separation often lead to dropout. Mentoring can help students to integrate into the university and college community.

\footnotetext{
${ }^{3}$ Note that mentoring, tutoring, coaching and advising are closely related. Hence, we use these terms interchangeably.
} 
Interventions in higher education and their effect on student success: a meta-analysis

Need-based grants. Need-based grants are a form of financial aid and are closely linked to family income and economic status. There are a number of measures which determine financial-aid status, such as the family's expected contribution, number of dependent family members, and student status. Besides family income, other factors are used to determine each student's financial-aid formula. Need-based aid can be provided by the government or by higher education institutions. Need-based grants are used in many countries such as the US, France, Canada, and Denmark.

Financial aid can have a large impact on the enrollment decision of low-income students. Students enroll in higher education if the perceived present discounted value of the benefits of a higher education career exceeds the present discounted value of the costs of enrollment. Reducing the cost of going to college should therefore stimulate enrollment. The influence on retention and graduation rates is less clear. Indeed, the grant can act on liquidity constraints. Due to a subsidy, the most disadvantaged students, who have to work to cover maintenance costs, can reduce the time taken by this work and make more time free for studying (Avdic \& Gartell, 2015). Next, students who receive the grant can feel that they have better opportunities than others. This can motivate them to study more effectively and with more commitment. However, even though financial aid reduces the hours spent doing part-time paid work, there is no guarantee that these hours are used for studying. Further, since it is less costly to study, the risk of retention decreases, but on the other hand, the time-to-completion increases (e.g. Bettinger, 2004). Aid can even have a negative effect on student success as students with a low probability of completion are induced to enroll due to the lower financial costs they incur for their education.

This meta-analysis investigates the effect of three interventions on student outcomes. The three discussed interventions (i.e. academic dismissal policy; grants; and studentfaculty mentoring) are all frequently used in educational institutions to promote student 


\section{Chapter 2}

performance. Their effects on student success, however, remain unclear as studies of different design quality are compared with each other. A systematic review of studies with an evidence-based design (i.e. experimental or quasi-experimental) seems imperative. To our knowledge, there are no previous meta-analyses of randomized trials and quasiexperiments on academic probation, need-based grants, and student mentoring and their effects on enrollment, retention, and graduation.

The reminder of the chapter is organized as follows. In Section 2.2, we present the methodology and selection of the literature. Section 2.3 reviews the results including the literature concerning the interventions. We conclude the chapter with policy advice.

\subsection{Methodology}

\subsubsection{Criteria for inclusion of studies in the review}

For this study, only these evaluation studies that had the following characteristics were included. First, included studies needed to assess the impact of: (I) academic dismissal (AD) policy; (II) merit-based grants; or (III) student-faculty mentoring, which included higher education outcomes relevant to the research questions. These studies also needed to use a randomized experiment or a quasi-experiment with evidence of baseline control on a main outcome. Moreover, this meta-analysis included studies that randomly assigned entities (at individual, class, or school level) to intervention or control conditions. The control or comparison condition comprises observations that received no intervention or were exposed to standard practice. We opted to include experiments because they can provide statistically unbiased estimates of the effect of an intervention and can control for both known and unknown covariates (Boruch, 1997). Because randomized trials (RCT) are not always an option (for example, because it is not ethical), we also included quasi-experimental designs that control for baseline differences between the control and intervention group. Quasi- 
Interventions in higher education and their effect on student success: a meta-analysis

experimental designs (QED) can thus provide causal evidence (e.g. Blundell and Dias, 2009; Van Klaveren \& De Wolf, 2015). We included three quasi-experimental designs: (I) regression discontinuity designs; (II) propensity score matching; and (III) difference-indifferences techniques. It is important to note that, although $\mathrm{AD}$ is a well-known intervention, little empirical evidence exists. As a result, we allowed the inclusion of cohort studies during the selection of academic probation studies. In cohort studies, an intervention and a control group is included. However, the units of analysis are not randomly assigned to one of the conditions and the equality of (un)observables is not guaranteed. We also run the analyses on a restricted sample which only includes experimental and quasiexperimental studies. Further, included studies need to discuss at least one quantifiable outcome measure of student enrollment, dropout, or graduation. We did not collect data on other intervention impacts, such as those on satisfaction, number of courses completed, or behavior. Also important is that the use of enrollment, dropout, and graduation as main measures may not match with how investigators in the original studies calculated their outcome measure. Fourth, the studies needed to be published or made available after January 2000. We also included both published and unpublished studies (e.g. dissertations, technical reports, and conference papers). Note that the inclusion of unpublished studies is controversial. Indeed, unpublished studies may have data driven or analytical problems. On the other hand, it is known that studies with positive and significant results have a higher likelihood of being published. This meta-analysis presents results that are not subject to upward bias (Van Klaveren \& De Wolf, 2015). Finally, we only selected studies that report the effect size (ES) or allowed us to extract the data needed for the calculation of the ES. Unfortunately, not many researchers report the ES of an intervention. Therefore, studies that did not report the ES of the intervention needed to provide us with the necessary data to calculate the ES. This sometimes required us to make assumptions concerning the assignment of control and intervention groups. If these assumptions had not been made, this meta-analysis would have consisted of a very limited number of studies. Still, while various 


\section{Chapter 2}

studies did meet all of our criteria, they did not provide the data necessary for the computation of an ES or required us to make too many assumptions in order to calculate the ES (e.g. Bettinger, 2004; Kane, 2003; Schudde \& Scott-Clayton, 2014).

We also excluded a number of studies based on three exclusion criteria. Studies that evaluated the effect of academic probation and focused on an increase of the AD threshold were not selected in this meta-analysis. This meta-analysis only includes studies that investigate the effect of an $\mathrm{AD}$ policy by comparing an intervention group with an $\mathrm{AD}$ policy and comparison group without the AD policy. A study by Woelders, Visser and Rijksbaron (2013) which investigated only the increase of the AD threshold was therefore excluded. Studies that focused on grants other than need-based grants (i.e. grants that are awarded based on income-level) were also not included. In addition studies that evaluate (partially) merit-based grants or grants awarded on the family status (e.g. death of father ${ }^{4}$ ), and studies that only focused on loans were excluded. Examples are the studies by Dynarski (2003), and van der Klauw (2002). Finally, we excluded studies that investigated the effect of mentoring but only focused on peer mentoring, online mentoring, or self-development mentoring. In this study, we are only interested in the effect of student-faculty mentoring (i.e. faculty-student mentoring) or mentoring executed by an external service. We believe that peer, online, and self-guidance mentoring have a different effect on the investigated parameters (such as the development of friendship). For this reason studies by Salinitri (2005) and Sandner (2015) were excluded.

\subsubsection{Search strategies for identification of relevant studies}

Our goal for the literature search is to identify relevant papers (published and unpublished). We opted to use three search strategies for the identification of relevant

\footnotetext{
${ }^{4}$ Although there is a correlation between the death of a parent and income, we cannot rule out that some wealthier families also benefit from these kind of grants. As a result, we did not incorporate studies that investigated grants based on loss of a family member.
} 
Table 2.1: Consulted databases

\begin{tabular}{c}
\hline Databases \\
\hline \hline CINAHL \\
EconLit \\
ERIC \\
greenFILE \\
PsycARTICLES \\
PsycINFO \\
SocINDEX \\
Psychology and Behavioral Sciences Collection \\
MEDLINE \\
PsycBOOKS \\
\hline
\end{tabular}

Table 2.2: Used search words

\begin{tabular}{cccc}
\hline Intervention & Effect & Context & Outcome \\
\hline \hline $\begin{array}{c}\text { Academic } \\
\text { dismissal policy }\end{array}$ & Experiment & College & Dropout \\
$\begin{array}{c}\text { Academic } \\
\text { probation }\end{array}$ & $\begin{array}{c}\text { Quasi- } \\
\text { experimental }\end{array}$ & University & Retention \\
Bindend & Empirical & Higher education & Persistence \\
studieadvies & Effect & Further education & Graduation \\
Mentoring & & Post-secondary & Completion \\
Coaching & education & \\
Advising & & Undergraduate & Performance \\
Guidance & & Enrollment \\
Need-based grant & & & \\
Need-based aid & & & \\
\hline
\end{tabular}


studies. We started with an electronic searcher of databases. Moreover, we searched available resources and databases at the University of Maastricht (through EBSCO host). Examples of the databases are ERIC, EconLit and Business Source Complete. Table 2.1 contains the complete list of databases and the keywords used can be found in Table 2.2. Next, we checked the Reference section of the selected papers in order to determine whether possible eligible studies were listed (i.e. snowballing method). We did not check the Reference section of ineligible studies. Lastly, Google and Google Scholar were used for a broad search of the World Wide Web.

\subsubsection{Keyword strategies for bibliographic databases}

In order to search the databases, we decided to conduct a relatively broad search. We preferred to have many titles and abstracts to go through with a broad search, rather than potentially miss relevant studies with a too narrow search. We used one search strategy, i.e. the combination of keywords. Therefore, we developed a list of keywords to identify the study eligibility criteria: (1) keywords that were relevant for the interventions; (2) keywords that were relevant for the outcomes of enrollment, retention or graduation; (3) keywords that were relevant for the education level; and (4) keywords that were relevant to the methodology. As we found new studies, we adapted our search terms. Table 2.2 represents the search words used for the final pass through the databases.

The search based on this search strategy identified a large number of studies. Many studies were easily excluded because they were not relevant for the proposed meta-analysis. Each citation was reviewed, and it was determined whether the study could proceed to a second screening. If so, the full text of the eligible study was retrieved. Unfortunately, we could not find a full text for all eligible studies. However, when a full text could be found, the study was read to make sure it fulfilled the inclusion criteria, did not fulfil the exclusion criteria, and included at least one of the relevant outcome measurements. When a study was 
Interventions in higher education and their effect on student success: a meta-analysis

selected, we used a coding instrument to extract the correct information from each study. The instrument allowed us to identify the following characteristics of each study: the author, the publication (i.e. type of document and year published), the context (i.e. country), the evaluation design (i.e. RCT, QED or cohort study), the treatment group, the control condition, the participants, and the outcomes (see Appendix).

\subsubsection{Criteria for handling statistical dependencies}

We used three criteria to be sure that our findings were independent. This insured that effect sizes were not correlated with each other because, for example, authors had used the same data set or had used multiple designs in one study. First, we considered an evaluation study as distinct if it uses a unique data set. Sometimes investigators publish multiple articles or reports on the same intervention and on the same sample (for example, when investigating the long-term effects of a study, Campbell \& Campbell, 1997, 2007). In this case, we opted to include the most recent study in our meta-analysis. Some authors opted to copy the intervention and the evaluation method of another researcher (for example, Casey, Cline, Ost \& Qureshi, 2015; Lindo et al., 2010). When there were two separate samples, we considered these studies as distinct and use them both in this review. Second, we chose to use the study design that was the "most rigorous", or the analysis that provided the most controls. In some studies, multiple designs were used on the same sample. We then included the outcomes of the strongest design in our review. In some cases, researchers reported the results of multiple estimation models. We chose to include the model that includes the most control variables. Because regression-adjusted estimates for the control versus experimental groups theoretically reduce statistical noise, we relied on these estimates and used them in the analyses. Statistical noise can occur due to chance fluctuations, violations of the randomization (in the case of experiments), or uncontrolled variables (in the case of quasi-experiments). We have allowed one exception in this study, i.e. when we used the percentage of observations in the control or intervention groups 


\section{Chapter 2}

and/or the mean of the dependent variable to calculate the ES (see Section 2.2.4.). This information is often based on the total number of observations without taking the missing values of the control variables into account. To ensure that we based our calculations of the ES on the correct data, we used the regression estimate of the model with the same number of observations that were used to calculate the two affected metrics. Unfortunately, this is almost never the regression-adjusted estimate with control variables (due to missing values). Finally, a number of studies only reported outcomes by specific subgroups such as gender (male/female) or status policy change (for example, a winner/loser due to changes in the grant system). Even though the outcomes for these subgroups can be very interesting for policy makers, they are difficult to handle in our meta-analysis. We decided to average the effect over the subpopulation and to use the overall effect in our meta-analyses.

\subsubsection{Statistical procedures}

In this study, we used the standardized mean difference (Cohen's d) as effect size metric for all outcome variables. We opted for the standardized mean difference (Cohen's d) because it is a flexible effect size metric, and many formulae are available to estimate the effect size from information reported in the selected studies (e.g. regression coefficients, probability levels). All effect sizes are coded in such a way that positive effect sizes represent better outcomes (i.e. higher enrollment, retention, and graduation). Standardized mean difference effect sizes were calculated as:

$$
d=\frac{\bar{X}_{T G}-\bar{X}_{C G}}{S D_{\text {Pooled }}},
$$

where the numerator is the difference in group means from the intervention group and the control group. The dominator consists of the pooled standard deviation of those groups. 
Since we often used the unstandardized regression coefficient to calculate the standardized mean difference, this formula is also mentioned:

$$
d=\frac{\beta_{\text {unstandardized }}}{S D_{D V}}
$$

where the numerator is the unstandardized regression coefficient (in the case of a binary intervention variable, this coefficient represents the difference between the mean of the intervention and that of the control group) and the dominator represents the standard deviation from the dependent variable (this information can be calculated from the mean of the dependent variable, since all outcomes in this study are binary).

The variance of the standardized mean difference was calculated using the following formula:

$$
V_{d}=\frac{n_{T G}+n_{c G}}{n_{T G} * n_{c G}}+\frac{d^{2}}{2\left(n_{T G}+n_{c G}\right)} .
$$

A transformation procedure, commonly used in this study, is the logit transformation of cells frequencies to standardized mean differences. In this calculation the odds ratios for these data is first computed. Moreover, the $d$ is calculated as follows:

$$
d=\left[\ln \left(\frac{A * D}{B * C}\right)\right] * \frac{\sqrt{3}}{\pi}
$$

where $A$ and $B$ are the counts of the "successes" and "failures" in the treatment group, and $C$ and $D$ are "successes" and "failures" in the comparison group. 
It should also be noted that, because of presumed heterogeneity in the true effects across samples and countries, we reported the results of the random effects models in our analyses. Under the fixed-effects model, the assumption is that there is one true effect size which underlies all studies in the analysis, and that all observed differences are due to sampling error (Borenstein, Hedges \& Rothstein, 2009). Under the random-effects model, the true effect size differs between studies since mixes of participants and the implementation of interventions also differ between studies. When we moved from the fixed-effects model to the random-effects model, the relative weights became more balanced. Consequently, extreme studies lost influence if they were large, and gained influence if they were small. We reported overall effects for all interventions on the corresponding outcomes (see Table 2.3).

Table 2.3: Organization of outcomes

Interventions

\begin{tabular}{|c|c|c|}
\hline Academic probation & $\begin{array}{l}\text { Faculty-student } \\
\text { mentoring }\end{array}$ & Need-based grants \\
\hline First-year retention & First-year retention & Enrollment \\
\hline $\begin{array}{c}\text { A student persists } \\
\text { from the first to the second } \\
\text { year }\end{array}$ & $\begin{array}{l}\text { A student persists } \\
\text { from the first to the second } \\
\text { year }\end{array}$ & $\begin{array}{l}\text { A student enrolls in a } \\
\text { study program in higher } \\
\text { education }\end{array}$ \\
\hline$\underline{\text { Graduation }}$ & $\underline{\text { Graduation }}$ & $\underline{\text { First-year retention }}$ \\
\hline \multirow[t]{2}{*}{$\begin{array}{c}\text { A student completes } \\
\text { the study program within } \\
\text { the nominal time or within } \\
6 \text { years }\end{array}$} & $\begin{array}{l}\text { A student completes } \\
\text { the study program }\end{array}$ & $\begin{array}{c}\text { A student persists } \\
\text { from the first to the second } \\
\text { year }\end{array}$ \\
\hline & & $\begin{array}{l}\text { Graduation } \\
\text { A student completes } \\
\text { the study program }\end{array}$ \\
\hline
\end{tabular}


Interventions in higher education and their effect on student success: a meta-analysis

\subsection{Results of the meta-analysis}

\subsubsection{Pipeline of studies}

524 studies were retrieved from our first search. As a second step, we determined whether a study seemed eligible based on the abstract and title. We also included extra studies through snowballing. Unfortunately, this left us with 71 studies. As a final step we retrieved the full-text reports and checked whether: (I) the studies matched with our research questions; (II) there was evidence of baseline control; and (III) the necessary information for the effect size calculation was present in each study. We maintained 25 studies which we coded for study characteristics and effect sizes. The pipeline of studies is illustrated in Figure 2.15.

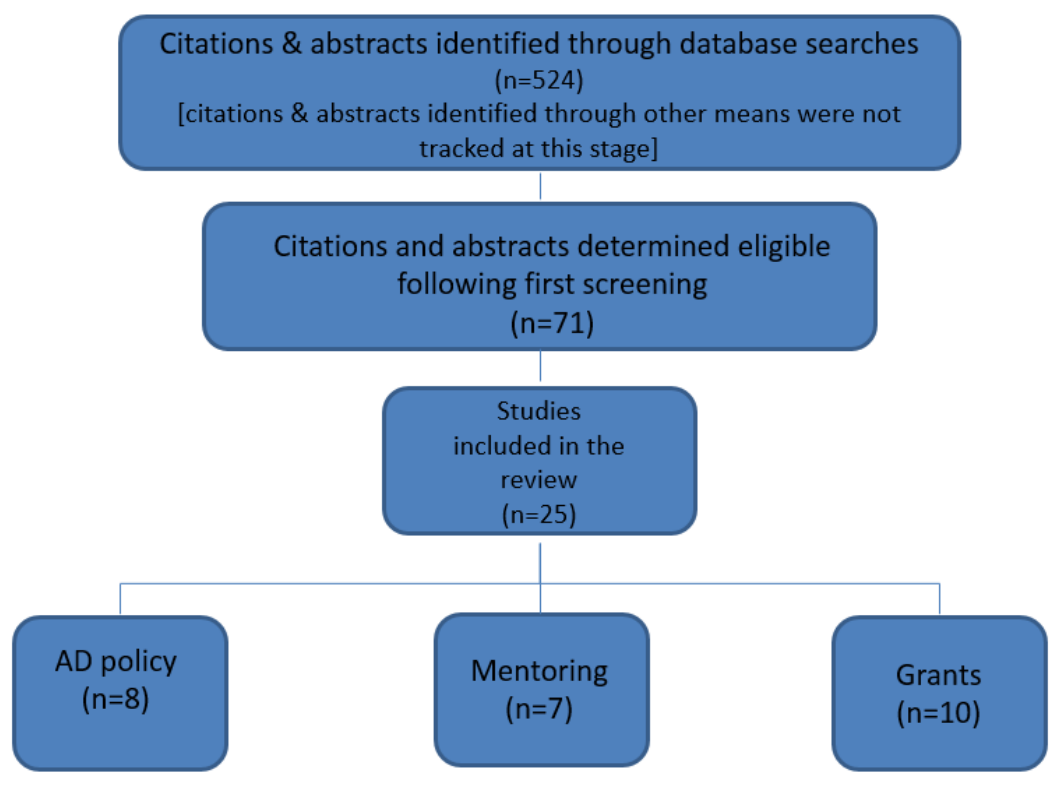

Figure 2.1: Pipeline for review sample

\footnotetext{
${ }^{5}$ Note that, when a study provides us with multiple effect sizes (e.g. when there are multiple independent samples present), we count this study as one in the descriptive statistics.
} 


\subsubsection{Descriptive statistics}

Three broad interventions were included in this review. Eight studies evaluate the AD policy; seven are about student-faculty mentoring; and 10 are about need-based grants (see Figure 2.1 and the Appendix for a detailed description of each study). Most of these programs target universities (68\%). Only $12 \%$ of the studies focused on colleges, and $20 \%$ focused on both types of institutions. The sample of studies was diverse concerning the nations of origin. Studies were conducted in seven different nations, with the US $(n=14)$, the Netherlands $(n=4)$, Canada $(n=2)$ and Denmark $(n=2)$ as the most common. In this review $24 \%$ of the studies used randomization while $60 \%$ made use of a quasi-experimental design. When randomization was in place, we found one study that assigned classes to the control or treatment condition instead of to the individual student level. Four studies (16\%) made use of cohort comparison. All of the studies were published between 2002 and 2015. Figure 2.2 shows that most of the eligible studies were conducted as of 2010 . Almost half of the studies were published in a journal (48\%). The majority of the other studies are discussion/working papers (20\%). We also include some reports of international organizations (16\%) such as the National Center for Postsecondary research, some conference papers (8\%), and dissertations (8\%). Most authors came to the conclusion that their intervention had a positive effect on the main outcomes (64\%). $24 \%$ of the studies reported a negative effect, and $12 \%$ found mixed effects. Note that some studies found only very small effects. 


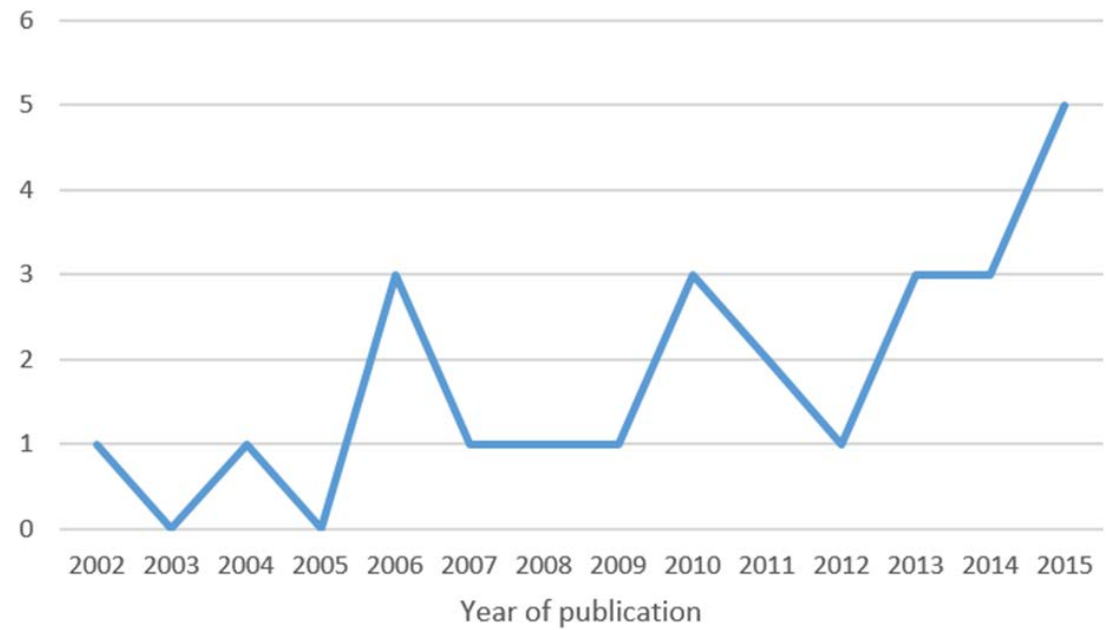

Figure 2.2: Number of included studies by year of publication

\subsubsection{Academic Dismissal (AD) policy}

We included eight studies concerning Academic Dismissal or Academic Probation. Half of the studies used a quasi-experimental design, mostly regression-discontinuity design (RDD). The other four made use of cohort comparison. Despite the fact academic probation is a well-known intervention in many countries (e.g. the Netherlands, the US, and Canada), little empirical evidence was found. This might be due to two reasons. First, in countries such as the US and Canada, academic probation is common practice and is installed in most universities and colleges. As a result, most studies focusing on academic dismissal policies in these countries try to find the effect of interventions on dropout rates and graduation rates of students already on probation, or try to find which characteristics predict whether a student will be on probation. Second, in other countries academic dismissal policies are a novelty. As a result, there are no good experimental or quasiexperimental studies.

Lindo et al. (2010) found that being placed on academic probation after the first year discourages some students from returning to school, while the students who remain improve 
their subsequent performance. Similarly, Fletcher and Tokmouline (2010), Casey et al. (2015) and Chi and Dow (2014) have also shown that retention rates decrease. While Casey et al. (2015) found a negative effect on graduation rates, Chi and Down (2014) found a positive effect on completion rates. Fletcher and Tokmouline (2010), however, showed mixed evidence concerning the effect on graduation rates. Duijndam and Scheepers (2009) indicated that compared with programs where no $\mathrm{AD}$ policy is in place, the introduction of an $\mathrm{AD}$ policy in a business management program resulted in earlier withdrawal of students in the first year. This shows that fewer students linger in the program because of the introduction of a credit threshold. In addition, Arnold (2015) compared Bachelor programs in the academic years 2002-03 and 2007-08. During these years some programs implemented an AD policy (i.e. intervention group), while others did not (i.e. the control group). He found that the introduction of an AD policy increased the first-year dropout rate and the 4-year completion rate of university students.

\subsubsection{Student-faculty mentoring}

We also found seven studies focusing on student-faculty mentoring. Four of these studies made use of a quasi-experimental design (such as matching or a Difference-indifferences (DiD) estimator). The other three studies made use of a random experiment. The studies were conducted in Germany and the US. Although student mentoring is a practice that is often applied, we did not find many studies investigating the effect of student-faculty mentoring on performance indicators of higher education students. We did, however, find many studies focusing on the effect of peer mentoring on student performance indicators. Peer mentoring is a practice whereby the mentoring function is often fulfilled by a more experienced student (e.g. a graduate student or a senior student). Since we are only interested in the effect of faculty-student interaction, we did not take the latter group of studies into account in our review. 
Interventions in higher education and their effect on student success: a meta-analysis

Given the costs of mentoring, one might expect a substantial number of papers on the effect of mentoring on student outcomes. However, the evaluation research in this field is limited. Bettinger and Baker (2014) used a randomized experiment to test the effectiveness of 'Inside Track'. This intervention consists of an individualized coaching service which has proved to increase retention and graduation rates. Using matching, Kot (2014) showed that centralized advising increased first-year attritions. A study of Brock and RichburgHayes (2006) investigated the effect of an open-door program on student outcomes. Moreover, they found that enhanced counseling layered with financial incentives leads to fewer dropouts. This is in line with a study of Campbell and Campbell (2007) which showed that retention increases due to mentoring. However, graduation rates remain unchanged ${ }^{6}$. Hoffer (2010) studied the effect of an experimental mentoring program in US university, and found a positive effect on retention. A study of Swanson (2005) investigated the different effects between normal advising meetings, development advising meetings, and strength-based advising meetings. It was shown that the most intensive advising led to higher retention rates compared with normal advising. The study of Visher, Butcher and Cerna (2011) showed no effect on retention.

\subsubsection{Need-based grants}

In this meta-analysis, 10 studies on the effect of need-based grants were included. One study made use of a randomized design. The other studies implemented quasi-experimental designs (mostly RDD). Most studies were conducted in the US and in Denmark. We also found a German, Italian and French study. We observed a number of studies focusing on merit-based aid. Students are eligible for this aid when they reach certain performance

\footnotetext{
${ }^{6}$ Note that in the study of Campbell \& Campbell (2007) the target group of the intervention consists of newly enrolled students (also transfer students). Although they are not defined as first-year students, they are in their first-year at the institution, and face the same issues as first-year students. Consequently, we include this study in the review.
} 


\section{Chapter 2}

thresholds. We did not include these studies in our review. Only studies whereby initial eligibility is based on socio-economic status or income are taken into account. Note that the criteria that students need to fulfil in order to retain the scholarship after the first-year are not important in this review.

Castleman \& Long (2012) examined the impact of the Florida Student Access Grant (FSAG) on academic outcomes such as enrollment and college persistence. Using a regression-discontinuity strategy, the authors showed that aid positively affects enrollment and persistence. Moreover, the grant also increases the likelihood of obtaining a Bachelor's degree by 4.6 percentage points. The finding concerning enrollment and retention is in line with many other studies, such as Goldrick-Rab, Douglas, Kelchen and Benson (2012) and Fack and Grenet (2015). Bettinger (2015) assessed the Ohio College Opportunity Grant initiative, and, through a difference-in-differences identification strategy, highlighted its positive effect on first-year performance, such as a reduction in dropout rates. Several outcomes of academic performance have been considered by Arendt (2013) to assess the effect of the Danish reform of the student grant and loan system. The results suggest a positive impact on the dropout rates, but no overall effect on completion rates. Agasisti and Murtinu (2014) assessed the impact of receiving a grant for a cohort of students enrolled at the “Politecnico di Milano” in the academic year 2007/2008. The empirical analysis focuses on a wider range of academic results, i.e. dropout and time to graduation. The authors found that obtaining a grant positively affected retention and completion, especially for immigrants, students whose family reside in another region, and those attending engineering courses. Studies of Fack and Grenet (2015) and Alon (2011), which both exploit a quasi-experimental design, also found no effect on graduation.

\subsubsection{Meta-analysis}

We estimate the overall mean effect size $(d)$ using inverse variance random effects weights. When the interventions have a positive impact on the outcome variables (e.g. an 
Interventions in higher education and their effect on student success: a meta-analysis

increase in enrollment or retention), we scale the standardized mean differences (Cohen's d) as positive. When the intervention has a negative impact (e.g. graduation decreased) or no effect (e.g. the enrollment rate in both groups remained the same), we scale the effect size as negative and zero, respectively. An effect size estimate of .5 reflects a 5/10 standard deviation improvement for students in the treatment condition compared with students in the control conditions. We also present heterogeneity data, including the $\mathrm{I}^{2}$, the tau ${ }^{2}$ (between studies) and the Q-test ${ }^{7}$ for each intervention analysis. All these metrics show how well the mean effects represent the sample of studies in the analysis. Given the expected variation in samples, countries, and design methods, the variability in effect size is also large.

\subsubsection{Effects of the Academic Dismissal (AD) policy}

In this section, we report the overall effects of academic probation on retention and graduation. In Figure 2.3, the results are represented for 8 studies (and 11 effect sizes) that measure the effect on retention rates. We observe that the average treatment effect is negative ( $d=-.17 ; 95 \%$ CI $[-.23 ;-.12])$, and ranges from -.45 to -.04. All studies report a negative effect size. The difference between students on academic probation and regular students is a fifth of a standard deviation. Moreover, based on the Percentage Improvement in Treatment over Control (BESD), an academic dismissal policy leads to an 8.5\% decrease in retention (see Table 2.5). Following Cohen (1988) and Hattie (2015) this is a small effect size. As expected, heterogeneity statistics indicate large variability across effect sizes $\left(\mathrm{Q}=155.09 ; \mathrm{df}=10 ; \mathrm{p}<.001 ; \mathrm{I}^{2}=93.06 ; \operatorname{tau}^{2}=.0077\right)$.

\footnotetext{
${ }^{7}$ For any observed Q, a low $\mathrm{P}$ value provides evidence of the heterogeneity of intervention effects (i.e. that studies do not share a common effect size). The Tau ${ }^{2}$ test presents an estimate of the magnitude of variation between studies. The $\mathrm{I}^{2}$ statistic describes the proportion of variability in effect estimates due to heterogeneity rather than to chance (Higgins, 2008)
} 


\section{Chapter 2}

Next, we consider the effect of AD policy on graduation within the nominal study time and within 6 years. Five studies or eight effect sizes are included in the analysis of graduation within the nominal time (see Figure 2.4). Collectively, the average effect size is zero ( $d=.00$; 95\% CI $[-.04 ; .04])$, and ranges from -.08 to -.13 . This suggests that an AD policy does not have an effect on graduation within the nominal study time. This is not surprising given that three cases report a negative effect size and two reported no effect size. Only three cases show a positive effect. We also find a lot of heterogeneity $(\mathrm{Q}=43.88$; $\left.\mathrm{df}=7 ; \mathrm{p}<.001 ; \mathrm{I}^{2}=84.00 ; \mathrm{tau}^{2}=.0024\right)$.

We also do not find a statistical effect of academic probation on graduation within 6 years (see Figure 2.5). Seven effect sizes are used in the analysis. A small overall negative effect size is found ( $d=-.01 ; 95 \%$ CI $[-.05 ; .02])$, and the effects range from -.05 to -.08. This suggests that an AD policy does not have an effect on graduation within 6 years. Moreover, five cases report a negative effect size and only two cases show a positive effect. We also find a moderate amount of heterogeneity $\left(\mathrm{Q}=11.78\right.$; $\mathrm{df}=6 ; \mathrm{p}<.010 ; \mathrm{I}^{2}=49.10$; $\operatorname{tau}^{2}=$ $.0010)$

\subsubsection{Effect of student-faculty mentoring}

This section reports the effect of student-faculty mentoring on two outcome variables (i.e. retention and graduation). Seven studies are included in estimating the effect of mentoring on student retention (see Figure 2.6). We observe an average positive effect size $(d=.15 ; 95 \% \mathrm{CI}[.06 ; .23])$, and the effects range from -.02 to .41. The difference in retention rate between the mentored and non-mentored students is .15 of a standard deviation. Although student-faculty mentoring seems to reduce dropout significantly, this effect size is perceived as small (Cohen, 1988; Hattie, 2015). Moreover, as a result of mentoring, dropout decreases by $7.5 \%$ (see Table 2.5 ). Only one study reports a negative effect, the 


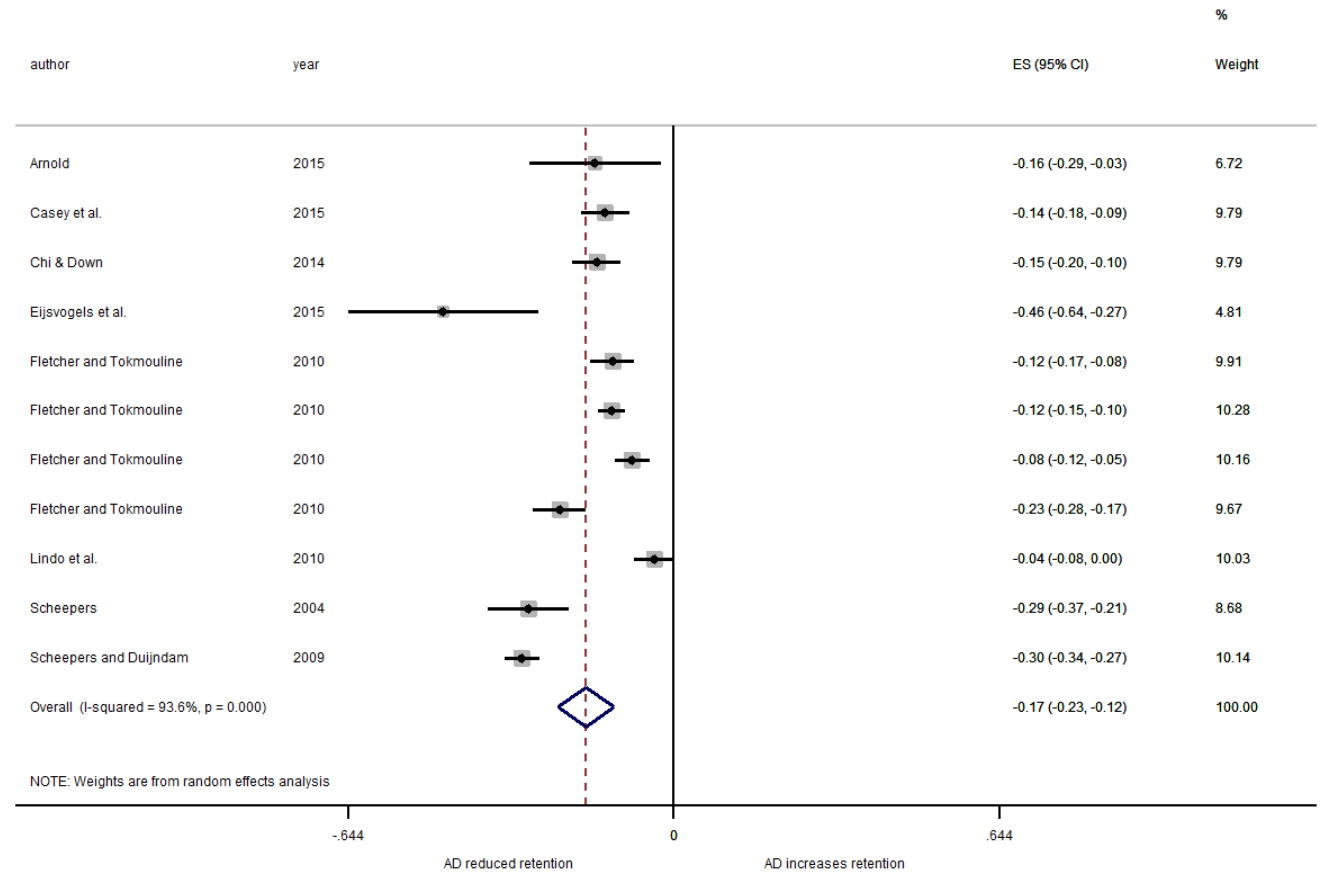

Figure 2.3: Main effects of $\mathrm{AD}$ policy on retention rates. In the forest plot, the area of each box represents the contribution of the corresponding study to the meta-analysis. The center of the box represents the size of the treatment effect. The confidence interval for the treatment effect is shown by the black line. The diamond shows the summary treatment effect with the left and right extremes representing the corresponding confidence interval. Stata 14 is used to produce this output. 


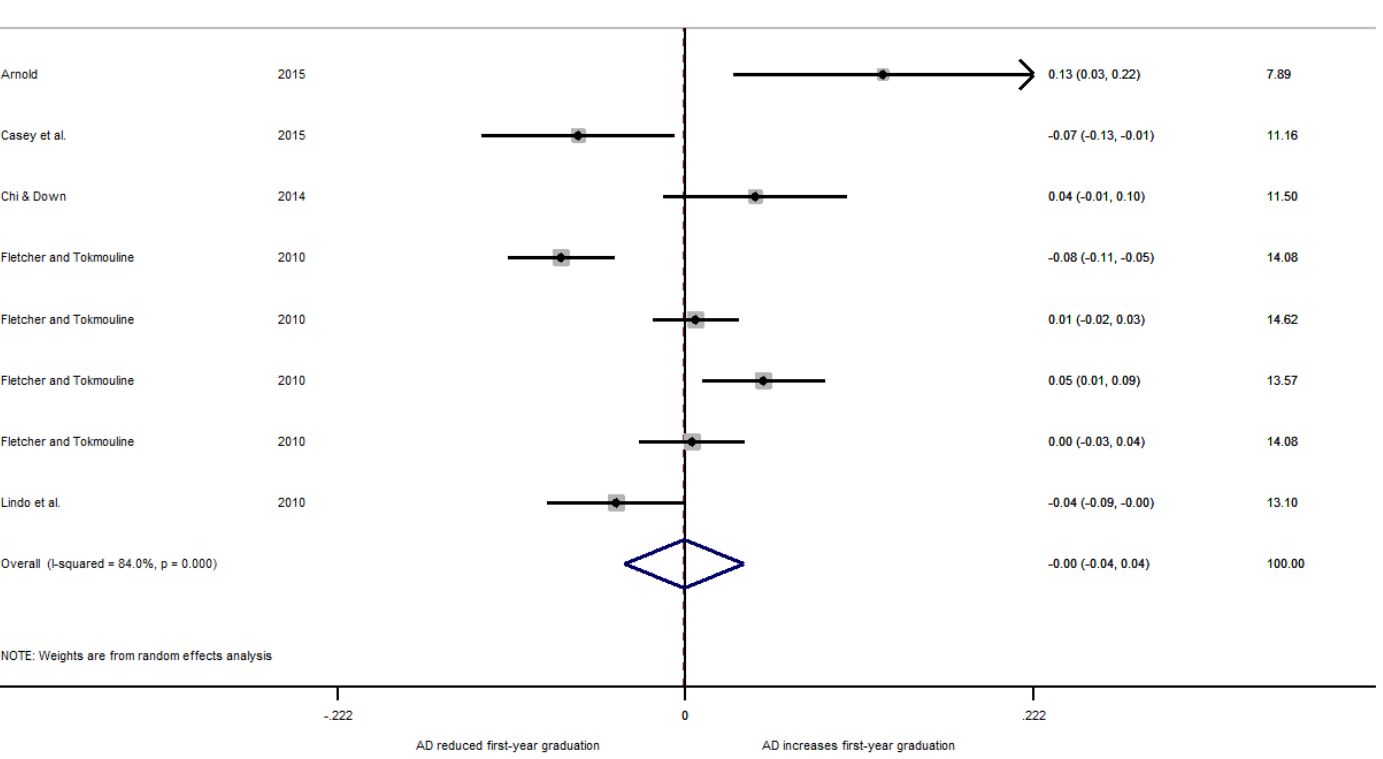

Figure 2.4: Main effects of AD policy on graduation within the nominal time. In the forest plot, the area of each box represents the contribution of the corresponding study to the meta-analysis. The center of the box represents the size of the treatment effect. The confidence interval for the treatment effect is shown by the black line. The diamond shows the summary treatment effect with the left and right extremes representing the corresponding confidence interval. Stata 14 is used to produce this output 


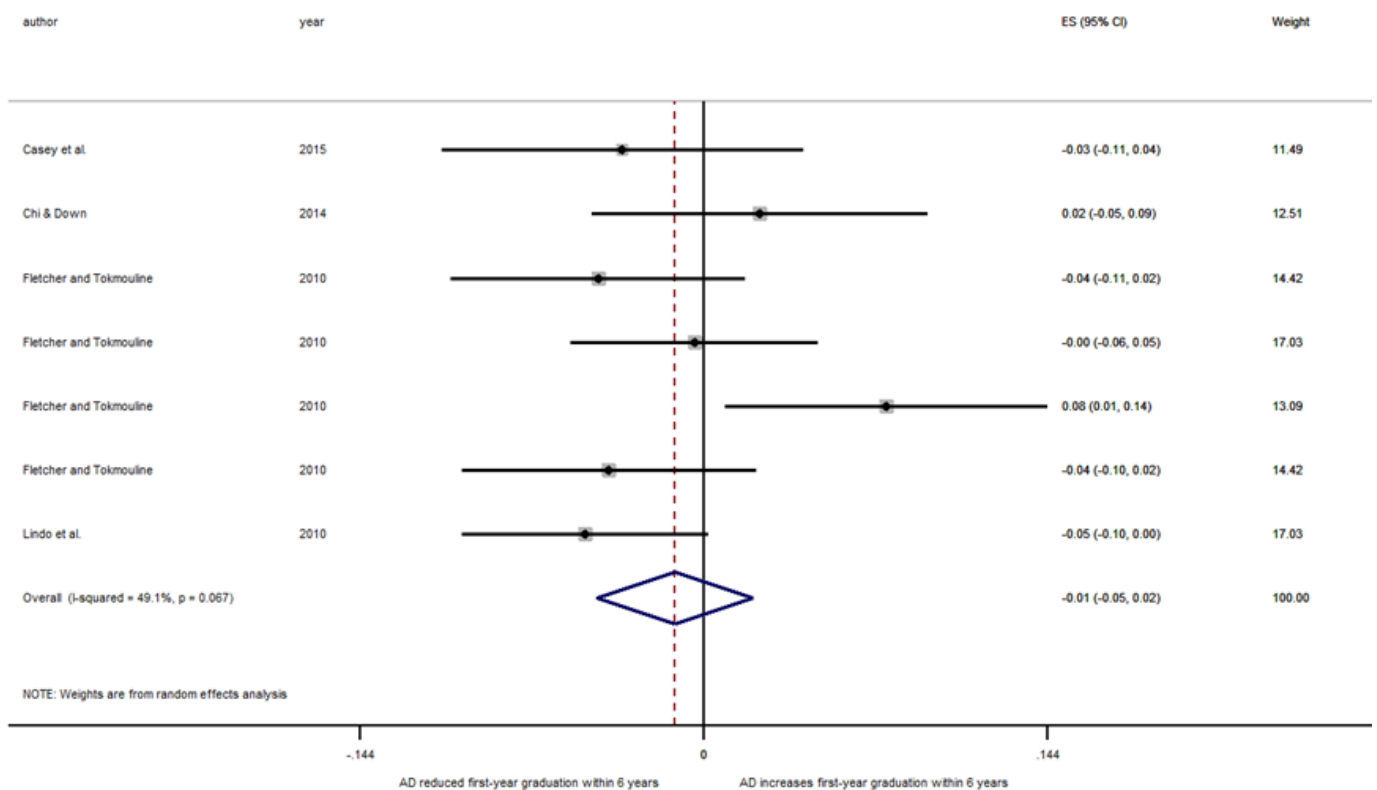

Figure 2.5: Main effects of AD policy on graduation within 6 years. In the forest plot, the area of each box represents the contribution of the corresponding study to the meta-analysis. The center of the box represents the size of the treatment effect. The confidence interval for the treatment effect is shown by the black line. The diamond shows the summary treatment effect with the left and right extremes representing the corresponding confidence interval. Stata 14 is used to produce this output. 


\section{Chapter 2}

other studies all show a positive effect. Again, we find a substantial amount of heterogeneity $\left(\mathrm{Q}=19.90 ; \mathrm{df}=6 ; \mathrm{p}<.05 ; \mathrm{I}^{2}=69.9 \% ; \mathrm{tau}^{2}=.0066\right)$.

Looking at the graduation rates $^{8}$, we find a positive average effect of mentoring $(d=.10$; 95\% CI $[.01 ; .19]$; range from .09 to .14) (see Figure 2.7). Between the students who received mentoring and those who did not there is a .10 difference of a standard deviation. This indicates that mentoring leads to a 5\% increase in graduation rates. Cohen (1988) and Hattie (2015) identify a Cohen's d of .10 as a small effect. However, the number of studies included in these analyses is limited (i.e. two studies), so the results have to be interpreted with caution. We do not find evidence of heterogeneity, but this is probably due to the small number of studies $\left(\mathrm{Q}=.27 ; \mathrm{df}=1 ; \mathrm{p}=.602 ; \mathrm{I}^{2}=0 \% ; \operatorname{tau}^{2}=.0000\right)$.

\subsubsection{Effects of need-based grants}

We consider the effect of need-based grants on three outcome variables ${ }^{9}$. We start by looking at the effect of need-based grants on enrollment (see Figure 2.8). For these analyses we include six studies. We observe an average positive effect of need-based grants $(\mathrm{d}=.05$; 95\% CI [.03; .07]; range from .03 to .13). Moreover, there is a .05 difference of a standard deviation between the control and intervention group. Due to need-based grants, enrollment has increased by $2.5 \%$ (see Table 2.5). This effect is highly significant but small (Cohen, 1988). Thus, all studies show positive effects. We find a moderate amount of heterogeneity $\left(\mathrm{Q}=9.45 ; \mathrm{df}=5 ; \mathrm{p}=.092 ; \mathrm{I}^{2}=47.1 \% ; \mathrm{tau}^{2}=.0001\right)$.

Next, we present the results of the effect of need-based grants on retention (see Figure 2.9). Six studies are included, and we observe an average positive, but small, significant

\footnotetext{
${ }^{8}$ Note that the authors speak about the completion of a degree, but do not mention in how many years after the start of the program.

${ }^{9}$ We transformed the effect sizes so they present the effect of a $€ 1000$ increase in grant. Castleman \& Long (2012) indicate that this is common practice.
} 


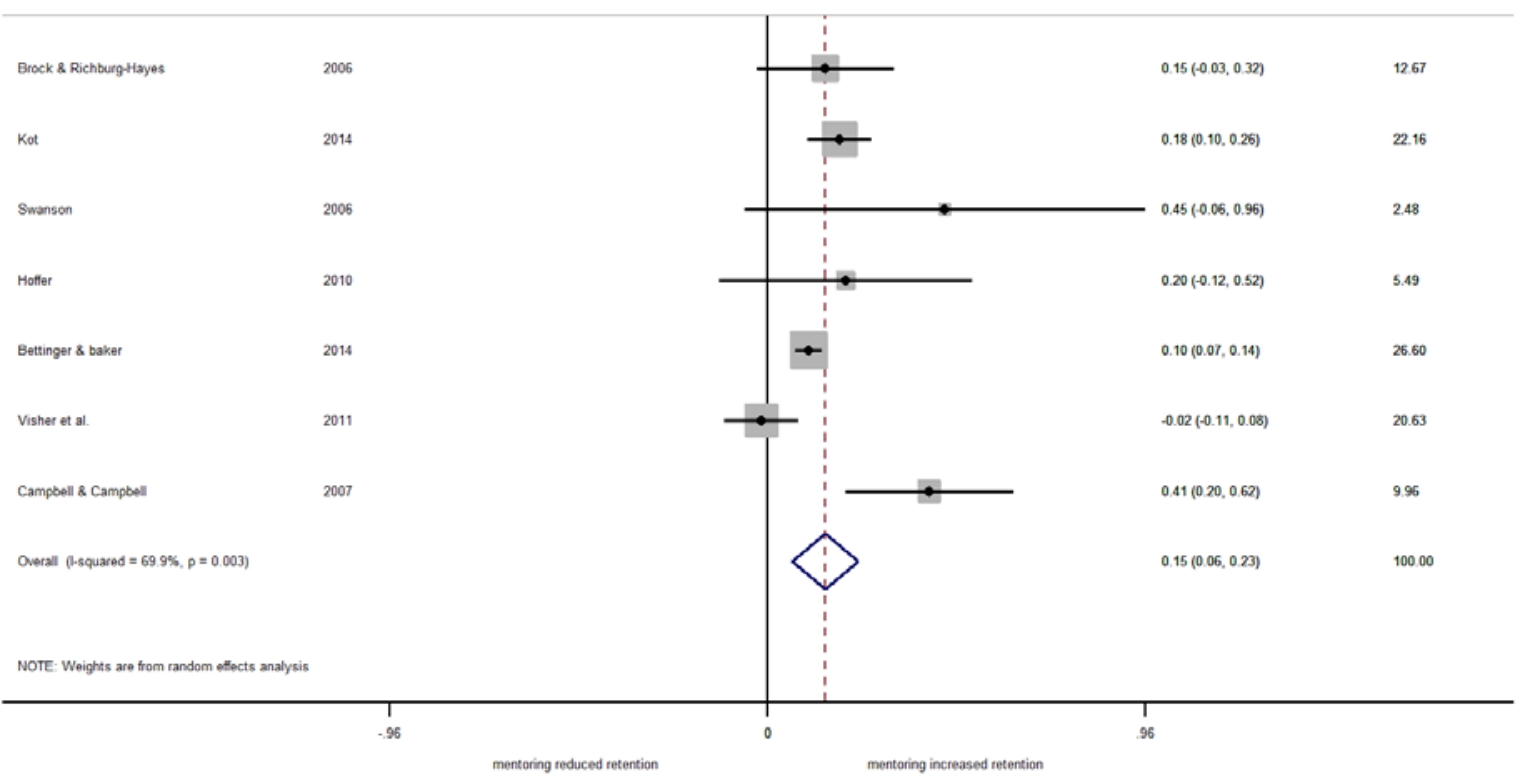

Figure 2.6: Main effects of mentoring on retention. In the forest plot, the area of each box represents the contribution of the corresponding study to the meta-analysis. The center of the box represents the size of the treatment effect. The confidence interval for the treatment effect is shown by the black line. The diamond shows the summary treatment effect with the left and right extremes representing the corresponding confidence interval. Stata 14 is used to produce this output. 


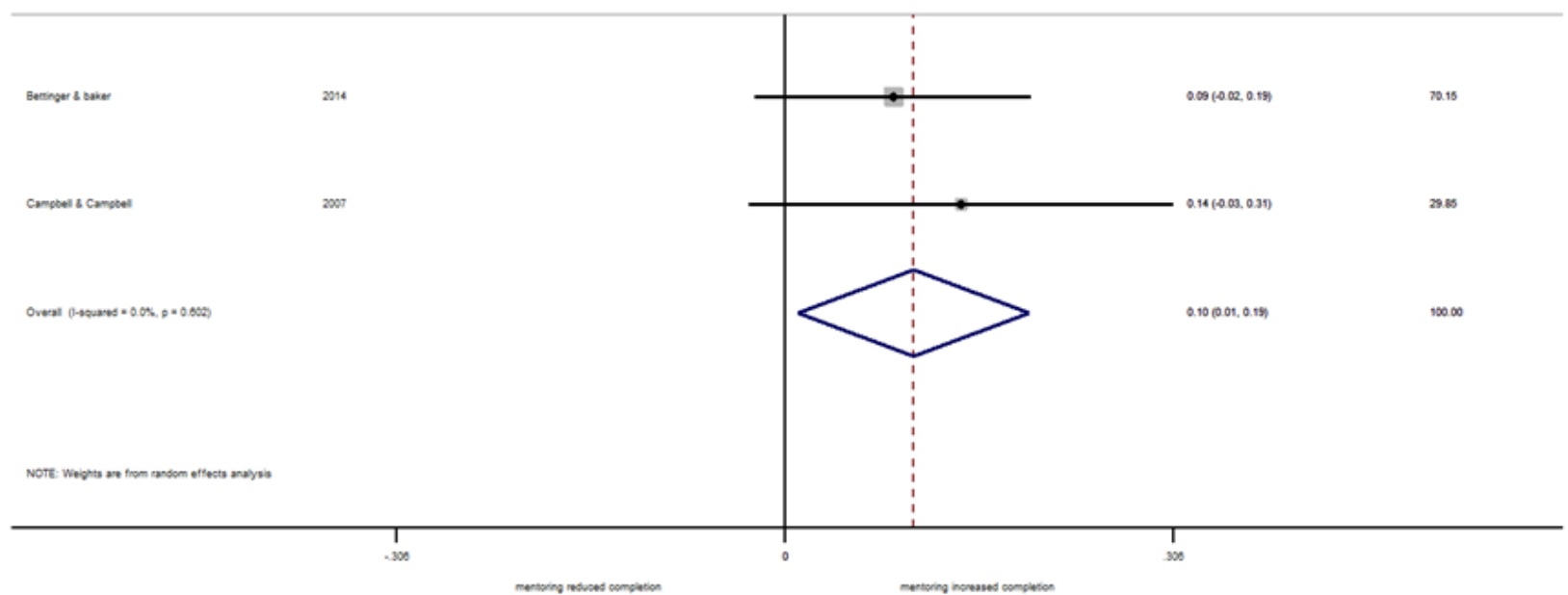

Figure 2.7: Main effects of mentoring on completion. In the forest plot, the area of each box represents the contribution of the corresponding study to the meta-analysis. The center of the box represents the size of the treatment effect. The confidence interval for the treatment effect is shown by the black line. The diamond shows the summary treatment effect with the left and right extremes representing the corresponding confidence interval. Stata 14 is used to produce this output. 
Interventions in higher education and their effect on student success: a meta-analysis

effect ( $d=.05 ; 95 \%$ CI $[.04 ; .06]$; range from .01 to .12). Hence, financed and non-financed students show a .05 difference of a standard deviation. This indicates that retention has risen by $2.5 \%$ (See Table 2.5). Again, all studies show a positive effect. We observe no heterogeneity $\left(\mathrm{Q}=4.85 ; \mathrm{df}=5 ; \mathrm{p}=.434 ; \mathrm{I}^{2}=0 \%\right.$; $\left.\operatorname{tau}^{2}=.0000\right)$.

Finally, we show the results of the effect of need-based grants on graduation (see Figure 2.10). It is important to note that some authors mention graduation within the nominal study time, others use graduation within 5 or 6 years and one author looks at graduation independently of the necessary time. We used five studies and seven effect sizes (i.e. some authors use multiple outcome variables). We observe an average positive, small significant effect of grants on graduation (d=.05; 95\% CI [.01; .08]). All the observed effect sizes range from .01 to .18. Graduation rates have increased by $2.5 \%$ due to need-based grants (see Table 2.5). Again, there is evidence of heterogeneity $(Q=13.06 ; \mathrm{df}=6 ; \mathrm{p}=.042$; $I^{2}=54.0 \%$; $\left.\operatorname{tau}^{2}=.0010\right)$. Notice that, when we rerun the analysis only for graduation within the nominal time, the overall effect is somewhat smaller and insignificant ( $d=.030$; 95\% CI $[-.01 ; .06])$. When we look at the effect of grants on graduation after the nominal study time, we find a bigger effect size (d=.06; 95\% CI $[-.005 ; .125])$. It seems that the effect of needbased grants increases over time. 


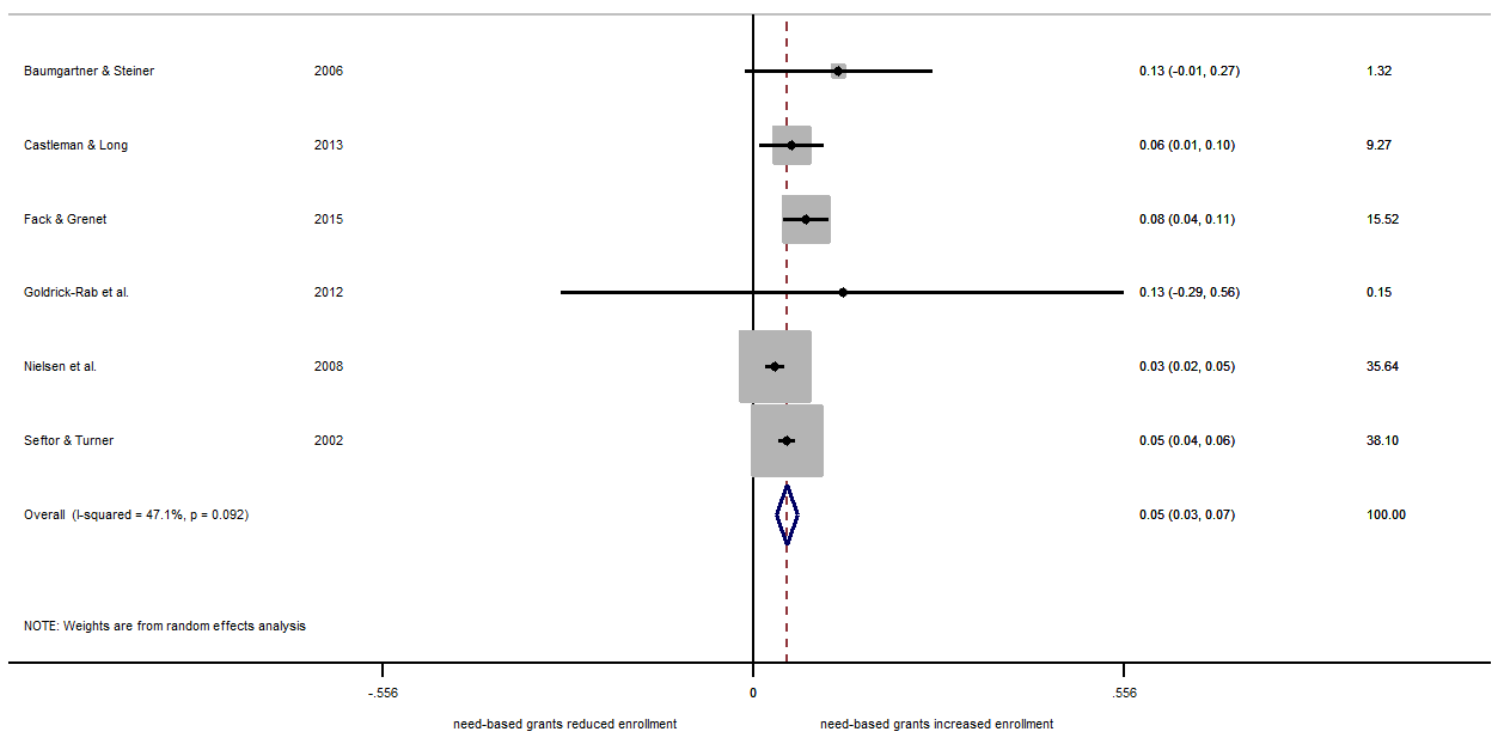

Figure 2.8: Main effects of need-based grants on enrollment. In the forest plot, the area of each box represents the contribution of the corresponding study to the meta-analysis. The center of the box represents the size of the treatment effect. The confidence interval for the treatment effect is shown by the black line. The diamond shows the summary treatment effect with the left and right extremes representing the corresponding confidence interval. Stata 14 is used to produce this output. 


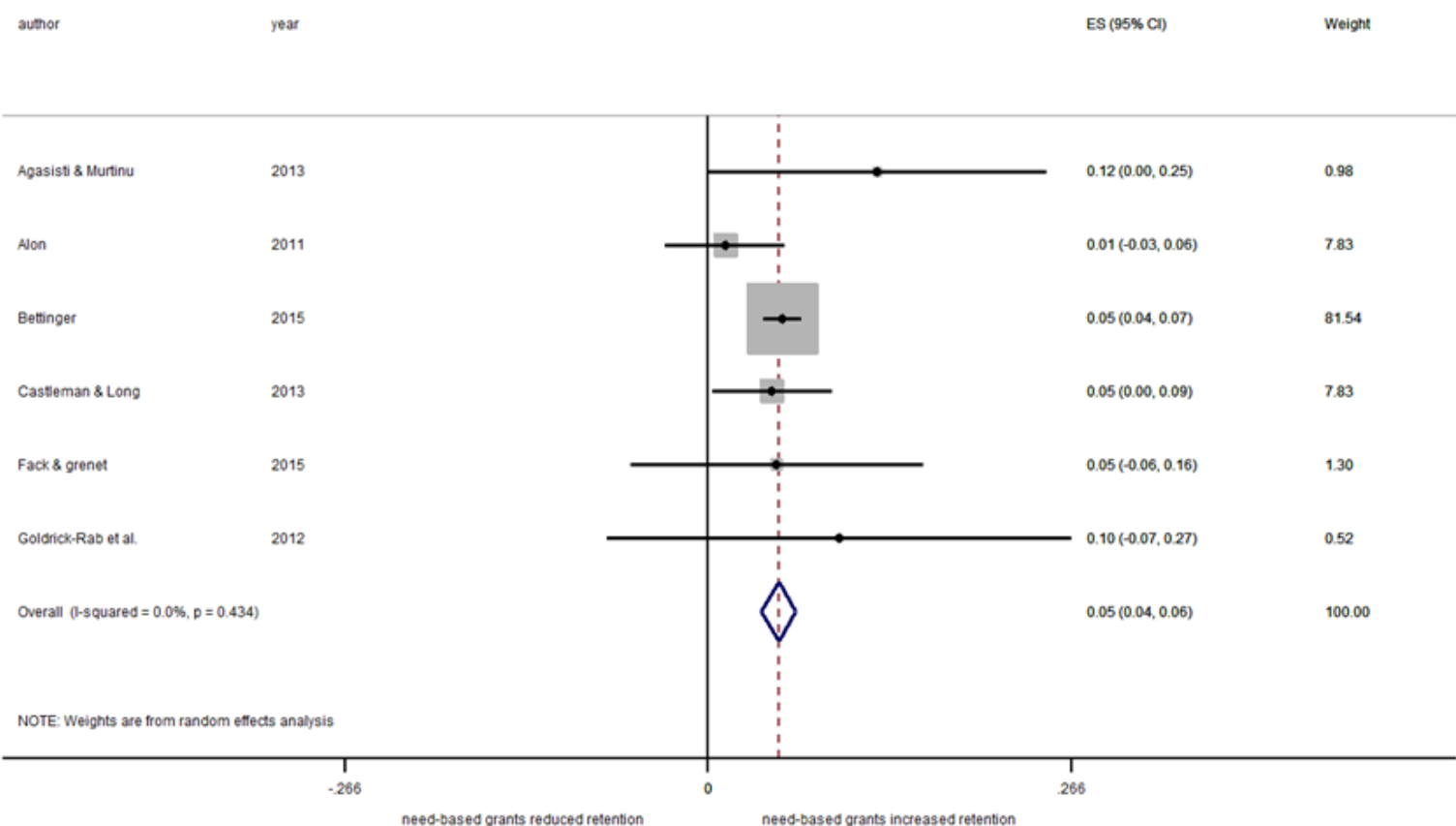

Figure 2.9: Main effects of need-based grants on retention. In the forest plot, the area of each box represents the contribution of the corresponding study to the meta-analysis. The center of the box represents the size of the treatment effect. The confidence interval for the treatment effect is shown by the black line. The diamond shows the summary treatment effect with the left and right extremes representing the corresponding confidence interval. Stata 14 is used to produce this output 


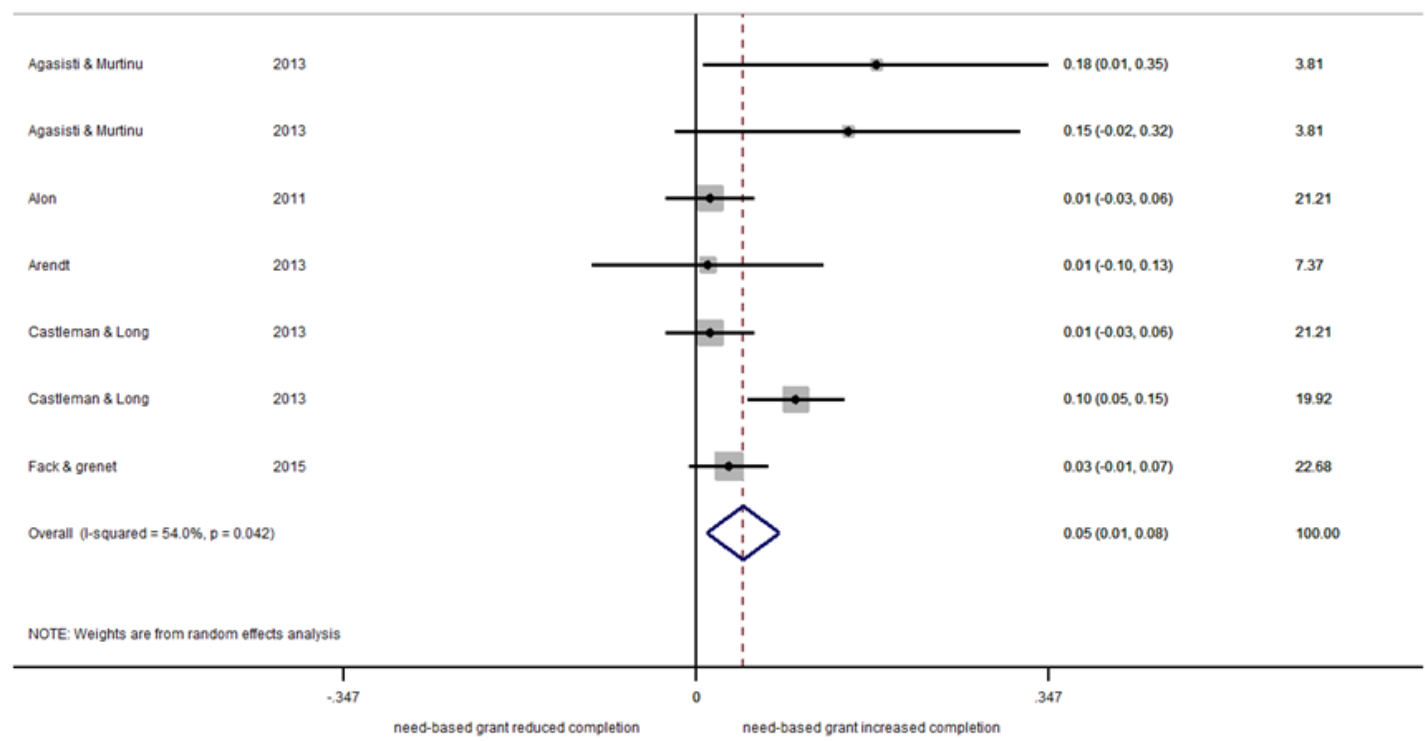

Figure 2.10: Main effects of need-based grants on graduation. In the forest plot, the area of each box represents the contribution of the corresponding study to the meta-analysis. The center of the box represents the size of the treatment effect. The confidence interval for the treatment effect is shown by the black line. The diamond shows the summary treatment effect with the left and right extremes representing the corresponding confidence interval. Stata 14 is used to produce this output. 
Interventions in higher education and their effect on student success: a meta-analysis

\subsubsection{Publication bias}

Publication bias is an issue that can lead to biased results in a meta-analysis. Publication bias occurs when not all research concerning mentoring, academic probation and need-based grants has been published or reported. Studies may not be reported or published because of non-significant results, or because the results are not valued properly by journal editors or by other researchers. When these studies report different results from those in the analysis, bias arises.

The majority of the studies used in this review are journal articles (46.15\%). Roughly half of the studies are located outside journals, and the possibility exists that we do not have to cope with publication bias. However, we also want to draw attention to two caveats. First of all, most articles in this review sample are in the field of education economics. A tradition in this field is that unpublished articles are often made available online because of the long time that elapses before publication. As a result, some of our "unpublished" papers may be published in the future. Secondly, it is not really clear what unpublished means in the digital area. Indeed, most documents can be easily obtained via internet searches independently of being controlled by commercial publishers.

To assess the possibility of publication bias we visually examine a funnel plot and examine an egger regression test for funnel plot asymmetry (Egger, Smith, Schneider \& Minder, 1997). Looking at the funnel plot (with our total review sample of 25 studies and 55 outcomes), we observe that it is fairly symmetric (see Figure 2.11). This is probably because that few studies have large standard errors. The egger test for funnel plot symmetry also indicates a positive insignificant association between the effect size and standard error $(\mathrm{b}=.024, \mathrm{p}=.19,95 \% \mathrm{CI}[-.01 ; .06])$. For completeness, we also executed the egger test for each intervention. We only conducted a trim and fill analysis (Duval \& Tweedie, 2000) if the egger test indicated publication bias. Note that a general effect size per intervention is not interpretable due to the different outcome variables. First of all, we do not observe a significant association between effect size and the standard error based on the egger test 
Chapter 2

$(b=-.073, p=.19,95 \%$ CI [-.19; .04]) for the effect of the AD policy. On the other hand, for faculty-student mentoring, the egger test indicates an asymmetric funnel plot $(\mathrm{b}=.079, \mathrm{p}=$ $.049,95 \%$ CI [.000; .1549]). However, after trimming and filling 12 hypothetical effect sizes, the random effects size is still positive and significant (see Table 2.4). Finally, we observe a significant positive association between the effect size and the standard error $(\mathrm{b}=.041, \mathrm{p}<.01,95 \% \mathrm{CI}[.028 ; .054])$ for the effect of need-based grants. Again, the trim and fill analysis makes it clear that after trimming and filling 23 hypothetical effect sizes, the random effect size remains positive and statistically significant (see Table 2.4). We can conclude that although the egger test of two of the interventions points towards publication bias, this bias is unlikely to have an appreciable effect on the findings.

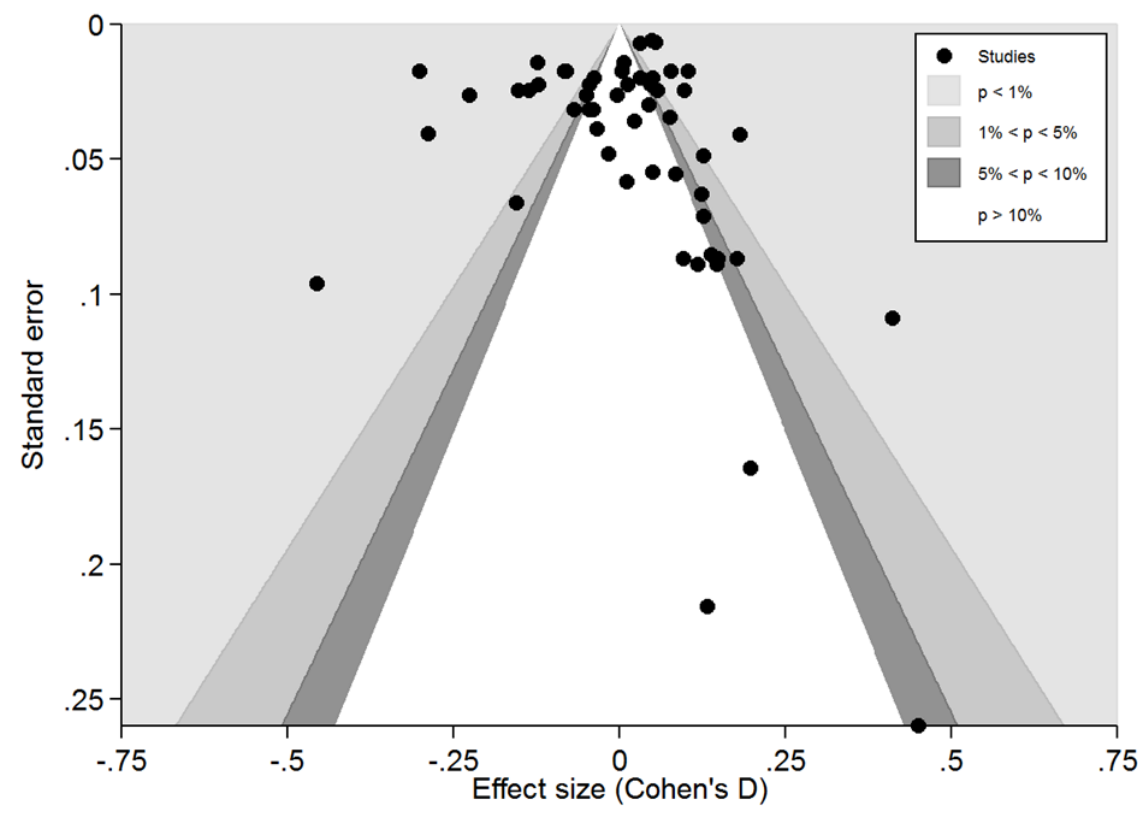

Figure 2.11: Funnel plot of Standard error by effect size. The center of the funnel plot indicates the fixed-effects summary estimates. The sloping lines indicate the expected $95 \%$ confidence interval for a given standard error when assuming that there is no heterogeneity between studies. Stata 14 is used to produce this output. 
Table 2.4: Trim and fill analysis.

\begin{tabular}{cccccc}
\hline Intervention & Status & Pooled & Conf. & $\mathbf{p}$ & No. of \\
& & Est. & Interval & & studies \\
\hline \multirow{2}{*}{ Mentoring } & regular & .131 & {$[.07 ; .20]$} & .00 & 9 \\
& filled & .103 & {$[.03 ; .17]$} & .00 & 12 \\
& regular & .05 & {$[.04 ; .05]$} & .00 & 19 \\
Grants & filled & .05 & {$[.04 ; .05]$} & .00 & 23 \\
& & & & & \\
\hline
\end{tabular}

\subsection{Conclusion}

In this study, we have identified 25 studies and 54 effect sizes of experimental, quasiexperimental, and cohort studies. All of these studies investigate the impact of an academic dismissal policy, faculty-student mentoring, or need-based grants on student outcomes. In particular, we studied the impact of these interventions on enrollment, retention, and graduation. Table 2.5 summarizes the results of our analyses.

In sum, we observe for two of the three interventions positive and significant effects on the outcome variables. The academic dismissal policy has a negative significant effect on retention ( $\mathrm{d}=-.17)$, no effect on graduation within the nominal study time $(\mathrm{d}=.00)$, and a small negative effect on graduation within 6 years $(\mathrm{d}=-.01)$. Thus, the AD policy has led to an increase of dropout of $8.4 \%$ of the intervention group in comparison to the control group (see Table 2.5). This indicates that because of an academic dismissal policy, eight extra students (out of a 100 students) drop out compared to the situation where there was no academic dismissal policy. Student-faculty mentoring, on the other hand, seems to have a positive and significant effect on retention $(\mathrm{d}=.15)$ and graduation $(\mathrm{d}=.10)$. From Table 2.5, we observe that the average intervention effect of mentoring on retention is equivalent 
Chapter 2

Table 2.5: Summary of average effect sizes for overall intervention effects

\begin{tabular}{|c|c|c|c|}
\hline Intervention & Outcome & $\begin{array}{l}\text { Standardized mean } \\
\text { effect (d) } \mathrm{N} \text { of } \\
\text { effect sizes in } \\
\text { parentheses }\end{array}$ & $\begin{array}{l}\text { BESD (Percentage } \\
\text { Improvement in } \\
\text { Treatment over } \\
\text { Control) }\end{array}$ \\
\hline \multirow{4}{*}{ AD policy } & Retention & $-.17(11)$ & $-8.4 \%$ \\
\hline & Graduation & $.00(8)$ & $0 \%$ \\
\hline & $\begin{array}{l}\text { within nominal } \\
\text { time }\end{array}$ & & \\
\hline & $\begin{array}{l}\text { Graduation } \\
\text { within } 6 \text { year }\end{array}$ & $-.01(7)$ & $-.5 \%$ \\
\hline \multirow{2}{*}{ Mentoring } & Retention & $.15(7)$ & $7.5 \%$ \\
\hline & Graduation & $.10(2)$ & $5 \%$ \\
\hline \multirow{3}{*}{ Need-based grants } & Enrollment & $.05(6)$ & $2.5 \%$ \\
\hline & Retention & $.05(6)$ & $2.5 \%$ \\
\hline & Graduation & $.05(7)$ & $2.5 \%$ \\
\hline
\end{tabular}

to a $7.5 \%$ improvement in retention and a $5 \%$ increase in graduation for the intervention groups. This implies that if 100 students are being mentored, 7 students are retained and 5 graduate compared with if they had received the control treatment. This is a more positive finding compared with the results of Hattie (2015) concerning the effect of mentoring ( $d=.09)$ on student achievement. Need-based grants also have positive significant effects on enrollment $(\mathrm{d}=.05)$, retention $(\mathrm{d}=.05)$, and graduation $(\mathrm{d}=.05)$. Need-based grants lead to an increase in enrolment, retention, and graduation of $2.5 \%$ for the intervention group. This implies that if 100 students receive need-based grants, 2-3 extra students enroll, are retained, and eventually graduate compared with if these students did not receive treatment. These findings are somewhat lower than the results of Hattie (2015), who found an effect 
Interventions in higher education and their effect on student success: a meta-analysis

size of .23 concerning the effect of finances on student outcomes. Despite the statistical significance of most findings, the average effect of all interventions are perceived as small (d<.40; Cohen, 1988; Hattie, 2015).

This meta-analysis provides some recommendations for policy makers. Even though the effect sizes of the discussed interventions are perceived as small, this does not indicate that they are not valuable. As Glass, McGaw and Smith (1981, p. 104) state “... the issue of whether an effect should be considered 'large' depends on a number of factors. These might include the costs of implementing the intervention, its practicable feasibility, the benefits associated with the difference produced and the value attached to those benefits, as well as the size of other effects produced by comparable interventions in the same context and with the same outcome”. In the higher education context, this means that policy makers and practitioners should consider the costs associated with implementing different types of interventions relative to the potential gains they can expect in educational outcomes.

The implementation of an AD policy does not come with many costs. Due to an AD policy, dropout in the first year increases by $8.4 \%$. Based on the assumption that students who dropped out because of the AD policy would also have dropped out in later years, an AD policy can lead to substantial cost savings. The average EU-28 country has a cost per student per year of €9,500 (Eurostat, 2016d, see Figure 1.2). Each year 2.8 million Bachelor students enter higher education in the EU (Eurostat, 2016a). If we can accelerate the dropout decision of first-year students ( $8.4 \%$ or 235,200 students) because of the AD policy, this leads to a cost saving of $€ 2,235$ million (see Appendix B for the calculations). However, the dismissed students need to be properly guided to a new higher education study and another higher education degree. As Larsen (2000, p3) states: "people without a degree in higher education, despite the fact that they use less time in the educational system, on average spend eight years less on the labor market, because they more often struggle with unemployment and more frequently end up on early retirement or welfare benefits”. A financial grant of $€ 1,000$ leads to a $2.5 \%$ increase in enrolment, retention and graduation. 
This implies that in the EU-28 countries 70,000 extra students enter and earn a degree. EU governments have to pay $€ 1000$ per student per year for the grant. If the average student graduates within 5 years, this implies a cost for the grant of $€ 350$ million (see Appendix B for the calculations). However, compared with high school graduates, Bachelor's degree holders have a return ${ }^{10}$ of $€ 154,000^{11}$ or $€ 10,800$ million for 70,000 students (OECD, 2014; see Appendix B for the calculations). For society, the return of the extra graduates comes down to $€ 6,300$ million (OECD, 2014; see Appendix B for the calculations). Mentoring leads to an increase of 210,000 first-year EU Bachelor students. The return for each Bachelor degree holder (i.e. the difference between the benefits and costs) is $€ 153,975$ and the return for the society is $€ 89,376$ per graduated student. So the total return for the EU countries will be $€ 51,100$ million (see Appendix B for the calculations). Although mentoring is perceived as a costly intervention, the benefits seem high enough to consider its implementation. Given the above cost-benefit analysis, the discussed interventions seem to be beneficial for students, higher educational institutions, and the society as a whole.

Other important considerations would be the scope of the problems of the higher education institutions or academic programs. Some policy makers may want to select the most promising students after the first year, while other practitioners may want to support students. For the former group, academic probation may be a good option, for the latter group need-based grants and mentoring seem to be the best intervention. Finally, practitioners need to take the effect of these interventions on other educational and personal outcomes into account (e.g. student satisfaction).

\footnotetext{
${ }^{10}$ The costs and benefits included in the calculations of the return are presented in Appendix C.

${ }^{11}$ We would like to note that OECD provides the net present values in American USD. We converted the American USD to EUR using the following exchange rate: $1 \mathrm{USD}=0.95 E U R$. This exchange rate was observed in the beginning of March 2017. The private and public net present earnings is the average of the private net present earnings for men and for woman (OECD, 2014).
} 
Interventions in higher education and their effect on student success: a meta-analysis

We make the observation that academic probation needs to be further exploited. Indeed, at the moment we only found quasi-experimental studies from the US and Canada. Studies from the Netherlands only investigated the effect of academic dismissal policy using cohort research. However, academic probation can still have different effects depending on the nation. Since academic probation is becoming very popular in the Netherlands, a study using a good quasi-experimental design in the Netherlands is necessary. Later chapter 4 will address this issue. Since the use of grants is a measure directly proposed by the European Commission, the need exists to investigate the heterogeneous effects of need-based grants within and between universities. As a result, policy interventions can be tailored. The effect of need-based grants is further exploited in chapter 5 . 


\section{Part II}

Student success on study program level 


\section{Chapter 3}

\section{Efficiency in higher education}

This chapter is based on: Sneyers, E. and De Witte, K. (2016). The interaction between dropout, graduation rates and quality ratings in universities. Journal of the Operational Research Society. In Press. doi: 10.1057/jors.2016.15 
Chapter 3

\subsection{Introduction}

From chapter 2, it has become clear that an academic dismissal policy leads to more dropout but not necessarily to more student graduation. Chapter 3 studies the efficiency of universities with respect to student success. In doing so, we will include the presence of an academic dismissal policy as one of the study program characteristics in the analysis.

Higher education institutions are increasingly held accountable for the quality and efficiency of education they deliver (Archibald \& Feldman, 2008). In order to increase the accountability of higher education institutions, many governments have introduced some form of performance-based funding (PBF). PBF links funding to prescribed performance measures agreed upon by the government and the institution(s). Most PBF mechanisms use a number of different indicators (e.g. the number of degrees awarded or the number of research publications) (Jongbloed \& Vossensteyn, 2001).

This chapter will focus on three important indicators in many PBF-mechanisms: student dropout, program quality ratings and graduation rates. These indicators are seen as indicators of institutional excellence and performance (e.g. Cave et al., 1991). Academic programs (i.e. programs delivered at universities) with high graduation rates and low dropout rates are often considered to be more efficient. They also tend to receive higher quality ratings than academic programs with high dropout and low graduation rates (OCW, 2011; Kokkelenberg, Shina, Porter \& Blose, 2008). Academic quality is often assessed by accreditations in which higher education institutions obtain quality ratings. The procedure involves a process of self-evaluation, a peer review by outside experts and discussion of statistical information and performance indicators (Van Damme, 2000; Van Vught \& Westerheijden, 1994). The accreditation is normally done by a national accreditation agency. Consequently, the quality ratings are measured in a nationwide standardized way and allow for benchmarking between institutions and even academic programs. It should be noted that a high dropout rate should not necessarily lead to low quality ratings as it can 
be the result of selection of the best and most motivated first-year students. By introducing high grading standards, a high difficulty level, heavy workloads and time investments in homework, academic programs try to select the students who have the highest chance of graduating within the nominal study time.

This chapter explores the interaction between student dropout, student graduation and program quality ratings. This is important for two reasons.

First, PBF systems include agreements between the government and the institutions on a (simultaneous) decrease of student dropout, an increase of graduation rates and high program quality ratings (OCW, 2011). Although the literature lacks empirical evidence on whether it is possible to observe these three directions simultaneously, the PBF system pays significant attention to them (e.g. in the Netherlands $7 \%$ of the total higher education budget is reserved for performance agreements which have dropout, completion rates and quality as main indicators). Therefore, it is important to provide empirical evidence regarding the relationship between dropout, graduation rates and quality ratings.

Second, we observe in the underlying data that some academic programs combine low first year dropout rates with high graduation rates (measured as the percentage of students who successfully passed the first year and graduated with maximum one year of delay). Other programs exploit the selective nature of the first year of higher education more (i.e. high grading standards, high workload, etc.) and combine high dropout rates with high graduation rates. However, some academic programs fail in obtaining high graduation rates independently of their dropout rates. This is an alarming finding given the increased attention from governments, higher education institutes, students and parents towards student success. It can be expected that the observed variation between dropout and graduation rates is correlated to program and institutional characteristics. Consequently, it can be interesting to identify program and institutional characteristics that, for given levels of dropout rates, lead to high graduation rates. 


\section{Chapter 3}

Using a non-parametric model, we explore the relationship between student dropout, student graduation and program quality ratings. Further, we explain what makes some academic programs more efficient than others. In the context of this study, a more efficient academic program indicates that, in comparison to academic programs with less or equal dropout, this program is able to achieve a higher graduation rate and quality rating. In particular, we answer the following research questions: (1) Do programs maximize their student graduation rates and program quality ratings given the first year student dropout rates? And (2) what institutional and program characteristics explain this relative efficiency?

Besides its research questions, this study is innovative in more technical ways. To conceptualize the interaction, we rely on recent innovations in efficiency models. While this is not the first study dealing with efficiency in higher education, it is the first focusing on efficiency with academic programs as a unit of analysis. Earlier work used the institution, the academic department, non-academic or auxiliary units within institutions as identification level (e.g. Jongbloed, Salerno \& Kaiser, 2003). Higher order units of analysis might result in aggregation bias as academic programs differ. This study avoids similar biases. Next, this chapter applies a recently developed fully non-parametric conditional efficiency method with continuous and discrete environmental variables. This method allows us to account for heterogeneity in performance assessment by evaluating the impact of environmental variables. Further, this method enables us to test the significance of the control variables on academic programs’ performance. Earlier literature studying higher education efficiency mainly applied standard regression analysis (e.g. Archibald \& Feldman, 2008), Stochastic Frontier Analysis (e.g. Robst, 2001), traditional Data Envelopment Analysis (e.g. Archibald \& Feldman, 2008) or the Free Disposal Hull (e.g. Agasisti , 2011). Each of those methodologies faces one or more of the following disadvantages: (1) specification biases due to their (semi-)parametric nature; (2) outlying 
observations which influence the results of deterministic models; (3) the influence of the control variables is required to be monotone; (4) whether the control variables serve as an input or output has to be chosen a priori; (5) it is often not possible to include multiple control variables; and (6) a separability condition needs to be imposed if one wants to take the operational environment into account (De Witte \& Kortelainen, 2013). The nonparametric conditional efficiency model as described by Cazals, Florend and Simar (2002) and Daraio and Simar (2005) does not suffer from these drawbacks and allows us to test for the direction of the influence of continuous institutional and program characteristics. While Bonaccorsi and Daraio (2008) were the first to apply a conditional efficiency model to higher education institutions, their approach was still unable to estimate direction of the influence of discrete control variables and to test the significance of the control variables on study programs' performance. Using recent extensions by De Witte and Kortelainen (2013), this study will do so.

This study focusses on Dutch universities for which we obtained a rich dataset on the universe of study programs. It includes various program and institutional characteristics such as student satisfaction and student-teacher ratios. The data on dropout, graduation, student satisfaction and quality rating are measured in a nation-wide standardized way. The latter avoids endogeneity issues arising from measurement errors. Despite its focus on the Netherlands, our study is of interest to an international audience. PBF mechanisms are also implemented in many other European and non-European countries. The mechanisms have in common that they aim for high graduation rates and low dropout rates (Benneworth et al., 2011).

The remainder of the chapter unfolds as follows. The next section presents a literature review on graduation rates and quality ratings and on the applied methodologies for measuring efficiency in higher education. Section 3.3 outlines the empirical model. Section 3.4 presents the Dutch setting and discusses the data. Section 3.5 presents the results, while 
Chapter 3

Section 3.6 points to endogeneity issues and presents a robustness test. Section 3.7 includes a conclusion and policy implications.

\subsection{Literature Review}

Despite the multiproduct nature of higher education institutions, i.e. they have to do both research, teaching and provide public services, we focus on the educational outcomes of higher education institutions (see De Witte, Rogge, Cherchye \& Van Puyenbroeck 2013a, 2013b for more discussion concerning the teaching-research nexus of higher education institutions). Particularly our focus on first-year dropout, student graduation rates and program quality ratings assure that concentrating on a single-product (i.e. education) is still valid, as the former three variables are less (or not) influenced by the research capacities of institutions.

There is an increasing attention towards the concepts of first-year dropout, student graduation and program quality ratings. While higher education institutions are able to tightly manage dropout rates by organizational factors, graduation rates and quality ratings are less controllable. Therefore, this chapter provides a framework to examine how student graduation and quality ratings can be increased for given levels of student dropout. We start by summarizing earlier literature that investigates the influence of program and institutional characteristics on graduation rates and quality ratings. Given that we rely on frameworks from the efficiency literature, we discuss in Section 3.2.2 earlier applied efficiency models in higher education.

\subsubsection{Graduation rates and quality ratings}

By following the incentives provided in the allocation of resources, universities are increasingly focusing on student graduation rates (Huisman \& Currie, 2004). Indeed, in the academic year 1998-1999 countries such as Australia, Germany, Japan, The Netherlands 
and the US allocated part of their PBF budget based on graduation rates (Jongbloed, 2001). In order to receive funding, universities were required to focus more on obtaining high graduation rates. Simultaneously, increased attention towards quality emerged in the European higher education sector due to the Bologna Process. This process stimulated international benchmarking to enable comparison between study programs in Europe. Hence, many European countries implemented an accreditation system because it led to independent quality ratings of academic programs or institutions (De Corte, 2014). While in 1998 only six out of 20 countries participating in the Bologna Scheme had an accreditation scheme implemented, 18 out of 20 countries had an accreditation mechanism in place in 2003. Note that accreditation systems had already been in place in the US since the 1980s (Schwartz \& Westerheijden, 2004).

Given those trends, it is important for higher education institutions to know what program and institutional characteristics influence graduation and quality ratings. The earlier literature is summarized in Figure 3.1, which makes a distinction between the influence on program quality and student graduation.

First, consider the characteristics that influence student graduation ${ }^{12}$. The first variable is student satisfaction. Hall (1999) has observed that students who took more than four years to graduate indicated that this was due to dissatisfaction with the teacher and decided to drop the course. Studies often point towards a positive relationship between graduation and satisfaction because of a sense of belonging at and loyalty to the institution that derives from student satisfaction (Tinto, 1993) ${ }^{13}$. Next, there is no consensus regarding the influence of an academic dismissal (AD) policy (see Section 3.3.4.2 for more information

\footnotetext{
${ }^{12}$ Note that graduation rates and quality ratings are often not measured in a consistent way.

${ }^{13}$ However, few studies have investigated the direct relationship between satisfaction and graduation rates.
} 


\section{Chapter 3}

regarding AD polices). Some studies (e.g. Gijbels et al., 2004) have pointed towards a positive influence of an $\mathrm{AD}$ policy on graduation rates. This may indicate that an academic dismissal policy is an effective tool for the selection of well-performing students. Other studies (e.g. Stegers-Jager, Cohen-Schotanus, Splinter \& Themmen, 2011) have found no significant correlation of academic dismissal policies with first-year completion rates. Previous studies which investigated teacher experience have found a positive influence on course graduation rates (e.g. De Paola, 2009). Next, a study by the Education Inspectorate (2009) has found that student graduation rates differ significantly across faculties and subjects (e.g. ICT and Law). These differences may be due to variations in teaching across various academic disciplines (e.g. Neumann, 2001). The literature is inconclusive concerning the influence of the percentage of first-year female students. Porter (2000) and Scott, Bailey and Kienzl (2006) have showed that institutions with a higher ratio of female students have higher six-year graduation rates. These gender differences in degree performance may, for example, be due to differences (i) in characteristics that are correlated with attainment (e.g. family background), and (ii) in psychological and/or biological factors (McNabb, Pal \& Sloane, 2002; Mellanby, Martin \& O’Doherty, 2000). Reason (2003), however, has found no significant relationship of the percentage of female students on student performance. Bailey et al. (2006) have observed a negative relationship between the percentage of female students and the graduation rate. Further, a high share of ethnic minority students has a negative influence on student graduation (e.g. Bailey et al., 2006). This can be explained by the fact that various racial groups have different educational experiences (Reason, 2009). Also, institutional size has a negative relationship with graduation (e.g. Calcagno et al., 2008). If the institution increases in size, the amount of students increases faster than the number of facilities. Consequently, the ratio of people to facilities increases and, in turn, academic and social support suffers (Chickering \& Reisser, 1993). Finally, a low student-teacher ratio correlates to high graduation rates (Bound, 
INSTITUTIONAL CHARACTERISTICS

Institutional size

- Positive influence: Astin \& Solmon, 1981; Sweitzer \& Volkwein, 2009

- Negative influence: Astin \& Solmon, 1981

Admission selectivity (combination of the acceptance rate, the average

standardized test score of enrolled students, and the average undergraduate GPA)

- Positive influence: Astin \& Solmon, 1981; Sweitzer \& Volkwein, 2009

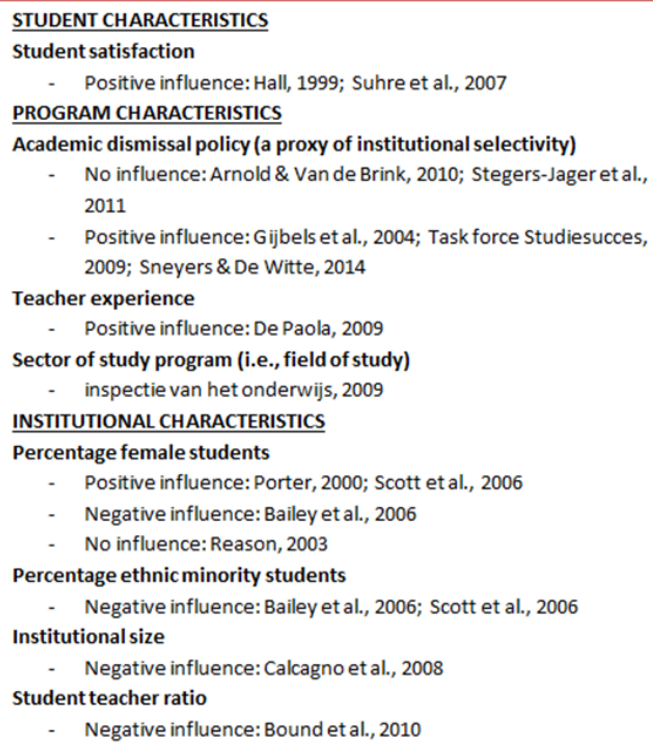

Figure 3.1: Influence of program and institutional characteristics on student graduation rates and program quality ratings observed in previous literature.

Lovenheim \& Turner, 2010). Due to a low student-teacher ratio, there will be frequent interaction between students and teachers what, in turn, will act as a key factor in promoting student academic integration and persistence (Tinto, 2002).

Second, consider the characteristics that influence program quality. Sweitzer and Volkwein (2009) have shown that quality ratings, measured by reputational scores, are positively influenced by a combination of institutional size and student admission selectivity (see Figure 3.1 for a definition of student admission selectivity). In the same line, 


\section{Chapter 3}

Astin and Solmon (1981) have concluded that large, highly selective institutions have substantive correlations with overall quality of undergraduate education. Note, however, that while selectivity in itself has a positive relationship to quality ratings, institutional size in itself has a negative relationship to quality ratings. We also observe that the studentfaculty ratio is negatively associated with quality measures (Drennan \& Beck, 2001).

\subsubsection{Applied methodologies for measuring efficiency in higher education}

One possible way to focus on the relationship between student dropout, student graduation rates, and quality ratings is by using an efficiency framework (see next section). While this is the first study to connect the three variables, it is not the first to apply efficiency models to higher education settings. Various techniques exist, which lead to different insights.

Regression analysis was the first methodology applied to study university efficiency. Johnes and Taylor (1990) have showed that variations in a small number of input variables determine large inter-university variations in output measures (e.g. student completion rates and labor market success of graduates). Furthermore, it became clear that rankings of universities based on raw output measures differ from those based on input variables. Johnes (2006) have concluded that although some information on performance can be derived from applying regression analysis, the construction of performance indicators by regression analysis is not recommended. Indeed, those performance indicators are derived from a production function which is an average line through the data rather than a frontier around the data.

Frontier methods such as Stochastic Frontier Analysis (SFA) and Data Envelopment Analysis (DEA) address the above problem and are both used in the context of higher education (see Salerno, 2003 for an excellent summary of efficiency studies in six countries using SFA and DEA). However, the production process of universities is largely unknown. Nevertheless, SFA requires a parametric specification and assumptions on how efficiency 
is distributed. Incorrect assumptions concerning the functional form will invariably lead to biased and inconsistent estimators (Salerno, 2003).

The non-parametric DEA effectively deals with this limitation. As efficiency estimates in DEA are based on the behavior of the other observations, no assumptions about efficiency have to be made a priori. Furthermore, due to the inclusion of distance functions in DEA it is also possible to examine multiple inputs and multiple outputs (Coelli \& Perelman, 1999, 2000; Kumbhakar \& Lovell, 2000; Lovell, Travers, Richardson \& Wood, 1994; Salerno, 2003). Not surprisingly, DEA is widely applied to universities. Examples exist for the United States (e.g. Kokkelenberg et al., 2008), the United Kingdom (e.g. Stevens, 2001), Australia (e.g. Abbott \& Doucouliagos, 2003), Canada (McMillan \& Datta, 1998), and the Netherlands (e.g. Jongbloed et al., 2003).

Efficiency estimations which do not account for the operational environment only have a limited value. Consequently, traditional nonparametric methods to estimate efficiency, such as DEA, are being directed towards the inclusion of exogenous covariates. Indeed, it is possible that some of the observations in the same sample are operating in different environments. For example, in measuring the grade averages of higher education institutions it is necessary to consider the type of higher education institution. Failure to account for this external factor may well discriminate the efficiency results in favour of the higher education institutions which are private. Private institutions select their students better and students in private institutions are often from more educated families. We can expect that these institutions reach a higher average grade. Failure to account for environmental factors is bound to confound results and may lead to unreliable economic decisions (Avkiran \& Rowlands, 2008). The literature discusses various approaches (e.g. one-stage approach, frontier separation approach, two stage approach) to take external control variables into account in nonparametric efficiency analysis. The conditional efficiency approach seems to be the most promising method to include exogenous control variables into nonparametric frontier models (see for a discussion De Witte \& Kortelainen, 
Chapter 3

2013). Not surprisingly, the conditional efficiency approach is increasingly used, including studies concerning the productivity of universities (e.g. Bonaccorsi, Daraio \& Simar, 2007; Bonaccorsi and Daraio, 2008; De Witte \& Hudrlikova, 2013).

\subsection{A non-parametric technique to estimate the interaction}

University programs can choose to exploit the selective nature of the first year in order to increase completion rates and quality ratings. Some university programs allow most students to enroll in the second year. Other programs select during the first year only the best students, which can continue to the second year. Consequently, this choice will influence the first-to-second-year dropout rate. This in turn will influence the quality and graduation rate of the programs.

From a conceptual point of view, this interaction resembles a production process where university programs are characterized by a set of inputs $x\left(x \in \mathbb{R}_{+}^{p}\right.$; in our case dropout rates) and outputs $y\left(y \in \mathbb{R}_{+}^{q}\right.$; in our case completion rates and quality ratings). All feasible combinations of the relationship are characterized by $\Psi=\{(x, y) \in$ $\mathbb{R}_{+}^{p+q} \mid x$ can produce $\left.y\right\}^{14}$. Within this interaction, we can identify programs which obtain for a given dropout rate $(x)$ the highest completion rates and quality ratings $(y)$. Vice versa, there are programs that do obtain the highest possible graduation rate and quality rating given their dropout level. By combining these 'best practice’ observations we obtain a 'trade-off line', which represents the maximum trade-off between dropout, completion and quality ${ }^{15}$. Indeed, observations on this trade-off line are non-dominated observations in the sense that they are the academic programs which reach the highest completion rates and

\footnotetext{
${ }^{14}$ Note that academic programs, given their dropout, can choose not to obtain the highest graduation rate and quality rating as possible (i.e. the Free Disposability Assumption). Further in the section, we discuss this more deeply.

${ }^{15}$ Note that in the DEA literature, this 'trade-off line' is known as the 'efficient frontier'.
} 
quality ratings for a given dropout rate. Vice versa, observations below the trade-off line could increase their completion and quality rates for a given level of dropout. The radial increase in completion rates and quality ratings can be estimated by $\lambda$ :

$$
\lambda(x, y)=\sup \{\lambda \mid(x, \lambda y) \in \boldsymbol{\Psi}\},
$$

Where $\lambda(x, y) \geq 1$ is the proportionate increase of outputs, which the academic program operating at level $(x, y)$ should attain to operate at the efficient combination of dropout, completion and quality rate (i.e. $\lambda(x, y)=1$ ).

We can operationalize the estimation of $\lambda$ by imposing a free disposability assumption. It is defined as: $\forall(x, y) \in \Psi$, if $\tilde{x} \geq x$ and $0 \leq \tilde{y} \leq y$ then $(\tilde{x}, \tilde{y}) \in \Psi$. The production possibility set is then estimated as:

$$
\widehat{\Psi}_{F D H}=\left\{(x, y) \in \mathbb{R}_{+}^{p+q} \mid y \leq y_{i}, x \geq x_{i},\left(x_{i}, y_{i}\right) \in x_{n}\right\}
$$

Where $x_{n}$ represents the sample set. Equation (1.2) resembles the Free Disposal Hull model by Deprins et al. (1984). The estimated shortfall in completion rates and quality ratings, for a given dropout level, is then measured by:

$$
\lambda(x, y)=\sup \{\lambda \mid(x, \lambda y) \in \widehat{\Psi}\},
$$

This non-parametric model has two major drawbacks: (1) it is deterministic, and (2) it does not take heterogeneity among programs into account. We start by discussing the first issue. The deterministic nature of the estimator arises from the fact that all $n$ programs in the sample $x_{n}$ are considered to be potential best practices: $\operatorname{Prob}((x, y) \in \Psi)=1$. Consequently, outliers and atypical observations heavily affect the trade-off line and thus 


\section{Chapter 3}

potential increase in outputs for given inputs. We follow Cazals et al. (2002) in estimating equation (1) relatively to a partial frontier. This partial frontier depends on a random set of $m<n$ programs. These observations are repeatedly drawn (B times) with replacement among the population of academic programs which use less inputs than the level of $x$. By considering the expected value of this less extreme benchmark, the robust efficiency estimate $\lambda_{m}(x, y)$ is obtained. A robust estimate $\lambda_{m}(x, y)$ can acquire a 'super-efficiency' score (i.e. an output-efficiency score of $\lambda_{m}(x, y)<1$ ) when it is on average performing superior than its $m$ randomly drawn (with $x_{i} \leq x$ ) reference units. These 'super-efficient' observations indicate that the program produces for a given input vector $x$ a higher output vector $y$ than the average $m$ evaluated programs in the reference set. In other words, the super-efficient program is thus doing better than expected (De Witte \& Kortelainen, 2013).

Next, we tackle the issue of heterogeneity. Traditional non-parametric models assume a separability condition such that the operational environment does not influence the level of inputs and outputs. However, in real life this is not realistic as, e.g. the student characteristics influence both the dropout and completion rates. The conditional efficiency approach, formulated by Cazals et al. (2002) and Daraio and Simar (2005, 2007), allows us to take the operational environment into account. While using the robust efficiency estimate, the idea is to draw the subsample of size $m$ so that similar programs have a higher chance of being drawn. The weights are obtained by estimating a kernel density function around the control variables:

$$
K\left(\frac{\left(z-z_{i}\right)}{h}\right)
$$

where $\mathrm{z}$ denotes a vector of continuous and discrete control variables, $\mathrm{K}($.$) is an$ appropriate Kernel and h is the bandwidth (see De Witte and Kortelainen, 2013 for a discussion on the appropriate Kernel and bandwidth). More precisely, the procedure works 
as follows. For a given $x$, draw a subsample of size $m$ with replacement and with a

probability $K\left(\frac{\left(z-z_{i}\right)}{h}\right) / \sum_{j=1}^{n} K\left(\frac{\left(z-z_{i}\right)}{h}\right)$ among those $\mathrm{yi}_{\mathrm{i}}$ such that $\mathrm{x}_{\mathrm{i}} \leq \mathrm{x}$. Compute for this subsample with only comparable observations the FDH output-oriented efficiency score. Finally, repeat this procedure at least 2000 times and take the average of the 2000 efficiency scores. It should be noted that the integral formulation as discussed in Daraio and Simar (2007) is faster to compute. The conditional efficiency estimates $\lambda_{m}(x, y \mid z)$ compare like with likes (comparable to a matching approach).

De Witte and Kortelainen (2013) have presented a procedure for statistical inference regarding the influence of the control variables. This procedure is implemented by nonparametrically regressing the control variables on the ratio of the conditional $\lambda_{m}(x, y \mid z)$ to the unconditional $\lambda_{m}(x, y)$ model. An increasing regression line indicates a positive influence, a decreasing line indicates an average negative influence and a horizontal line indicates a neutral influence. A positive relationship implies that the control variable $Z$ acts as an additional free disposal input, while a negative relationship means that the control variable $Z$ uses more inputs than expected and thus constraints the production like an undesired output (Daraio \& Simar, 2007). Finally, using a non-parametric bootstrap on this non-parametric regression permits us to obtain statistically inference on the correlation between the efficiency score and the control variables.

\subsection{The Dutch setting and variables}

\subsubsection{Dutch setting}

Universities prime students for independent scientific work in an academic or professional setting. Approximately one-third of the Dutch higher education students enroll in universities (Huisman, 2008). Academic education comprises of 17 governmental funded universities. Since secondary education, students are tracked for continuing education and 


\section{Chapter 3}

prepared for specific disciplines (De Koning et al., 2014). In the Netherlands, there is an open higher education system in place. Students who hold a certificate of pre-university education or a first-year certificate of vocational education can enter universities (Huisman, 2008). There are no other entry requirements in place ${ }^{16}$.

In line with the European Credit Transfer System, Dutch universities offer programs of 60 study points per year since 2002. Credit points represent the workload or 'study time' necessary to complete a course or program. The workload consists of the actual hours spend in classes and the hours needed to prepare for classes, exams and other assessments. In the Netherlands, as in most European countries, a credit point represents a workload of 28 hours, meaning that a program year comprises of 1680 hours.

\subsubsection{The data}

The data are provided by the Dutch Ministry of Education ('Dienst Uitvoering Onderwijs', DUO). The data consist of information at program-level regarding the number of first-year students, the dropout rate, the switch rate (i.e. students changing between programs within an institution), the number of students who re-enroll after the first year, and student success for Dutch universities for the academic years 2010-11 and 2011-12. All indicators concern Bachelor students.

Student dropout and student graduation rates, two program-level variables of interest, are defined as follows. Student dropout is defined as the percentage of full-time Bachelor students that cease their education at the institution during the first year of enrolment. Note that in order to be included in this variable, students need to dropout from the institution. Student dropout can be a voluntary action (i.e. dropout due to illness or mismatch with the

\footnotetext{
${ }^{16}$ The only exceptions are the numerus fixus programs in medicine, dentistry and other areas that have a limited number of student places. Numerus fixus means that programs can choose which students they will accept. Note that only .30 percent of the available places can be filled in by this practice (Jongbloed, 2003).
} 
program/institution), or an involuntary action (i.e. because one did not acquire sufficient credits). Student graduation rates are defined as the share of re-enrolled full-time Bachelor students that complete their degree at the institution one year after the nominal study time ${ }^{17}$. Consequently, in order to be included in the latter indicator, students enrolled in universities need to graduate in four years (see Table 3.1 for the definition of the variables).

Next, we add a quality rating to the data. This latter variable is based on accreditations of the Dutch-Flemish Accreditation Organization (NVAO). Accreditation by the NVAO is a precondition to receive funding from the government. Furthermore, a positive accreditation gives academic programs the right to award diplomas and to grant financial assistance to students. Accreditation thus entails that an academic program satisfies certain quality standards. The report of an external peer-reviewed panel leads to the decision to accredit. This report, in turn, is based on the NVAO framework which consists of 30 criteria (Stensaker \& Harvey, 2006). We focus on one of these criteria, i.e. the program-level variable program quality ratings. This latter variable ranges between 0 (insufficient) and 3 (excellent). It is a composite indicator of three underlying scores: the level of the academic program, the orientation of the program and domain specific requirements (see Table 2.1 for an overview of this variable and its definition). The level of the academic program represents the degree to which the achieved qualifications correspond to general, internationally accepted descriptions of the qualifications of a Bachelor. Next, the accreditation domain specific requirements is linked to the extent to which the program fulfills the requirement for similar (foreign) programs. The accreditation orientation reflects (i) whether holders of university Bachelor's degrees have obtained the qualifications to allow admission to at least one subsequent university course at the Master's level and/or to allow access to the labor market, and (ii) whether the achieved qualifications

${ }^{17}$ Thus, the student graduation rate is measured conditional on first-year dropout. 


\section{Chapter 3}

are derived from the requirements of scientific disciplines, international scientific practice and relevant practice in the occupational field.

The data are further enriched by information at the program-level obtained from the annual national questionnaire on student satisfaction ('nationale studentenenquête', NSE), which is annually carried out by the organization Studiekeuze123. The survey includes data on the opinion of students about the higher educational program they are taking. The data also contain program features and institutional information (see Table 3.1 for an overview of the variables and their definition). In particular, we are interested in the following program characteristics. Program satisfaction of students (measured by the following question "give your overall judgment about the program") which gives qualitative information at program-level about student satisfaction and which is proxied by a variable between 1 (very dissatisfied) and 5 (very satisfied). Further, we include the variables percentage of first-year female students (i.e. the percentage of first-year female students enrolled in the academic program), percentage of first-year ethnic minority students (i.e. the percentage of first-year foreign students) and $A D$ policy threshold (i.e. the threshold of the academic dismissal policy). The latter variable serves as a proxy for selectivity. The academic dismissal policy is grounded on the number of credits. Students who do not earn sufficient credits after the first-year are dismissed from the program and from the institution. The higher the AD policy threshold of an academic programs, the higher the degree of selectivity since students have to earn more credits to enroll in the second year. The variable Academic program denotes the subject of the academic program (e.g. math, ICT or law). Including it in the analysis allows us to capture the unobserved heterogeneity at subject level which could arise, e.g. from the different nature of the academic curriculum. 
Table 3.1: Overview of the definition of the variables

\begin{tabular}{|c|c|}
\hline Variables & Definition \\
\hline Student dropout & $\begin{array}{l}\text { The percentage of full-time Bachelor students that cease their } \\
\text { education at the institution during the first year of enrollment. } \\
\text { These students will not enroll in the second year. }\end{array}$ \\
\hline Graduation rate & $\begin{array}{l}\text { The share of re-enrolled full-time Bachelor students that } \\
\text { complete their degree at the institution one year after the } \\
\text { nominal study time. The student graduation rate is measured } \\
\text { conditional on first-year dropout. }\end{array}$ \\
\hline Quality ratings & $\begin{array}{l}\text { A composite indicator of three underlying scores: the level of } \\
\text { the academic program, the orientation of the program and } \\
\text { domain specific requirements. It is measured by an } \\
\text { independent organization NVAO. }\end{array}$ \\
\hline $\begin{array}{l}\text { Student program } \\
\text { satisfaction }\end{array}$ & $\begin{array}{l}\text { Measured by the following question "give your overall } \\
\text { judgment about the program". }\end{array}$ \\
\hline $\begin{array}{l}\text { First-year female students } \\
(\%)\end{array}$ & $\begin{array}{l}\text { The percentage of first-year female students enrolled in the } \\
\text { academic program. }\end{array}$ \\
\hline $\begin{array}{l}\text { First-year ethnic minority } \\
\text { students (\%) }\end{array}$ & $\begin{array}{l}\text { The percentage of first-year foreign students enrolled in the } \\
\text { academic program. }\end{array}$ \\
\hline $\begin{array}{l}\text { AD-policy threshold (credit } \\
\text { points) }\end{array}$ & $\begin{array}{l}\text { The threshold of the academic dismissal policy in place at the } \\
\text { academic program. This variable serves as a proxy of } \\
\text { selectivity. }\end{array}$ \\
\hline Academic program & $\begin{array}{l}\text { Denotes the subject of the academic program (e.g. math, ICT } \\
\text { or law). }\end{array}$ \\
\hline Number of students & The number of students enrolled at the institution. \\
\hline Student-teacher ratio & $\begin{array}{l}\text { The number of students per teacher employed at the } \\
\text { institution. }\end{array}$ \\
\hline Faculty > 50 years $(\%)$ & $\begin{array}{l}\text { The percentage of faculty older than } 50 \text { years employed at the } \\
\text { institution. }\end{array}$ \\
\hline
\end{tabular}




\section{Chapter 3}

As institutional characteristics we include: the number of students as a proxy of institutional size, the student-teacher ratio, and the percentage of faculty older than 50 years. This latter variable measures the percentage of faculty older than 50 years employed at the institution. The former variable measures the number of students per teacher employed at the institution.

While the dropout rate deals with the students that started in 2010-11 or 2011-12, student graduation concerns students that graduated in 2010-11 and 2011-12. The underlying assumption is that the trend of the dropout rates between different years, and thus between different cohorts of students, is comparable. This seems very likely given observations by the Dutch association of universities (VSNU, 2012) that showed that the trend of the first-year dropout rate remained stable between the academic years 2005-06 and 2010-11.

Given the different nature of the Open University, which focusses on distance learning, and of three religious universities, which prepare students for religious duties (e.g. priest), we leave them aside in the analysis even though they are state funded institutions. The sample is further restricted to Bachelor programs since the data only contain information on Bachelor programs. Next, we eliminate programs for which the student success or student dropout rate is zero or 100 percent. Such atypical rates can influence our analysis and are probably linked to programs that have just started or that are going to be terminated. The final sample includes 420 higher educational programs (i.e. an average of 210 study programs per year) at 13 universities. For the academic year 2010-11 we have a sample size of 200, while we have a sample size of 220 for the academic year 2011-12 ${ }^{18}$.

\footnotetext{
${ }^{18}$ Note that these sample sizes differ because we only included programs which have information on all the control variables. Programs with missing values are thus removed. There are more academic programs with missing values in the academic year 2010-11 compared to 2011-12. This is not surprising since the data gathering of Studiekeuze123 is improving every year.
} 


\subsubsection{Descriptive statistics of the interaction between dropout and quality adjusted}

\section{graduation rates}

Given the dropout level in the first-year, academic programs have to maximize completion rates and quality ratings. Dropout is an appropriate input variable given the Dutch open higher education system. In the Netherlands, students with the right qualifications can enter the study programs of their choice. Therefore we expect that the student body of academic programs is fairly homogenous and that differences in dropout level are due to choices of the programs themselves (i.e. guidance of students, grading standards, and workload). Note, that the combination of the output variables (i.e. graduation rates and quality ratings) can be interpreted as a quality corrected graduation rate.

Although this study is innovative in the way it deals with the relationship between student dropout, graduation rates and program quality ratings, those variables have been used in earlier efficiency literature. Avkiran (2001) has conducted an efficiency analysis of 36 Australian universities in which the student retention rates has been included in the analysis. Completion and graduation rates have been used as outputs before by, e.g. Johnes (1996, 2006), Johnes and Taylor (1990), and Kokkelenberg et al. (2008). As argued by Johnes (2006), the advantage of such degree measures is that they capture an element of both quantity and quality of teaching output.

Some descriptive statistics at program-level are presented in Table 3.2. We observe that academic programs have an average first-year student dropout of 20 percent. This suggests that, on average, 20 percent of the full-time Bachelor students cease their education at the institution after the first year of enrollment. However, while some programs have an extremely low dropout rate (i.e. 2 percent), other programs have to deal with an extremely high dropout rate (i.e. 52.2 percent). Moreover, it appears that medical programs (such as a dentistry program) have on average the lowest dropout rate. Artistic programs (such as music science) often have high dropout rates. Academic programs have, on average, a 
Table 3.2: Descriptive statistics at program level

\begin{tabular}{|c|c|c|c|c|c|c|}
\hline & & Minimum & Median & Mean & Maximum & St. Dev. \\
\hline \multirow[t]{2}{*}{ Output } & Student graduation rates (\%) & 8.30 & 62.50 & 61.40 & 93.80 & 16.50 \\
\hline & $\begin{array}{l}\text { Program quality ratings }(0=\text { insufficient; } \\
1=\text { sufficient; } 2=\text { good; } 3=\text { excellent })\end{array}$ & 1.00 & 1.00 & 1.20 & 3.00 & 0.50 \\
\hline \multirow{4}{*}{$\begin{array}{l}\text { Control } \\
\text { variables }\end{array}$} & First-year female students (\%) & 2.00 & 52.40 & 49.30 & 100.00 & 24.70 \\
\hline & First-year ethnic minority students (\%) & 2.10 & 19.10 & 23.20 & 96.40 & 14.30 \\
\hline & Student-teacher ratio & 14.46 & 32.04 & 29.21 & 43.11 & 6.35 \\
\hline & Faculty > 50 years $(\%)$ & 13.90 & 29.30 & 29.20 & 66.00 & 8.00 \\
\hline
\end{tabular}


student graduation rate of 61.4 percent. This means that, on average, 61.4 percent of the students who re-enrolled after the first year complete their degree in maximum four years. Again we observe that some programs achieve a high student graduation rate (i.e. 93.8 percent), while others achieve very low graduation rates (i.e. 8.3percent). We observe that study programs of liberal arts colleges and Medical programs have, on average, the highest graduation rate. More technical study programs appear to have, on average, the lowest graduation rate. Next, we see that the average program achieves a quality rating of 1.2 (i.e. sufficient). A limited number of linguistic academic programs achieved an excellent rating. Concerning program satisfaction, the summary statistics show that students rate their academic programs on average 4.1. This means that students are, on average, satisfied with their study program. Furthermore, we observe that the first-year student population of academic programs consists on average of 49.3 percent female students and 23.2 percent minority students. Academic programs with an AD policy have on average a threshold of 41.3 credit points. Finally, the average program is part of an institution with 21,590 students enrolled, a student-faculty ratio of 29.2 and a faculty that consists for 29.2 percent of people older than 50 years.

The optimal size of the partial frontier $m$ is selected following Daraio and Simar (2005). They suggested to use the value of $m$ for which the percentage of super-efficient observations (i.e. $\lambda_{F D H}^{m}<1$ ) stabilizes. In the sample under study, $m$ corresponds to 100 . Finally, for statistical inference, we use 2000 bootstrap replications. ${ }^{19}$

${ }^{19}$ The number of bootstrap replications only matters for the statistical inference. The conditional order-m model has been estimated in $\mathrm{R}$ by using the integral formulation, as this procedure is more time efficient and precise. 


\subsection{Results of the efficiency analysis}

\subsubsection{Relationship between the input and the output variables}

We start by correlating the input and output variables in order to obtain some intuitive information on the data. The results are presented in Table 3.3. We observe a significant negative relationship between student dropout and student graduation for the academic year 2010-11 and a negative insignificant correlation for the academic year 2011-12. These findings suggest that a lower dropout rate often leads to a higher graduation rate. This is in line with, e.g. Hosch (2008) and Lau (2003). However, the relatively weak negative correlation also indicates that programs with a high dropout rate do not necessarily succeed in obtaining high graduation rates. This is surprising since a high dropout rate after the firstyear is not necessary a bad thing in the open higher education system in place in the Netherlands. Moreover, a high dropout rate can be an indication of selection in the first year for retaining the best and most motivated students while rejecting the 'worst' students (e.g. based on the accumulated study points). If this is the case, a high dropout rate should enable a high graduation rate. Since this is not observed for all programs, it is interesting to identify the characteristics that enable programs to obtain a higher graduation rate.

Table 3.3: Correlation of the input variable (dropout) on the output variables (graduation rates and quality ratings).

\begin{tabular}{lcccc}
\hline \hline $\begin{array}{l}\text { Independent } \\
\text { variable }\end{array}$ & $\begin{array}{c}\text { Graduation } \\
\text { rates }\end{array}$ & $\begin{array}{c}\text { Graduation } \\
\text { rates }\end{array}$ & Quality ratings & Quality ratings \\
\hline student dropout & $-0.369 * * *$ & -0.020 & -0.001 & $-0.007^{*}$ \\
& $(0.132)$ & $(0.117)$ & $(0.003)$ & $(0.004)$ \\
Year & $2010-11$ & $2011-12$ & $2010-11$ & $2011-12$ \\
$\mathrm{R}^{2}$ & 0.038 & 0.0001 & 0.0003 & 0.02 \\
$\mathrm{~N}$ & 200 & 220 & 200 & 220 \\
\hline \hline
\end{tabular}

Note: The regression includes a constant. Standard error between brackets. ${ }^{* * *}$ and $*$ denote significance at $1 \%$ level and $10 \%$-level respectively. 
In a similar vein, we regress program quality ratings (i.e. the second output variable) on student dropout. The results in the third and fourth column of Table 3.3 indicate an insignificant negative relationship between quality ratings and student dropout for the academic year 2010-11 and a significant negative relationship for the academic year 201112. This suggests that programs that obtain higher quality ratings suffer less from student dropout in comparison to programs that achieved lower quality ratings. This finding is in line with studies that imply that retention is a relevant measure of academic quality improvement ${ }^{20}$ (e.g. Lee \& Buckthorpe, 2008).

\subsubsection{Student graduation rates and program quality ratings for given dropout rates}

We estimate the extent to which programs are able to exploit student dropout in order to acquire higher quality ratings and graduation rates. The results of this interaction are presented in Table 3.4. In column 1 , we summarize the results of the robust order- $m$ estimations (i.e. the unconditional efficiency). We obtain an average score of 1.37. This indicates that, on average and for a given first-year dropout level, Dutch academic programs can increase their quality adjusted graduation rates by approximately $37 \%$ if they would operate as good as the best practices (i.e. those academic programs that are obtaining the highest student graduation rates and quality ratings for a given student dropout). However, there is a significant variation in the performance across academic programs, as can be seen from the sizeable standard deviation around the mean. We observe that technical programs are, on average, the least efficient. Furthermore, some academic programs have an efficiency score below 1. These 'super-efficient' programs (mostly medical study programs) are performing better than the average $\mathrm{m}(\mathrm{m}=100)$ academic programs in their

\footnotetext{
${ }^{20}$ Note that when we combine the two years in one dataset and we do the above analyses again we find similar results. Moreover, we find a significant negative correlation between the graduation and dropout rate and an insignificant negative relation between graduation rate and the quality ratings.
} 
Table 3.4: Efficiency scores which exclude (unconditional) and include (conditional) the program and institutional characteristics

\begin{tabular}{lc|cc}
\hline \hline & Unconditional (robust & \multicolumn{2}{c}{ Conditional } \\
& FHD) & Model 1 & Model 2 \\
\hline Average & 1.371 & 1.002 & 1.004 \\
St. Dev. & 0.354 & 0.024 & 0.040 \\
Min & 0.821 & 1.000 & 1.000 \\
Max & 2.766 & 1.490 & 1.562 \\
\hline \hline
\end{tabular}

The efficiency scores denote the proportionate increase of completion rates and quality ratings, which an academic program with a given dropout level could achieve if it would operate as efficient as the best practice observation.

reference sample. Concerning language studies we find mixed results. Some linguistic programs obtain a very low efficiency rating while others are 'super-efficient'.

To examine how this relationship is influenced by institutional and academic program characteristics, we apply the conditional efficiency model

with a mix of 8 discrete and continuous control variables ${ }^{21}$. Our previous findings change in two important ways. First, we can accurately explain the variation among programs. After including the control variables, the average efficiency score does not longer significantly deviate from 1 . Taking all exogenous variables into account, the conditional efficiency score reduces to 1.002 (Model 1). By excluding the percentage of faculty older than fifty years as exogenous variable, the conditional efficiency reduces to 1.004 (Model 2). Now, the least efficient academic programs are the technical academic programs. In both

${ }^{21}$ In line with Jongbloed et al. (1994, 2003), we divided the academic programs into an arts, a sciences and a medical cluster and reran the analyses. The results of the arts cluster are robust with the current findings. The results of the sciences cluster showed differences concerning the influence of the control variables. Due to insignificant power we did not find results for the medical cluster. 
models there are also no 'super-efficient' units anymore. Second, the standard deviation around the average reduces significantly in both models.

These results show that a large part of the initial variation in program efficiency can be explained by the control variables. Consequently, we are able to determine the variables which explain why some programs do not succeed in obtaining high student graduation rates and program quality ratings for a given dropout level.

We examine the direction of the influence (i.e. favorable or unfavorable) of the program and institutional characteristics by non-parametrically regressing the control variables on the ratio of the conditional to the unconditional efficiency scores. After examining the significance tests and the partial regression plots for the discrete and continuous variables, we observe that the program characteristics have a significant influence on the efficiency scores. In other words, program characteristics matter for the degree to which completion rates and quality ratings can improve, for given dropout rates. For institutional characteristics we only find a significant influence for the variable percentage of faculty older than 50 years (see Table 3.5).

We start by discussing the relationship of the program characteristics. The favorable influence of program satisfaction indicates that, for a given dropout level, programs with a high level of student program satisfaction succeed in obtaining higher quality adjusted graduation rates in comparison to programs with a low level of student program satisfaction. Next, we observe a favorable significant influence of the percentage of first-year female students. This indicates that, for a given dropout rate, a high percentage of first-year female students is a characteristic of programs with high student graduation rates and high quality ratings. For first-year ethnic minority students we found a significant unfavorable influence. Thus, for a given level of student dropout, the presence of a high share of ethnic minority students will result in low graduation rates and low quality ratings. For the variable 


\section{Chapter 3}

Table 3.5: Influence and significance of program and institutional characteristics that influence the relationship between dropout, graduation rates and quality ratings

\begin{tabular}{|c|c|c|}
\hline & Model 1 & Model 2 \\
\hline \multirow[t]{2}{*}{ Student program satisfaction } & Favorable & Favorable \\
\hline & $(<2 \mathrm{E}-16)^{* * *}$ & $(<2 \mathrm{E}-16)^{* * *}$ \\
\hline \multirow[t]{2}{*}{ First-year female students (\%) } & Favorable & Favorable \\
\hline & $(0.004)^{* * *}$ & $(0.022)^{* *}$ \\
\hline \multirow[t]{2}{*}{$\begin{array}{l}\text { First-year ethnic minority } \\
\text { students (\%) }\end{array}$} & Unfavorable & Unfavorable \\
\hline & $(<2 \mathrm{E}-16)^{* * *}$ & $(<2 \mathrm{E}-16)^{* * *}$ \\
\hline \multirow[t]{2}{*}{ AD-policy threshold } & Favorable & Favorable \\
\hline & $(<2 \mathrm{E}-16)^{* * *}$ & $(<2 \mathrm{E}-16)^{* * *}$ \\
\hline \multirow[t]{2}{*}{ Academic program } & Favorable & Favorable \\
\hline & $(<2 \mathrm{E}-16)^{* * *}$ & $(0.022)^{* *}$ \\
\hline \multirow[t]{2}{*}{ Number of students } & Unfavorable & Unfavorable \\
\hline & $(1.000)$ & $(1.000)$ \\
\hline \multirow[t]{2}{*}{ Student-faculty ratio } & Unfavorable & Unfavorable \\
\hline & $(1.000)$ & $(1.000)$ \\
\hline \multirow[t]{2}{*}{ Faculty>50 years (\%) } & Favorable & \\
\hline & $(<2 \mathrm{E}-16)^{* * *}$ & \\
\hline
\end{tabular}

$\overline{\text { Note: Bootstrapped p-values between brackets; } * * *, * *, * \text { denote significance at } 1 \%, 5 \% \text { and } 10 \% \text { - }}$ level.Where 'favorable' ('unfavorable') denotes that the variable has a positive (negative) influence on the proportionate increase of completion rates and quality ratings, which an academic program with a given dropout level could achieve if it would operate as efficient as the best practice observation. 
academic dismissal policy threshold we observe a favorable significant influence on student graduation and program quality ratings (for given dropout rates). We further observe that there are significant differences between subjects.

Although we did not find a significant relationship for all the different institutional characteristics, we discuss the results of all variables for completeness. First, we observe a significant positive influence of the percentage of faculty older than 50 years. Thus, for a given dropout level, programs with high quality adjusted graduation rates are characterized by a high percentage of faculty older than 50 years. The next two institutional variables, number of students enrolled and student-teacher ratio, have an unfavorable insignificant relationship on

student graduation and program quality ratings (for given dropout rates). The former indicates that student graduation and quality ratings (for given dropout rates) is harmed when more students are enrolled. Finally, a low student-faculty ratio is a significant characteristic of programs with high graduation rates and high quality ratings (for a given dropout rate).

While the non-parametric technique does not allow us to directly examine whether the control variables are more influential for one output or another, we run some correlations to investigate this. We observe that the satisfaction of the students has a larger favorable association with quality ratings than with the graduation rate. The opposite is found for the variables academic dismissal policy and percentage of first-year female students. The level of the academic dismissal policy and the percentage of female students have a larger positive association with graduation rates compared to quality ratings. We also found that the percentage of ethnic minority students and the percentage of faculty older than 50 years have a similar influence on both output variables. 


\subsection{Self-selection of students and a robustness test}

The results might be prone to endogeneity, due to self-selection of students in study programs. The presented results assume that students do not choose a study program on the basis of the selection criteria. We expect that this assumption holds as all students, with the necessary certifications, can start in a study program in the Netherlands (i.e. there is little or no selection at the gate). Consequently, study programs have a fairly homogenous student population.

However, recently, selection after the gate became possible. The AD policy selection tool only allows students to enroll in the second year when they have earned a sufficient number of credits. Study programs decide on the credit norm that students have to pass. In this context, it is possible that students base their choice of study program on the presence and size of the AD policy. Students who are talented and motivated will attend study programs with a high AD policy threshold. Students with less motivation and talent will probably attend study programs without or with a low AD policy threshold. As a result, the student population of study programs becomes more heterogeneous and endogenous ${ }^{22}$.

To account for this possibility, we make a robustness check with the AD policy threshold as input (i.e. a proxy for selectivity). The size of the AD policy might be a good input since study programs decide upon the level of the AD policy threshold. The output and control variables remain unchanged. This robustness check delivers similar outcomes as the previous models (see Table 3.6, Table 3.7 and Section 3.5.2). Moreover, we find that, for a given AD policy threshold, programs with a high student satisfaction succeed in obtaining higher graduation rates and high quality ratings. The percentage of female firstyear students and the percentage of faculty older than 50 years also have a significant

\footnotetext{
${ }^{22}$ However, we do not expect a big influence on the student population since previous literature concerning the AD policy in the Netherlands has shown that students are indifferent to studying at an institution with an AD policy and do not see it as a threat (Felsö, van Leeuwen \& Zijl, 2000).
} 
positive influence. In contrast to our previous results, we find that the percentage of ethnic minority students has a significant positive influence. This indicates that a high percentage of ethnic minority students is a characteristic of programs with a high graduation rate and quality rating. We can conclude that our results are fairly robust.

In a next step, we examine which program characteristic has the largest influence on the efficiency model. We do not focus on the institutional information since these variables were not significantly different from 0 (see Section 3.5.2). The question is examined by rerunning model 1 and by removing the significant variables one by one. The results show that student satisfaction influences the conditional efficiency estimates the most. Removing this variable from the model results in a decrease of $5 \%$ of the R-squared. Furthermore, it leads to an increase in variation in performance of the programs (i.e. the standard deviation increased to .0031). The average performance of the programs, however, remains fairly stable (i.e. 1.003) (see Table 3.7).

Table 3.6: Efficiency scores which exclude (unconditional) and include (conditional) the program and institutional characteristics

\begin{tabular}{lllll}
\hline \hline & Unconditional & (robust & Conditional & \\
& FHD) & & Model 1 & Model 2 \\
\hline Average & 1.312 & & 1.004 & 1.008 \\
St. Dev. & 0.331 & 0.038 & 0.048 \\
Min & 0.740 & 1.000 & 1.000 \\
Max & 2.631 & 1.741 & 1.793 \\
\hline \hline
\end{tabular}

The efficiency scores denote the proportionate increase of completion rates and quality ratings, which an academic program with a given dropout level could achieve if it would operate as efficient as the best practice observation 


\section{Chapter 3}

Table 3.7: Influence and significance of program and institutional characteristics that influence the relationship between dropout, graduation rates and quality ratings

\begin{tabular}{lcc}
\hline \hline & Model 1 & Model 2 \\
\hline Student program satisfaction & Favorable & Favorable \\
& $(<2 \mathrm{E}-16)^{* * *}$ & $(<2 \mathrm{E}-16)^{* * *}$ \\
First-year female students (\%) & Favorable & Favorable \\
& $(0.004)^{* * *}$ & $(<2 \mathrm{E}-16)^{* * *}$ \\
First-year ethnic minority students & Favorable & Favorable \\
(\%) & $(<2 \mathrm{E}-16)^{* * *}$ & $(<2 \mathrm{E}-16)^{* * *}$ \\
& Unfavorable & Favorable \\
Academic program & $(1.000)$ & $(0.994)$ \\
& Favorable & Unfavorable \\
Number of students & $(1.000)$ & $(1.000)$ \\
& Unfavorable & Favorable \\
Faculty $>50$ years (\%) & $(.986)$ & $(1.000)$ \\
& Favorable & \\
& $(<2 \mathrm{E}-16)^{* * *}$ & \\
& &
\end{tabular}

$\overline{\text { Note: Bootstrapped p-values between brackets; }{ }^{* * *},{ }^{* *}, * \text { denote significance at } 1 \%, 5 \% \text { and } 10 \% \text { - }}$ level.

We would like to remark that the influence of the variable average program satisfaction on the conditional model is larger than the other variables, but not much. Removing the other variables from the model specification results in decreases of the Rsquare as well. This indicates that each single variable has no major influence on the conditional model. This implies that institutions should focus on multiple characteristics in order to improve their performance. Efficiency cannot be improved by, for example, only improving student satisfaction or by becoming more selective. 


\subsection{Conclusions, policy implications and further research}

This chapter models the interaction between student dropout, program quality ratings and graduation rates. Using data from Dutch universities, we examine the heterogeneity in the interaction between the three variables, and the program and institutional characteristics that influence it.

The results suggest large variation in how academic programs are able to use the selective nature of first year dropout to increase student graduation and program quality ratings. While some programs could increase their quality ratings and graduation rates if they would learn from best practice observations, other programs have higher than expected quality ratings and success rates. Our findings indicate that program characteristics can significantly influence the relationship between student graduation and program quality ratings (for given dropout rates). Institutional characteristics, on the other hand, have a limited impact on the relationship between dropout, graduation and program quality ratings. Moreover, we observe the following characteristics of programs that succeed in obtaining high graduation rates and high quality ratings: (i) high student program satisfaction, (ii) high percentage of first-year female students, (iii) low percentage of first-year ethnic minority students, (iv) the presence of an academic dismissal policy, and (v) high percentage of faculty older than 50 years. Finally, we found that the student success and program quality (for given dropout rates) differ between subjects (e.g. ICT, math, economics) of academic programs.

In terms of policy implications this chapter indicates that not all academic programs effectively exploit first-year dropout to increase program quality ratings and graduation rates. By making this relation more explicit, policy makers can increase the efficiency of higher education. Moreover, the results indicate that certain program and institutional characteristics explain the variation in outcomes among study programs. In this respect, policymakers can introduce some measures to improve program satisfaction. High 


\section{Chapter 3}

satisfaction can lead to high rates of performance due to a sense of belonging and loyalty to the institution (e.g. Tinto, 1993). Further, we show that a lower share of male students and minority students leads to higher student success. Therefore, a policy implication for society is to better prepare male students and ethnic minority students for higher education. This is in line with recommendations by Bradley, Johnes and Little (2010) for vocational and further education. On the other hand, policymakers of academic programs can try to improve the support services for these groups of students at risk. Next, academic programs should increase the academic dismissal policy threshold. One can also opt to attract older faculty. However, the mechanism on why older faculty can influence the efficiency of programs is not clear yet. Older teachers may have, for example, more experience which may lead to a higher student's performance. Finally, our results show an insignificant influence of the student-faculty ratio on the efficiency of study programs.

This chapter provides several lines for further research. First, due to data constraints student graduation and student dropout does not deal with the same cohort of students. Consequently, our results may capture some changes related to different cohorts of students. Further research can replicate our method using data from similar cohorts of students. Second, the study used a sample of Dutch academic programs. The extent to which the results are generalizable to academic programs in other countries is unknown. Future research should explore the external validity of our findings.

This chapter is the first step towards analysing the relationship between dropout and quality adjusted graduation rates. Moreover, we found that an $\mathrm{AD}$ policy has a positive influence on the trade-off between both outcome measures. This is in line with the results of chapter one. However, as causal research concerning the effect of an AD policy in the Netherlands is missing, we will focus on this issue in Chapter 4 . We also found that the relationship between students and faculty is of importance. This is in accordance with the 
Efficiency in higher education

meta-analysis were we showed a positive effect of mentoring on retention and graduation.

We will include a faculty measurement as a control variable in the next chapters. 


\section{Chapter 4}

\section{Academic dismissal policy in Dutch higher education}

This chapter is based on: Sneyers, E and De Witte, K (2015). The effect of an academic dismissal policy on dropout, graduation rate and student satisfaction. Evidence from the Netherlands. Studies in Higher Education, Published online. doi:

$10.1080 / 03075079.2015 .1049143$ 


\section{Chapter 4}

\subsection{Introduction}

Chapter 2 and 3 have shown that an academic dismissal policy has an influence on student success. These results are, however, only correlational evidence. In this fourth chapter we will study the effect of an academic dismissal policy using a quasi-experimental design.

Performance-based funding (PBF) mechanisms are implemented by governments to pressure higher education institutions to become more accountable, more efficient and more productive in the use of public resources (Alexander, 2000). To reflect the multiple dimensions of the outputs of higher education institutes in terms of quantity and quality, most PBF mechanisms use a number of different indicators, including the number of credits accumulated by students, the number of degrees awarded, or the number of research publications (Jongbloed \& Vossensteyn, 2001). The PBF mechanism provides several related challenges to higher education institutions. We focus on three major ones, while ignoring others (e.g. keeping and improving quality standards; improving research performance).

First, stakeholders of higher education institutes are increasingly focusing on student graduation rates as it is considered as a measure of institutional effectiveness (Fike \& Fike, $2008)^{23}$. Since the introduction of cost-sharing, parents and students benefit from students who graduate 'on time' as no extra tuition has to be paid (Johnstone, 2004). Because of the implementation of PBF, higher education institutes also benefit from graduation within the nominal study time, as graduation will lead to higher and sooner funding.

Second, higher education institutions have put more emphasis on student satisfaction. Evidence indicates that dissatisfied students often become dropouts (Bryant, 2006). Moreover, it has been argued that students prefer to enroll in institutions with high

${ }^{23}$ We use the terms 'success' and 'graduation' interchangeably throughout the study. 
perceived student satisfaction. Therefore, many institutions are investing in measures that increase student satisfaction (e.g. mentoring and coaching, sports facilities, study choice centrums; Bettinger \& Baker, 2011). Other advantages of high student satisfaction, as indicated by Miller (2003), are high retention and graduation rates, low loan default rates and increased alumni giving.

Third, higher education institutes have become increasingly selective in accepting students as they are held accountable for the relative efficiency in awarding diplomas. Current practices fall apart in two mechanisms. There is selection 'at the gate' which accepts only students with a high possibility of successfully obtaining the degree within the study period (Beller, 2001; Salvatori, 2001). Examples of such selection mechanisms include the use of the Scholastic Assessment Test (SAT) score and/or selection interviews. Next, there is selection 'after the gate', which allows all students to enroll in the first year of study. However, it has some strict rules on who can continue in or after the first year (Duijndam \& Scheepers, 2009; Lindo et al., 2010). Examples of these screening tools include the use of first-year credits (ECTs) and first-year grade point averages (GPA).

In the Netherlands, $7 \%$ of the total higher education budget is reserved for performance agreements between the government and higher education institutions (both universities and higher vocational education). The main indicators of these agreements are dropout and completion rates. Due to the performance agreements many institutions decided to introduce an 'academic dismissal' (AD) policy. This intervention is based on a law of 1993 which obliged higher education institutions to provide first-year students with an advice regarding the continuation of their studies. Since 1997, some institutions have chosen to make this advice obligatory and to expel students who did not reach a predetermined credit threshold from the study program and the institution. Due to the performance agreements and the increased attention towards graduation and dropout rates, the popularity of the AD policy has increased rapidly the last couple of years. 


\section{Chapter 4}

This chapter contributes to the literature in three ways. First, while selection 'after the gate' is growing in popularity (e.g. in The Netherlands, Canada, US), little is known about its effects on student dropout, graduation rates and student satisfaction (see Lindo et al., 2010; Van Heerden, 2013). This chapter is the first to test the following research hypothesis: The introduction of an academic dismissal $(A D)$ policy results in higher first year student dropout, increased graduation rates and a decrease in student satisfaction.

As a second contribution, earlier literature on the influence of student selection has mainly used descriptive and correlational methodologies (e.g, Leverett-Main, 2004; Arnold and van den Brink, 2010; Moore, Offenstein \& Shulock, 2009). Unfortunately, if a proper control group is lacking, one cannot obtain causal evidence. This chapter exploits the rich panel structure of the data and identifies the effect of an academic dismissal policy by a difference-in-differences (DiD) type of estimator. The estimator examines the effect of a treatment by comparing the treatment group after treatment against the treatment group before treatment and against a control group. To test the robustness of the results, we also use propensity score matching.

As a third contribution, we focus on the Netherlands for which we have a rich data set at program level (also denoted by academic degree). The Netherlands make an interesting case study for two reasons. Performance indicators as student dropout, student graduation rates and student satisfaction are measured in a nation-wide standardized way, which limits measurement errors and results in uniform data across institutions and academic degrees.

The remainder of this chapter unfolds as follows. In Section 4.2, we outline the literature review on student selection mechanisms, student dropout, student graduation, and student satisfaction. Section 4.3 presents the Dutch setting. The next sections discuss the identification strategy, the assumptions behind the methodology and the data. Section 4.6 
presents the results, which are followed by robustness tests. We conclude the study with policy advice.

\subsection{Literature Review of student indicators}

Higher education institutions are increasingly held accountable for their students (Huisman \& Currie, 2004). In some countries, financial agreements between the government and higher education institutions even include targets on student dropout, student graduation and student satisfaction (in Australia, the Netherlands, Hong Kong) (OCW, 2011; Benneworth et al., 2011). We review the literature on student performance indicators and student satisfaction.

\subsubsection{Student performance indicators.}

\subsubsection{Student dropout and student graduation}

Different studies show that high freshman attrition rates go hand in hand with a higher percentage of students graduating on time (e.g. Lau, 2003; Levitz, Noel \& Richter, 1999). As a result, institutions try to stimulate graduation rates by keeping first-to-second-year dropout under control. The student integration model of Tinto $(1975,1993)$ and the student attrition model of Bean (1989, 1990) conceptualize the dropout phenomenon. These conceptual models acknowledge the important role of organizational factors and the commitment to the institution. Furthermore, there is a wide variation of dropout rates within groups of similar institutions which suggests that institutions can control their dropout rates (first noted by Forrest, 1982). Not surprisingly there exists an extensive body of research 


\section{Chapter 4}

that identifies the conditions in which institutions should place their students in order to promote student retention and student graduation ${ }^{24}$.

First, student/faculty ratios are positively correlated with dropout rates (e.g. Scott, Shah, Grebennikov \& Singh, 2008) and negatively with graduation rates (Bound et al., 2010). Indeed, a low student/faculty ratio will lead to frequent interaction between student and faculty which in turn will lead to academic integration and persistence (Tinto, 2002). Next, differences in student success and student dropout can be due to differences in institutional size. Most studies (e.g. Calcagno et al, 2008) have found a negative relationship between institutional size and individual success. Chickering and Reisser (1993) have offered one explanation as to why student outcomes are negatively affected by institutional size. Moreover, if the institution increases in size, the amount of students increases faster than the number of settings such that the ratio of people to settings increases. Consequently, social and academic support suffers. Conversely, Titus (2004) has found that the average chance of retention can be increased by four percent by a one standard deviation increase in institutional size.

Besides institutional structures, student characteristics can also influence educational outcomes. Research finds mixed results regarding the influence of gender on dropout and student achievement. Several studies (e.g. Scott et al., 2006; Peltier, Laden \& Matranga, 1999) have found that gender is significantly related to student dropout and graduation. Peltier et al. (1999) have concluded that women are less likely to dropout than men. In the same vein, Porter (2000) and Scott et al. (2006) have indicated that vocational institutions that are more female are expected to have higher graduation rates. These gender differences in degree performance may be the result of differences (i) in psychological and/or biological factors and (ii) in characteristics that are correlated with attainment (e.g. family

\footnotetext{
${ }^{24}$ Note that graduation and dropout are complex concepts which are influenced by other factors than discussed above. Because we want to keep the literature section to the point we only discuss the factors we used in our study.
} 
background), (McNabb et al., 2002; Mellanby et al., 2000). Nevertheless, Reason (2003) has failed to find a significant relationship between dropout and gender. Bailey et al. (2006), on the other hand, has found a negative relationship between the percentage of female students and graduation rates. The class level of students can also influence the dropout process. The class level (graduate or undergraduate) is based on the number of credit hours a student has earned, and hence the study year the student is enrolled at. Bean and Bradley (1986) have claimed that class level has a positive impact on performance. This finding is in line with a more recent study which finds that cumulative GPA is negatively related to dropout (Okun, 1998). Adelman (2006) also has shown that the cumulative credits and GPA are negatively associated with dropout and positively linked to graduation. The above findings can be attributed to the fact that students learn how to get better grades as they progress through their educational careers. Finally, academic effort, measured by study skills, also predicts student dropout and student graduation. Pantages and Creedon (1978) have found that students with poor study habits have a higher likelihood of becoming a dropout. It is also shown that students who participated in a study skills course acquired higher grades than predicted by their previous academic performance (Cone \& Owens, 1991). In a similar vein, more recent studies (e.g. Hughes \& Pace, 2003; Kuh et al., 2008; Chambers, 2009) have shown that student engagement, as a proxy of student effort, is negatively related to dropout.

\subsubsection{AD policy as a form of selection after the gate}

Due to the increased accountability towards their students and the financial agreements which are often in place, institutions try to improve the earlier discussed performance indicators. Many institutions focus on interventions aimed at first-year students since Levitz et al. (1999) have noted that this is the most crucial period for students. Some institutions try to achieve this by introducing more selective admission standards, which reduce the number of applicants, and make a distinction between the students who are likely to succeed 


\section{Chapter 4}

and the students who are likely to dropout (Duncan-Hewitt, 1996; Hagedorn \& Nora, 1996; Beecher \& Fischer, 1999). Cox, Schmitt, Bobrowski and Graham (2005) have indicated that more selective admission standards have been related to higher retention rates. While in the past admission standards often had a focus 'at' the gate, today admission standards “after’ the gate are becoming increasingly popular.

Selection 'after the gate' denotes performance based mechanisms to remove students making unsatisfactory academic progress from the institution. Performance based selection systems have a general structure. If a student's performance falls below the minimum standards of the enrolled institution, the student gets a warning which serves as a wake-up call and can lead to escalating penalties. Ideally, selection 'after the gate' should happen in the first year as Yorke and Longden (2004) have called this a critically important period for the connection between students and their programs. Bénabou and Tirole (2003) have argued that the impact of performance standards on students differs by the type of students. Setting performance standards can motivate some students to improve their performance while others can be discouraged from making any attempt at all.

In the Netherlands, many universities and vocational institutes implemented such system in the form of an AD policy (Van Heerden, 2013). This system requires students to make satisfactory study progress during their first year (see Section 4.3.2). Studies find mixed results concerning the influence of AD policies on dropout and graduation. Duijndam and Scheepers (2009) have indicated that the introduction of an AD policy in a business management program resulted in earlier students’ withdrawal in the first year, compared to programs where no AD policy is in use. This shows that fewer students linger in the program because of the introduction of a credit threshold. According to Gijbels et al. (2004) an $\mathrm{AD}$ policy is an effective tool for the identification of well-performing students. By comparing two cohorts of students (one in which an $\mathrm{AD}$ policy was implemented and one in which this was implemented fictitiously) evidence was found that students who would have been dismissed, if their institute applied a credit threshold, obtained lower numbers of 
credits in their second year. Also a lower first-year completion rate was found. Next, Arnold (2015) has compared Bachelor programs between the academic years 2002-03 and 200708. During these years some programs implemented an AD policy (i.e. intervention group) while others did not (i.e. control group). He proves that the introduction of an AD policy increased the first-year dropout rate and the 4-year completion rate of university students. Another study shows that an increase in credit threshold leads to an increase of student success (Task force studiesucces, 2009). Nevertheless, Stegers-Jager et al. (2011) has observed that the presence of an $\mathrm{AD}$ policy did not lead to early dropout or higher completion rates during the first two years at medical school. Further, Arnold and Van den Brink (2010) have claimed that the number of students languishing in scientific education will not necessarily be reduced by the introduction of a credit-threshold because students who are dismissed often do not get any help in selecting a new program, resulting in a poor performance in their next program. Finally, it is shown that while the introduction of a credit threshold leads to a positive change in study behavior, this introduction does not necessarily translate into a higher level of performance. This may indicate that students rather try to reach the credit requirements than acquiring as much knowledge as possible (De Koning et al., 2015).

\subsubsection{Student satisfaction}

As students nowadays are more "consumer oriented" and as higher education institutions are rewarded through performance-based funding, student satisfaction becomes increasingly important. Students who do not feel satisfied by their institution of choice, due to a mismatch between student expectations and institutional performance, have a high risk of dropping-out or transferring to another institution. Moreover, student satisfaction has a positive influence on student motivation, student retention, recruiting efforts and fundraising (Schertzer \& Schertzer, 2004). 


\section{Chapter 4}

Student satisfaction is a highly complex concept, influenced by various observed and unobserved factors. It is influenced by all experiences related to campus life, and not only to what happens to them in the classroom. However, universities and vocational institutes typically focus on the academic dimension of a student's educational experience (e.g. student-to-faculty ratios and quality programs) (Elliott \& Shin, 2002). As a consequence, Kotler and Fox (1995) have observed that while students are, on average, highly satisfied with their academic programs, their satisfaction with the support services is low. We identify a number of institutional and student characteristics which literature argued to affect satisfaction.

First, it seems that a substantive relationship with faculty or faculty affects students' satisfaction by deepening institutional connections and commitment (Peterson, Wagner \& Lamb, 2001). Elliott (2002) has indicated that faculty accessibility increases student satisfaction and positive feelings about college. Next, Wiers-Jenssen, Stensaker and GrØgaard (2002) have observed that while students in universities and large state colleges are less satisfied, students at university colleges are more satisfied. They argue that the reason for this result is two-fold. First, the institutional size can have an independent influence on student satisfaction. Second, universities and large state colleges may be more research-oriented than smaller higher education institutes, resulting in research drift of faculty (Dill, 2001) and a lower focus on teaching-activities which might result in lower satisfaction (De Witte et al., 2013a). Third, male-female differences result into significant differences in satisfaction with college (Adelman, 1991; Rienzi, Allen, Sarmiento \& McMillin, 1993). Most studies find that woman report lower levels of satisfaction with college compared to men. However, Umbach and Porter (2002) have reported that the proportion of female undergraduates in a department is highly correlated with satisfaction concerning education in the major and with personal skill development. The class level (graduate of undergraduate) can also influence satisfaction. Tan and Kek (2004) have found mixed results concerning satisfaction with service quality and class level. While at 
university A graduates perceived a higher level of service quality in comparison to undergraduates, the opposite was true in university B. Finally, Krohn and O’Conner (2005) have suggested that academic effort has a positive association with satisfaction. The effort devoted to a course or program may produce satisfaction directly if students find the activity of studying satisfying in itself. In addition, the results of that effort, e.g. knowledge and grades, may lead to satisfaction.

The combination of increased institutional accountability, performance agreements with student satisfaction as target and the increased use of AD policies, makes it important to know what will happen to student satisfaction. However, this relationship has not yet been empirically investigated. One Dutch descriptive study (Onderwijs Evaluatie Rapport, 2007) has mentioned that students judge the AD policy as something positive. However, students who obtained almost all first-term credits found it a more positive measure in comparison to students who obtained a limited number of first-term credits. These findings tend towards an increase of student satisfaction since students who obtained a high number of credits are likely to be retained by the AD policy.

\subsection{Dutch Setting}

\subsubsection{The Dutch higher education system}

Dutch higher education is organized as a binary system and consists of governmental funded and private funded institutes. Approximately $88 \%$ of the students attend a governmental funded institution (Jongbloed et al., 2003). This study focusses only on the group of institutions with governmental funding, which consists of 17 universities and 39 institutes for higher vocational education. In addition, the Open University provides higher education through distance learning. While the universities prepare students for independent scientific work in an academic or professional setting, higher vocational 


\section{Chapter 4}

institutes prepare students for the practice of a profession. Approximately one-third of the higher education students enroll in universities, while two-thirds enroll in the higher vocation institutes (Huisman, 2008). By following specific tracks in secondary education, Dutch students are sorted for continuing education and prepared for specific disciplines (De Koning et al., 2015). Admission to universities is open to students who have a certificate of pre-university education or a first-year certificate from a vocational higher education institute. Students who hold a certificate of senior general secondary education, secondary vocational education or pre-university education can enter higher vocational institutes (Huisman, 2008).

As of 2002, Dutch higher education institutes offer programs of 60 credit points per year in accordance to the European Credit Transfer System (ECTS). Credit points measure the workload or 'study time' that is required to complete a course or program. In the Netherlands, as in most European countries, a norm for a credit point is a workload of 28 hours, meaning that a program year consists of 1680 hours of work a year. The workload of students consists of the hours in classes and the hours needed to prepare for classes, exams and other forms of assessments.

\subsubsection{Academic dismissal policy}

In the Netherlands, universities and higher vocational institutes are legally obliged to provide each student with an advice on the continuation of their studies by the end of the first year of enrollment (Law on Higher Education and Scientific Research, art. 7.8b). Based on this law, higher vocational institutions can issue obligatory (binding) advice to students (Onderwijs Evaluatie Rapport, 2007). Issuing obligatory (binding) advice can be seen as an AD policy (in Dutch 'Bindend Studie Advies'). Whether a binding advice is positive or negative depends on the number of study credit points ${ }^{25}$ obtained by the student during the

\footnotetext{
${ }^{25}$ Note that the performance requirements of the AD policy also can be qualitative, such as passing essential courses (Mennen, 2013). However we will not focus on this type
} 
first year. Every course that students follow is linked to a number of credits, depending on the workload. When students pass the course, they earn the corresponding credits. Students who do not earn a sufficient number of credits to reach the threshold, and thus make substandard progress after the first year, are dismissed. The credit-threshold students must pass is decided by each institution and can vary by program, and type of higher education (De Koning et al., 2014). On average, the standard is 41 ECs in higher vocational education, whereas the credit-norm is 38 ECs at universities (Inspectie van het onderwijs, 2010). Before an AD policy is issued, students receive an academic warning, hereby giving them a wake-up call and a chance to improve their performance (Rijksoverheid, n.d.). When academic dismissal is issued it leads to the termination of the student's enrollment for the current program. Further, dismissed students cannot register for the same study program for a certain period, often three years (De Koning et al., 2014). During the academic year 2007/2008, the vocational institutes issued more than 14,000 academic warnings, while in the scientific education over 3,900 academic warnings were given (Inspectie van het onderwijs, 2010).

By using an AD policy, two objectives are pursued. First, it helps students to learn at an early stage whether the program fits them. Second, it allows programs to select and continue with the most talented and motived students after the first year (De Koning et al., 2014). Because the AD policy is in line with the orienting, selecting and referential function of the propaedeutic phase in higher education, it is used in many universities and vocational institutes (Onderwijsraad, 2008).

While non-obligatory study warnings are a tradition in Dutch higher education, the use of AD policies increased considerably in the last few years. In 1997, only one university had implemented an AD policy (Onderwijs Evaluatie Rapport, 2007). In 2000, 67\% of all

of AD policy, as it is difficult to measure and interpret this kind of performance requirements. 


\section{Chapter 4}

vocational study programs made use of an $\mathrm{AD}$ policy against $10 \%$ of the study programs at university level. Due to the increased attention towards the increase of graduation rates and the decrease of dropout more institutions started to implement AD policies. Moreover, $98 \%$ of the study programs at vocational level and $43 \%$ of the study programs at university level had an AD policy by 2007. These study programs were localized at 40 higher vocational institutions and seven universities. At university level, the use of an AD policy is most common in the study fields Economics, Law, Linguistics \& Culture, and Behavioral \& Social Sciences. The interest concerning the use of an AD policy is still increasing (Inspectie van het onderwijs, 2010). This process is represented in Figure 4.1 which shows the percentage of programs with an AD policy ${ }^{26}$. We observe a steep increase in the use of AD policies between the academic years 2006-07 and 2008-09. During this time period, an extra $10 \%$ of the programs decided to implement an AD policy. Figure 4.2 presents the number of programs per credit threshold. We observe that the majority of the credit threshold is 36-40 ECTS, followed by 41-45 ECTS. There is also a tendency towards higher thresholds.

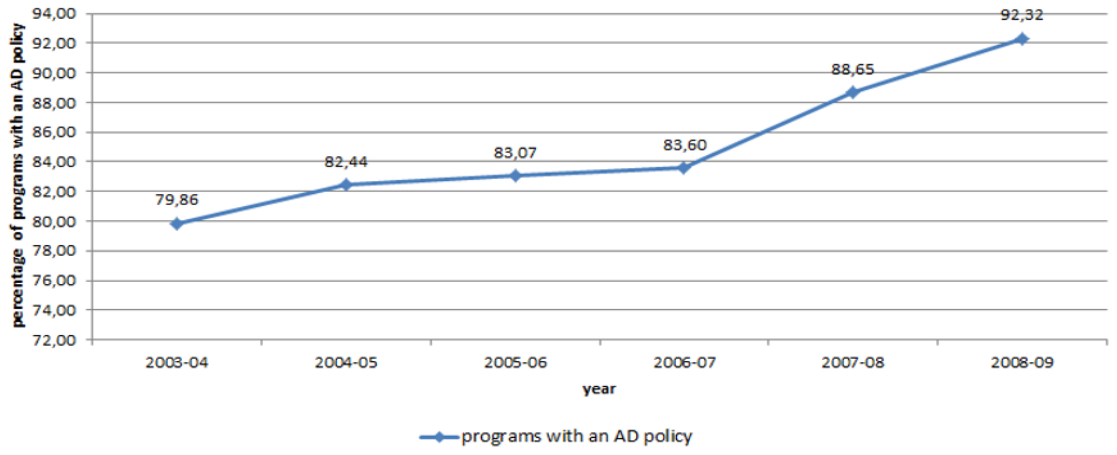

Figure 4.1: Percentage of academic programs with an AD policy per year. The blue line shows for each academic year which percentage of programs has implemented an AD policy. In 2005-06, for example, $83 \%$ of the study programs have implemented the AD policy.

${ }^{26}$ Both figures make use of information extracted from our data. Since we only have information as of 2003, we are not able to provide a visual representation of the implementation process and the use of credit thresholds before 2003. 


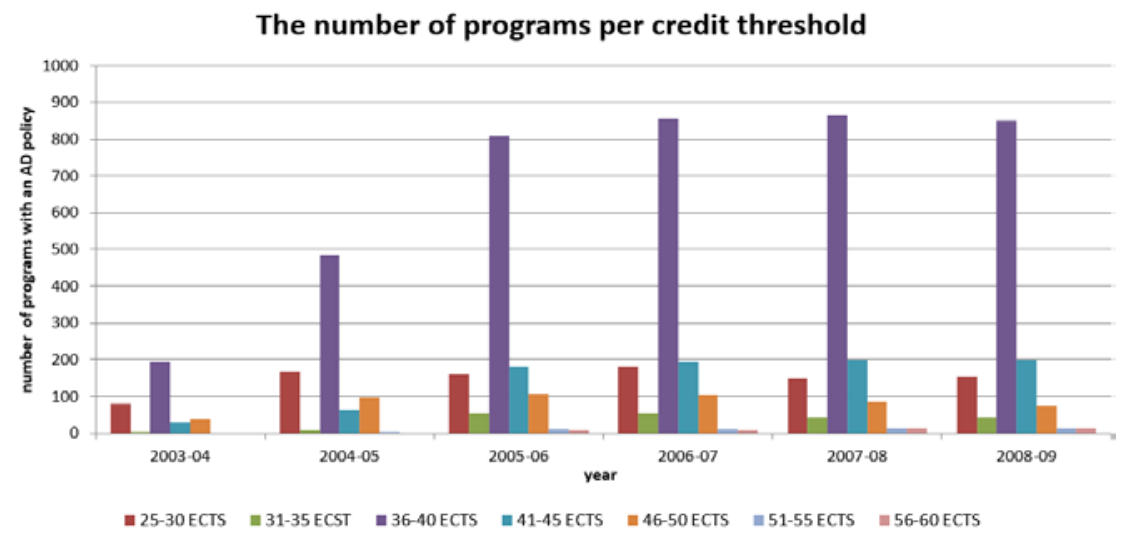

Figure 4.2: The number of programs per credit threshold per year. Each bar represents the total number of study programs which handle the corresponding AD policy threshold. The purple bar, for example, shows that in the academic year 2005-06 800 programs installed a threshold between 36-40 credits.

\subsection{Data and descriptive statistics}

\subsubsection{Data}

The data are obtained from the Dutch Ministry of Education ('Dienst Uitvoering Onderwijs', DUO). They include information at academic degree level (e.g. biology, applied linguistics) concerning the number of first-year students, the dropout rate, the number of students who re-enroll after the first year, and student graduation rates for all higher education institutes for the years 2010 and 2011. The academic degree is the set of courses that a student follows in order to obtain a degree (e.g. Bachelor in economics). The data also include the above indicators on the field of study for all years between 2003 and 2011. The field of study (e.g. technique, law, nature and economics) denotes to which academic field the program belongs.

The data have two limitations, which we need to deal with. First, we lack academic degree-level data from 2003-09. We deal with this by effectively combining the field of study data of 2003-09 with the program level data of 2010-11. The underlying assumption is that the trend of the indicators on program-level is similar to the trend of the indicators 


\section{Chapter 4}

on field of study-level. ${ }^{27}$ This assumption holds as the final data are similar to reports by field organizations. As a second limitation, we cannot make a distinction between programs at different locations of the institution. Therefore, we exclude the programs that did not implement an AD policy simultaneously at all locations.

The output variables are defined as follows. Student dropout is defined as the percentage of full-time Bachelor students that leave the institution during the first year of enrollment. Student graduation is defined as the share of re-enrolled full-time Bachelor students that obtained a degree at the institution one year after the nominal study time. Consequently, in order to be included in this latter indicator, students enrolled in universities need to graduate in four years, while students enrolled at higher vocational institutes need to graduate in five years.

We also obtained academic degree level (also called program) data from the annual national questionnaire on student satisfaction ('nationale studentenenquête', NSE). The survey is carried out by the organization Studiekeuze123 and includes information on the opinion of students about the program they are taking. The data also contain institutional information (e.g. the number of students and programs in the institution) and student characteristics (e.g. the percentage of woman or the percentage of first-year students). Although the NSE is an annual survey since 1991 it was not until 1995 that the NSE was carried out on sufficient large scale. In 1995, the NSE became a questionnaire with a fixed division of student issues (Steenkamp, Timmers \& van Schilt, 2008b). As of 2003, the organization started to document the student outcomes of the surveys in (publicly available) digital databases (Steenkamp, Timmers \& van Schilt, 2008a).

\footnotetext{
${ }^{27}$ When the interpolation resulted in values larger than 100 percent or smaller than zero percent for the performance variables, this value is replaced by 100 percent or zero percent respectively. Further, we excluded programs that were terminated in 2010 or 2011, since this event can influence student success and student dropout of previous years.
} 
The NSE data have three limitations. First, the student outcomes of the NSE were not (or just limited) registered in digital databases until 2003-04. Consequently, we do not have NSE information before 2003-04. Second, there is a break in the survey questions in 200910 which creates data comparability issues. Therefore, we only consider the surveys between 2003-04 and 2008-09. Third, at the time the data were collected, it was not yet possible to survey every program each year. Therefore large programs were surveyed every two years and small programs every three years (Steenkamp et al., 2008a). In order to obtain a balanced panel data set, Studiekeuze123 replaced missing data on student opinions by records from a previous year. The institutional characteristics, on the other hand, are annually adjusted.

Between January and March, students in participating programs are invited to complete the questionnaire and to give their opinion about different aspects of the program. The main purpose of the NSE, the measurement of student opinions, is evaluated by 30 items on a ten point scale ranging from (1) very dissatisfied to (10) very satisfied. These 30 items are grouped into 10 dimensions and one measure of overall satisfaction. The categories are: content of the academic degree, electives, consistency, teaching methods, career preparation, teachers, campus facilities, campus buildings, communication, and feasibility (Steenkamp et al., 2008a).

In the study at hand, we focus on three central questions in the NSE questionnaire. First, students are asked about their overall satisfaction with the program ("Are you satisfied with your choice for this program at this institution? $\left.{ }^{28 ”}\right)$. The next outcome variable focuses on a specific subject of student satisfaction, namely feasibility of the program ("Is the program feasible in the available time”). It measures whether students think they are able to complete the degree. In order to exploit the richness of the data, we construct an outcome

${ }^{28}$ In the NSE of 2007 the central question changed into "give your overall judgment about the program". An analyses of the density functions of both questions, shows that they are comparable. 


\section{Chapter 4}

variable (i.e. average NSE score) consisting of the average of all items surveyed in the NSE data. The latter variable has the advantage of being rather comprehensive and reducing the influence of extremely high or low items, which comes at the cost of having an imprecise interpretation (i.e. the average of all items). Note that the three outcome indicators applied in the study are well behaved in terms of homogeneous variance and normal underlying distributions, such that parametric analyses can be applied.

Because participation to the NSE is voluntary for each individual student the threat of selection bias exists. Although we are not able to investigate the bias at the individual student level, we do not expect selection to be a serious issue. First, response rates are comparable with the response rates of other college student surveys. From the 588,571 students addressed in 2011, 35.2 percent returned a usable NSE survey. In 2010 a similar response rate of 35.1 percent was found (van der Broek, Kurver, \& Hampsink et al., 2012). For comparison, the National Survey of Student Engagement (NSSE) had an average institutional response rate of 30\% in 2013 (NSSE, 2013). Second, by all stakeholders (university management, program directors, civil servants, student bodies) the NSE data are generally considered as a reliable and representative instrument. Third, as illustrative evidence of its importance and reliability, the data are also used in a new performancebased scheme to finance institutions based on performance agreements.

Results of the NSE questionnaires are made public and are used for different purposes. On the one hand, the student assessments are used to maintain or improve internal quality. By analysing the results it becomes clear which aspects already satisfy students and which aspects should be improved. On the other hand, the results are used to provide comparable information to students about the different academic programs and help them to make a good study choice. The latter is facilitated by a website and publication in influential magazines (studiekeuze123, 2012). 
To obtain our final sample, we combine the DUO and NSE data. We take a few restrictions into account. First, although AD policies were first implemented in 1997 we only focus on data between the years 2003-04 and 2008-09. This is the result of the limited data availability before 2003-04 and the break in NSE survey questions in 2009-10. We also focus on state funded institutions since these institutions have to decrease student dropout and increase graduation rates and student satisfaction in order to obtain funds. Consequently, these institutions will be more likely to introduce an AD policy. Next, the sample is restricted to Bachelor programs as Master programs do not have an AD policy. Thus, the final sample includes all Bachelor programs in state funded higher vocational and university institutions between 2003-04 and 2008-0929. This dataset contains information about the dropout rate, the graduation rate, student satisfaction opinions, student characteristics and institutional information for each study program. The final sample includes 6,012 higher education degrees (i.e. an average of 1002 study programs per year).

\subsubsection{Descriptive statistics}

Table 4.1 presents descriptive statistics for the study programs with (i.e. the treated group) and without (i.e. the control group) an $\mathrm{AD}$ policy. We observe that there are 266 unique programs in the control group, against 1,486 unique programs in the treatment group $^{30}$. The institutional characteristics indicate that programs that implemented an AD policy tend to have more students enrolled and have a higher student-faculty ratio. The descriptive statistics show no significant difference concerning the percentage of woman

\footnotetext{
${ }^{29}$ Note that since programs which already implemented an AD policy before 2003-04 do not influence the regression specification, we exclude these programs from the analysis (it should be noted that including those observations results in very comparable outcomes; available upon request).

${ }^{30}$ Note that the total sample consists of 6,012 study programs (see Section 4.3.1). For clarity, in the descriptive statistics we present only the number of unique programs. Moreover, when a study program appears every year in the data set it is considered in the descriptive statistics as one unique program while in the total sample it is counted as six observations (i.e. one for every year).
} 


\section{Chapter 4}

between program with an $\mathrm{AD}$ policy and programs without an $\mathrm{AD}$ policy. Further, programs with an $\mathrm{AD}$ policy have a higher percentage of students for the second and fourth year enrolled compared to programs without an AD policy. However, there is no significant difference concerning the percentage of students enrolled for the third year between both groups of programs. Finally, students in programs without an AD policy tend to study more as is indicated by the variable study time.

Table 4.2 presents some descriptive statistics for the different outcome variables. The descriptive statistics show that all five outcome variables differ significantly between programs with and without an AD policy. The statistics show that more students drop out after the first year of enrollment in programs with an AD policy compared to student in programs without an AD policy. Students in programs that implement an AD policy also have a higher graduation rate compared to students in programs that do not employ an $\mathrm{AD}$ policy. Students in a program without an AD policy have, on average, a higher overall satisfaction with their program than students in programs with an AD policy. Students in programs with an $\mathrm{AD}$ policy indicate that they find the program more feasible. 
Table 4.1: Descriptive statistics of student characteristics and equality of means between control and treatment group

\begin{tabular}{|c|c|c|c|c|c|c|c|c|c|}
\hline Variable & $\begin{array}{l}\text { Control/ } \\
\text { treatment } \\
\text { group }^{\delta}\end{array}$ & $\begin{array}{c}\text { Number of } \\
\text { obs. }\end{array}$ & $\begin{array}{c}\text { First } \\
\text { quartile }\end{array}$ & Mean & $\begin{array}{l}\text { Third } \\
\text { quartile }\end{array}$ & $\begin{array}{l}\text { Minimu } \\
\text { m }\end{array}$ & $\begin{array}{c}\text { Maximu } \\
\mathrm{m}\end{array}$ & $\begin{array}{c}\text { Standar } \\
\mathrm{d} \\
\text { deviatio } \\
\mathrm{n}\end{array}$ & $\begin{array}{c}\text { T-test }(\mathrm{dif}=\text { mean }(0)- \\
\text { mean }(1))\end{array}$ \\
\hline \multicolumn{10}{|c|}{ Institutional Characteristics } \\
\hline \multirow{2}{*}{$\begin{array}{l}\text { Number of unique } \\
\text { programs }\end{array}$} & 0 & 266 & & & & & & & \\
\hline & 1 & 1,486 & & & & & & & \\
\hline \multirow{3}{*}{ Number of students } & 0 & 812 & $17,220.00$ & $18,621.33$ & $23,794.00$ & 990.00 & $29,524.0$ & $6,742.8$ & \multirow{3}{*}{$-3,551.43^{* * *}$} \\
\hline & & & & & & & 0 & 2 & \\
\hline & 1 & 5,200 & $15,298.00$ & $22,172.76$ & $32.074,00$ & 281.00 & $\begin{array}{c}38,551.0 \\
0\end{array}$ & $\begin{array}{c}10,686 . \\
20\end{array}$ & \\
\hline \multirow{2}{*}{ Student-faculty ratio } & 0 & 812 & 5.30 & 6.08 & 6.81 & 1.92 & 16.56 & 2.99 & \multirow{2}{*}{$-6.57 * * *$} \\
\hline & 1 & 5,200 & 11.87 & 12.65 & 14.82 & 1.98 & 17.81 & 3.58 & \\
\hline
\end{tabular}




\begin{tabular}{|c|c|c|c|c|c|c|c|c|c|}
\hline Variable & $\begin{array}{c}\text { Control/ } \\
\text { treatment } \\
\text { group }^{\delta}\end{array}$ & $\begin{array}{c}\text { Number of } \\
\text { obs. }\end{array}$ & $\begin{array}{c}\text { First } \\
\text { quartile }\end{array}$ & Mean & $\begin{array}{l}\text { Third } \\
\text { quartile }\end{array}$ & $\begin{array}{l}\text { Minimu } \\
\text { m }\end{array}$ & $\begin{array}{l}\text { Maximu } \\
\text { m }\end{array}$ & $\begin{array}{c}\text { Standar } \\
\mathrm{d} \\
\text { deviatio }\end{array}$ & $\begin{array}{c}\text { T-test }(\text { dif }=\text { mean }(0) \text { - } \\
\text { mean }(1))\end{array}$ \\
\hline \multicolumn{10}{|l|}{ Student characteristics } \\
\hline Woman in the program & 0 & 811 & 27.8 & 50.0 & 71.4 & .0 & 100.0 & 26.3 & \multirow{2}{*}{.91} \\
\hline (\%) & 1 & 5,197 & 25.0 & 49.0 & 74.6 & .0 & 100.0 & 28.9 & \\
\hline \multirow{2}{*}{ First-year students (\%) } & 0 & 811 & 24.5 & 33.2 & 41.2 & .0 & 86.7 & 13.4 & \multirow{2}{*}{$1.82 * * *$} \\
\hline & 1 & 5,197 & 22.4 & 31.4 & 39.1 & .0 & 100.0 & 13.0 & \\
\hline \multirow{2}{*}{$\begin{array}{l}\text { Second-year students } \\
\text { (\%) }\end{array}$} & 0 & 811 & 18.8 & 24.4 & 28.6 & .0 & 61.9 & 9.3 & \multirow{2}{*}{$-.75^{* *}$} \\
\hline & 1 & 5,197 & 19.3 & 25.2 & 30.6 & .0 & 64.7 & 9.1 & \\
\hline \multirow{2}{*}{$\begin{array}{l}\text { Third-year students } \\
\text { (\%) }\end{array}$} & 0 & 811 & 13.8 & 20.2 & 25.8 & .0 & 61.5 & 9.4 & \multirow{2}{*}{-.16} \\
\hline & 1 & 5,197 & 14.3 & 20.4 & 26.0 & .0 & 62.2 & 9.0 & \\
\hline \multirow{2}{*}{$\begin{array}{l}\text { Fourth-year students } \\
\text { (\%) }\end{array}$} & 0 & 811 & 6.3 & 11.8 & 16.7 & .0 & 57.1 & 7.7 & \multirow{2}{*}{$-4.96 * * *$} \\
\hline & 1 & 5,197 & 9.8 & 16.8 & 23.1 & .0 & 61.5 & 9.6 & \\
\hline
\end{tabular}




\begin{tabular}{|l|c|c|c|c|c|c|c|c|c|}
\hline \multirow{3}{*}{ Fifth-year students (\%) } & 0 & 811 & .0 & 5.4 & 8.2 & .0 & 30.0 & 5.9 & \multirow{2}{*}{$1.67^{* * *}$} \\
\cline { 2 - 10 } & 1 & 5,197 & .0 & 3.7 & 5.9 & .0 & 46.2 & 4.4 & \\
\hline \multirow{3}{*}{ Seniors (\%) } & 0 & 811 & .0 & 4.1 & 5.3 & .0 & 61.8 & 4.1 & \multirow{2}{*}{$1.97^{* * *}$} \\
\cline { 2 - 10 } & 1 & 5,197 & .0 & 2.1 & 3.1 & .0 & 33.3 & 2.1 & \\
\hline \multirow{3}{*}{ Study time } & 0 & 787 & 25.88 & 29.36 & 33.46 & 11.27 & 44.60 & 6.21 & \multirow{2}{*}{$3.13^{* * *}$} \\
\cline { 2 - 10 } & 1 & 5,161 & 20.19 & 26.23 & 31.55 & 10.50 & 50.14 & 7.28 & \\
\hline
\end{tabular}

Where $* * *$ denotes significant at $0.01 \%$-level. $* * \mathrm{p}<0.05 ; * \mathrm{p}<0.1$

${ }^{\delta} 0$ : No AD policy implemented (the control group). 1: AD policy has been eventually implemented (the treatment group) 
Table 4.2: Descriptive statistics of the outcome variables, and equality of means between control and treatment group

\begin{tabular}{|c|c|c|c|c|c|c|c|c|c|}
\hline Variable & $\begin{array}{c}\text { Control/trea } \\
\text { t-ment } \\
\text { group }^{\delta}\end{array}$ & $\mathrm{N}$ & $\begin{array}{l}\text { First } \\
\text { quartile }\end{array}$ & Mean & $\begin{array}{l}\text { Third } \\
\text { quartile }\end{array}$ & Min & Max & SD & $\begin{array}{c}\text { T-test }(\mathrm{dif}= \\
\text { mean(0)-mean }(1)\end{array}$ \\
\hline \multirow{2}{*}{ Student dropout } & 0 & 607 & 10.5 & 17.3 & 23.2 & 0.0 & 100.0 & 11.2 & \multirow{2}{*}{$-8.83 * * *$} \\
\hline & 1 & 2,954 & 18.5 & 26.1 & 32.1 & 0.0 & 100.0 & 12.3 & \\
\hline \multirow{2}{*}{ Student graduation } & 0 & 593 & 40.9 & 52.5 & 64.6 & 0.0 & 100.0 & 17.8 & \multirow{2}{*}{$-10.61^{* * *}$} \\
\hline & 1 & 2,418 & 52.3 & 63.1 & 75.7 & 0.0 & 100.0 & 18.3 & \\
\hline \multirow{2}{*}{$\begin{array}{l}\text { Overall Satisfaction with } \\
\text { the program }\end{array}$} & 0 & 560 & 7.30 & 7.52 & 7.75 & 6.37 & 8.57 & .34 & \multirow{2}{*}{$.48^{* * *}$} \\
\hline & 1 & 2,909 & 6.69 & 7.04 & 7.37 & 5.00 & 9.00 & .48 & \\
\hline \multirow{2}{*}{$\begin{array}{l}\text { Average NSE score (own } \\
\text { constructed variable) }\end{array}$} & 0 & 812 & 6.91 & 7.07 & 7.24 & 6.19 & 7.97 & .26 & \multirow{2}{*}{$.31^{* * *}$} \\
\hline & 1 & 5,200 & 6.54 & 6.76 & 6.96 & 5.43 & 8.11 & .32 & \\
\hline \multirow{2}{*}{ Feasibility of the program } & 0 & 367 & 6.23 & 6.51 & 6.96 & 3.87 & 8.05 & $\begin{array}{l}.72 \\
\end{array}$ & \multirow{2}{*}{$-.43^{* * *}$} \\
\hline & 1 & 2,062 & 6.67 & 6.94 & 7.28 & 3.40 & 8.67 & .53 & \\
\hline
\end{tabular}

${ }^{\delta} 0$ : No AD policy implemented (the control group). 1: AD policy has been eventually implemented (the treatment group 


\subsection{Identification strategy and assumptions}

\subsubsection{Identification strategy}

To estimate the influence of the introduction of an AD policy on student dropout, graduation and satisfaction, we apply a difference-in-differences (DiD) type of estimator. It is one of the most popular tools to evaluate the effect of interventions on some relevant outcome variables (Abadie, 2005). Although we claim that $\mathrm{AD}$ policies are introduced in a rather exogenous way (see Section 4.5.2), we have to account for the time trend as the control and intervention group in this study are not identified at the same time but in a different chronological academic year. A chronological time trend can lead to a biased estimate of the effect of introducing an $\mathrm{AD}$ policy. The $\mathrm{DiD}$ approach accounts for this time trend by including an extra control group of academic programs which will never implement an AD policy. Moreover, the traditional DiD examines the effect of a treatment by comparing the treatment group after treatment against the treatment group before treatment and against a control group. The outcome $\mathrm{Y}$ for study program $i$ is traditionally modeled by the following equation:

$$
Y_{i}=\alpha+\beta D_{i}+\gamma t_{i}+\delta\left(D_{i} \cdot t_{i}\right)+\varepsilon_{i}
$$

Where the $\alpha$ denotes a constant term, $\beta$ the treatment group ( $D=1$ : treatment) specific effect, $\gamma$ is the estimated coefficient for the time trend $(t=0$ : pre-treatment, $\mathrm{t}=1$ : posttreatment) common to control and treatment group, $\delta$ stands for the variable of interest as it estimates the effect of the treatment, and $\varepsilon_{\mathrm{i}}$ is an error term. As revealed by the interaction effect, the DiD estimator is defined as the difference in average outcome in the treatment group before and after the treatment minus the difference in average outcome in the control group before and after treatment (Albouy, 2004): 


\section{Chapter 4}

$$
\hat{\delta}_{D i D}=\bar{Y}_{1}^{T}-\bar{Y}_{0}^{T}-\left(\bar{Y}_{1}^{C}-\bar{Y}_{0}^{C}\right)
$$

In typical DiD estimations the treatment is a one-time change in policy equally applied to all members of the treatment group. Due to the equal application, the treatment and control groups can be identified. Because it is a one-time change, specific pre- and posttreatment points in time can easily be selected. Our study tends to differ from the typical treatment in one important way. $\mathrm{AD}$ policies have not been one-time events but have been implemented gradually over multiple years. Taking this issue in consideration, we apply the following model:

$$
Y_{i}=\alpha+\beta\left(D_{i}\right)+\gamma \sum_{t} t+\delta D_{-}{ }_{p} \text { olicy } y_{i t}+\mu X_{i t}+\varepsilon_{i t}
$$

Where $t_{t}$ is a dummy variable for each year (from 2003-04 until 2008-09, where 200304 is the reference year) and $D_{i}$ a dummy variable that assumes 1 for all programs which eventually applied an AD policy and else 0 . The model is completed by the AD policy intervention dummy, a categorical interaction variable that is 1 for programs after the start of an AD policy and 0 else (see Table 4.3). We further add additional time (t) and program (i) specific control variables $\mathrm{X}$. This increases the efficiency and consistency of the variables of interest. Note that in the suggested identification strategy, the control group consists of all study programs which have never implemented an AD policy, whereas the treatment group is created from all study programs which eventually have implemented a study program. We discuss and test the assumptions behind this identification strategy in Section 4.4.2. 
Figure 4.3 presents the identification strategy graphically. The horizontal axis represents the time and the vertical axis the outcome variable. The upper curve represents the outcome variables of the control group, and the lower curve represents the outcome

Table 4.3: Schematic presentation of the identification strategy

\begin{tabular}{lcc}
\hline & Control group & Treatment group \\
\hline Before implementation AD & $\mathrm{d}=0 ; \mathrm{t}=0$ & $\mathrm{~d}=1 ; \mathrm{t}=0$ \\
policy & & \\
After implementation AD & $\mathrm{d}=0 ; \mathrm{t}=1$ & $\mathrm{~d}=1 ; \mathrm{t}=1$ \\
policy & & \\
\hline
\end{tabular}

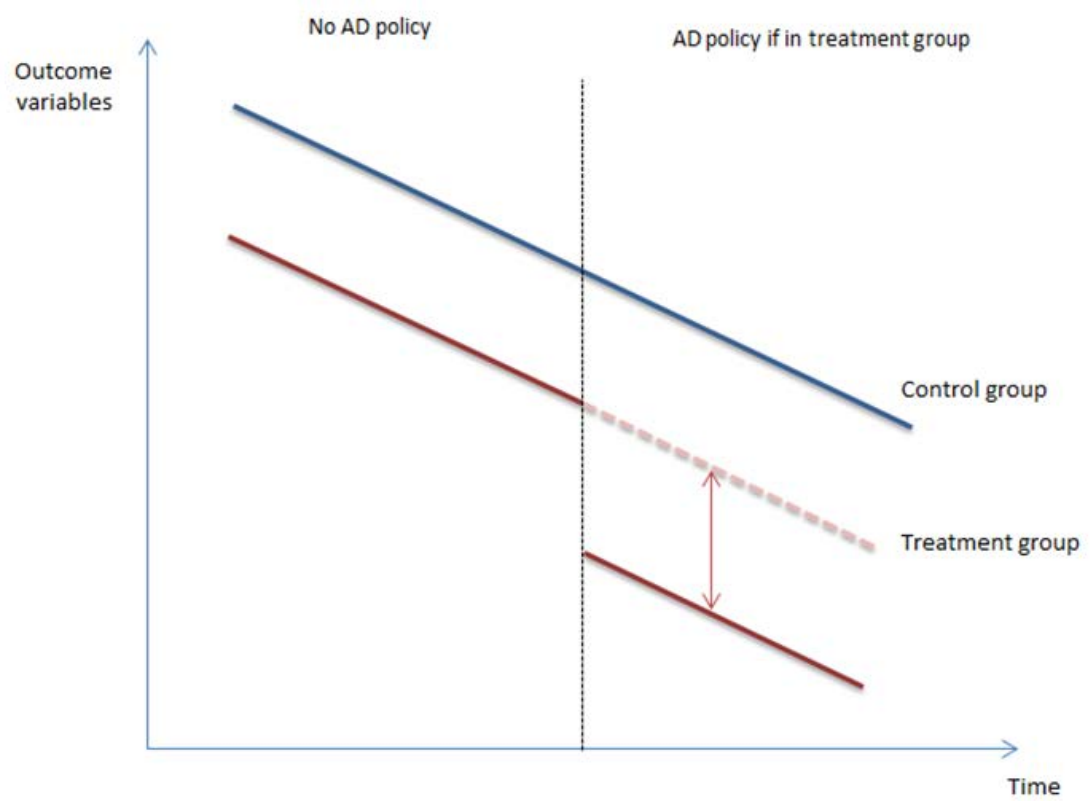

Figure 4.3: Visual representation of the identification strategy. The blue line represents the trend of the control group, while the red line represents the trend of the treatment group. The dashed line represents the moment the AD policy was introduced and the arrow represents the treatment effect. 


\section{Chapter 4}

variables of the treatment group. The dashed line indicates the implementation of the AD policy at a certain moment in time, while the arrow measures the difference in outcome variables caused by the treatment (i.e. the difference between the observed and counterfactual outcome). The figure illustrates that our analyses take three different effects into account: the 'period/cohort' specific effects, the 'treatment group' specific effects and the effects due to the implementation of an AD policy. Including the 'treatment group' specific effects is important as academic degrees which implement an AD policy might have different (un)observed characteristics than academic degrees without an AD policy (see Section 4.3.1 for an extensive discussion).

\subsubsection{Assumptions behind the identification strategy}

The identification strategy relies on some assumptions, which we discuss and test next. First, the control group should be a well comparable group for the treatment group. We test this assumption by checking whether characteristics of the control and intervention group differ significantly (see Section 4.4.2). Since some of the characteristics are significantly different, we cope with this issue in two ways. First, we include the variables as control variables in the regression analysis such that existing heterogeneity among the control and treatment group is absorbed. Second, as a robustness test, we use propensity score matching to select a well comparable control group. The matching results (see Section 4.6.1) confirm the robust outcomes.

As a second assumption, the 'common trend assumption' ${ }^{31}$ argues that, before the implementation of an $\mathrm{AD}$ policy, the trend of the observed and unobserved variables between the group of programs that eventually will implement an AD policy and the control group should be similar. We test the assumption by examining whether the difference between the two described groups changes significantly between two subsequent years in

${ }^{31}$ These results can be found back in the paper of Sneyers et al. (2016). 
the period before the introduction of an $\mathrm{AD}$ policy. The results indicate that the common trend assumption is met for all years for the variables student dropout and student graduation. The results for the variables concerning satisfaction show that the assumption is not always met. Specifically for the subsequent years 2003-04 and 2004-06, and 200506 and 2006-07. Consequently, observations for those years will be included in a second robustness check (see Section 4.6.2). The above results may be explained by the fact that student satisfaction can rapidly change due to changes in the educational environment (Elliott \& Shin, 2002). Student dropout and graduation do not respond as quickly.

The 'Stable Unit Variance Assumption' (STUVA) requires that the observations in the control and treatment group do not influence each other. The common perception that an AD-policy is implemented institution-wide is wrong. Often programs in the same institution decide individually whether they implement an AD policy. Students who follow different programs and who are at different faculties or even at different institutions have few possibilities to interact and influence each other. Students who received a negative AD and decided to follow a new program at a different institution are able to influence the opinions of their new peers. However, we do not expect that this situation will reshape the perceptions of the fellow students drastically.

Fourth, the AD policy should be introduced in a rather exogenous way. Proving that the AD policy is introduced exogenously would require qualitative evidence, which is beyond the scope of this study. Nevertheless, from the annual reports we know that the introduction and strengthening of an AD policy does not depend on certain institutional or program characteristics. Moreover, we can test the correlation between the introduction of an $\mathrm{AD}$ policy and program and/or institutional characteristics such as quality and the number of students. To have an indication on the program quality, we make use of the accreditations of the Dutch-Flemish Accreditation Organization (NVAO). The NVAO is an independent agency, founded by the Dutch and Flemish (i.e. the Dutch speaking region of Belgium) government to assess the quality of higher education. To test for potential 


\section{Chapter 4}

correlation between program quality and program admission criteria, we estimate an institution fixed effect model with the introduction of AD policy as dependent variable, and various quality indicators as independent variables. The fixed effect regression mitigates the influence of institution fixed variation. The results, presented in Table 4.4, indicate that the introduction of an $\mathrm{AD}$ policy does not correlate with the quality of an institution. In a second model we include the institutional characteristics student enrollment and studentfaculty ratio to account for fast growing institutions (Table 4.4). The results indicate that the variable $A D$ policy is independent of the student-faculty ratio. However, the variable $A D$ policy depends on the number of students enrolled. This indicates that when an institution has a sudden growth of students, it often introduces an AD policy. To control for the influence of student enrollment, we add this variable to the analyses.

Table 4.4: Institution fixed effect model with the variable "AD policy" as outcome variable.

\begin{tabular}{|c|c|c|c|c|}
\hline \multirow[t]{2}{*}{ Variable } & \multicolumn{2}{|c|}{ Model 1} & \multicolumn{2}{|c|}{ Model 2} \\
\hline & Coef. & SE & Coef. & SE \\
\hline Constant & $.848^{* * *}$ & .019 & $.520 * * *$ & .093 \\
\hline \multicolumn{5}{|l|}{ Quality indicators: } \\
\hline - Program requirements & -.001 & .012 & .001 & .012 \\
\hline - Faculty requirements & -.019 & .012 & -.020 & .012 \\
\hline - Improvement measurements & -.003 & .012 & -.004 & .012 \\
\hline - Achieved level & .004 & .008 & .004 & .008 \\
\hline Student enrollment & & & $.000 * * *$ & .000 \\
\hline Student-faculty ratio & & & -.002 & .003 \\
\hline Number of observations & \multicolumn{2}{|c|}{1,978} & \multicolumn{2}{|c|}{1,962} \\
\hline $\begin{array}{l}\text { Number of groups (fixed effects at } \\
\text { institution level) }\end{array}$ & 50 & & \multicolumn{2}{|c|}{47} \\
\hline
\end{tabular}

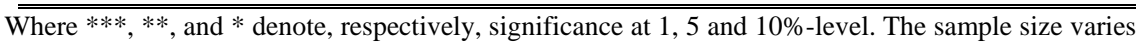
due to missing values in the covariates 
Given that we fulfil the above conditions, we are able to estimate the average treatment effect of the treated (ATT). Specifically, ATT is the average effect on student dropout, student graduation, and student satisfaction caused by to the introduction of an AD policy. In Figure 4.3, this effect is presented by the dashed arrow (see Section 4.4.1).

\subsection{Results}

\subsubsection{Trend analysis}

Before presenting the estimation results, we obtain some intuitive information on the data by a trend analysis. In particular, we plot the relationship between the $\mathrm{AD}$ policy and the outcome variables at different points in time before and after the implementation. To do so, we create a variable equal to 0 for the year in which the $\mathrm{AD}$ policy is introduced in the academic program. The years after the introduction receive a positive number, while the years before the introduction correspond to a negative number.

We observe that student dropout and student graduation both increased around the introduction of an AD policy (see Figure 4.4-4.5). The trend is in line with Bénabou and Tirole (2003) who have predicted that setting a performance standard results in motivating some students to improve their performance while discouraging others to making an attempt at all. Consequently this latter group will drop out.

The trend analysis for overall satisfaction with the program (see Figure 4.6) suggests a decline of overall student satisfaction in the year the AD policy is first employed. This trend is confirmed for the average NSE score, which indicates a steep decline the year the AD policy is introduced (see Figure 4.7). The above trend is in line with labor market studies that report that organizational stress and job satisfaction are inversely related (e.g. Hollon \& Chesser, 1976; Miles, 1976). In a similar vein, Cotton et al. (2002) have linked characteristics of student work environment, such as high work pressure, low control and low support, to psychological stress. The work design influences satisfaction in a similar 


\section{Chapter 4}

way, meaning that high demands and low control results in low satisfaction (Cotton et al. 2002). The implementation of an AD policy can have a similar effect on the work design of students, causing more pressure to perform well during their first year of enrolment. In turn this pressure can result in higher levels of stress and lower levels of satisfaction.

Figure 4.8 represents the relationship between students' opinions regarding the feasibility of the program before and after the implementation. Concerning the feasibility of the program, the trend of the student opinions can go two ways. First, first-year students may find the program less feasible as they have to achieve a minimum number of credits, resulting in lower opinions. Second, students who passed the credit threshold, may find the program more feasible and rate the likelihood of completing the program higher. Looking at the figure, we observe that students find the program more feasible in the year the $\mathrm{AD}$ policy is first introduced. Further, we observe a steep decline in satisfaction with program feasibility one year before the introduction of an AD policy. This decrease can be due to an announcement effect.

It should be noted that Figure 4.1 and 4.2 provide evidence for the rather 'exogenous' introduction of an $\mathrm{AD}$ policy. As we do not observe that academic degrees introduce an $\mathrm{AD}$ policy because of increasing dropout rates or declining graduation rates, it makes us more confident on the exogeneity assumption.

While the described analyses describe the trends of the outcome variables in relation to different points before and after the introduction of an AD policy, one drawback of this method is that we do not have a control group. The use of a control group is needed in order to eliminate temporary trends in the outcome variable or effects of events, other than the treatment, that occurred between the measuring periods. To overcome this problem, we will apply the suggested difference-in-differences type of estimator. 

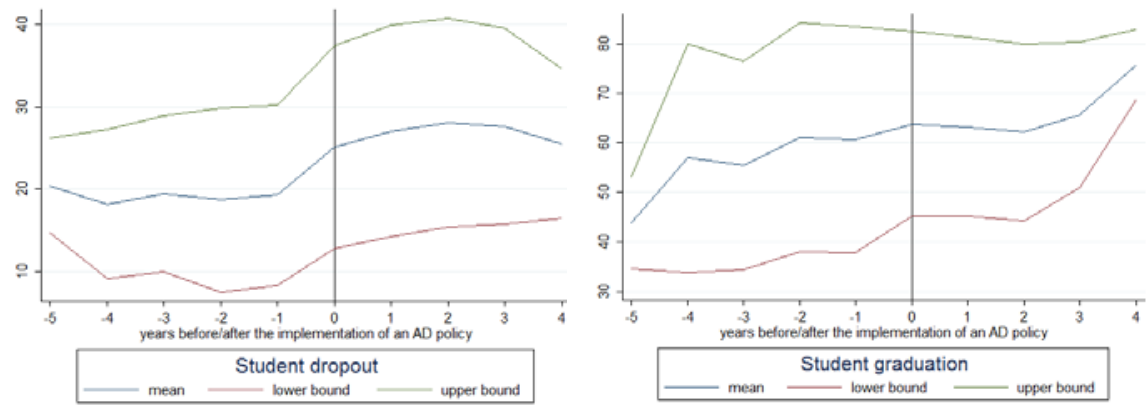

Figure 4.4 (left): Trend of student dropout before (negative numbers) and after (positive numbers) the introduction of an $\mathrm{AD}$ policy. The blue line represents the trend of student dropout. The red and green lines represent the upper and lower bound. The black line represents the moment an AD policy is introduced.

Figure 4.5(right): Trend of student graduation before (negative numbers) and after (positive numbers) the introduction of an $\mathrm{AD}$ policy. The blue line represents the trend of student dropout. The red and green lines represent the upper and lower bound. The black line represents the moment an AD policy is introduced
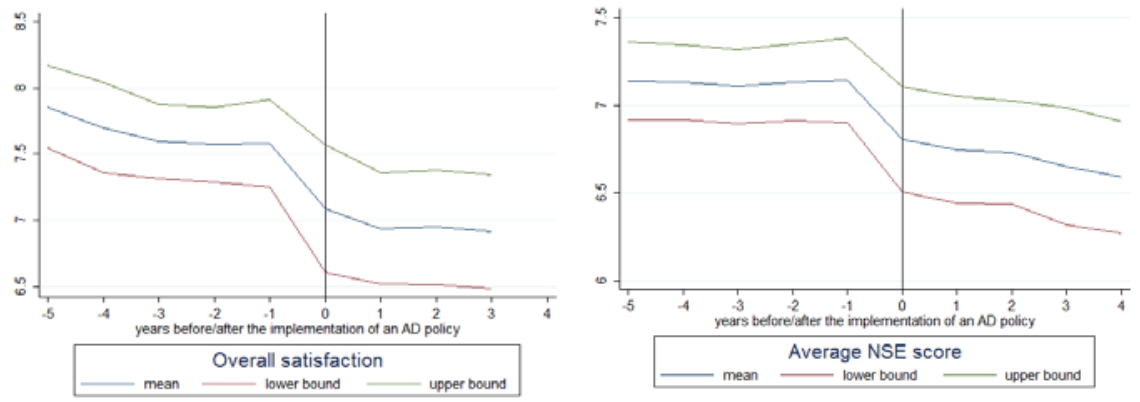

Figure 4.6 (left): Trend of overall student satisfaction of Bachelor's students before (negative numbers) and after (positive numbers) the introduction of an $\mathrm{AD}$ policy. The blue line represents the trend of student dropout. The red and green lines represent the upper and lower bound. The black line represents the moment an AD policy is introduced.

Figure 4.7 (right): Trend of average NSE score of Bachelor's students before (negative numbers) and after (positive numbers) the introduction of an $\mathrm{AD}$ policy. The blue line represents the trend of student dropout. The red and green lines represent the upper and lower bound. The black line represents the moment an AD policy is introduced. 


\section{Chapter 4}

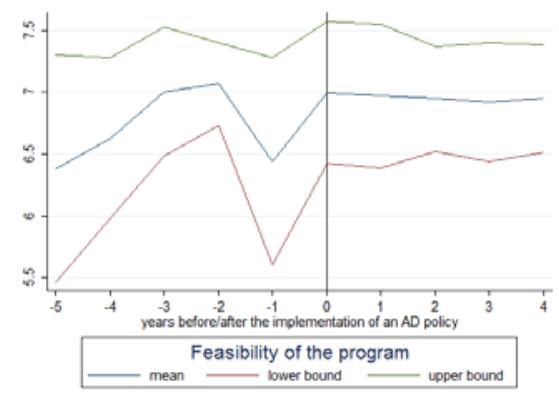

Figure 4.8: Trend of feasibility of the program perceived by Bachelor's students before (negative numbers) and after (positive numbers) the introduction of an AD policy. The blue line represents the trend of student dropout. The red and green lines represent the upper and lower bound. The black line represents the moment an AD policy is introduced.

\subsubsection{Difference-in-Differences type of estimator}

The estimation results for Equation (4.3) are presented in Table 4.5. The results indicate that the introduction of an $\mathrm{AD}$ policy (captured by the variable of interest $A D$ policy) is significantly correlated to all outcome variables. The results suggest that the introduction of an AD policy leads to a significant increase of student dropout and student graduation $^{32}$. Moreover, due to the introduction of an AD policy, student dropout increases by $7.5 \%$ while student graduation increases by $3.3 \%$. The results further show that the introduction of an $\mathrm{AD}$ policy leads to a significant decrease of overall satisfaction (i.e. .48 point on a ten point scale) and average NSE score (i.e. .36 point on a ten point scale). Perceived program feasibility increases significantly due to the implementation of an AD policy (i.e. .43 point on a ten point scale).

The group specific effects explain also a part of the variation in student performance and student satisfaction. The results show that programs that eventually will implement an AD policy have a higher level of student dropout and student graduation in comparison

${ }^{32}$ A factor analysis points out that student dropout and student graduation are no substitutes (uniqueness of the estimates is .9455) and thus should be included separately in the analyses. 
Table 4.5: Regression outcomes of Equation (4.3)

\begin{tabular}{|c|c|c|c|c|c|c|c|c|c|c|}
\hline & \multicolumn{2}{|c|}{ Student dropout } & \multicolumn{2}{|c|}{ Student graduation } & \multicolumn{2}{|c|}{ Overall satisfaction } & \multicolumn{2}{|c|}{ Average NSE score } & \multicolumn{2}{|c|}{$\begin{array}{l}\text { Satisfaction with program } \\
\text { feasibility }\end{array}$} \\
\hline & Coef. & $\mathrm{SE}$ & Coef. & $\mathrm{SE}$ & Coef. & $\mathrm{SE}$ & Coef. & SE & Coef. & SE \\
\hline Intercept & $\begin{array}{c}17.028 * * \\
*\end{array}$ & 1.636 & $\begin{array}{c}54.346^{* *} \\
*\end{array}$ & 2.527 & $7.804 * * *$ & .031 & $7.072 * * *$ & 0.183 & $6.647^{* * *}$ & .045 \\
\hline $\begin{array}{l}\mathrm{D}(0=\text { never an } \\
\mathrm{AD} \text { policy })\end{array}$ & $1.934^{* *}$ & .908 & $6.856 * * *$ & 1.399 & 0.050 & .033 & $.046 * *$ & .021 & .059 & .058 \\
\hline \multicolumn{11}{|l|}{$\begin{array}{l}\text { Year }(2003-04= \\
\text { ref. year) }\end{array}$} \\
\hline 2004-05 & -2.169 & 1.730 & 0.977 & 2.672 & -0.061 & .038 & -.016 & .012 & -0.038 & .054 \\
\hline 2005-06 & -0.083 & 1.688 & -3.420 & 2.608 & $-.183^{* * *}$ & .034 & $.051^{* * *}$ & .012 & $-.280 * * *$ & .056 \\
\hline 2006-07 & 1.567 & 1.687 & -3.381 & 2.605 & $-.412 * * *$ & .036 & $-.090 * * *$ & .021 & $-.212 * * *$ & .055 \\
\hline 2007-08 & 1.061 & 1.700 & $-4.604 *$ & 2.626 & $-.351 * * *$ & .037 & $-.104 * * *$ & .021 & $-.216 * * *$ & .053 \\
\hline
\end{tabular}




\begin{tabular}{|c|c|c|c|c|c|c|c|c|c|c|}
\hline \multirow[b]{2}{*}{ 2008-09 } & \multicolumn{2}{|c|}{ Student dropout } & \multicolumn{2}{|c|}{ Student graduation } & \multicolumn{2}{|c|}{ Overall satisfaction } & \multicolumn{2}{|c|}{ Average NSE score } & \multicolumn{2}{|c|}{$\begin{array}{c}\text { Satisfaction with } \\
\text { program feasibility }\end{array}$} \\
\hline & -0.240 & 1.708 & 2.878 & 2.774 & & & $.118 * * *$ & 0.025 & $-.158 * * *$ & .057 \\
\hline $\begin{array}{l}\text { AD policy } \\
(0=\text { before the } \\
\text { implementation } \\
\text { of an } A D \text { policy })\end{array}$ & $7.469 * * *$ & .820 & $3.271 * * *$ & 1.196 & $-.481 * * *$ & .030 & $-.357 * * *$ & .019 & $.425 * * *$ & .056 \\
\hline $\mathrm{N}$ & \multicolumn{2}{|c|}{3,561} & \multicolumn{2}{|c|}{3,011} & \multicolumn{2}{|c|}{3,092} & \multicolumn{2}{|c|}{5,600} & \multicolumn{2}{|c|}{2,429} \\
\hline $\mathrm{R}^{2}$ & \multicolumn{2}{|c|}{.102} & \multicolumn{2}{|c|}{.071} & \multicolumn{2}{|c|}{.291} & \multicolumn{2}{|c|}{.206} & \multicolumn{2}{|c|}{.108} \\
\hline Adjusted R² & \multicolumn{2}{|c|}{.100} & \multicolumn{2}{|c|}{.069} & \multicolumn{2}{|c|}{.289} & \multicolumn{2}{|c|}{.205} & \multicolumn{2}{|c|}{.105} \\
\hline
\end{tabular}

Where ***, **, and * denote, respectively, significance at 1, 5 and 10\%-level. The sample size varies due to missing values in the covariates. 
with programs that will never employ an AD policy. Next, programs that apply an AD policy (i.e. $\mathrm{D}=1$ ) receive a higher average NSE score compared to programs that never apply an $\mathrm{AD}$ policy at some point in time.

Looking at the time-specific effects, we observe mixed results. First, the results for student dropout show no time-specific results. For student graduation we only detect a decline in the academic year 2007-08 in comparison to the reference year. Furthermore, it seems that overall student satisfaction and satisfaction with program feasibility decreases in time. However, while the average NSE score in the years 2005-06 and 2008-09 is higher than in 2003-04, it is lower in the years 2006-07 and 2007-08 compared to 2003-04.

We additionally run a second model specification which includes various covariates (see Table 4.6). We also cluster the standard errors at the level of the academic field of the program (i.e. field of study), such as economics, medicine or law. Finally, we add the variable student enrollment, which was indicated in Section 4.4 .2 to correlate with the introduction of an $\mathrm{AD}$ policy. The results are in line with our previous outcomes. In particular, we observe that an $\mathrm{AD}$ policy has a significant positive influence on student dropout, student graduation and satisfaction with program feasibility. Specifically, student dropout, student graduation and satisfaction with program feasibility rise by $5.8 \%, 7 \%$ and .33 point (on a ten point scale) respectively. The implementation of an AD policy has again a significant negative influence on overall student satisfaction (i.e. .35 point on a ten point scale) and average NSE score (i.e. .26 point on a ten point scale). 
Table 4.6: Regression outcomes for the DiD type of estimation with covariates for the outcome variables

\begin{tabular}{|c|c|c|c|c|c|c|c|c|c|c|}
\hline & \multicolumn{2}{|c|}{ Student dropout } & \multicolumn{2}{|c|}{ Student graduation } & \multicolumn{2}{|c|}{ Overall satisfaction } & \multicolumn{2}{|c|}{ Average NSE score } & \multicolumn{2}{|c|}{$\begin{array}{l}\text { Satisfaction with } \\
\text { program feasibility }\end{array}$} \\
\hline & Coef. & SE & Coef. & SE & Coef. & SE & Coef. & SE & Coef. & SE \\
\hline Intercept & $20.851^{* * *}$ & 2.610 & $34.799 * * *$ & 3.985 & $7.487^{* * *}$ & .074 & $7.069 * * *$ & .040 & $7.547 * * *$ & .111 \\
\hline $\begin{array}{l}\mathrm{D} \\
(0=\text { never an } \mathrm{AD} \\
\text { policy }) \\
\text { Year }\end{array}$ & $1.772 * *$ & .823 & $6.426 * * *$ & 1.279 & $.065^{* *}$ & .030 & $.056^{* * *}$ & .019 & -.057 & .052 \\
\hline $\begin{array}{l}\text { ( } 2003-04= \\
\text { reference year) }\end{array}$ & & & & & & & & & & \\
\hline 2004-05 & -.621 & 1.695 & -1.417 & 2.461 & $-.153^{* * *}$ & .039 & -.013 & .020 & $-.129^{* * *}$ & .052 \\
\hline 2005-06 & .807 & 1.658 & -3.917 & 2.408 & $-.209 * * *$ & .035 & $.045^{* *}$ & .020 & $-.307 * * *$ & .056 \\
\hline 2006-07 & 2.362 & 1.673 & $-4.708^{*}$ & 2.430 & $-.399 * * *$ & .035 & $-.068 * * *$ & .021 & $-.296 * * *$ & .051 \\
\hline 2007-08 & 2.037 & 1.679 & $-6.465 * * *$ & 2.440 & $-.250 * * *$ & .038 & -.021 & .021 & $-.352 * * *$ & .051 \\
\hline 2008-09 & .575 & 1.678 & .160 & 2.558 & & & $.093 * * *$ & .024 & $-.387 * * *$ & .053 \\
\hline
\end{tabular}




\begin{tabular}{|c|c|c|c|c|c|c|c|c|c|c|}
\hline \multirow[b]{2}{*}{$\begin{array}{l}\text { AD policy }(0= \\
\text { before the } \\
\text { implementation } \\
\text { of an } \mathrm{AD} \text { policy) }\end{array}$} & \multicolumn{2}{|c|}{ Student dropout } & \multicolumn{2}{|c|}{ Student graduation } & \multicolumn{2}{|c|}{ Overall satisfaction } & \multicolumn{2}{|c|}{ Average NSE score } & \multicolumn{2}{|c|}{$\begin{array}{l}\text { Satisfaction with } \\
\text { program feasibility }\end{array}$} \\
\hline & $5.793 * * *$ & .823 & $6.980 * * *$ & 1.193 & $-.345^{* * *}$ & .029 & $-.264 * * *$ & .018 & $.329 * * *$ & .050 \\
\hline $\begin{array}{l}\text { Gender } \\
(0=\text { men })\end{array}$ & $-.022^{* *}$ & .010 & .162 & .017 & $.001^{* * *}$ & .000 & $.001^{* * *}$ & .000 & $.002^{* * *}$ & .001 \\
\hline \multicolumn{11}{|l|}{$\begin{array}{l}\text { Number of years } \\
\text { in the program } \\
\text { ( reference } \\
\text { category= } 1 \\
\text { year) }\end{array}$} \\
\hline 3 years & -.001 & .024 & $.232 * * *$ & .038 & -.001 & .001 & -.001 & .000 & $.003 * * *$ & .001 \\
\hline 4 years & -.028 & .025 & $.127^{* * *}$ & .041 & $-.004 * * *$ & .000 & $-.004 * * *$ & .000 & $.006^{* * * *}$ & .001 \\
\hline 5 years & -.053 & 0.049 & $-.316^{* * *}$ & .077 & .001 & .001 & -.001 & .001 & $-.028 * * *$ & .003 \\
\hline$>5$ years & -.035 & .058 & -.014 & .089 & .001 & .002 & $.003 * *$ & .001 & $-.028 * * *$ & .003 \\
\hline
\end{tabular}




\begin{tabular}{|c|c|c|c|c|c|c|c|c|c|c|}
\hline \multirow[b]{2}{*}{ Study time } & \multicolumn{2}{|c|}{ Student dropout } & \multicolumn{2}{|c|}{ Student graduation } & \multicolumn{2}{|c|}{ Overall satisfaction } & \multicolumn{2}{|c|}{ Average NSE score } & \multicolumn{2}{|c|}{$\begin{array}{l}\text { Satisfaction with } \\
\text { program feasibility }\end{array}$} \\
\hline & $-.318 * * *$ & .049 & $.197 * *$ & .077 & $.012 * * *$ & .001 & $.006 * * *$ & .001 & $-.027 * * *$ & .002 \\
\hline $\begin{array}{l}\text { Number of } \\
\text { students }\end{array}$ & $.0001^{* * *}$ & .000 & $-.0001^{* * *}$ & .000 & -.00001 & .000 & -.000 & .000 & $.000^{* * *}$ & .000 \\
\hline Field of study & \multicolumn{2}{|c|}{ YES } & \multicolumn{2}{|c|}{ YES } & \multicolumn{2}{|c|}{ YES } & \multicolumn{2}{|c|}{ YES } & \multicolumn{2}{|c|}{ YES } \\
\hline $\mathrm{N}$ & \multicolumn{2}{|c|}{3,539} & \multicolumn{2}{|c|}{2,997} & \multicolumn{2}{|c|}{3,032} & \multicolumn{2}{|c|}{5,489} & \multicolumn{2}{|c|}{2,409} \\
\hline $\mathrm{R}^{2}$ & \multicolumn{2}{|c|}{.096} & \multicolumn{2}{|c|}{.159} & \multicolumn{2}{|c|}{.316} & \multicolumn{2}{|c|}{.267} & \multicolumn{2}{|c|}{.237} \\
\hline
\end{tabular}

Where $* * *, * *$, and * denote, respectively, significance at 1, 5 and 10\%-level. The sample size varies due to missing values in the covariates. 
Significantly more students in programs that eventually implement an AD policy drop out and graduate on time in comparison to students in programs that never introduce an AD policy. Students in programs that eventually introduce an AD policy have a significantly higher overall satisfaction and NSE scores compared to students in programs that never employ an $\mathrm{AD}$ policy.

It is observed that student graduation is declining in later years. The results indicate that programs receive significantly lower ratings for overall satisfaction and satisfaction with program feasibility in later years. The average NSE scores decline in the academic years 2005-06 and 2008-09 in comparison to the academic year 2003-04. These results are consistent with a study of Steenkamp et al. (2008b) which found that satisfaction of students, measured by the NSE, decreased slightly from 1996 until 2005.

We find with respect to the covariates that programs with a high percentage of female students have a lower dropout rate and receive higher satisfaction compared to programs with a low percentage of female students. This is in line with findings by Bruinsma (2004), Andrews, Higson, Green and Jones (2012), and Umbach and Porter (2002). Further, we observe that programs with a higher percentage of students who are enrolled for two, three or four years have a significantly higher graduation rate than programs with a higher percentage of first-year students. Programs with a high percentage of students enrolled for the fifth year have a significant lower graduation rate than programs with a high percentage of first-year students. This finding is not surprising since students enrolled for the fifth time (in the same program) will not graduate within the nominal study time, while students enrolled for the second, third or fourth time can still graduate on time. The results also show that programs with a high percentage of students who are enrolled for four years have significantly lower scores on overall satisfaction than programs with a high percentage of first-year students. We find similar results for the average NSE score. More specifically, students enrolled for two or four years have a significantly lower average NSE score compared to first-year students. Interestingly, we find that students enrolled for more than 


\section{Chapter 4}

five years have a significantly higher NSE score. Concerning the feasibility of the program, programs with a high percentage of students who are three or four years enrolled score significantly higher on the feasibility of the program compared to programs with a high percentage of first-year students. This result was expected as most students enrolled for the third or fourth year passed the credit-threshold, resulting in a higher likelihood of graduating compared to first-year student. However, programs with a high percentage of students who are five years or longer enrolled show significantly lower satisfaction with program feasibility compared to programs with a high percentage of first-year students. These students may fear that they will not pass, resulting in a lower satisfaction with the feasibility of the program compared to students enrolled for the first time. Next, as expected, we find a significant negative relationship between study time and student dropout and a significant positive relationship between study time and student graduation. We also observe that programs receive higher overall satisfaction and average NSE score when students study more. Surprisingly, satisfaction regarding feasibility of the program is negatively correlated with study time. As we do not know the direction of the correlation, reverse causality might be an issue here. Finally, we observe that the variable student enrollment has a small significant influence on all outcome variables.

Various alternative specifications deliver similar outcomes, but are not reported here to save some space (available upon request). Additional control variables include the average number of credits achieved by the students in the program and the type of admission criteria to enter the program. Similar results are found when the variables number of years enrolled and study time are excluded from the analysis. By clustering at the institutional level, at location level and at program level, we find robust outcomes concerning the direction of the relationships. The significance of the results sometimes decreases, but this is not surprising since the analyses are done in smaller groups of observations. 


\subsection{Robustness tests}

\subsubsection{Propensity score matching}

As a first robustness test we use propensity score matching (PSM). PSM is a statistical analysis that allows us to match treated units to non-treated units who have similar characteristics, hereby reducing the bias arising from working with an inappropriate control group (Dehejia \& Wahba, 2002; Peikes, Moreno \& Orzol, 2008; Rosenbaum \& Rubin, 1983). In particular, the possibility of bias arises when we estimate a treatment effect on groups with different characteristics. This increases the risk that the difference in outcome depends on the difference in characteristics, rather that it is caused by the treatment. Observational studies often have a problem of biasedness, because the assignment of treatment to research subjects is not randomized, resulting in a control and treatment group that are not balanced regarding covariates. Matching attempts to mimic randomization by creating a treatment group that is comparable on all observable characteristics to the control group.

We match on the covariates at the institutional-level and student-level described in Ttable 4.1. The former group of covariates consists of the student-faculty ratio, and the number of students enrolled, while the latter group consists of gender, number of years enrolled, study time (as a proxy for the requirements of the program), and year of the questionnaire (given that students are more critical in later years than earlier years). Further, we include the variable vocational-university that indicates if the program is at university level or at vocational higher institute level and the variable field of study. To assess the validity of the comparison groups, we compare treatment-control group differences in outcomes (based on the quasi-experimental design) with treatment-comparison differences (based on the non-experimental PSM design).

Table 4.7 shows that, for the treated units, student dropout and satisfaction regarding feasibility of the program decreases when based on the matched sample. However, student graduation, overall satisfaction and average NSE score are underestimated when based on 


\section{Chapter 4}

the unmatched sample. Subsequently, with the exception of student graduation, the estimated effects by the PSM method are smaller than under the earlier estimations.

More precisely, for student dropout, we find by the PSM a significant positive influence $(\mathrm{t}$-stat $=19.00)$, but compared to the regression specifications the effect loses some of its strength $(\mathrm{t}-\mathrm{stat}=8.79)$. Based on the unmatched sample, we find a significant positive impact $(t-s t a t=12.44)$ for student graduation. For the matched sample, we find a larger significant influence $(\mathrm{t}$-stat= 14.85 ) for student graduation. Regarding the average student satisfaction and the overall NSE score, we find a negative significant influence based on the unmatched sample (respectively, t-stat $=-28.40$ and $\mathrm{t}$-stat $=-32.66$ ), compared to a smaller significant negative influence based on the matched sample (respectively, t-stat $=-12.90$ and $\mathrm{t}$-stat $=-11.74)$. For satisfaction with program feasibility both methods estimated impacts to be positive and significant (respectively, t-stat $=14.89$ and $\mathrm{t}$-stat $=$ 7.94). Note, that adding extra covariates, such as the average number of ECTS achieved by the students in the program and the type off admission criteria, deliver similar results.

Table 4.7: Robustness check of the five outcome variables using propensity score matching

\begin{tabular}{lcccccc}
\hline Variable & Sample & Treated & Controls & Difference & SE & t-stat \\
\hline \multirow{2}{*}{ Student dropout } & Unmatched & 26.731 & 17.788 & 8.943 & .471 & 19.00 \\
& Matched & 22.343 & 17.788 & 4.555 & .518 & 8.79 \\
\hline $\begin{array}{l}\text { Student } \\
\text { graduation }\end{array}$ & Unmatched & 63.642 & 54.394 & 9.248 & .743 & 12.44 \\
\hline $\begin{array}{l}\text { Overall } \\
\text { satisfaction }\end{array}$ & Matched & 67.450 & 54.394 & 13.056 & .879 & 14.85 \\
\hline $\begin{array}{l}\text { Average NSE } \\
\text { score }\end{array}$ & Mnmatched & 7.007 & 7.530 & -.523 & .018 & -28.40 \\
\hline $\begin{array}{l}\text { Satisfaction with } \\
\text { program } \\
\text { feasibility }\end{array}$ & Matched & 7.284 & 7.530 & -.246 & .019 & -12.90 \\
\hline
\end{tabular}




\subsubsection{Different subsamples}

As a second robustness test we estimate Equation (4.3) for different subsamples. The first subsample consists of observations from the years 2003-04 and 2004-05. Between those years, the common trend assumption was not met. The results, presented in Table 4.8, are identical to those obtained by the full sample, which yields confidence in the earlier results.

Second, as the common trend assumption was not met for the years 2005-06 and 200607 , we only include observations from those years in the second subsample. The results, presented in Table 4.9, indicate the robustness of the outcomes.

Third, we include only observations from higher education institutes in urban areas. This distinction is made as students from urban and rural areas can differ in background, ethnicity, grade point average, socio-economic situation (SES), enrollment curriculum and

Table 4.8: Regression outcomes for Equation (4.3) using observations from the years 200304 and 2004-05

\begin{tabular}{|c|c|c|c|c|c|}
\hline & Student dropout & Student graduation & Overall satisfaction & Average NSE score & $\begin{array}{l}\text { Satisfaction with } \\
\text { program feasibility }\end{array}$ \\
\hline \multicolumn{6}{|c|}{ Model 1 (without covariates) } \\
\hline & Coef. & Coef. & Coef. & Coef. & Coef. \\
\hline \multirow[t]{2}{*}{ treatment effect } & $5.968 * * *$ & $8.945^{* * *}$ & $-.362 * * *$ & $-.295 * * *$ & $.297 * * *$ \\
\hline & [1.443] & [2.259] & {$[.068]$} & {$[.024]$} & {$[.074]$} \\
\hline $\mathrm{N}$ & 471 & 460 & 640 & 1,921 & 670 \\
\hline $\mathrm{R}^{2}$ & .091 & .178 & .192 & .195 & .151 \\
\hline adjusted $\mathrm{R}^{2}$ & .086 & .173 & .188 & .193 & .148 \\
\hline \multicolumn{6}{|c|}{ Model2 (with covariates) } \\
\hline & Coef. & Coef. & Coef. & Coef. & Coef. \\
\hline \multirow[t]{2}{*}{ treatment effect } & $6.288 * * *$ & $10.717^{* * *}$ & $-.344 * * *$ & $-.275 * * *$ & $.274 * * *$ \\
\hline & {$[1.599]$} & {$[2.420]$} & {$[.068]$} & {$[.024]$} & {$[.068]$} \\
\hline $\mathrm{N}$ & 468 & 458 & 610 & 1,853 & 666 \\
\hline $\mathrm{R}^{2}$ & .115 & .225 & .207 & .267 & .259 \\
\hline
\end{tabular}




\section{Chapter 4}

Table 4.9: Regression outcomes for Equation (4.3) using observations from the years 200506 and 2006-07

\begin{tabular}{|c|c|c|c|c|c|}
\hline & Student dropout & Student graduation & Overall satisfaction & Average NSE score & $\begin{array}{l}\text { Satisfaction with } \\
\text { program feasibility }\end{array}$ \\
\hline \multicolumn{6}{|c|}{ Model 1 (without covariates) } \\
\hline & Coef. & Coef. & Coef. & Coef. & Coef. \\
\hline \multirow[t]{2}{*}{ treatment effect } & $7.711^{* * *}$ & $3.217^{*}$ & $-.513 * * *$ & $-.397 * * *$ & $.886^{* * *}$ \\
\hline & [1.157] & [1.750] & {$[.041]$} & {$[.028]$} & {$[.104]$} \\
\hline $\mathrm{N}$ & 1,594 & 1,577 & 1,920 & 2,345 & 801 \\
\hline $\mathrm{R}^{2}$ & .088 & .044 & .258 & .209 & .136 \\
\hline adjusted R² & .086 & .043 & .257 & .208 & .133 \\
\hline \multicolumn{6}{|c|}{ Model2 (with covariates) } \\
\hline & Coef. & Coef. & Coef. & Coef. & Coef. \\
\hline \multirow[t]{2}{*}{ treatment effect } & $5.833^{* * *}$ & $6.794 * * *$ & $-.307 * * *$ & $-.239 * * *$ & $.644^{* * *}$ \\
\hline & [1.188] & {$[1.712]$} & {$[.035]$} & {$[.027]$} & {$[.099]$} \\
\hline $\mathrm{N}$ & 1,586 & 1,569 & 1,892 & 2,311 & 789 \\
\hline $\mathrm{R}^{2}$ & .080 & .124 & .252 & .232 & .270 \\
\hline
\end{tabular}

Where ***,**, and * denote, respectively, significance at 1, 5 and 10\%-level, standard errors between brackets. The sample size varies due to missing values in the covariates.

educational level of parents (McCracken and Barcinas, 1991), which in turn may influence the findings. Again, the results confirm our previous findings (see Table 4.10).

We conclude that the estimation outcomes are robust for the different subsamples.

\subsection{Conclusions, further research and policy implications}

The growing accountability of higher education institutes makes them increasingly selective in accepting students. Students in programs with academic dismissal (AD) policies can be removed from the study program when they do not make satisfactory study progress. It is thus a form of selection after the gate. The credit-threshold students must pass differs by institution and by academic degree. Although the effect of such an AD policy on performance is measured by a few studies (e.g. De Koning et al., 2014; Gijbels et al., 2004), little is known about the effect of this type of selection tool on student satisfaction. This 
Table 4.10: Regression outcomes for Equation (4.3) using observations from higher educational institutes in urban areas

\begin{tabular}{|c|c|c|c|c|c|}
\hline & Student dropout & Student graduation & Overall satisfaction & Average NSE score & $\begin{array}{c}\text { Satisfaction with } \\
\text { program feasibility }\end{array}$ \\
\hline \multicolumn{6}{|c|}{ Model 1 (without covariates) } \\
\hline & Coef. & Coef. & Coef. & Coef. & Coef. \\
\hline \multirow{2}{*}{ treatment effect } & $7.354 * * *$ & $3.234^{* *}$ & $-.484 * * *$ & $-.352 * * *$ & $.338 * * *$ \\
\hline & {$[.946]$} & [1.452] & {$[.033]$} & {$[.020]$} & {$[.061]$} \\
\hline $\mathrm{N}$ & 2,113 & 1,814 & 1,910 & 3,406 & 1,417 \\
\hline $\mathrm{R}^{2}$ & .010 & .059 & .355 & .242 & .102 \\
\hline adjusted R² & .097 & .055 & .352 & .240 & .098 \\
\hline \multicolumn{6}{|c|}{ Model2 (with covariates) } \\
\hline & Coef. & Coef. & Coef. & Coef. & Coef. \\
\hline \multirow{2}{*}{ treatment effect } & $4.754 * * *$ & $6.170^{* * *}$ & $-.329 * * *$ & $-.243^{* * *}$ & $.290 * * *$ \\
\hline & {$[.946]$} & {$[1.384]$} & {$[.031]$} & {$[.019]$} & {$[.056]$} \\
\hline $\mathrm{N}$ & 2,109 & 1,810 & 1,881 & 3,357 & 1,415 \\
\hline $\mathrm{R}^{2}$ & .101 & .143 & .341 & .236 & .244 \\
\hline
\end{tabular}

Where ***, **, and * denote, respectively, significance at 1, 5 and 10\%-level, standard errors between brackets. The sample size varies due to missing values in the covariates.

study is the first to examine empirically the effect of the introduction of an AD policy on both student performance and student satisfaction. Using Dutch nationwide data, the effect of the introduction of a student selection tool on student graduation, student dropout and student satisfaction is investigated.

Our results suggest that, on average, student dropout and student graduation increased due to the introduction of an AD policy. Next, we found that the introduction of an AD policy leads to a decrease of student satisfaction. The outcomes also indicate that student satisfaction regarding program feasibility increases because of the implementation of an AD policy. Looking at the period specific effects, we observe that student graduation rates are lower in more recent years. This is an alarming finding since higher educational institutes are increasingly aware of the benefits of graduation 'on time'. The results also 


\section{Chapter 4}

indicate that student satisfaction used to be higher in the past. This result can be explained by the relationship between satisfaction and expectations. As students increasingly perceive themselves to be customers, due to the tuition fees and growth of consumerism in public services, their expectations rise (Tricker, 2005). In this context, expectations of students are high and include, for example, flexibility and choice in the delivery of education, and a two way communication process between themselves and the university (Davies, 2002). Due to this increase in expectations it is possible that the actual performance of the higher educational institutes is below the expectations of the students, resulting in dissatisfaction (Appleton-Knapp \& Krentler, 2006; Bitner \& Hubbert, 1994). Important to note is that the observed results are very robust.

Two final remarks are in place at this point. First, the study at hand does not advocate stimulating student dropout. Given the social and individual costs, student dropout should be kept to a minimum. This can be achieved by a good matching practice at the gate or by student guidance practices during the first-year. Despite these practices there are always some students that did not enroll into the correct program and thus have a high probability of dropping out. Selection after the gate can be a solution for this phenomenon. Indeed, a good selection mechanism, such as an AD policy, ensures high student graduation rates. Our study shows that first-year student dropout, due to selection .after the gate has a positive influence on graduation rates. Consequently, although selection after the gate leads to more dropout in the first-year, it will lead to a reduced dropout in the following years of the program. This, in turn, will lead to a substantial cost saving. During the academic year 2015-16 45,980 first-year students enrolled in Dutch universities and 85,210 in Dutch higher vocational institutions (DUO; 2015). In the Netherlands, the government costs per student are, on average, €6650/year. Based on the assumption that students who dropped out because of the $\mathrm{AD}$ policy (i.e. 5.8\%) would also have dropped out in later years, an $\mathrm{AD}$ policy will lead to a minimum cost saving of $€ 50.6$ million (see Appendix B for the 
calculations). Simultaneously, the number of graduates will increase (7\%). Given that Dutch Bachelor's degree holders have a return of $€ 113,000^{33}$ compared to high school graduates, the benefits for the individuals will come down to €1,037 million (OECD, 2014; see Appendix B for the calculations). However, there are also social benefits through spill overs such as increased tax revenues, decreased costs on income support programs and reduced health care costs ${ }^{34}$ (Baum et al., 2013). The social net present value of the graduates will come down to $€ 937$ million (see Appendix B for the calculations). Note that the above benefits can only be accomplished if the introduction of an admission policy is complemented by measures to improve, or at least stabilize, student satisfaction. Higher educational institutions also need to implement instruments that help students switch to other study programs or find suitable jobs.

Second, as we observe that the AD policy is an effective selection tool, we have to mention that the level of the AD policy norm is also important. A very high AD policy threshold will probably not only result into a steep increase of graduation rates but also in a considerate increase in dropout rate. This can lead to the dismissal of many students who would have graduated on time. A too low AD policy norm, on the other hand, can result in too few dismissed students. Moreover, the optimal AD threshold is not easy to determine and depends on the type of academic program and the current dropout rate. A study program in the medical field, for example, will require more from students than a program in the social field, and will thus need a higher AD policy threshold to be an effective selection tool. Study programs which already have a high dropout rate may not want to introduce an high AD policy norm because this can result in few students who are able to enroll in the second year. Programs with a low dropout rate can opt to start with a low credit norm during

\footnotetext{
${ }^{33}$ We would like to note that OECD provides the net present values in American USD. We converted the American USD to EUR using the following exchange rate: 1USD $=0.95 E U R$. This exchange rate was observed in the beginning of March 2017.

${ }^{34}$ The costs and benefits included in the calculations of the return are presented in Appendix C.
} 


\section{Chapter 4}

the first years after introduction and increase it if the selection does not seem sufficient. Important to note is that there is no 'one-size-fits-all' AD policy norm.

This chapter provides several lines for future research. First, the current study does not focus on the underlying mechanisms between an $\mathrm{AD}$ policy, student performance and student satisfaction, as we do not measure intervening process variables. Additional research is necessary to exploit the mechanisms between an $\mathrm{AD}$ policy and its outcome variables. Second, we investigated the effect of the introduction of an $\mathrm{AD}$ policy on performance and satisfaction using program-level data. As such we could not distinguish students in their first year and students in later years. Those two groups of students will respond differently on an AD policy. Indeed, first-year students still need to face the AD policy while students in later years do not. We expect that the former group will be more affected by an AD policy in terms of performance. By using data at student-level, the effect of the introduction of an AD policy on performance and satisfaction of first-year students can be exploited. Third, because we could not distinguish students who received a negative obligatory advice, the threat of a selection problem exist. Future research can focus solely on this type of students and investigate the effect of receiving a negative advice on student satisfaction and on the academic career. Future research could also focus on whether students that received a negative obligatory advice and started a new study are more or less satisfied than students who never received a negative obligatory advice. This can have a large impact on the policy decisions of institutions. Fourth, it is also possible that students choose a study program based on the presence of an AD policy. If this is the case, more motivated and talented students will attend study programs with an AD policy. Future research can focus on investigating this matter. Finally, the study has used a sample of higher education programs in the Netherlands, and the extent to which the results can be generalized to other countries is not known. Further research can focus on this issue. In 
Academic dismissal policy in Dutch higher education

the next chapters, we will investigate student success at an institutional level. Chapter 5 will handle the effect of need-based grants on various student outcomes in an Italian context. 


\section{Part III}

\section{Student success at institutional level}




\section{Chapter 5}

\section{Need-based grants in Italian tertiary education}

This chapter is based on: Sneyers, E., Agasisti, T., De Witte, K. and Graziosi, G. (2016).

The impact of scholarschips on students'performance: a study on five Italian universities.

DEAMS Research Paper series. 


\section{Chapter 5}

\subsection{Introduction}

In line with the recommendations of the European Commission outlined in the Introduction and the evidence from Chapter 1 , it is interesting to explore the effects of needbased grants on study success in a more detailed way. This chapter analyses the effect of need-based grants in five Italian universities.

The Horizon 2020 strategy aims to achieve 40\% of young people successfully completing tertiary education, or equivalent, by 2020. In the last decade, tertiary education attainment levels have grown significantly across much of Europe (see Figure 5.1). As groups traditionally excluded now participate in tertiary education, the student population is becoming increasingly heterogeneous (OECD, 2014). However, there are persistent inequalities in European higher education systems concerning both access and the completion of tertiary studies. In particular, students from poor socioeconomic backgrounds, as measured by their parents' occupational status, have a low chance to access higher education in most European countries (EQUNET, 2010).

The recent analysis of data from the Survey of Adult Skills (PIAAC - OECD, 2013), presented by Van Damme (2014), stresses the relationship between skills and social inequality, on the one hand, and economic performance, on the other. Countries with a higher degree of inclusivity in their skills distribution do better in terms of economic output (per capita GDP) and social equality (Gini coefficient) than countries with a similar average level of skills but with larger differences in skills proficiency across the population. Moreover, parents' educational background still strongly affects the likelihood of their children obtaining a tertiary degree: among the age group $25-34$, only $23 \%$ of those with low-educated parents attain a tertiary qualification (OECD, 2014).

Governments address the issues of access to tertiary education and equality of opportunity by providing several forms of public support and subsidies to students and their 


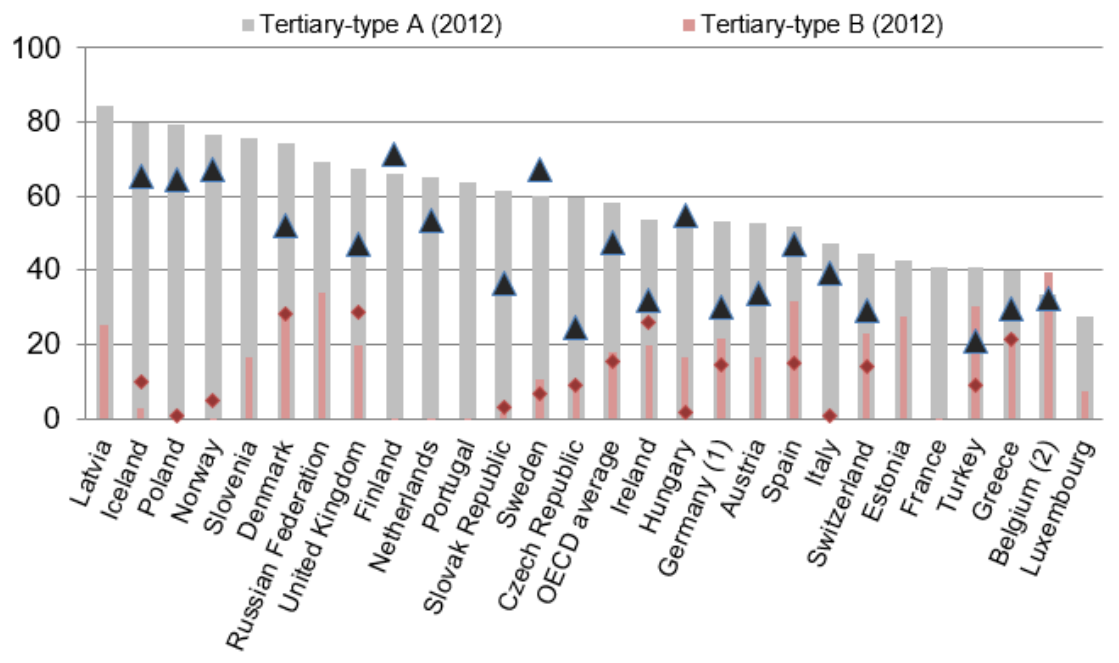

Figure 5.1: Entry rates into tertiary-type A and B education (2000, 2012). Source: OECD. Table C3.2a. (www.oecd.org/edu/eag.htm). (1) Break in time series between 2008 and 2009 due to a partial reallocation of vocational programs into ISCED 2 and ISCED 5B. (2) Year of reference 2001 instead of 2000.

families. In particular, low-income students are able to cover part of the costs of their education and related expenses. This support is supplied in many forms, including incomebased and merit-based subsidies (i.e. grants or scholarships), loans, tax allowances for students or their parents or other household transfers. The right balance between these different kinds of subsidies may help to reduce financial disparities among students. Moreover, in the context of austerity with decreasing higher education funds and difficulties in financing the essential resources to ensure high quality educational levels, there is a need to evaluate the impact of need-based support interventions by examining their effects on students' tertiary education performance.

Italy makes an interesting case to study the effects of similar need-based grants. In the Italian higher education system, the government mainly provides public scholarships to targeted groups, on the basis of both family income and student merit. The objective of this public funding is to decrease economic barriers for deserving poor students and to reduce 


\section{Chapter 5}

socioeconomic inequalities, as explicitly stated in the Italian Constitution. However, despite the efforts, the social inequalities are noticeable where the rates of completion of tertiary education are concerned (Checchi, Fiorio, \& Leonardi, 2013; Bratti, Checchi \& de Blasio, 2008).

This study aims to evaluate the effect of income-based public scholarships for students. We take advantage of a unique, micro data set collected by the researchers with the support of five universities' administrative offices. All these universities are located in the North of Italy.

We perform both cross-sectional (between-universities) and within-universities analyses in order to evaluate the effect of grants on several student performance indicators: (i) the number of formative credits obtained during the first year; (ii) first-year dropout; (iii) graduation in the legal duration of the Bachelor course (where the formal duration of Bachelor courses is 3 years); and (iv) graduation within 4 years. Furthermore, we are also interested in the heterogeneity of impact of the received scholarships for different subpopulations of students: (i) Italian vs. immigrant students; (ii) near-home students vs. students from different regions; and (iii) students from different university departments. The aim is to model scholarship effects on student performance indicators using a matching approach. Therefore, we apply a Propensity Score Matching (PSM) technique. The method of propensity score (Rausenbaum and Rubin, 1983) is a popular strategy for causal analysis in observational studies. Indeed, many prominent statisticians (Rubin, 2007), social scientists (Morgan \& Winship, 1999), and economists (Heckman \& Vytlacil, 2007) have used and endorsed PSM. However, other empirical studies have taken a more critical view of PSM, claiming that it can lead to substantial bias (e.g. King \& Nielsen, 2015). In order to reduce the bias in the estimation of treatment effects with observational data sets, considerable attention has to be paid to the choice of covariates. Not controlling for unobserved confounders will lead to low reliability. In this study, we were able to construct 
a well-balanced and comparable control group for the students receiving a need-based grant. We rigorously show that we avoid selection effects and endogeneity arising from unobserved heterogeneity. However, in view of the afore mentioned controversy surrounding propensity score matching, the results need to be interpreted with care.

In the perspective of the existing literature (see Section 5.2), this study is innovative for several reasons. First, it provides empirical evidence about the effectiveness of financial aid in the higher education system. Previous work has mostly focused on single universities or on short-term effects, e.g. enrollment and dropout by the end of the first year, neglecting the long-term effects, such as graduation. This questions its external validity, as universities differ significantly in their nature, scope, and mission. Second, this chapter contains a discussion about the heterogeneous effects of financial aid, and analysis how targeted support to subpopulations of students can increasingly become a crucial theme for the effectiveness of aid. From a policy perspective, it is useful to explore the potential heterogeneity of the impact of grants on different subpopulations of students, since the 'average student', de facto, does not exist. Finally, the study examines the effectiveness of the grant with respect to the degree course. As degree courses among departments differ in terms of the student selection process, program regulations, and the efforts required to pass the exams, the impact of financial aid also highlights both the ability and the inherent motivations of students.

The chapter is organized as follows: Section 5.2 presents a literature review on the effects of university financial aid; Section 5.3 discusses the characteristics of student subsidies in the Italian higher education system. Section 5.4 provides details about the method that we apply to analyse the data presented in Section 5.5. The results on both between and within universities effects are reported in Section 5.6; while in Section 5.7 robustness tests are carried out. Finally Section 5.8 discusses the results and concludes. 


\section{Chapter 5}

\subsection{Literature Review}

The effect of the various types of university financial aids on students' enrollment and academic career has already been investigated in the literature. Nevertheless, earlier theoretical and empirical research estimates the average effects for a population, failing to consider the heterogeneous effects on sub-populations. A recent review by Dynarski and Scott-Clayton (2013) confirmed that university incentives positively affect the enrolment; however, the question remains whether the financial aid is correlated to the student characteristics, as well as to academic outcomes, such as persistence, performance, and completion.

Since the causal effect of financial aid on student performance is not easy to identify in observational data, several studies focus on programs that randomly assign students to the financial aid. The randomization overcomes endogeneity issues arising from selection bias. For instance, Angrist et al. (2009) investigated the Student Achievement and Retention (STAR) Project implemented in 2005 at one of the larger Canadian universities. Students enrolled in the first year were randomly assigned to one of the following treatments: the Student Support Program that provided academic support services; the Student Fellowship Program that supplied financial incentives for good grades; and a third intervention that offered both services. Students assigned to the control group were not involved in the STAR Project. The results suggested that support services without fellowships did not help treated students in improving their academic performance with respect to the control group, while the combined treatment increased only the academic level of women. These effects persisted until the end of the second year even though the incentives were only supplied during the first year. This gender dissimilarity has been broadly observed in the literature. Dynarski (2008) evaluated the impact of tuition subsidy programs on college completions, finding that effects are stronger among women, while Goldin et al. (2006) reported that American women had substantially higher college attendance and completion rates than men. Bettinger (2015) assessed the Ohio College Opportunity Grant initiative, and, through 
a difference-in-differences identification strategy, highlighted its positive effect on first year performances, such as a reduction in dropout rates, and an increase in grade point averages.

A further critical aspect concerns the outcome under study. While most educational policies aim at long-term effects, such as performance and graduation, most of the research focuses on the short-term effects, such as enrollment and retention. Bettinger (2015), however, has claimed that it is necessary to explore how need-based aid policies have an (in)direct effect on the long-term outputs, such as completion and academic performance. Using a treatment-comparison research design, Dynarski (2008) estimated that the scholarships awarded by the program HOPE in Arkansas and Georgia increased the number of graduates in these two states. Scott-Clayton (2012) has investigated the effect of a large financial incentive program, the West Virginia PROMISE scholarships, which consisted of free tuition for students who attained a good academic performance. The author found a significant impact on many end-of-college outcomes, with particularly large impacts on time-to-degree. Castleman \& Long (2012) have examined the impact of the Florida Student Access Grant (FSAG) on long-term outcomes such as college persistence and degree completion. Using a regression-discontinuity strategy, the authors found that the aid positively affects persistence and the cumulative number of credits earned by students. Moreover, the grant also increased the likelihood of gaining a Bachelor's degree by 4.6percentage points.

As far as the European context is concerned, there is limited evidence on how financial aid influences higher education outcomes. Häkkinen and Uusitalo (2003) evaluated the Finnish reform of student financial aid designed to shorten the duration of university studies. Using a duration model on data of all Finnish students enrolled in the first year between 1987 and 1995, the authors observed that the effect of the reform on graduation time was modest and concentrated in those fields which have a long average duration. Similar results were obtained by Glocker (2011), who focused on two aspects: the duration 


\section{Chapter 5}

of the students' career and the probability of actually graduating with a degree. Applying a discrete-time duration model on German university students from 1984 to 2007, she found that students who obtained aid actually experienced lower dropout, but did not graduate faster. Several outcomes of academic performance were considered by Arendt (2013) to assess the effects of the Danish reform on the student grant and loan system, which consisted of increasing the amount of the aid. The results suggested a positive impact on lowering the dropout rates, but no overall effect on completion rates. Further, the heterogeneity of this effect was investigated for particular subgroups of students. The author showed the positive influence of increasing the amount of grants on reducing dropout for student workers, but there was no evidence of higher completion rates. Finally, Belot, Canton and Webbink (2007) have studied the impact of a reform in the case of the Dutch higher education system, which reduced the duration of (mostly merit-based) grants to 1 year. The authors considered several dimensions of academic performance such as passing the first-year exam, drop-out, and graduation mark. The results showed, through a difference-in-differences approach, that the reform positively affects students’ results.

Among the recent Italian literature on the effect of higher education scholarships, Mealli and Rampichini (2006) analysed the effect of financial aid on two dimensions of the educational process: persistence (enrollment in the second year), and productivity (exams passed in the second year). The analysis focuses on 11 universities evenly distributed throughout Italy and considered students enrolled in the academic years 1998/99, $1999 / 2000$ and 2001/02. The causal effect of the grant is estimated by employing a regression discontinuity design. The effectiveness of the grant on the probability of enrollment in the second year is demonstrated only for 'far from home' students ${ }^{35}$ in 9 of the 11 observed universities, while it is almost never effective for commuters and resident students. In the second year, and with respect to the passing of the exams, students who

\footnotetext{
${ }^{35}$ Students whose family lives far from the city where the university is located, and who cannot commute.
} 
receive the grant show greater progress. Subsequently, Mealli and Rampichini (2012) have examined the impact of the scholarship on student dropout enrolled in the academic year 1999 in four Italian universities. The effectiveness of the grant on the probability of enrollment in the second year for non-grant applicant students is significant at the threshold for all universities, while the effect of the treatment on the grant applicant students at the cut-off point is not significant for 3 out of 4 universities. Furthermore, the authors show how the effect of the grant on the continuation of studies decreases with a decrease in income. In other words, for the poorest students, receiving the grant does not affect the decision to drop out. A randomized experiment was conducted by De Paola, Scoppa, and Nisticó (2012) at the University of Calabria involving, 462 students enrolled in the academic year 2008/09. Students were assigned to three different groups: two treated groups (a top award group, and a modest award group) and a control group (without any awards). Bonuses were assigned to the 30 best-performing students in each treated group. The authors observed that financial aid effects are positive on student performance both in terms of collected formative credits and exam grades. High ability students strongly react, whereas the effect is null for low ability students. Graziosi (2012) has investigated the impact of different forms of incentives, income-based and merit-based financial aid, on both the probability of enrolling in the second year and graduating within the regular time frame at the university of Trieste. Applying matching techniques, the author demonstrated that income-based grants reduce dropout, while merit-based ones allow students to graduate in time. With respect to the effect of grants on the completion of studies for students enrolled at the Bocconi university, Garibaldi, Giavazzi, Ichino and Rettore (2012) provided evidence that, if the economic incentives were increased by $€ 1,000$, the probability that students would graduate on time would decrease by 5.2\%. Finally, Agasisti and Murtinu (2014) assessed the impact of receiving a grant for a cohort of students enrolled at the 'Politecnico di Milano’ in the 2007/2008 academic year. The empirical analysis focused on both a wider 


\section{Chapter 5}

range of academic results (i.e. dropout, formative ${ }^{36}$ credits acquired and time taken for graduation) and various dimensions of the heterogeneity of effects, related to students' characteristics and courses attended. The authors find that obtaining a grant positively affects academic performance, especially for immigrants, students whose family reside in another region, and those attending engineering courses.

The decision to study the role of need-based aid on students' performance is particularly important in Italy, as previous studies demonstrate that higher education attendance and results are still very dependent on students' socioeconomic background (Bratti et al., 2008; Triventi \& Trivellato, 2009). While most prior Italian research has focused on single universities or short-term outcomes, this chapter provides an empirical analysis employing an innovative micro data set of five Italian universities. Furthermore, the aim is to understand both the relationship between scholarships and several student performance indicators and the heterogeneity effect of the scholarships for different subpopulations of students, thus revealing the real effectiveness of grants to help students in improving their academic performance.

\subsection{Setting: student subsidies in the Italian higher education system}

The Italian student financial support system mainly relies on public scholarships to targeted groups. Other forms of incentives, such as loans and transfers to other private entities, are negligible. Also, the main 'rules of the game' - such as eligibility criteria, the amount of grants, etc. - are defined centrally by the Ministry of Education, and are not directly under the responsibility of single universities. Another key feature of the system is that the overall financial aid system involves a low percentage of students, around $19 \%$

\footnotetext{
${ }^{36}$ The term "formative credits" is translated from the Italian term "Crediti Formativi Universitari" and is defined as the number of credits obtained by a student.
} 
(OECD, 2014), and depends heavily on public funding. In the relevant years for the analysis (i.e. 2007/08), the proportion of students who received a need-based grant was $13 \%$, with some regions where this proportion was relatively low (i.e. Campania and Lombardy: 8.9\%) and others in which it was substantially higher (i.e. Piedmont: 17.9\%, and Calabria: 19.3\%) (source of the data: the Regional Observatory of the University System in Piedmont).

\subsubsection{The need-based grant}

In the financial aid system that operated in $2007 / 08^{37}$, students are ranked on the basis of (i) their economic needs, measured by an indicator that considers family income and assets, and (ii) their merit, the latter measured by their final high school grade based on a national standardized exam (at the moment of the enrollment) and, after the first year, by the number of formative credits earned. In our analysis, applicants enrolled in the first year provide information about their family income (only one University also required a merit criterion related to the high school mark) that, in order to be eligible for income-based scholarships, must not exceed $€ 21,000$. The beneficiaries are exempted from paying university fees, and receive a first instalment of the grant to cover educational costs. For maintaining the scholarship, students must acquire a certain number of formative credits by the middle of August. This number depends on the degree course, and typically ranges from 20 to 40 formative credits for enrolling in the second year (a full academic year consists of 60 credits) and 80 to access the third year. If students do not acquire the minimum number of formative credits, they do not receive the second stage of the grant. Moreover, if the

\footnotetext{
${ }^{37}$ The recent Italian university reform (Law 30 December 2010 n. 240) establishes both minimum standards of services for students from a low socioeconomic background and a national merit-fund to support the most successful students; nevertheless, the income-based scholarships remain the main tool for promoting investment in tertiary education and reducing socio-economic inequalities. The actual implementation of the reform is still not in operation (it is expected to be effective from 2015/16), so in reality the only existing financial aid is represented by the traditional grants discussed in this study.
} 


\section{Chapter 5}

merit criterion is not achieved by the beginning of the second year, students must return the first half of the scholarship.

The amount of the scholarship is fixed, but it is subject to some (small) degrees of flexibility. On the one hand, it depends on the income indicators of the student and his/her family. On the other hand, it varies according to the status of the students, classified as follows: 'near-home' students (those whose family lives in the same city in where they are attending university); 'commuting' students ( whose family lives in cities located near the city where they are attending university, and who commute daily); and 'far-from-home' students ( whose family lives far from the university’s city). Depending on the combination of both economic indicators and student status, the grant amount ranges from $€ 1,500$ up to $€ 5,700$, the latter amount being provided to student with the lowest economic level who are also classified as ‘far-from-home’. Students who are awarded the grant are exonerated from the payment of tuition fees and are exempted (or partially exempted) from other educational costs, e.g. accommodation, meal, and so on.

\subsubsection{Underlying mechanisms for need-based grants to be effective}

Having outlined the main features of the student support system, it is necessary to discuss why it is reasonable to expect that a grant can have an impact on student performance, and where we see the potential heterogeneity of this effect a priori. First, the grant can act on liquidity constraints: for instance, the most disadvantaged students may be forced to work during their studies in order to cover their living costs, so obtaining a subsidy can reduce the time for this duty, and making more time free for studying (Avdic \& Gartell, 2015). The exemption from fee payments, which is automatic for students eligible for grants, also acts in this direction. Given that the amount of the grant is different for various categories of students (see above), it is also likely that its eventual effect is not homogeneous for the different groups. Secondly, the grant has an impact on motivation: students who receive the grant may feel they have a better opportunity than others, and may 
consider it as a stimulus to study more effectively and with more commitment. In this perspective, it is not the amount of aid that matters, but the motivation that moves students to choose different courses.

There are also mechanisms that lead us to expect a heterogeneous effect of the needbased grant. First, since immigrants tend to enroll at university less frequently and have a higher probability of dropping out than native students, we would expect that the scholarship would have a higher impact on immigrants (Cingano \& Cipollone, 2007). Next, some studies (e.g. Catalano \& Figà Talamanca, 2002) show that the most important expenditures for higher education are related to housing costs. Therefore, we also suppose that relatively poor students who move to another region/city to attend university will need more financial aid compared with near-home students. The receipt of a scholarship can have a positive impact on the academic performance of students from different regions, since they do not need to work to cover their expenses. We expect that students moving from regions different from the one in which the university is located will benefit more from receiving the scholarship than near-home students. Furthermore, courses in different departments are, by construction definition, from each other. So scholarships can have a heterogeneous impact on students in different departments.

\subsection{Methodology}

In order to investigate the effect of receiving the grant on student performance, we apply a counterfactual analysis. According to the potential outcome model, each student has two outcomes (Rubin, 1974): $Y^{T}$ represents the students' performance if he/she received the scholarship (i.e. the Treated), $Y^{U T}$ represents the students' performance when he/she did not receive the scholarship (i.e. the Untreated). Since we do not observe both outcomes at the same time for any student, the outcome that is not observed is referred to 


\section{Chapter 5}

as the "counterfactual outcome" (Holland, 1986), and indicates how treated students would behave if they had not been exposed to the treatment.

The average effect of the receipt of the scholarship on student performance is the Average Treatment effect on the Treated (ATT), i.e. the average difference between $Y^{T}$ and $Y^{U T}$, conditional on the treatment:

$$
A T T=E\left(Y^{T}-Y^{U T} \mid T=1\right)=E\left(Y^{T} \mid T=1\right)-E\left(Y^{U T} \mid T=1\right),
$$

where $T=\{0,1\}$ is the indicator of exposure to treatment. While the first outcome, $E\left(Y^{T} \mid T=1\right)$, is (relatively) simple to estimate using observations for treated students, the second outcome, $E\left(Y^{U T} \mid T=1\right)$, i.e. the counterfactual outcome, is unobserved and must be estimated referring to the untreated student, balanced with respect to all explanatory variables. Due to the limited number of students who received a need-based grant (see Section 5.3), it is reasonable to assume that the potential outcome of students is independent of the assignment of grants to other students. This corresponds to the Stable Unit Treatment Value Assumption (SUTVA) (Rubin, 1980), which states that the outcomes of students should not be influenced by each other.

Since in observational studies the assignment of units to the treatment is not random, the estimation of the treatment effect may lead to mistakes due to selection bias. In order to avoid this, we choose to apply a Propensity Score Matching (PSM) approach (Rosenbaum \& Rubin, 1983). PSM is a two-step procedure, which starts by estimating the Propensity Score (PS) for each student using a logit model where the dependent variable is the receipt of the grant. Moreover, the Propensity Score, i.e. the conditional probability of treatment, given background variables, is estimated as follows:

$$
P(T=1 \mid X)=\pi(X)
$$


where $\pi$ is a continuous variable. In the next step, we will match each treated student with the most similar untreated student (i.e. the student with the closest propensity score) who did not receive the grant. This approach will help us to balance the control and treatment groups with respect to all the pre-treatment variables that could affect the outcomes. In this way, we are able to meet the Conditional Independent Assumption (CIA), which states that, conditional on the observable pre-treatment variables $X$, the allocation to the program is independent of the potential outcomes. The other assumption behind the PSM technique is that, by controlling for a wide range of observable factors, we create a balanced control group in which also the unobservable factors are similar between the control and the treatment group.

If both CIA and Common Support are satisfied, the ATT under PSM could be written as:

$$
\left.\widehat{A T T}^{P S}=E_{\pi(X) \mid T=1}\{E[Y(1) \mid T=1, \pi(X)]-E|Y(0)| T=0, \pi(X)]\right\},
$$

where the average difference between the outcome of both treated and untreated students is weighted according to the distribution of the PS.

Since we condition the matching procedure on the propensity score, it is necessary to check whether the distribution of covariates is balanced in both the treatment and the control group (Caliendo \& Kopeinig, 2008). One suitable indicator proposed by Rosenbaum and Rubin (1985) is the Absolute Standardized Bias (ASB), i.e. a measure of both the average imbalance in each covariate $X$ and the overall matching performance between treated and control units. As a general rule, the balancing is acceptable for values of the ASB smaller than $5 \%$, after matching.

In our PSM approach, the treatment is defined as: 
- the receipt of the grant in the first academic year, where the dependent variables are either the number of formative credits obtained in the first year or the dropout rate by the end of the first year;

- $\quad$ the receipt of the scholarship in the first, second, and third year, where the dependent variable is graduation (either in the formal duration of the academic program or 4 four years).

\subsection{Data}

We collected a unique dataset concerning first-year students who entered five large and traditional universities located in Northern Italy. Interestingly, the universities under analysis differ in terms of size and educational offer. Three of them are located in the Northwest of Italy. University $A$, the smallest one, is specialized in communication strategies and foreign languages, i.e. the humanities; University $B$ covers three thematic areas: architecture, design and engineering, i.e. science; while University $C$ offers science, social studies and medicine undergraduate courses. The other two universities are based in the Northeast of Italy and provide a widerange of undergraduate courses: University $D$ covers all the academic disciplines, but University $E$ does not provide courses in medicine. As can be observed from Table 5.1, the five universities provide evidence for five different typologies: specialized; broad; comprehensive with medical center; and comprehensive without medical center.

For all universities, we include the students who enrolled in the first Bachelor year in the academic year 2007-2008, except for University $E$ where we include students enrolled in 2008-2009 (due to some practical issues in the data collection process). We follow a total of 7,415 students for four years (i.e. until the academic year 2010/11 or 2011/12). 
Table 5.1: Typology of the analysed universities

\begin{tabular}{|c|c|c|c|c|c|}
\hline University & A & B & C & $D$ & E \\
\hline Typology & Specialized & Specialized & Broad & $\begin{array}{l}\text { Comprehensive } \\
\text { incl. Medical } \\
\text { Center }\end{array}$ & $\begin{array}{l}\text { Comprehensive } \\
\text { excl. Medical } \\
\text { Center }\end{array}$ \\
\hline Humanities & $x$ & & & $x$ & $x$ \\
\hline Sciences & & $x$ & $x$ & $x$ & $x$ \\
\hline Social & & & $x$ & $x$ & $x$ \\
\hline Medicine & & & $x$ & $x$ & \\
\hline
\end{tabular}

Note: This table shows the education provided by universities, gathered in different typologies: specialized, broad, comprehensive with medical center, and comprehensive without medical center.

In order to consider the most relevant student characteristics that simultaneously influence the treatment and the outcome, we follow the approach by Sianesi (2004) and include the following observables as control variables: a dummy that equals 1 if the student is a male; a dummy that equals 1 if the student is a 'regular' student ${ }^{38}$; three mutually exclusive dummies that equals 1 if the student was born in the region where the university operates $^{39}$, in an Italian region different from the region where the university operates, or in a foreign country; four mutually exclusive dummies that equal 1 when the secondary school attended by the student was a Lyceum (i.e. he/she has a general education), Technical school, Vocational school, or Foreign school; and an indication of the socioeconomic status (SES) of the student. With respect to the SES, we do not have direct information. However, for three universities we are able to collect indirect information regarding the SES of students, as at these universities the students' fees are calculated on the basis of her/his family's income. University A establishes 3 levels, which correspond to

${ }^{38}$ At universities $A, B, C, D$ we follow the cohort of students of the academic year 200708 . Hence, regular students (i.e. students who followed the regular education track without delays) for these universities are the students who were born in the year 1988 or 1989. For University $E$, we have data of a later cohort. Therefore, regular students are students born in the year 1989 or 1990.

${ }^{39}$ For universities $A, B, C$ the near-home region is Lombardia. For universities $D$ and $E$ the near-home region is respectively Friuli-Venezia Giulia and Veneto. 


\section{Chapter 5}

an increasing fee. Universities $B$ and $E$ define 10 and 8 levels, respectively. Students who refuse to declare their family's income are classified in the highest scale and have to pay the highest fee. Hence, students coming from disadvantaged backgrounds have a strong incentive to declare their family's income. In addition, in order to receive the scholarship, information about the income level needs to be provided. We observe for University $B$ that $96 \%$ of the students who received the scholarship are classified in level 2 of the fee scale. At University A, $92 \%$ of the students with grants are classified in level 1 , while, at University $E$, $80 \%$ are classified in levels $1,2,3$ or 4 . Students with similar fee levels are expected to have the same SES. We need to mention that we do not have any information about the fee level of students at universities $C$ and $D$. Therefore, we do a robustness check whereby we exclude all the information regarding the income level (see Section 5.7).

Some students are in the eligible fee scale, but did not receive a grant. Meetings with university officers informed us that there are multiple reasons for why a student did not get a grant even though he/she is eligible for it. First, students may not request the treatment because they lack the appropriate information or fear the administrative burden. This prevents them from access in the procedure for obtaining a scholarship. Second, students may be able to cover their living expenses without the scholarship (by living in their parents' home) and prefer this solution. Third, some students may have applied for the scholarship but did not receive it because of errors in the administrative procedure. It is clear that not receiving a grant does not necessarily correspond to unobserved heterogeneity or differences in ability among students.

We define four output variables regarding the academic performance of students: (i) the number of formative credits obtained after the first year; (ii) the dropout status at the first year (1=yes, $0=$ no); (iii) graduation in the formal ( 3 year) duration of the course ( $1=y e s$, $0=$ no); and (iv) graduation within 4 years ( $1=$ yes, $0=$ no).

Table 5.2 provides the unmatched sample descriptive statistics on the control and treatment group for each university. We only include students who are in the eligible fee 
scale, and who have no missing data. Our sample comprises of 6,058 untreated students (i.e. the control group) and 1,357 treated students. If we look at the total in columns 11 and 12, we observe some interesting differences between the control and the treatment group. First, the proportion of students who followed the regular education track without delays, i.e. the proportion of the regular group, is barely lower than that of the control group (63.3\% vs. $66.4 \%$ ). Second, the proportion of students living close to home is significantly higher than it is in the control group (64.8\% vs. $40.2 \%)$, excepts for University E, while the proportion of students from other region is insignificantly lower in the control group (27.3\% vs. $28.8 \%$ ). Not surprisingly, the proportion of immigrant students is very high among the treated students (32.5\% vs. 8.6\%). Further, on average, fewer students who received a grant attend a lyceum and technical high school $(42.8 \%$ vs. $52.1 \%$ and $27.0 \%$ vs. $39.3 \%$, respectively). For the unmatched sample, it is clear that the characteristics of the students differ significantly on some of the variables. This strengthens the importance of using the PSM technique.

A glance at the four performance indicators already reveals that:

(i) the average number of formative credits (CFU) acquired by the beneficiaries in the first-year is higher than the credits obtained by the untreated students;

(ii) the percentage of students who drop out of the first year is lower for those students who received a grant;

(iii) the proportion of students who graduate in the formal duration of the course is higher in the treated group;

(iv) a higher proportion of treated students graduated within four year compared to the control group. 
Table 5.2: Descriptive statistics of the unmatched sample

\begin{tabular}{|c|c|c|c|c|c|c|c|c|c|c|c|c|}
\hline \multirow[b]{2}{*}{ Variable } & \multicolumn{2}{|c|}{ University $A$} & \multicolumn{2}{|c|}{ University $B$} & \multicolumn{2}{|c|}{ University $C$} & \multicolumn{2}{|c|}{ University $D$} & \multicolumn{2}{|c|}{ University $E$} & \multicolumn{2}{|c|}{ Total } \\
\hline & Untreated & Treated & Untreated & Treated & Untreated & Treated & Untreated & Treated & Untreated & Treated & Untreated & Treated \\
\hline Number of Observations & 396 & 35 & 869 & 354 & 1319 & 153 & 3037 & 442 & 437 & 373 & 6058 & 1357 \\
\hline Male $(=1)$ & $28.5 \%$ & $14.3 \%$ & $65.1 \%$ & $58.2 \%$ & $47.9 \%$ & $37.2 \%$ & $40.4 \%$ & $44.6 \%$ & $32.7 \%$ & $24.9 \%$ & $44.2 \%$ & $41.1 \%$ \\
\hline Regular (=1) & $58.8 \%$ & $68.6 \%$ & $73.65 \%$ & $63.0 \%$ & $53.7 \%$ & $77 \%$ & $65.7 \%$ & $64.5 \%$ & $59.5 \%$ & $71.0 \%$ & $63.3 \%$ & $66.4 \%$ \\
\hline $\begin{array}{l}\text { Living close to home } \\
\qquad(=1)\end{array}$ & $48.7 \%$ & $17.1 \%$ & $58.9 \%$ & $20.3 \%$ & $84.1 \%$ & $60.8 \%$ & $59.8 \%$ & $25.3 \%$ & $67.5 \%$ & $70.2 \%$ & $64.8 \%$ & $40.2 \%$ \\
\hline $\begin{array}{l}\text { Living in another region } \\
(=1)\end{array}$ & $44.9 \%$ & $77.1 \%$ & $23.0 \%$ & $39.3 \%$ & $11.8 \%$ & $13.7 \%$ & $32.2 \%$ & $21.0 \%$ & $32.5 \%$ & $29.8 \%$ & $27.3 \%$ & $28.8 \%$ \\
\hline Immigrant (=1) & $3.0 \%$ & $2.8 \%$ & $18.1 \%$ & $40.4 \%$ & $4.1 \%$ & $25.5 \%$ & $7.8 \%$ & $53.6 \%$ & $13.9 \%$ & $5.6 \%$ & $8.6 \%$ & $32.5 \%$ \\
\hline Lyceum (=1) & $59.3 \%$ & $71.4 \%$ & $57.5 \%$ & $52.5 \%$ & $52.4 \%$ & $42.5 \%$ & $49.7 \%$ & $28.1 \%$ & $50.1 \%$ & $48.5 \%$ & $52.1 \%$ & $42.8 \%$ \\
\hline Vocational (=1) & $13.1 \%$ & $14.3 \%$ & $1.8 \%$ & $0.8 \%$ & $8.7 \%$ & $9.2 \%$ & $0.1 \%$ & $0 \%$ & $8.0 \%$ & $10.5 \%$ & $3.6 \%$ & $4.5 \%$ \\
\hline Technical (=1) & $26.3 \%$ & $14.3 \%$ & $29.0 \%$ & $15.3 \%$ & $36.5 \%$ & $30.1 \%$ & $45.9 \%$ & $27.37 \%$ & $35.5 \%$ & $37.5 \%$ & $39.3 \%$ & $27.0 \%$ \\
\hline Foreign (=1) & $1.2 \%$ & $0 \%$ & $11.6 \%$ & $31.4 \%$ & $2.4 \%$ & $18.3 \%$ & $4.4 \%$ & $35.8 \%$ & $5.0 \%$ & $2.4 \%$ & $4.8 \%$ & $26.1 \%$ \\
\hline $\begin{array}{c}\text { Formative credits } \\
\text { (number) }\end{array}$ & 31.30 & 50.14 & 34.32 & 42.43 & 40.48 & 46.95 & 32.29 & 34.56 & 45.27 & 51.91 & 35.24 & 43.18 \\
\hline
\end{tabular}




\begin{tabular}{|c|c|c|c|c|c|c|c|c|c|c|c|c|}
\hline $\begin{array}{l}\text { First-year dropout (\% of } \\
\text { all students) }\end{array}$ & $12.6 \%$ & $0 \%$ & $21.1 \%$ & $8.2 \%$ & $2.1 \%$ & $0 \%$ & $20.0 \%$ & $10.4 \%$ & $2.97 \%$ & $0.8 \%$ & $14.5 \%$ & $5.7 \%$ \\
\hline $\begin{array}{l}\text { Graduation in the formal } \\
\text { duration of the course } \\
\text { (\% of all students) }\end{array}$ & $29.5 \%$ & $57.1 \%$ & $19.6 \%$ & $26.5 \%$ & $39 \%$ & $49 \%$ & $13 \%$ & $12 \%$ & $20.6 \%$ & $29.5 \%$ & $21.2 \%$ & $26.1 \%$ \\
\hline $\begin{array}{l}\text { Graduation within } 4 \\
\text { years (\% of all students) }\end{array}$ & $46.7 \%$ & $77.1 \%$ & $41.1 \%$ & $49.7 \%$ & $53.5 \%$ & $70.6 \%$ & $37.3 \%$ & $33.7 \%$ & $47.1 \%$ & $60 \%$ & $42.7 \%$ & $50.4 \%$ \\
\hline
\end{tabular}

Note: This table presents the summary statistics before applying the propensity score matching technique (i.e. the unmatched sample). The last four rows present the outcome variables of the analysis, while row 2-10 provide summary statistics on the control variables. 'Treated' indicates that a student received a need-based grant. 'Untreated' indicates that a student did not receive a need-based grant 


\section{Chapter 5}

We investigate the entire distribution of both the number of first-year credits and the cumulative credits obtained at the end of the third year acquired by both the control and the treatment group, by university ${ }^{40}$. We observe that in both cases the distribution of the treated students dominates that of the untreated students. Hence, we observe that there are already some significant differences in student performance between students who did receive a scholarship and those who did not. However, this evidence must be interpreted with caution, as we did not control for the composition of the control and the treatment group. The matching analysis should circumvent this shortcoming.

\subsection{Results}

\subsubsection{The effect of the scholarship}

In order to assess the matching quality, we check the distribution of the covariates in both the control and the treatment group. Moreover, we assess the situation before and after matching and check if there remain any differences after conditioning on the propensity score (Caliendo \& Kopeinig, 2008). First, consider Table 5.3. The results point toward a satisfactory reduction of the original imbalance, as in most empirical studies a bias reduction below $3 \%$ or $5 \%$ is seen as sufficient (Smith \& Todd, 2005) ${ }^{41}$.

The estimated impact of receiving a scholarship on student performance is reported in Table 5.4. The PSM estimates point towards a positive impact of receiving the grant for all performance indicators for all universities, except for the comprehensive universities: universities $D$ and $E$. For the latter two universities, the impact of the grant is not significantly different from 0 with respect to the acquired credits and the first-year dropout.

40 The distribution figures can be found in Sneyers et al. (2016).

${ }^{41}$ We also made figures that illustrate the distribution of the propensity scores before and after matching. We observe that in most cases the distributions of the propensity scores are similar. This also shows that the covariates are balanced after matching. These figures can be checked in Sneyers et al. (2016) 
Table 5.3: Summary of the distribution of the Absolute Standard Bias (ASB) before and after matching

\begin{tabular}{|c|c|c|c|c|}
\hline & \multicolumn{2}{|c|}{ Formative credits and Dropout first-year } & \multicolumn{2}{|c|}{$\begin{array}{l}\text { Graduation in time and Graduation within } \\
\qquad 4 \text { years }\end{array}$} \\
\hline & $\begin{array}{c}\% A S B \text { before } \\
\text { matching }\end{array}$ & $\begin{array}{l}\% A S B \text { after } \\
\text { matching }\end{array}$ & $\begin{array}{c}\% A S B \text { before } \\
\text { matching }\end{array}$ & $\begin{array}{c}\% A S B \text { after } \\
\text { matching }\end{array}$ \\
\hline University $A$ & $32.8(27.771)$ & $0.0(0)$ & $40.7(26.408)$ & $0.0(0)$ \\
\hline University $B$ & $27.0(25.176)$ & $3.7(3.283)$ & $34.0(23.878)$ & $.1(.368)$ \\
\hline University $C$ & $22.7(22.555)$ & $2.2(2.270)$ & $23.1(19.99)$ & $3.6(2.349)$ \\
\hline University $D$ & $37.0(41.476)$ & $.4(.519)$ & $36.2(37.76)$ & $1.6(2.13)$ \\
\hline University $E$ & $10.8(8.341)$ & $1.5(1.342)$ & $18.6(13.74)$ & $3.0(2.991)$ \\
\hline
\end{tabular}

Note: Standard deviations are reported in brackets. The table presents the ASB for both treatments: the receipt of the grant in the first academic year, if the dependent variables are the number of formative credits and first-year dropout; the receipt of the scholarship in the first, second and third year, if the dependent variable is graduation. The ASB is an indicator to assess the overall distance in marginal distributions of the $X$ variables in both the control and treatment group before and after matching. As general rule, the balancing is acceptable for values of the ASB smaller than 5\%, after matching.

The scholarship increases the probability of acquiring formative credits from $9.2 \%$ to $23.1 \%$ for universities A and C. This is a large effect as it should be compared with the average number of formative credits of 39.2 for treated and untreated students. An increase of $9 \%$ to $23 \%$ indicates that the formative credits soar from 42 to 48 (out of 60 in a regular year). This large growth in study efficiency suggests that grants might be an effective and potentially a cost-effective tool to increase learning efficiency.

As students acquire more credit points, they drop out less frequently during the first year. For universities A and C, receiving the grant reduces the probability of dropping out in the first-year from $3.4 \%$ up to $22.8 \%$, compared with the mean. This corresponds to a decrease in the dropout rate from $10 \%$ to $9.7 \%$. For university B, the dropout rate reduces by $17 \%$ thanks to the grant. 
Table 5.4: Impact of receiving the need-based grant on student performance

\begin{tabular}{|c|c|c|c|c|c|c|c|c|}
\hline & $\begin{array}{c}\text { Matched } \\
\text { Observations }\end{array}$ & \multicolumn{2}{|c|}{ Formative credits } & \multirow{2}{*}{$\begin{array}{c}\text { First-year Dropout } \\
\qquad \widehat{A T T}\end{array}$} & \multirow{2}{*}{$\begin{array}{l}\text { Matched } \\
\text { Observations } \\
\text { Controls }\end{array}$} & \multicolumn{2}{|c|}{$\begin{array}{l}\text { Graduation on } \\
\text { time }\end{array}$} & \multirow{2}{*}{$\begin{array}{l}\text { Graduation within } \\
4 \text { years } \\
\widehat{A T T}\end{array}$} \\
\hline & Controls & Treated & $\widehat{A T T}$ & & & Treated & $\widehat{A T T}$ & \\
\hline University $A$ & 396 & 35 & 23.071 & -.228 & 304 & 17 & .294 & .176 \\
\hline & & & $(5.28)$ & $(-3.17)$ & & & $(1.80)$ & $(1.46)$ \\
\hline \multirow[t]{2}{*}{ University $B$} & 869 & 354 & 10.289 & -.169 & 670 & 166 & .277 & .319 \\
\hline & & & $(5.83)$ & $(-6.20)$ & & & $(2.59)$ & $(2.55)$ \\
\hline \multirow[t]{2}{*}{ University C } & 1,319 & 147 & 9.198 & -.034 & 1,236 & 87 & .299 & .299 \\
\hline & & & (4.64) & $(-2.27)$ & & & $(4.16)$ & (4.65) \\
\hline \multirow[t]{2}{*}{ University $D$} & 3,035 & 436 & -1.964 & -.037 & 2,354 & 180 & .1 & .217 \\
\hline & & & $(-.051)$ & $(-.52)$ & & & $(2.47)$ & $(4.20)$ \\
\hline
\end{tabular}


Note: The T-statistic is reported in brackets. The table presents the estimated Average Treatment effect on the Treated (ATT), which corresponds to the difference between the outcomes of the treated and the outcomes of the matched sample of untreated students. The matching variables in the analysis include: gender; regular student (i.e. without study delay); proxy for distance to the university; type of secondary education school; and socioeconomic status of the student. We consider four outcome variables: formative credits; first-year dropout; graduation in time (i.e. in 3 years); and graduation within 4 years. A positive sign suggests a favorable impact of the need-based grant on the outcome variables. 


\section{Chapter 5}

Considering the in-time graduation and graduation by the end of the fourth year, we notice a positive and significant effect of the scholarship for all universities, except specialized University A (positive but no significant effect, which is mainly due to the low number of treated observations and the corresponding lack of power in the analysis). We observe an increase in the probability of graduating on time from $10 \%$ to $29.9 \%$, while the probability of graduation within 4 years rises from $21.7 \%$ to $31.9 \%$. Compared with their respective means, these are, again, large improvements in the outcome variables.

We can conclude that the impact of the scholarship is positive and relatively large for all performance indicators.

\subsubsection{The heterogeneous impact of the scholarship}

This section investigates whether the effect of receiving a scholarship is conducive to different results for: (i) native vs. immigrant students; (ii) near-home students vs. students from different regions; and (iii) students from different departments. There are a number of reasons for expecting a heterogeneous effect within and between universities, as discussed in Section 5.3.

\subsubsection{Native students vs immigrants}

The results presented in Table 5.5 do not provide a clear-cut pattern of difference between the two sub-populations. The most prominent differences are observed universitywise (it should be noted: university $A$ is excluded for the excessively low number of observations for immigrant students). A positive significant impact of the scholarship on the number of formative credits acquired is observed for immigrants in both universities B and C. In those universities the number of formative credits increases by $10 \%$ and $8 \%$, respectively. Compared with the average number of credits for natives (41.14) and immigrants (24.43), the grant increases the formative credits to 47.38 and 35.12 , respectively. These are clearly significant increases. Given that the ATT is almost double 
Table 5.5: Heterogeneity of the impact of receiving the scholarship: Native Italian students versus immigrants

\begin{tabular}{|c|c|c|c|c|c|c|c|c|}
\hline & \multirow{2}{*}{$\begin{array}{c}\text { Matched } \\
\text { Observations }\end{array}$} & \multicolumn{2}{|c|}{ Formative credits } & \multirow{2}{*}{$\begin{array}{c}\text { Dropout first-year } \\
\overline{A T T}\end{array}$} & \multirow{2}{*}{$\begin{array}{c}\text { Matched } \\
\text { Observations }\end{array}$} & \multicolumn{2}{|c|}{ Graduation on time } & \multirow{2}{*}{$\begin{array}{c}\begin{array}{c}\text { Graduation within } \\
\text { years }\end{array} \\
\widehat{A T T}\end{array}$} \\
\hline & & Treated & $\widehat{A T T}$ & & & Treated & $\widehat{A T T}$ & \\
\hline \multicolumn{9}{|l|}{ University $B$} \\
\hline Native Italian students & 711 & 210 & $\begin{array}{l}10.131 \\
(4.88)\end{array}$ & $\begin{array}{c}-.128 \\
(-4.24)\end{array}$ & 574 & 104 & $\begin{array}{c}.135 \\
(1.96)\end{array}$ & $\begin{array}{c}.211 \\
(3.92)\end{array}$ \\
\hline Immigrants & 157 & 143 & $\begin{array}{c}17.098 \\
(2.05) \\
\end{array}$ & $\begin{array}{l}-.091 \\
(-.68)\end{array}$ & 96 & 62 & $\begin{array}{c}.242 \\
(1.85) \\
\end{array}$ & $\begin{array}{c}.371 \\
(2.07) \\
\end{array}$ \\
\hline \multicolumn{9}{|l|}{ University $C$} \\
\hline Native Italian students & 1,265 & 114 & $\begin{array}{l}8.111 \\
(3.99)\end{array}$ & $\begin{array}{c}-.017 \\
(-1.42)\end{array}$ & 1,178 & 69 & $\begin{array}{c}.304 \\
(3.87)\end{array}$ & $\begin{array}{c}.232 \\
(3.33)\end{array}$ \\
\hline Immigrants & 54 & 32 & $\begin{array}{l}12.659 \\
(2.42) \\
\end{array}$ & $\begin{array}{c}-.093 \\
(-1.79) \\
\end{array}$ & 58 & 18 & $\begin{array}{c}.333 \\
(1.21)\end{array}$ & $\begin{array}{c}.666 \\
(2.52) \\
\end{array}$ \\
\hline \multicolumn{9}{|l|}{ University D } \\
\hline Native Italian students & 2,783 & 205 & $\begin{array}{l}1.860 \\
(0.91)\end{array}$ & $\begin{array}{c}-.054 \\
(-1.53)\end{array}$ & 2,113 & 84 & $\begin{array}{c}.131 \\
(2.02)\end{array}$ & $\begin{array}{c}.238 \\
(3.30)\end{array}$ \\
\hline Immigrants & 237 & 228 & $\begin{array}{c}-2.756 \\
(-.41) \\
\end{array}$ & $\begin{array}{l}-.061 \\
(-.55) \\
\end{array}$ & 234 & 97 & $\begin{array}{c}.072 \\
(1.45) \\
\end{array}$ & $\begin{array}{c}.227 \\
(3.37) \\
\end{array}$ \\
\hline
\end{tabular}




\begin{tabular}{|c|c|c|c|c|c|c|c|c|}
\hline & $\begin{array}{c}\text { Matched } \\
\text { Observations } \\
\end{array}$ & \multicolumn{2}{|c|}{ Formative credits } & \multirow{2}{*}{$\begin{array}{c}\text { Dropout first-year } \\
\overline{A T T} \\
\end{array}$} & \multirow{2}{*}{$\begin{array}{c}\text { Matched } \\
\text { Observations } \\
\text { Controls } \\
\end{array}$} & \multicolumn{2}{|c|}{ Graduation on time } & \multirow{2}{*}{$\begin{array}{c}\text { Graduation within } 4 \\
\text { years } \\
\widehat{A T T} \\
\end{array}$} \\
\hline & Controls & Treated & $\widehat{A T T}$ & & & Treated & $\widehat{A T T}$ & \\
\hline \multicolumn{9}{|l|}{ University E } \\
\hline Native Italian students & 437 & 373 & $\begin{array}{c}-1.892 \\
(.28)\end{array}$ & $\begin{array}{l}-.019 \\
(-.26)\end{array}$ & 597 & 156 & $\begin{array}{c}.288 \\
(5.54)\end{array}$ & $\begin{array}{c}.288 \\
(5.54)\end{array}$ \\
\hline Immigrants & 61 & 21 & $\begin{array}{r}4.809 \\
(.30) \\
\end{array}$ & $\begin{array}{c}-.095 \\
(-1.45)\end{array}$ & 64 & 6 & $\begin{array}{l}.1667 \\
(1.00)\end{array}$ & $\begin{array}{c}.667 \\
(2.00) \\
\end{array}$ \\
\hline
\end{tabular}


for immigrants than it is for natives, it is likely that the mechanism of liquidity constraint dominates the other mechanisms (see Section 5.2). Only for university D do we observe a negative ATT for immigrants, although this is not significantly different from 0

With respect to first-year dropout, we observe that receiving the grant significantly reduces dropout. Nevertheless, the difference is not very marked, as for universities B, D and E, either the ATT for the natives or for the immigrants is not significantly different from 0 . The grants also have a positive influence on the sub-population of both immigrants and Italian students with respect to the probability to graduate on time and with one year delay. Some, of the ATT, are insignificant, but this might be due to the low power of the subanalysis. Overall, we observe that graduation on time increases by about $24 \%$ for natives and $13 \%$ for immigrants for university B. Other universities have similar effect sizes. This ATT should be compared with the average graduation rate of $23 \%$ and $12 \%$ for natives and immigrants, respectively.

Summarizing, a general positive effect for immigrant students is detectable and could drew the attention of policy makers to promote inclusion via financial aid

\subsubsection{Near-home students versus students from other regions}

Within the group of native Italian students, the impact of receiving a scholarship might be different between near-home students and students from other regions, as the latter group may suffer from higher living costs and thus may benefit more of the scholarship. From Table 5.6, we observe that students from other regions have a higher probability to acquire formative credits in all universities (except for university E, where we do not observe a significant ATT). Receiving a grant significantly reduced dropout for students from other regions for most universities (except for universities B and C). Distributing the grant among students from other regions results in a significant increase in graduation on time, and graduation with a one-year delay. 
Table 5.6: Heterogeneity of the impact of receiving the scholarship: Near-home students versus students from other regions

\begin{tabular}{|c|c|c|c|c|c|c|c|c|}
\hline & Matched & \multicolumn{2}{|c|}{ Formative credits } & Dropout first-year & \multirow{2}{*}{$\begin{array}{c}\text { Matched } \\
\text { Observations }\end{array}$} & \multicolumn{2}{|c|}{ Graduation on time } & $\begin{array}{c}\text { Graduation within } 4 \\
\text { years }\end{array}$ \\
\hline & Controls & Treated & $\widehat{A T T}$ & $\widehat{A T T}$ & & Treated & $\widehat{A T T}$ & $\widehat{A T T}$ \\
\hline \multicolumn{9}{|l|}{ University $A$} \\
\hline Near home students & 193 & 5 & $18.5(1.70)$ & $-.2(-1.00)$ & 150 & 2 & - & - \\
\hline $\begin{array}{l}\text { Students from other } \\
\text { regions }\end{array}$ & 178 & 27 & $22.685(4.36)$ & $-.222(-2.73)$ & 136 & 14 & $.214(1.15)$ & $.214(1.49)$ \\
\hline \multicolumn{9}{|l|}{ University $B$} \\
\hline Near home students & 497 & 72 & $11.764(3.24)$ & $-.125(-2.49)$ & 397 & 34 & $-.059(-.49)$ & $.029(.29)$ \\
\hline $\begin{array}{l}\text { Students from other } \\
\text { regions }\end{array}$ & 200 & 138 & $12.866(1.26)$ & $-.087(-.48)$ & 177 & 70 & $.286(3.54)$ & $.371(5.79)$ \\
\hline \multicolumn{9}{|l|}{ University $C$} \\
\hline Near home students & 1,109 & 93 & $8.784(3.94)$ & $-.011(-1.00)$ & 1,045 & 58 & $.313(3.54)$ & $.259(3.26)$ \\
\hline $\begin{array}{l}\text { Students from other } \\
\text { regions }\end{array}$ & 156 & 21 & $14.328(2.74)$ & $-.048(-1.00)$ & 119 & 11 & $.545(2.34)$ & $.273(1.17)$ \\
\hline
\end{tabular}




\begin{tabular}{|c|c|c|c|c|c|c|c|c|}
\hline & \multirow{2}{*}{$\begin{array}{c}\text { Matched } \\
\text { Observations } \\
\text { Controls }\end{array}$} & \multicolumn{2}{|c|}{ Formative credits } & Dropout first-year & \multirow{2}{*}{$\begin{array}{c}\text { Matched } \\
\text { Observations } \\
\text { Controls }\end{array}$} & \multicolumn{2}{|c|}{ Graduation on time } & \multirow{2}{*}{$\begin{array}{c}\begin{array}{c}\text { Graduation within } 4 \\
\text { years }\end{array} \\
\overline{A T T}\end{array}$} \\
\hline & & Treated & $\widehat{\overline{A T T}}$ & $\widehat{\overline{A T T}}$ & & Treated & $\widehat{A T T}$ & \\
\hline \multicolumn{9}{|l|}{ University $D$} \\
\hline Near home students & 1810 & 112 & $-.279(-0.10)$ & $-.009(-.18)$ & 1367 & 43 & $.163(1.77)$ & $.279(2.66)$ \\
\hline $\begin{array}{l}\text { Students from } \\
\text { other regions } \\
\text { University } E\end{array}$ & 973 & 93 & $\begin{array}{c}3.784 \\
(1.21)\end{array}$ & $-.150(-2.84)$ & 746 & 41 & .097 (1.06) & $\begin{array}{c}.146 \\
(1.33)\end{array}$ \\
\hline Near home students & 295 & 262 & $6.565(.75)$ & $-.382(-.32)$ & 414 & 113 & $.257(4.16)$ & $\begin{array}{c}.221 \\
(3.99)\end{array}$ \\
\hline $\begin{array}{l}\text { Students from other } \\
\text { regions }\end{array}$ & 142 & 110 & $\begin{array}{l}3.236 \\
(0.38)\end{array}$ & $-.109(-1.36)$ & 183 & 41 & .341 (3.30) & $\begin{array}{l}.366 \\
(3.99)\end{array}$ \\
\hline
\end{tabular}

Note: The T-statistic is reported in brackets. The table presents the estimated Average Treatment effect on the Treated (ATT), which corresponds to the difference between the outcomes of the treated and the outcomes of the matched sample of untreated students. The matching variables in the analysis include: gender; regular student (i.e. without study delay); proxy for distance to the university; type of secondary education school; and socioeconomic status of the student. We consider four outcome variables: formative credits; first-year dropout; graduation in time (i.e. in 3 years); and graduation within 4 years. A positive sign suggests a favorable impact of the need-based grant on the outcome variables. 


\section{Chapter 5}

To sum up, although the direction of the effect is not unequivocal, the general tendency is towards a stronger effect of aid on students who decide to move from their home area to study - this evidence is somehow consistent with the idea of aid as a tool for lowering maintenance costs.

\subsubsection{Different departments}

Finally, concerning the department effect, the estimates in Table 5.7 reveal that receiving the scholarship has a different impact on the performance of students depending on both the department they attended and the outcome considered. The effect of receiving a grant on formative credits and dropout, when significant, is positive for the humanities and social sciences departments. With regard to the science department, the positive impact of the scholarships is detected only at University $C$ (the broad university), while no significant effect is observed for both comprehensive universities: Universities $D$ and $E$. A potential explanation for the estimates for science faculties is that a non-negligible student self-selection effect is at work. It is particularly interesting to note that for medicine this effect is never significant - this result is consistent with the selection procedure of students in this faculty, which includes a test at the beginning (thus, students are self-selected and aid would not play a decisive role in their subsequent performance). As regards the probability of graduation, we observe a different impact of the scholarship with respect to both the department attended by students and the time for graduation. Receiving a scholarship has a positive significant effect on the likelihood of taking the degree within 4 years and graduating on time for students enrolled in the humanities and the social sciences; further, the effect of the scholarship significantly depends on the interaction between the university and the courses attended.

We can conclude that the results show a heterogeneous impact, with the effect of scholarships diverging more within universities than across them. Although, in most 
Table 5.7: Heterogeneity of the impact of receiving the scholarship: Different departments

\begin{tabular}{|c|c|c|c|c|c|c|c|c|}
\hline & \multirow{2}{*}{$\begin{array}{c}\begin{array}{c}\text { Matched } \\
\text { Observations }\end{array} \\
\text { Controls } \\
\end{array}$} & \multicolumn{2}{|c|}{ Formative credits } & \multirow{2}{*}{$\begin{array}{c}\text { Dropout first-year } \\
\widehat{A T T}\end{array}$} & \multirow{2}{*}{$\begin{array}{c}\begin{array}{c}\text { Matched } \\
\text { Observations }\end{array} \\
\text { Controls } \\
\end{array}$} & \multicolumn{2}{|c|}{ Graduation on time } & \multirow{2}{*}{$\begin{array}{c}\begin{array}{c}\text { Graduation within } 4 \\
\text { years }\end{array} \\
\overline{\text { ATT }} \\
\end{array}$} \\
\hline & & Treated & $\overline{A T T}$ & & & Treated & $\widehat{A T T}$ & \\
\hline \multicolumn{9}{|l|}{ University $C$} \\
\hline Sciences & 156 & 17 & $20.470(4.16)$ & - & 148 & 10 & $.7(4.58)$ & $.9(9.00)$ \\
\hline Social & 618 & 68 & $8.956(2.85)$ & $-.073(-2.31)$ & 561 & 43 & $1.860(1.76)$ & $.256(.102)$ \\
\hline Medicine & 538 & 60 & $7.107(1.34)$ & -1 & 520 & 34 & $.441(2.86)$ & $.147(1.07)$ \\
\hline \multicolumn{9}{|l|}{ University D } \\
\hline Humanities & 1,230 & 168 & $5.482(2.34)$ & $-098(-2.32)$ & 912 & 75 & $.08(1.34)$ & $.029(.29)$ \\
\hline Sciences & 984 & 161 & $-1.903(-.27)$ & $.025(.17)$ & 792 & 57 & $0(0.00)$ & $.371(5.79)$ \\
\hline Social & 573 & 72 & $1.903(.30)$ & $-.153(-1.35)$ & 418 & 23 & $.348(2.62)$ & \\
\hline Medicine & 248 & 37 & $-1.405(-.22)$ & $-027(-.27)$ & 232 & 25 & $.16(.84)$ & \\
\hline University $E$ & & & & & & & & $.259(3.26)$ \\
\hline Humanities & 243 & 215 & $-.819(-.09)$ & $-.065(-.67)$ & 319 & 104 & $.260(3.87)$ & $.273(1.17)$ \\
\hline Sciences & 27 & 27 & $9.297(.86)$ & $-.185(-.98)$ & 36 & 9 & $.222(1.51)$ & $.222(.97)$ \\
\hline Social & 167 & 129 & 13.279 (1.67) & $-.039(-.33)$ & 231 & 41 & $.390(5.06)$ & .707 (3.53) \\
\hline
\end{tabular}

Note: The T-statistic is reported in brackets. The table presents the estimated Average Treatment effect on the Treated (ATT), which corresponds to the difference between the outcomes of the treated and the outcomes of the matched sample of untreated students. The matching variables in the analysis include: gender; regular student (i.e. without study delay); proxy for distance to the university; type of secondary education school; and socioeconomic status of the student. We consider four outcome variables: formative credits; first-year dropout; graduation in time (i.e. in 3 years); and graduation within 4 years. A positive sign suggests a favorable impact of the need-based grant on the outcome variables. 


\section{Chapter 5}

cases, the direction of the baseline results is maintained, we observe different significance levels depending on the investigated sub-population within each institution. This finding points to promoting the use of scholarships as a general policy.

\subsection{Robustness tests}

The student's socioeconomic status (SES) is an important driver to successfully complete higher education. Although none of the universities collect information regarding the students' SES, three universities provided an indirect proxy of family income level (see Section 5.5), which we used in the earlier results. However, owing to lack of information from both Universities $C$ and $D$, we could not identify this control group for all five universities. Consequently, it is possible that the results of Universities C and D are biased. We tried to get an idea of the robustness of the results by using students from all income levels, also for the universities $A, B$ and $E$. If we were to observe significant changes in the new set of results, then the previous results might be questionable.

The robustness results are presented in Table 5.8. We observe similar directions of the impact of scholarships for the four performance indicators at the three universities A, B and E, compared with the baselines results. We also see robust results regarding the significance level with the exception of the performance indicators "formative credits" and "first-year drop-out” at the comprehensive University E (as in the previous analysis), and 'graduation on time' at the specialized University B. Further, in the baseline results we observe no significant positive impact of the receipt of a grant on graduation on time and graduation within 4 years for specialized University A. But we find a significant positive result for both outcomes. However, since this is the only notable change, and given that all the other results are qualitatively and quantitatively similar, we can fairly conclude that our results are robust to this proxy of SES. 
Table 5.8: The impact of receiving scholarships while not taking the income level into account

\begin{tabular}{|c|c|c|c|c|c|c|c|c|}
\hline & \multirow{2}{*}{$\begin{array}{c}\text { Matched Observations } \\
\text { Controls }\end{array}$} & \multicolumn{2}{|c|}{ Formative credits } & \multirow{2}{*}{$\begin{array}{c}\text { First-year Dropout } \\
\widehat{A T T}\end{array}$} & \multirow{2}{*}{$\begin{array}{c}\text { Matched Observations } \\
\text { Controls }\end{array}$} & \multicolumn{2}{|c|}{ Graduation in time } & \multirow{2}{*}{$\begin{array}{c}\begin{array}{c}\text { Graduation within } 4 \\
\text { years }\end{array} \\
\overline{\text { ATT }}\end{array}$} \\
\hline & & Treated & $\widehat{A T T}$ & & & Treated & $\widehat{A T T}$ & \\
\hline \multirow[t]{2}{*}{ University $A$} & 1,047 & 37 & 17.703 & -.108 & 1,065 & 19 & .421 & .421 \\
\hline & & & $(4.28)$ & $(-2.09)$ & & & $(3.27)$ & (3.27) \\
\hline \multirow[t]{2}{*}{ University $B$} & 4,300 & 379 & 9.108 & -.224 & 3,260 & 173 & .046 & .173 \\
\hline & & & (5.19) & $(-8.04)$ & & & $(.88)$ & (3.53) \\
\hline \multirow[t]{2}{*}{ University $E$} & 437 & 373 & 4.571 & -.064 & 597 & 155 & .264 & .271 \\
\hline & & & $(.67)$ & $(-.86)$ & & & $(4.98)$ & $(5.71)$ \\
\hline
\end{tabular}

$\overline{\text { Note: The T-statistic is reported in brackets. The table presents the estimated Average Treatment effect on the Treated (ATT), which corresponds to the difference between }}$ the outcomes of the treated and the outcomes of the matched sample of untreated students. The matching variables in the analysis include: gender; regular student (i.e. without study delay); proxy for distance to the university; type of secondary education school; and socioeconomic status of the student. We consider four outcome variables: formative credits; first-year dropout; graduation in time (i.e. in 3 years); and graduation within 4 years. A positive sign suggests a favorable impact of the need-based grant on the outcome variables. 


\section{Chapter 5}

\subsection{Discussion and concluding remarks}

This study has used a rich and novel dataset of Italian universities to examine the effect of obtaining a need-based grant on the academic performance of students. By matching students with a scholarship on multiple observed characteristics to students without having a control group, we simulated an experimental setting. The matching variables included, among others; gender; distance to the university; and a proxy for socio-economic status. The results indicate that receiving a scholarship results in a higher probability of acquiring formative credits. Compared with students who have similar observed characteristics, students with a scholarship have a significantly lower probability of dropping out at the end of the first year. In particular, their odds decreased by $3 \%$ to $22 \%$. Moreover, students who receive the grant are more likely to graduate (by between $18 \%$ and $32 \%$ ) and also to graduate on time (by between $10 \%$ and $30 \%$ ). All these estimations are statistically significant, and also robust to alternative specifications.

In terms of policy conclusions, the role of financial aid seems positive, as it leads to higher performances of disadvantaged students, there by sustaining better performances for universities as a whole. In this perspective, the interventions do not solely deal with equity issues, but instead aim to developing higher efficiency of the higher education system. In this context, financial aid is a tool that can create the right incentives. Indeed, if universities compete with each other to attract better students (as in Agasisti, 2009), the financial aid that helps students to obtain better results is consistent with the strategic target of improving overall performance through market mechanisms. With respect to the heterogeneity of the grant effect, we observe different significance levels depending on the investigated subpopulations. The latter finding points to the efficient use of scholarships for particular groups of students, for instance, by exploring the better targeting of the aid to the most needy student population. Therefore, such heterogeneity is more evident within universities than across them. It suggests that managing tailored interventions should be the responsibility of each higher education institution. 
Next, we looked at the costs and benefits of the implementation of need-based grants. As we do not know the grants of each university separately, we assume that the average grant is $€ 3500$. In the current study, 1,345 students received a grant. The costs are thus $€ 4.7$ million (see Appendix B for the calculations). Because of the grants, 355 extra students will earn a degree after 4 years. Each Italian Bachelor degree holder has a private return ${ }^{42}$ of $€ 111,000$ compared with high school graduates. The public return is $€ 113,000$ for each Bachelor degree holder. The total return comes down to $€ 79.520$ million (see Appendix B for the calculations). From a financial perspective, the implementation of need-based grants seems to be positive. Moreover, by rethinking the whole articulation of responsibilities for higher education funding, costs can further be decreased. At the present time, low fees and limited availability of financial aid characterize the Italian higher education system. Empirical evidence shows that in many contexts there has not been a negative effect of introducing or increasing fees on enrolment (see Bruckmeier and Wigger (2014) for Germany, and Chapman and Ryan (2005) for Australia), so within a cost-sharing framework (Johnstone, 2004), fees could slightly increase further in the Italian universities ${ }^{43}$. With the money raised from fees, increases in the amount and number of grants could be funded, in order to improve the general academic results of Italian universities, by targeting the financial incentives to the disadvantaged and promising students, so leaving the market mechanisms to work better.

Lastly, it is recommended that the study of the effects of grants on student performance should be further deepened in the future, by increasing the collection of fine-grained administrative datasets. If researchers are able to understand more of the single students' and institutional characteristics that are associated with stronger positive effects, it will be

\footnotetext{
42 The costs and benefits included in the calculations of the return are presented in Appendix C.

${ }^{43}$ Garibaldi et al. (2012) even conclude that, in an Italian private university, an increase in tuition fees led to an improvement of time-to-graduation.
} 


\section{Chapter 5}

increasingly possible to develop predictive models for maximizing the effectiveness of financial aid policies and interventions. Such a perspective is in line with the evolution of big data usage in higher education (Timms, 2015) and must be considered as a future priority for policy makers and analysts in the field.

The study should be interpreted with caution when considering its external validity. Two factors undermine application to the whole (Italian) higher education system. First, the group of five universities is not completely representative of the articulated and diversified reality of the university setting: all the selected institutions are located in the North of Italy, where education institutions have a relatively high performance (see Agasisti \& Dal Bianco, 2006). Second, not all the disciplines/subjects are adequately represented in the same proportion that they occupy in the entire spectrum of the formative offer. Keeping these limitations in mind, we can conclude that the findings suggest positive effects from the financial aid system for improving students' results in most cases. In this perspective, a potential practical implication is to devote more money to this policy - eventually, reducing proportionally other lines of direct funding to universities.

Note that we do not explore the exact mechanism through which financial aid improves students' results. Further research is needed in this respect, and also for drawing coherent policy consequences. For instance, if students look at the 'merit threshold' as a goal (i.e. the number of formative credits to be acquired), then a gradual increase in this requirement could act as an efficiency improvement of academic performance. If, however, the main positive factor is related to the removal of liquidity constraints, the amount of the grants should be periodically revised to test adequate levels that could turn out to be more effective for helping needy students 
Chapter 6

Mergers of higher vocational institutions and their influence on student success: the case of the Netherlands 


\subsection{Introduction}

From Chapter 2, it has become clear that organizational changes have an impact on student success. In this perspective, it is interesting to examine the mergers that have occurred in the higher educational landscape in the Netherlands during the last decade. Mergers influence the organization of higher education institutions and, consequently, may have an effect on student success. Investigating the potential effect of mergers on student outcomes is important as the Ministry of Education, Culture and Science (OCW) has introduced a law for merger control ("fusietoets") in education in 2011. This law is based on the notion that scale enlargement in education leads to less study choice and to negative student outcomes. The law requires that possible mergers in higher education have to be approved by a government-led commission. The effect of mergers on student success has, however, not yet been empirically investigated. This chapter will examine the type of mergers that have occurred between various higher vocational institutions in the Netherlands during the period 2002-09 and their effect on student dropout and graduation.

Mergers have been observed across many Western higher education systems in the past four decades (Harman \& Harman, 2008; Wan \& Peterson, 2007). Mergers, as a radical form of institutional reorganization, are often seen as an answer to various external and internal forces. Government policymakers have mandated or encouraged mergers in order to eliminate perceived deficiencies in the existing systems. In particular, they have been used to address problems of institutional fragmentation, low efficiency and quality, and lack of academic and financial viability (Wan \& Peterson, 2007). In Australia, the UK, Canada, the Netherlands and Norway, policymakers have rationalized college sectors by creating larger and more comprehensive institutions through mergers. In Australia, for example, stronger and larger institutions were considered to be necessary to: increase participation; 
to decentralize the system with subsequent accountability; and introduce more competition among institutions (Meek, 2000). In Norway, colleges have merged in an attempt to create a viable, non-fragmented counterpart for the university sector that is able to deal with more autonomy (Kyvik, 2002).

Mergers can also be a voluntary institutional response to internal and external challenges (Wan \& Peterson, 2007). The reasons for incidental mergers are three-fold: improving cost efficiency; brand leverage; and optimizing the scale of operations (PriceWaterhouseCoopers, 2010). Cost efficiencies relate to the cost savings that occur owing to ,for example, economies of scale or infrastructure efficiencies. Optimizing the scale of operations aims at gaining economies of scale in specific elements of an organization's operations in order to increase competiveness. Brand leverage relates to the strengthening of the existing brand to get better opportunities (e.g. attraction of more and better students).

The existing research on institutional mergers in higher education explores the drivers and outcomes of mergers (e.g. Kyvik, 2002; Ripoll-Soler \& de-Miguel-Molina, 2013; Van Vught, 2012). This earlier research has rarely investigated whether spatial competition plays a role in the decision to merge. Spatial competition is, in this chapter, defined as: "the competition for students between higher education institutions that are located close to each other”. In many countries, competition for higher vocational students is local as the average student will choose a higher vocational education institution within close distance from his/her home. In this chapter, we investigate whether the distance between higher education campuses was a driver for the mergers at the higher vocational level that occurred in the Netherlands between 2002 and 2009.

This chapter also contributes to the existing literature by investigating whether the higher vocational institutions in the Netherlands that merged between 2002-2009 searched for comparable or diversified merging partners. Diversified partners offer academic 


\section{Chapter 6}

programs in different fields of study, while comparable partners offer academic programs in the same fields of study. Horizontal mergers consist of comparable partners, while vertical mergers consist of complementary partners. In particular, while taking the distance into account, we discuss which type of mergers occur (i.e. horizontal or vertical mergers).

The existing literature mainly focuses on the effect of mergers on finances, and the efficiency of organization (e.g. Goedegebuure, 2012; Lang, 2003). This ignores whether mergers can also have an effect on student dropout and student graduation. For instance, in a recent merger of two Dutch universities it was argued that the merger resulted in high dropout rates and low graduation numbers (PThU, 2015), as study programs at one location had been dissolved leading to difficulties for students. In addition, student failure can emerge because the merged institutions become too bureaucratic, too large, or suffer from organizational difficulties. Mergers may have positive effects on student success when the merging institutions have, for example, greater opportunities for the diversification of courses, better infrastructures, and higher quality support services for students. This can improve student success rates since such institution may create a better match between students' expectations and learning preferences and the learning environment of the institution.

In this chapter, student dropout is defined as the percentage of full-time Bachelor students who leave the institution during the first year of enrollment. Student graduation is defined as the share of re-enrolled full-time Bachelor students who obtained a degree at the institution one year after the nominal study time. Both outcome variables relate to the same cohort of students. For a student who enrolls, for example, in the academic year 2003-04 dropout can be observed one year after the enrollment, while graduation can be observed at the earliest 4 year after the enrolment. Student dropout can thus be seen as a proxy for the short-term effect of mergers, while student graduation can be seen as a long-term proxy.

In this chapter, we answer four research questions. The first three research questions are related to the type of mergers which occurred in higher vocational education in the 
Netherlands during 2002 and 2009: (I) What institutional characteristics influence the probability of merging?; (II) Does spatial competition influence the probability of a merger?; and (III) Do mergers occur between diversified or comparable higher education institutions?. In the second part of this chapter we investigate the effect of higher vocational mergers in the Netherlands at the beginning of the $21^{\text {st }}$ century on student outcomes: (IV) What is the effect of mergers on student dropout and student graduation?

The remainder of the chapter is structured as follows. In Section 6.2, we present a literature review of mergers in higher education and their possible effects on student dropout and graduation. In Section 6.3, the setting in the Netherlands is briefly described, while Section 6.4 presents the data. Next, we outline the identification strategies which allows us to: (I) incorporate distance, the differentiation variable, and control variables; and (II) investigate the effect on student outcomes. Thereafter, we present the results.

\subsection{The literature on mergers in higher education}

Higher education institutions tend to merge as a response to a variety of institutional challenges. A merger combines two separate higher education institutes into one entity with a single governing body that is in control of all assets, obligations and, responsibilities (Wan \& Peterson, 2007). Mergers can be induced by the government or by individual institutions. In the following section, we discuss the reasons for, and the outcomes of, mergers from both perspectives.

\subsubsection{Drivers for mergers in higher education}

Between the 1960s and 1990s, mergers have been government-initiated and aimed at solving social challenges. Governmental policymakers have used mergers to: increase efficiency and effectiveness in higher education; widen access; make sure that higher 


\section{Chapter 6}

education more directly serves national and regional economic and social objectives (i.e. to reduce unemployment and to increase higher education access); and deal with narrow specialization and institutional fragmentation (Wan \& Peterson, 2007). The authorities have used different incentives to implement mergers, and have allowed different degrees of autonomy for the involved institutions. In the Netherlands and Australia, for example, the merging institutions have had to meet certain criteria in order to be eligible for state support. These institutions have been relatively free to choose a merging partner. In other countries, like Norway, Finland, and the Flemish part of Belgium, mergers have been publicly steered with little autonomy for the institutions (Wan \& Peterson, 2007).

While most mergers have been induced by government policies in the past, nowadays mergers are typically initiated by individual institutions. The reasons for incidental mergers are three-fold: to secure cost efficiency; to optimize scale of operations; and to create brand leverage (PWC, 2010). Some institutions try to achieve economies of scale by combining administrative functions, the adoption of common processes, and the removal of duplication within back-office administrative functions. It is also possible to realize property and infrastructure efficiencies or synergies by eliminating duplication. An Australian review of the efficiency and effectiveness of higher education has presented data that shows that the average per capita costs decrease steeply up to 2,000 full-time students. Once this student number is reached, the decline of the average cost per capita continues at a decelerating rate up to a critical size of 10,000 students (Patterson, 2000).

A second reason to merge is the optimization of the scale of operations. Institutions try to achieve efficiencies of scale in specific elements of the organization's activities in order to increase competitiveness. A distinction is made between horizontal and vertical mergers. In the case of horizontal mergers, the idea is: to improve the quality of research and education; optimize the scale of the institutions; and cover larger areas of knowledge (Mok, 2005, Ripoll-Soler and de-Miguel-Molina, 2013). Vertical mergers aim at 
collaboration between different areas of knowledge by increasing multidisciplinarity (Kyvik, 2002). This will allow institutions to diversify their academic profiles (Kyvik, 2002). The benefits of increased size and scale may include: higher success in attracting students and funding; an improved research profile; and a higher international reputation (PWC, 2010). Finally, institutions may strive for brand leverage by merging. A more established brand can lead to an increased (inter)national market position and more competitiveness in terms of attracting students, faculty, and funds (e.g. Kitagawa, 2010).

\subsubsection{Possible effects of mergers on student success}

Mergers can have different effects on student success. Vertical mergers can result into more diverse institutions with a wider range of study programs. As a result, students have the opportunity to switch between study programs if they do not experience a good match with their initial study program (Capuccinallo \& Bradley, 2014). A horizontal merger may rationalize the course-offering of institutions. This may lead to an improvement of higher quality study programs. In both cases, this organizational change may cause a decrease in dropout and an increase in graduation rates.

Mergers may also increase the international reputation of an institution which, in turn, results in attracting more qualified faculty. Previous research has emphasized the importance of high quality faculty (Tinto, 2002; Bound et al., 2010; Scott et al., 2008). Consequently, mergers may have a positive effect on persistence and graduation of students due to the changes in staff.

Mergers may affect student success through student services. Harman \& Harman (2003) claimed that mergers correlate with improved student support services. These student services have a positive influence on student success. The research of Pike and Pike (2008) showed that participation in a student support services program is a predictor of student persistence. Counseling also proved to have a positive influence on retention (e.g. Boyd et al., 1996). Remediation courses, student coaching, peer mentoring and counseling 


\section{Chapter 6}

centers, all result in less dropout and more graduation (Bettinger \& Baker, 2011; Salinitri, 2005; Turner \& Berry, 2000).

On the other hand, mergers may have a negative effect on student success. Because of mergers in higher education, it is possible that student choice is reduced. Because of the merging of two closely-located campuses, one campus may be closed. Another option is that the identity of study programs weakens (Kyvik, 2002). Both elements may result in more dropouts and less student success.

Institutions that merge become more complex and larger. This growth results in more tasks and units. The increased complexity can occur horizontally (e.g. more departments), vertically through more management levels (e.g. central administration), or even geographically (Skodvin, 1999). Because of the increased complexity, institutions become more bureaucratic and face difficulties with the integration and duality of the administrative services (Fielden and Markham, 1997). It is also possible that faculty can spend less time on students, since they have extra duties due to the increased complexity of the institution. The number of students can also increase faster than the number of facilities (Chickering \& Reisser, 1993). All the above elements can negatively affect student success.

Few studies have focused on the effect of mergers on student outcomes. Two empirical studies are those of Capuccinello and Bradley (2014) and Cappuccinello (2012). The second study has used matching to estimate the effect of mergers in higher education in England on student dropout. Cappuccinello (2012) found that there was a negative significant effect of enrolling in a merged college on the likelihood of dropping out. Cappuccinello claimed that this is in line with the fact that merged institutions can obtain a reduction in costs and a greater diversification of the teaching and student services. Capuccinello and Bradley (2014) extended the data set of Cappuccinello (2012). They used more cohorts of students and made use of propensity score matching and difference-in-differences methods to 
estimate the effect of mergers on attrition. Capuccinello and Bradley claimed that the effect of mergers on dropout differs depending on the cohort. Earlier cohorts benefited from mergers as dropout decreased by $1-2 \%$. Later cohorts, on the other hand, suffered from the mergers as the attrition rate increased by $5 \%$. Furthermore, the latter study showed that the effects remained for 2 years. The researchers concluded that the type of merger (voluntary vs. forced) determines the effect on student success. A correlational study by Payne (2008) found that there is no evidence that merged institutions have a higher success rate.

\subsection{The setting in the Netherlands}

\subsubsection{Higher education in the Netherlands}

Higher education in the Netherlands is organized as a binary system which consists of privately-funded and government-funded institutions. In this chapter, we focus on 39 government funded institutions for higher vocational education (i.e. "hogescholen”). Around two-thirds of the higher education students enroll in vocational education institutions (Huisman, 2008). Students of higher vocational education institutes are being prepared for a profession. From the start of their secondary education, students are tracked for continuing education and prepared for specific disciplines (De Koning et al., 2014). Students who hold a certificate from senior general education (havo), secondary vocational education $(\mathrm{mbo})$ or pre-university education ( $v w o$ ) can enroll in higher vocational education institutes. In this present study, we focus on Bachelor programs which normally take four years.

\subsubsection{Mergers in higher vocational education}

Around 1980, there were about 350 higher vocational institutions in the Netherlands (Harman \& Harman, 2008). These vocational institutions were considered to be too small to efficiently organize education. In 1983, the government published the White Paper 


\section{Chapter 6}

"Scale-enlargement, Task-allocation and Concentration" (STC), which marked the beginning of a massive government-initiated merger process. One of the main priorities of the STC operation was the increase in the organizational scale of higher vocational institutions (Goedgebuurde \& Meek, 1991). The government imposed a minimum enrollment level of 600 students that institutions were required to meet in order to receive government funding ${ }^{44}$. This was a radical requirement, as for $63 \%$ of the existing institutions, merging with another institution was the only viable option (Goedgebuure \& Meek, 1991). After the STC operation, the number of higher vocational institutions was reduced from 350 to 58 (Harman \& Harman, 2008).

Research has shown that between 1985 and 2012 the number of higher vocational institutions in the Netherlands decreased by $83 \%$ due to mergers. Today, higher vocational institutions in the Netherlands are 12 times as large compared with the higher vocational institutions in 1985 (Blank, 2015). Skodvin (1999) indicated that the mergers in the Netherlands that occurred between 1992 and 1999 are mergers between institutions that complement each other. Recent mergers in the Netherlands are voluntary. Mergers forced by the Dutch policymakers are no longer common because there have been some signals that scale enlargement in the educational context has a negative influence on students and parents. As a result, OCW has introduced the merger test in 2011. Every merger in education in the Netherlands has to be requested and approved by a commission. The goal of this merger test is to guarantee sufficient study choice for parents and students (OCW, 2016).

\footnotetext{
${ }^{44}$ Note that the government imposed two other conditions which focused on the enlargement of the autonomy of the institutions and a greater efficiency in the use of resources. As these conditions do not directly have implications for mergers, we ignore them in this study.
} 


\subsection{Data}

The data are obtained from the national questionnaire on student satisfaction (“nationale studentenenquête”, NSE). The administration of this questionnaire is carried out annually by the organization Studiekeuze123. The NSE data include program level information regarding the opinion of students on the academic program they are taking. The data also include program and institutional characteristics. We take the following institutional characteristics into account: the number of students enrolled in the institution, which serves as a proxy for the institutional size; the student-faculty ratio, which indicates how many students there are per faculty member; and the percentage of faculty older than 50. The students' program satisfaction is measured by their answer to the following question "Give your overall judgements about the program". This variable represents qualitative information at program-level about student satisfaction, and is measured on a Likert-scale from 1 (very dissatisfied) to 10 (very satisfied).

While the NSE data are available at program level, we aggregate them at campus level, as this is the relevant unit of observation for our study, for two reasons. First, we are interested in the influence of institutional and campus characteristics on the decision to merge. Second, it is possible that some institutions merge because of potential cooperation between two or more campuses. The number of campuses of an institution is based on the number of cities where the higher education institution has a location.

Next, we combine the NSE data with data obtained from the Ministry of Education (“Dienst Uitvoering Onderwijs”, DUO). They include information at academic degree level (e.g. biology, applied linguistics) on the number of first-year students, the dropout rate, and the student graduation rate for all higher education institutes for the years 2010 and 2011. The academic degree is the set of courses that a student follows in order to obtain a degree (e.g. Bachelor in economics). The data also include the aforementioned indicators on the field of study for all years between 2003 and 2011. The field of study (e.g. technology, law, the natural sciences and economics) denotes to which academic field the program belongs. 


\section{Chapter 6}

The DUO data set lacks academic degree-level data from 2002-2009. We deal with this by combining the field of study data of 2002-2009 with the program level data of 20102011. The underlying assumption is that the trend of the indicators on the program-level is similar to the trend of the indicators on the field of study-level. ${ }^{45}$ This assumption holds as the final data are similar to reports by field organizations. Next, we transform the obtained data from program-level to campus level by using the weighted average of the academic programs on each campus.

The output variables are defined as follows. Student dropout is defined as the percentage of full-time Bachelor students who leave the institution during the first year of enrollment. Student graduation is defined as the share of re-enrolled full-time Bachelor students who obtained a degree at the institution one year after the nominal study time. Consequently, in order to be included in this latter indicator students enrolled at higher vocational institutes need to graduate within 5 years. It is important that both outcomes refer to the same cohort of students.

We enrich the data with five additional variables at campus level. We include a binary outcome variable that identifies whether an institution, and its underlying campuses, is merged (merge $=1$ ) or not (merge $=0$ ). This information is gathered from extensive desk research of the annual reports and websites of higher education institutes. Second, we add the number of academic programs at each campus. This information is obtained from the NSE data. Similarly, we add a variable that indicates the number of study fields on each campus (i.e. we observe 10 fields of study in this data set such as economics, law and health). Fourth, we include a variable that represents the exact geographical location of all higher vocational campuses; i.e. its latitude and longitude. The information was obtained from maps.google.com.

\footnotetext{
${ }^{45}$ When the interpolation resulted in values larger than $100 \%$ or smaller than $0 \%$ for the performance variables, this value is replaced by $100 \%$ or $0 \%$ respectively. In addition, we excluded programs that were terminated in 2010 or 2011, since this termination can influence the student success and student dropout of previous years.
} 


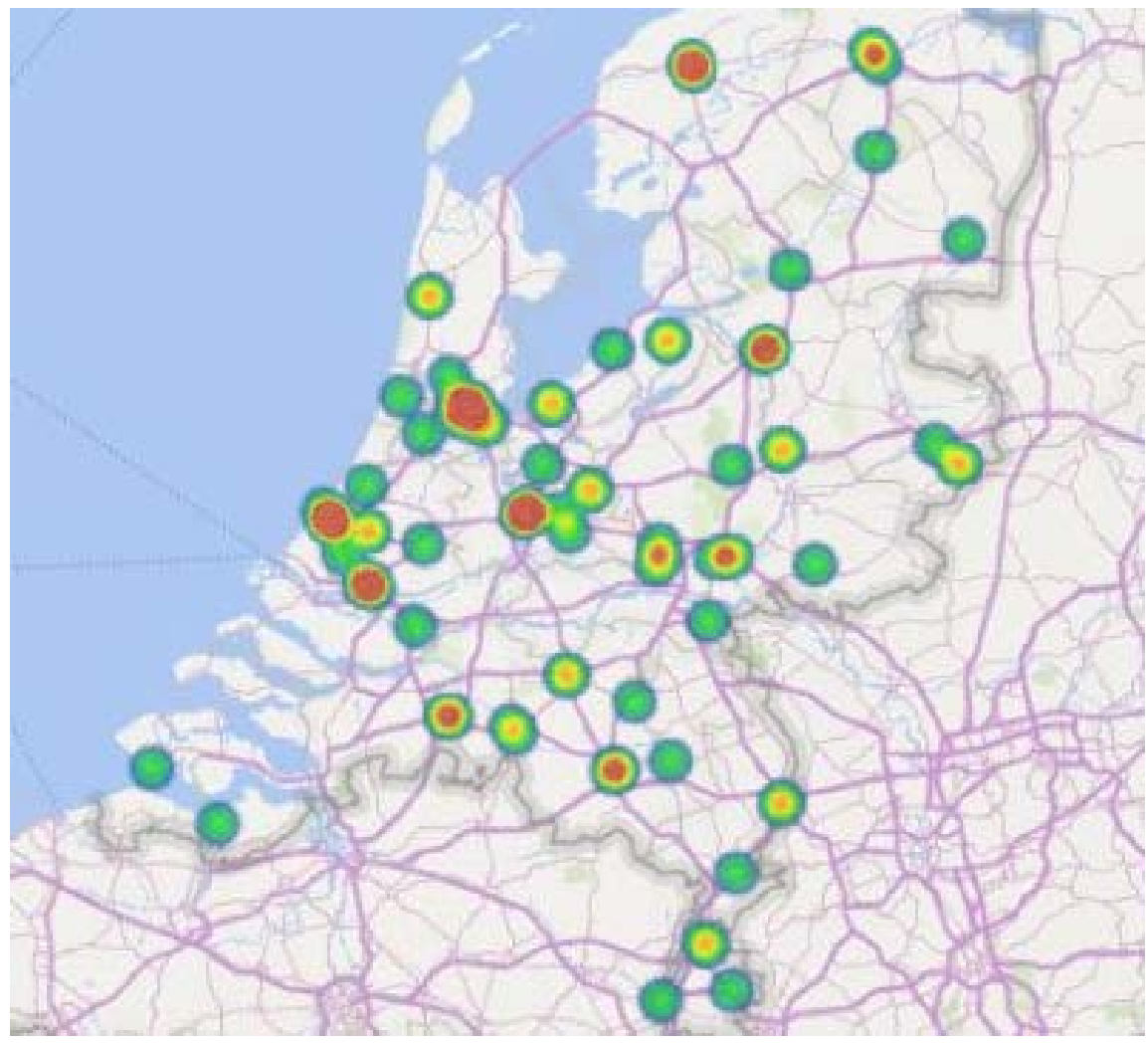

Figure 6.1: Heat map of the location of the different Dutch higher vocational institutions at the start of the academic year 2002-03. Note: The colors of the dots on the heat map range from green to red, whereby a green dot represents an area with a low number of campuses, and a red dot an area with a very high concentration of campuses. The larger the dot, the higher the number of campuses in the area.

Finally, there is the variable differentiation, which shows how comparable different campuses are in terms of field of study (i.e. economics, health, law, etc.). A high value for this variable indicates that two campuses are very different in terms of study program, while a low value indicates that two campuses are very comparable regarding their fields of study. Note that, since this variable is at campus level, it is created for each campus of each institution. In Section 6.5, we explain in detail how we construct this variable. 


\section{Chapter 6}

The final data set includes all campuses of state-funded higher vocational institutions between the academic years 2002-03 and 2008-0946. This corresponds to 605 observations (i.e. an average of 86 campuses per year). In our data set, 27 campuses are involved in the mergers that occurred between 2002-03 and 2008- 09. Figure 6.1 represents a heat map of all the campuses of the different institutions at the start of the academic year 2002-03. The colors of the dots on the heat map range from green to red, whereby a green dot represents an area with a low number of campuses (often only one campus). and a red dot an area with a very high concentration of campuses. The larger the dot, the higher the number of campuses in the area. An area such as Amsterdam with many campuses is thus represented by a large, red dot.

Some descriptive statistics at campus level are presented in Table 6.1. An important observation is that around $25 \%$ of the campuses have been involved in a merger between 2002-03 and 2008-09. We also see that the average dropout rate of a campus is $26.7 \%$. However there are large differences between campuses, as the minimum dropout rate is $8.1 \%$ and the maximum dropout level $54.1 \%$. The average graduation rate is $69 \%$. Again we observe large differences between campuses. The minimum graduation rate is $36.4 \%$ while the maximum is $91.2 \%$. Next, we observe that the average higher vocational institution has 12,321 enrolled students. The vocational institutions have, on average, a student-faculty ratio of 12.5 , indicating that there is one faculty member for every 12 students. About a third of the faculty is older than 50. Further, we observe that the average campus receives a score of 7.1 on a 10 -point scale regarding student satisfaction. This suggests that the average campus consists of students who are fairly satisfied with their study program. Finally, we see that the average campus has three fields of study. This indicates that most campuses are fairly specialized.

${ }^{46}$ Note that in comparison to Chapter 4, we included an extra year in the data set. This was possible because the data is on campus level and not on study program level. 
Table 6.1: Descriptive statistics at campus level

\begin{tabular}{lccccc}
\hline \hline Variable & Observations & Mean & St. Dev. & Minimum & Maximum \\
\hline $\begin{array}{l}\text { Variables of } \\
\text { interest }\end{array}$ & & & & & \\
\hline Merger & 605 & 0.2 & 0.4 & 0.0 & 1.0 \\
$\begin{array}{l}\text { Dropout (\%) } \\
\text { Graduation (\%) }\end{array}$ & 369 & 26.7 & 8.0 & 8.1 & 54.1 \\
$\begin{array}{l}\text { Institutional characteristics } \\
226\end{array}$ & 69.0 & 9.9 & 36.4 & 91.2 \\
\hline $\begin{array}{l}\text { Number of } \\
\text { students }\end{array}$ & 605 & 12,321 & 12,568 & 281 & 38,551 \\
$\begin{array}{l}\text { Student-faculty } \\
\text { ratio }\end{array}$ & 605 & 12.5 & 3.2 & .0 & 19.1 \\
$\begin{array}{l}\text { Faculty }>\text { 50 years } \\
\text { (\%) }\end{array}$ & 605 & 33.7 & 14.7 & .0 & 66.9 \\
\multicolumn{1}{c}{ Campus characteristics } & & & & & \\
\hline $\begin{array}{l}\text { Number of study } \\
\text { fields }\end{array}$ & 605 & 3.0 & 3.1 & 0.0 & 10.0 \\
$\begin{array}{l}\text { Student } \\
\text { satisfaction }\end{array}$ & 342 & 7.1 & & & \\
\hline \hline
\end{tabular}

\subsection{Identification strategies}

\subsubsection{Spatial analysis}

As we believe that distance (as a proxy for spatial competition) between institutions is likely to be an important element in the decision to merge, we work with a spatial lag model. Moreover, we investigate whether the distance between competing campuses of the higher vocational institutions in the Netherlands that merged between 2002 and 2009 directly influenced the decision to merge. A spatial lag model determines whether the potential spatial relationship between the variables is random or responds to a pattern of spatial 


\section{Chapter 6}

dependence. It allows us to investigate the influence of different institutional and campus characteristics $^{47}$. The spatial lag model can be expressed as follows (e.g. Geys, 2006; Kalnins, 2003):

$$
\operatorname{Merger}_{i}=\beta_{0}+\beta_{1} X_{1}+\rho W_{i} \operatorname{Merger}_{i}+\varepsilon_{i},
$$

Where Merger $_{i}$ is a binary variable that is 0 when campus $i$ was never involved in a merger, and 1 when the campus was involved in a merger; $\beta_{0}$ and $\beta_{1}$ are parameters to be estimated; $X_{1}$ represents the control variables; and $\varepsilon_{i}$ is the error term. $W_{i}$ represents the $\mathrm{n} \times \mathrm{n}$ spatial weight matrix. The spatial weight matrix is based on the inverse distance between the different campuses and is row standardized. We also use a distance-based approach which allows us to assume a kilometre threshold, within which all campuses are competitors, and beyond this they are not. This follows directly from work by Mattern and Wyatt (2009), who showed that the average American student attends higher education within $151 \mathrm{~km}$ of his/her parents' house. Consequently, higher education institutions within this distance of each other are competing for the same students. In contrast to the US, Dutch students will not travel this far (Dutch higher education institutions lie much closer to each other, the country is smaller, etc.). Therefore, a maximum distance cut-off of $55 \mathrm{~km}$ was chosen for the results in this chapter. A positive value of $\rho$ shows that distance plays a role in the decision to merge.

\subsubsection{Differentiation}

As a second step, we investigate whether the higher vocational institutions that merged in the Netherlands between 2002 and 2009 tried to achieve differentiation with respect to

${ }^{47}$ It is important to note the existence of a spatial error model (Ward \& Gleditsch, 2007). However, this model is not appropriate for our study, since it treats spatial correlation mainly as nuisance. 
the academic programs offered. This requires us to measure the differentiation for each campus. We therefore construct the following variable:

$$
\begin{gathered}
\operatorname{diff}_{i j}=\mid \text { field }_{1 j}-\text { field }_{1 i}|+| \text { field }_{2 j}-\text { field }_{2 i} \mid+\cdots \\
+\mid \text { field }_{11 j}-\text { field }_{11 i} \mid
\end{gathered}
$$

Where $\operatorname{diff}_{i j}$ measures the differentiation between campus $i$ and campus $j$; field $k i$ represents the percentage of programs from campus $i$ in field $k$ (where field denotes the study field like law, economics, engineering, etc.); and field $_{k j}$ represents the percentage of programs from campus $j$ in field $k$. The lower the variable differentiation, the more comparable two campuses are in terms of fields of study. Or, the higher the variable differentiation, the more two campuses differ in terms of fields of study. Earlier studies that investigated differentiation in higher education made use of cluster analysis (Huisman, 2000) or ordination based on, for example, the size of the institution, the number of disciplines, and the number of campuses (Andrews et al., 1998). We prefer not to use the latter approaches as they are discontinuous and only allow for partial effect measurement. On the contrary, our differentiation measure is continuous in nature and does not require subanalyses.

Since the search for differentiation can vary by the type of institution, we create three 'average' campuses. We start by ranking the campuses based on the following criteria: (i) number of academic program fields; (ii) number of program fields; and (iii) number of students. Higher vocational campuses at the top of the ranking will be small and specialist while campuses at the bottom of the ranking will be big and comprehensive. We will run the analyses (see Section 6.6.3) using the differentiation variable of the campus at the first quartile (i.e. the specialized campus), at the second quartile (i.e. the medium campus - 


\section{Chapter 6}

neither specialized nor comprehensive), and at the third quartile (i.e. the comprehensive campus).

\subsubsection{Difference-in-Differences estimator}

The second part of this chapter consists of investigating the effect on student dropout and graduation of the higher vocational mergers in the Netherlands that occurred between 2002 and 2009. In order to do this, we apply a difference-in-differences (DiD) estimator. The DiD estimator is a popular tool to evaluate the effect of intervention on outcome variables (Abadie, 2005). We opt for this identification strategy as it allows us to take a time trend into account. Indeed, the intervention and control groups are not identified at the same time but in a different chronological academic year. Hence, a possible chronological time trend can thus result in biased results of the effect of mergers on student success. The DiD estimator enables us to account for this time trend by including an extra control group of campuses which never came into contact with mergers. As mergers are not a one-time event but rather implemented gradually over multiple years, we apply the following model:

$$
Y_{i}=\alpha+\beta\left(D_{i}\right)+\gamma \sum_{t} t+\delta \text { Merger }_{i t}+\mu X_{i t}+\varepsilon_{i t}
$$

Where $t_{t}$ is a dummy variable for each year (from 2002-03 until 2008-09, where 200203 is the reference year), and $D_{i}$ a dummy variable that assumes 1 for all programs which eventually were part of a merger, and else 0 otherwise. The model is completed by the Merger $_{i t}$ intervention dummy, a categorical interaction variable that is 1 for campuses that merged, and 0 otherwise. We further add additional time ( $t$ ) and program (i) specific control variables $X$. This increases the efficiency and consistency of the variables of interest. Note that, in the suggested identification strategy, the control group consists of all campuses that 
have never been merged which, the treatment group is created from all campuses that were part of a merger.

\subsection{Results}

\subsubsection{Model specifications}

We estimate various spatial lag models which include an increasing number of campus and institutional characteristics. The first base line model includes only distance as an independent variable. In the second model, we add year fixed-effects to the base-line model. This will capture time-invariant cohort specific variation. Furthermore, we augment the second specifications with the number of students in the institution, the student-faculty ratio, the percentage of faculty older than 50 and the number of study fields at each campus. By adding these covariates we try to correct for observed heterogeneity. Because of limited data, we opted to include the above variables. These variables will allow us to control for differences between campuses, but they may also correlate with unobserved characteristics. Consequently, the results of the covariates do not have policy implications. To investigate the search for differentiation, we include the differentiation variable. This variable can change depending on the type of institution. Small specialized institutions, for example, may seek to achieve differentiation from the study programs. Large, comprehensive institutions, on the other hand, may seek for a comprehensive partner to remove duplicate study programs. As discussed in the previous section, we run the most complete model three times: for the average "specialized", the average "medium” (i.e. neither specialized nor comprehensive), and the average "comprehensive” campus.

In Section 6.6.4, we run the DiD analyses. All models have student dropout or student graduation as the outcome variable. The first specification consists of the dependent variable (i.e. student dropout or student graduation), year fixed-effects, and a group indicator. The next specification is augmented with the number of students in the institution, 


\section{Chapter 6}

the student-faculty ratio, the percentage of faculty older than 50 , the number of study sectors at each campus, and student satisfaction.

\subsubsection{Results of the spatial lag analysis}

Table 6.2 presents the results of the spatial lag model. First, we observe that we cannot reject the null hypothesis of no spatial effects. Indeed, the Lagrange multiplier (LM) tests are statistically significant at conventional levels for the three models (Anselin et al., $1988)^{48}$. Both tests show the presence of a spatial pattern. We observe that, while the distance variable ( $\rho$, see Section 6.5.1) is different from zero in each model, it is not statistically significant in each case.

The first model, without any covariates, shows that distance plays a role in the decision to merge. If campuses of higher education institutions lie close to other campuses of higher education institutions, those institutions have a higher probability of merging. However, when we include the campus and institutional control variables, we observe that the distance variable is no longer significant $(\mathrm{p}=.12)$. Other factors, on the other hand, do significantly influence the decision to merge. The number of students has a positive significant influence on the likelihood of merging. This means that the more students are enrolled in a higher vocational institution, the higher the probability of merging. Larger institutions tend to grow further. There is also a positive significant relationship between the student-faculty ratio and the chances of merging. The higher the student-faculty ratio in a higher vocational institution, the higher is the likelihood of merging. The latter result, in combination with the insignificant negative relationship between the percentage of faculty older than 50 and the probability of merging, is a weak indication that merging institutions are looking for more than just costs-efficiencies. Indeed, institutions with a high student-faculty ratio and

\footnotetext{
${ }^{48}$ It should be noted that there is a test for the spatial lag model and for the spatial error model. In our study, we only focus on the first model. It is, however, important to note that the spatial error tests indicate that the spatial lag model has the best goodnessof-fit.
} 
few faculty older than 50 already have low personnel costs. Next, we observe that the number of study fields has a positive significant impact on the decision to merge. Campuses of vocational institutions with programs in a broad range of fields have a higher chance of merging. In particular, we observe that institutions that are quite big and comprehensive have a higher probability of merging. These higher vocational institutions may aim to strengthen further their international position, or aim to obtain economies of scale or scope. These findings may also be explained by the observation that mergers between partners of a different size have a higher probability of succeeding (Skodvin, 1999).

Table 6.2: Results of the spatial lag model of Equation (6.1)

\begin{tabular}{|c|c|c|c|c|}
\hline \multirow{2}{*}{$\begin{array}{l}\text { Dependent variable = } \\
\text { merger }\end{array}$} & \multicolumn{2}{|c|}{ Model 1} & \multicolumn{2}{|c|}{ Model 2} \\
\hline & Coef. & $\mathrm{SE}$ & Coef. & SE \\
\hline Intercept & $.211^{* * *}$ & .03 & $-.371 * * *$ & .080 \\
\hline Number of students & & & $.001^{* * *}$ & .001 \\
\hline Student-faculty ratio & & & $.031 * * *$ & .006 \\
\hline Faculty > 50 years $(\%)$ & & & -.002 & .002 \\
\hline Number of study fields & & & $.011^{* *}$ & .005 \\
\hline \multicolumn{5}{|l|}{ Differentiation } \\
\hline Year-fixed effects & \multicolumn{2}{|c|}{ NO } & \multicolumn{2}{|c|}{ YES } \\
\hline Distance & $.141^{*}$ & .08 & (123 & .075 \\
\hline $\bar{N}$ & \multicolumn{2}{|c|}{605} & \multicolumn{2}{|c|}{605} \\
\hline $\mathrm{R}^{2}$ & \multicolumn{2}{|c|}{.000} & \multicolumn{2}{|c|}{.200} \\
\hline Lagrange multiplier & \multicolumn{2}{|c|}{$10.112 * * *$} & \multicolumn{2}{|c|}{$6.866 * * *$} \\
\hline Robust Lagrange multiplier & \multicolumn{2}{|c|}{$2.975^{*}$} & \multicolumn{2}{|c|}{$10.407 * * *$} \\
\hline
\end{tabular}


Chapter 6

\subsubsection{Results of the diversification analysis}

The above results are based on the average institution. However, the incentives to merge can change depending on the type of institution. To check this possibility we run the previous model for the three types of institutions: average "specialized", average "medium" (i.e. not specialized nor comprehensive) and average "comprehensive” campus. The results can indicate that higher vocational institutions seek comparability (i.e. horizontal merger) or differentiation (i.e. vertical merger) with the merging partner.

In Model 3 (see Table 6.3) we observe that by merging, specialized campuses strive for differentiation by increasing the number and variety of courses offered. Distance does not play a significant role. These results show that specialized campuses merge with complementary campuses without taking distance into account. These campuses may want to become more visible and different in study programs and study fields. As there is the option that mergers arise between partners who are located close to each other, cost savings may occur by removing duplicate resources (i.e. back offices and infrastructures). If the mergers happen between partners who are not located close to each other, cost savings will be limited (i.e. ICT services). Even so, scale optimization may be the main reason for the mergers of specialized campuses. Note that the percentage of faculty older than 50 has a positive significant influence on the decision to merge. This is in contrast to the results of Model 2. The number of fields of study no longer has an impact. Next, we observe that, in the model of the medium campus, the distance becomes statistical significant. This implies that campuses which are neither comprehensive nor specialized, have a higher likelihood of merging with other campuses close by. Whether the merging partners are comparable or complementary does not play a role (as indicated by the insignificant differentiation variable). Depending on the study fields of the merging partner, the medium campuses may differentiate themselves in study fields and study programs (i.e. partner with different study fields), or may opt to remove duplicate study programs and fields (i.e. partner with similar study fields). Because the campuses lie close to each other, the institutions may opt to 
remove duplicate resources. Hence, both scale optimization and cost efficiencies may occur in these types of mergers. Furthermore, the institution may become more visible, have more success in attracting students and funding and have a higher international reputation. The last model shows us that comprehensive campuses have a higher likelihood of merging with other campuses that are close by, and that they prefer to merge with more dissimilar partners. This suggests that comprehensive campuses may prefer to cover larger areas of knowledge, and hence become more comprehensive. Furthermore, they may opt to eliminate some of the duplicate resources (e.g. faculty and buildings). By merging, these campuses may also aim for scale optimization and cost efficiencies. Brand leverage may also be an option. For comprehensive campuses, the percentage of faculty older than 50 years also has a positive significant impact on the decision to merge. We conclude that

Table 6.3: Results of the robustness test of Equation (6.2)

\begin{tabular}{|c|c|c|c|c|c|c|}
\hline \multirow[t]{2}{*}{$\begin{array}{l}\text { Dependent variable }= \\
\text { merger }\end{array}$} & \multicolumn{2}{|c|}{$\begin{array}{c}\text { Model } 3 \\
\text { Specialized }\end{array}$} & \multicolumn{2}{|c|}{ Model 4 Medium } & \multicolumn{2}{|c|}{$\begin{array}{c}\text { Model } 5 \\
\text { Comprehensive }\end{array}$} \\
\hline & Coef. & $\mathrm{SE}$ & Coef. & $\mathrm{SE}$ & Coef. & $\mathrm{SE}$ \\
\hline Intercept & $.758 * * *$ & .089 & \multicolumn{2}{|l|}{$.503^{* * *}$} & $-.928 * * *$ & .108 \\
\hline Number of students & $.001^{* * *}$ & .001 & $.001^{* * *}$ & .001 & $.001^{* * *}$ & .001 \\
\hline Student-faculty ratio & $.052 * * *$ & .006 & $.041^{* * *}$ & .007 & $.047 * * *$ & .006 \\
\hline Faculty > 50 years $(\%)$ & $.004 *$ & .002 & .003 & .002 & $.003^{*}$ & .002 \\
\hline Number of study fields & -.006 & .006 & $.010^{*}$ & .006 & $.013^{* *}$ & .005 \\
\hline \multirow{2}{*}{$\begin{array}{l}\text { Differentiation } \\
\text { Year-fixed effects }\end{array}$} & $.137 * * *$ & .022 & .007 & .027 & $.266 * * *$ & .046 \\
\hline & \multicolumn{2}{|c|}{ YES } & \multicolumn{2}{|c|}{ YES } & \multicolumn{2}{|c|}{ YES } \\
\hline Distance & .095 & .072 & $.146 * *$ & .074 & . $.125^{*}$ & . .072 \\
\hline $\mathrm{N}$ & \multicolumn{2}{|c|}{2598} & \multicolumn{2}{|c|}{598} & \multicolumn{2}{|c|}{598} \\
\hline $\mathrm{R}^{2}$ & \multicolumn{2}{|c|}{.279} & \multicolumn{2}{|c|}{.214} & \multicolumn{2}{|c|}{.257} \\
\hline Lagrange multiplier & \multicolumn{2}{|c|}{$4.356 * * *$} & \multicolumn{2}{|c|}{$9.728 * * *$} & \multicolumn{2}{|c|}{$7.643^{* * *}$} \\
\hline $\begin{array}{l}\text { Robust Lagrange } \\
\text { multiplier }\end{array}$ & \multicolumn{2}{|c|}{$9.761^{* * *}$} & \multicolumn{2}{|c|}{$11.442^{* * *}$} & \multicolumn{2}{|c|}{$9.899 * * *$} \\
\hline
\end{tabular}

Where $* * *, * *, *$ denote significance at, respectively, $1 \%, 5 \%$ and $10 \%$ level.

Notes: The table presents estimates of the spatial lag model, in which we increasingly control for observed heterogeneity at campus and institution level 


\section{Chapter 6}

different campuses, have different reasons and seek for different partners (i.e., based on distance and type of campus).

\subsubsection{Results of DiD analyses}

As observed in the previous section, the recent mergers in higher education in the Netherlands aim at for more differentiation. Hence, students have the option to switch between study programs. This, and other organizational changes, might result in lower dropout rates and higher graduation rates.

\subsubsection{Short-term effects of mergers}

Table 6.4 shows the results of the DiD analyses. From Model 1, we observe that mergers seem to have a positive influence on first-year dropout. Moreover, because of mergers, less first-year students drop out. Note that the variable is not statistically different from 0 . Further, we detect that those campuses that have merged have a statistically significant higher dropout rate than campuses that did not merge. Once we add covariates, we see similar results. Mergers still lead to less dropout. These results may be caused by higher quality education, better student services, the option to switch study programs etc. Again, campuses that merged have a statistically significant higher average dropout rate compared with campuses that did not merge. Other covariates also predict the dropout rate. Indeed, the student-faculty ratio and the percentage of faculty older than 50 both correlate with significantly more dropout. A higher student-faculty ratio may induce less interaction between students and personnel and lead to dropout. The latter finding is surprising, since older, more experienced faculty, is related to lower student dropout (De Paola, 2009). Next, we observe that student satisfaction correlates with significant lower dropout. This is in line with earlier studies (e.g. Hall, 1999). The number of students in the institution and the number of study fields both have statistically insignificant negative impact on dropout (i.e. less dropout). 


\subsubsection{Long-term effects of mergers}

Mergers lead to less student dropout. However, what dropout there is can be seen as a short-term effect. It is also interesting to observe whether more students graduate 5 years after the merger. Looking at Model 3 in Table 6.4, we observe that the average campus graduation rate declines significantly after the merger. The latter result seems to be surprising. However, the number of study fields may have increased because of the merging activity. As seen in the previous section, mergers in the Netherlands often result in differentiation. Hence, students have the option to switch more. Students who have switched during or after the second year are not included in the graduation rates because they will graduate at a slower pace (i.e. in order to be included in the graduation rate, a student has to graduate one year after the nominal study time). This may cause the decline in graduation rates. We also observe that the average graduation rate of merged campuses is significantly lower than that of non-merged campuses. If we add the covariates, we observe similar effects. Mergers lead to lower graduation rates. The results have, however, become insignificant. Again the non-merged campuses have a significantly higher average graduation rate compared with merged campuses. We observe that a higher student-faculty ratio, higher student numbers, and more fields of study, all lead to less graduation. This latter result is in line with the finding of declining graduation rates. As the number of study fields increases, students switch more, they experience study delay, and are not included in the graduation numbers. Further, we observe that the percentage of faculty older than 50 and student satisfaction both have an insignificant negative relationship with student graduation. We can state therefore, that the promising short term effects of mergers (i.e. the positive effects on student retention) appear not to be maintained in later years. 
Table 6.4: Regression outcomes of Equation (6.3)

\begin{tabular}{|c|c|c|c|c|c|c|c|c|}
\hline & \multicolumn{2}{|c|}{$\begin{array}{l}\text { Student dropout } \\
\text { Model } 1\end{array}$} & \multicolumn{2}{|c|}{$\begin{array}{l}\text { Student dropout } \\
\text { Model } 2\end{array}$} & \multicolumn{2}{|c|}{$\begin{array}{c}\text { Student graduation } \\
\text { Model } 3\end{array}$} & \multicolumn{2}{|c|}{$\begin{array}{c}\text { Student graduation } \\
\text { Model } 4\end{array}$} \\
\hline & Coef. & SE & Coef. & SE & Coef. & SE & Coef. & SE \\
\hline Intercept & $21.519 * * *$ & .811 & $45.694^{* * *}$ & 12.358 & $73.171^{* * *}$ & 1.493 & $81.951^{* * *}$ & 17.469 \\
\hline $\begin{array}{l}\text { Merger ( } 0=\text { before the merger } \\
\text { occurred) }\end{array}$ & -1.992 & 1.131 & $-2.367 *$ & 1.232 & $-5.109 * * *$ & 1.712 & -1.053 & 1.735 \\
\hline $\mathrm{D}(0=$ never a merger $)$ & $6.646^{* * *}$ & 1.137 & $4.344 * * *$ & 1.232 & $-3.111^{* *}$ & 1.243 & $-2.655^{*}$ & 1.469 \\
\hline Number of students & & & -.00004 & .00005 & & & $-.0002 * *$ & .00008 \\
\hline Student-faculty ratio & & & $.690 * * *$ & .152 & & & $-.447 *$ & .251 \\
\hline Faculty > 50 years (\%) & & & $.085^{* *}$ & .042 & & & -.018 & .096 \\
\hline Number of study fields & & & -.211 & .136 & & & $-.529 * *$ & .244 \\
\hline Student satisfaction & & & $-4.178 * *$ & 1.601 & & & -.045 & 2.219 \\
\hline Year-fixed effects & \multicolumn{2}{|c|}{ YES } & \multicolumn{2}{|c|}{ YES } & \multicolumn{2}{|c|}{ YES } & \multicolumn{2}{|c|}{ YES } \\
\hline $\mathrm{N}$ & \multicolumn{2}{|c|}{368} & \multicolumn{2}{|c|}{279} & \multicolumn{2}{|c|}{226} & \multicolumn{2}{|c|}{210} \\
\hline $\mathrm{R}^{2}$ & \multicolumn{2}{|c|}{.159} & \multicolumn{2}{|c|}{.336} & \multicolumn{2}{|c|}{.165} & \multicolumn{2}{|c|}{.316} \\
\hline
\end{tabular}




\subsection{Conclusions, further research and policy implications}

Mergers are common practice in higher vocational education in the Netherlands. Between 1980 and 1992, most mergers were induced by the government (i.e. forced mergers). From 1992, more mergers were voluntary, as higher vocational institutions have tried to achieve cost savings, optimize the scale of operations, and strengthen their position in the international and national market. We have investigated the influence of institutional and campus characteristics on the probability of merging for the vocational institutions in the Netherlands. We also examined whether the higher vocational mergers in the Netherlands seek to achieve differentiation or comparability between the partners. We also focused on the effect of Dutch vocational mergers between 2002 and 2009 in both the short term (i.e. student dropout) and the long term (i.e. student graduation).

Our results show that different types of mergers have occurred depending on the type of partners and the distance. Specialized campuses merged with a diversified partner, but distance did not play a role. Medium-sized campuses, on the other hand, merged with campuses which were located close by. Finally, comprehensive campuses wanted to merge with complementary partners who were located close by.

Regarding the effect of mergers on student outcomes, we observe that mergers have a significant positive influence on student retention. Moreover, students of merged campuses have a lower dropout rate. However, the positive results are not maintained in the long run as the graduation rate is not affected by the mergers.

On the basis of the results of the mergers of vocational institutions in the Netherlands between 2002 and 2009, this chapter can provide some general conclusions. First, we find that there is no "one size fits all” type of merger. Whether merging is attractive for a higher education institution depends on the type of the institution. Second, our results suggest that 
the achievement of cost efficiencies might be a reason for institutional mergers. Cost savings are an option for mergers between nearby campuses by eliminating duplicate infrastructures or services. Specialized campuses, on the other hand, do not take the distance into account when they decide to merge, and thus have fewer options to remove duplicate resources. Third, our results indicate that mergers do not result in lower student outcomes. This suggests that institutions should not be reluctant to merge because they fear negative effects on student outcomes.

Finally, the work in this chapter suggests some avenues for further research. First, the study focuses on higher vocational education in the Netherlands. Therefore, it would be interesting to test the external validity of the results, and replicate the analysis for other countries and education systems. The higher education system in the Netherlands is a dual system with a clear distinction between universities and higher vocational institutes. Replicating the analysis for other systems would be insightful. Second, from a methodological perspective, we focus just on the spatial lag model. An extension to a spatial error model could deliver complementary insights. Third, this study provides quantitative evidence for the correlation between mergers and observed heterogeneity. Further research could open the "black box" and examine by qualitative research how stakeholders in higher vocational education perceive the drivers which encourage mergers. It would also be of interest to investigate why the graduation rates do not increase because of mergers. Indeed, we observe that, while the dropout rates decrease the first-year after the merger, this positive finding is not maintained in later years. We could look into this phenomenon by investigating the effect of mergers on student dropout and graduation a couple of years after the merger. Another option would be to investigate not only the dropout rate of the firstyear students but also of students in the later years of their study. Lastly, we could opt to use qualitative research to investigate what caused the positive effects to diminish. 
The final chapter of this dissertation will focus, in turn, on the concluding statements of each individual chapter, and then provides, on an overall conclusion. Furthermore, this closing chapter clarifies how some of the issues introduced in the general introduction are addressed, and how these findings relate to the theoretical framework. 
Chapter 7

Conclusions and Discussion 


\subsection{Introduction}

The five main chapters of this thesis have explained complementary strategies to improve student success. In particular, this thesis includes: (I) a review study on the effect of needbased grants, academic dismissal (AD) policies, and student-faculty mentoring; (II) an empirical analysis of the efficiency of universities in the Netherlands; (III) an evaluation of the effect of AD policies in higher education in the Netherlands on student success; (IV) an exploration of the effectiveness of need-based grants in four Italian universities with respect to student success; and (V) an analysis of mergers in higher vocational education in the Netherlands during 2002-09 and their effect on student success.

From a methodological perspective, this thesis employed a number of different techniques to evaluate student success. These included a meta-analysis; a difference-indifferences estimator; an efficiency model (conditional efficiency estimator); propensity score matching; and a spatial-lag analysis. The meta-analysis allowed us to investigate the general effect of an AD policy and need-based grants on student outcomes in multiple countries. We also explored whether this general effect is found in specific EU Member Countries (i.e. the Netherlands and Italy). The use of multiple methodologies and techniques to investigate a comparable research question has contributed to the reliability of our results.

The remainder of this chapter is organized as follows. In Section 7.2, the main conclusions of this dissertation are presented. These general conclusions combine the insights from the different chapters of the thesis. Section 7.3 discusses the valorisation of the research findings. Lastly, Section 7.4 covers study limitations and the implications of the findings for further research. 


\subsection{General conclusions}

An academic dismissal policy has a positive effect on student dropout, graduation and program feasibility. Its effect on student satisfaction is negative.

Our results showed that the introduction of an AD policy results in higher dropout levels. Because of an $\mathrm{AD}$ policy, student dropout from university increased by $5.80 \%$. However, graduation rates and program feasibility significantly increased by, respectively, $7 \%$ and .33 of a point (on a 10-point scale). The implementation of an AD policy has a small but significant negative influence on overall student satisfaction (i.e. -.35 of a point on a 10-point scale) and average NSE score (i.e. -.26 of a point on a 10-point scale).

Compared with the effect sizes from the meta-analysis, where a negative significant effect size on retention (i.e. -.17 of a standard deviation) and no effect size on graduation was found, the effect sizes of the difference-in-differences (DiD) analysis are larger (see Table 7.1, respectively, -.47 of a standard deviation and .38 of a standard deviation). The differences in effect sizes can be explained by the higher educational context. The majority of the studies included in the meta-analysis make use of data from the USA and Canada. Both countries have a closed educational system. Students need to compete with each other to enter the best universities and colleges, and there is already some form of selection at the gate (based on, for example, past educational performance, interviews, and extra-curricular activities). In the Netherlands this is not the case. Students with the right entry qualifications can enter the institution and program of their choice. As a result, academic probation can show smaller effects in the USA and Canadian studies compared with studies in the Netherlands.

Table 7.1 shows the combined results of the meta-analysis and the DiD analysis performed in this thesis. In other words, Table 7.1 provides an updated meta-analysis with the new empirical evidence as observed in Chapter 4. Once the latter effect is included in the meta-analysis, the average treatment effect of retention becomes more negative and 
Table 7.1: Input data for and the results of extra meta-analyses

\begin{tabular}{lccc}
\hline & $\begin{array}{c}\text { Effect size (ES) } \\
\text { from Chapter 4 }\end{array}$ & \multicolumn{2}{c}{ ES from meta-analyses (Chapter 2) } \\
Variable & ES & $\begin{array}{c}\text { Previous Average } \\
\text { Treatment Effect }\end{array}$ & $\begin{array}{c}\text { New Average } \\
\text { Treatment Effect }\end{array}$ \\
\hline \hline Student retention & -.47 & -.17 & -.20 \\
$\begin{array}{l}\text { Student graduation within the } \\
\text { nominal time }\end{array}$ & .38 & .00 & .04 \\
\end{tabular}

Note: The first column indicates the calculated ES from the results of Chapter 4. The second column shows the ATE from Chapter 2. The last column indicates the ATE if we include the ES of Chapter 4 in the meta-analysis.

remains significant (i.e. -.20 of a standard deviation, see Table 7.1). Once the effect size of the DiD analysis regarding graduation within the nominal study time is included in the meta-analysis, the average treatment effect becomes somewhat bigger but remains insignificant (see Table 7.1). Hence, we cannot state that an AD policy has an overall positive effect on graduation.

Based on the results from Table 7.1, we can conclude that, on average, the implementation of an $\mathrm{AD}$ policy helps to remove students who do not have a good match with their study program early in their educational career. Surprisingly, the AD policy does not significantly influence the number of graduates. This may show that students who are removed in the first-year because of the AD policy also may have dropped out in later years if no $\mathrm{AD}$ policy was in place. As we have shown, an $\mathrm{AD}$ policy has a negative effect on student satisfaction. While students perceive their study program as more feasible because of the implementation of an AD policy, they also become more dissatisfied. Institutions need to deal with this decrease in student satisfaction, since we showed in Chapter 3 that, for a given dropout level, student satisfaction has a favorable influence on graduation and quality ratings. 
We found in Chapters 2 and 4 that the implementation of an AD policy leads to positive returns for both tertiary education graduates and society ${ }^{49}$. The average EU-28 country has an expenditure per student per year of $€ 9,500$ (Eurostat, 2016c). An AD policy can accelerate the dropout decision of 235,200 students (i.e. $8.4 \%$ of 2.8 million first-year Bachelor students who enter higher education in the EU). This will lead to cost savings of $€ 2,235$ million. In the context of the Netherlands, government expenditures per student are, on average, €6,650/year. Based on the assumption that students who dropped out because of the AD policy would also have dropped out in later years, an AD policy will lead to a minimum cost saving of $€ 50.6$ million (i.e. $5.8 \%$ or 7,600 students).

Simultaneously, the number of graduates will increase (by $7 \%$ or 9,183 students). The return $^{50}$ on having a tertiary degree compared with high school graduates is $€ 113,000$ for each graduate. This amount is the difference between the costs of going to higher education (e.g. foregone earnings) and the benefits of having a tertiary degree (e.g. higher income and less chance of unemployment). In total, this will come down to a return of $€ 1,037$ million (OECD, 2014). However, there are also social benefits through spill-overs such as: increased tax revenues, decreased costs of income support programs and, reduced health care costs. Because of the extra graduates, society will have a return of $€ 937$ million. It should be noted that these numbers represent the maximum returns. To make the estimates more precise, we should also take the costs of implementing an AD policy into account. While there are not many direct costs when implementing an $\mathrm{AD}$ policy, there are some indirect costs because of, for example, increased administrative duties and increased student guidance. We do not, however, have information concerning these expenditures. Additionally, the above return can only be accomplished if the introduction of an admission

\footnotetext{
${ }^{49}$ The calculations of the costs and benefits can be found in the corresponding chapters.

${ }^{50}$ The costs and benefits included in the calculations of the return are presented in Appendix C.
} 
policy is complemented by measures to improve, or at least stabilize, student satisfaction. Higher educational institutions also need to implement instruments that help students switch to other study programs or find a suitable job.

\section{Need-based grants improve access to higher education and student success for low- income students.}

We came to the conclusion that the effect of grants is fairly homogeneous between universities in Italy, and that the impact of the Italian grants is positive and relatively large for all performance indicators. For three of the five Italian universities we found a positive significant effect on the number of credits and student retention. For the other two an insignificant effect was found. Considering in-time graduation and graduation by the end of the fourth year, we observed a positive and significant effect of the scholarship for all Italian universities, except for one university where we found a positive but insignificant effect.

As shown by the meta-analysis, need-based grants have a positive effect on the number of enrolled students, student retention, and student graduation. The effects of the metaanalysis and the matching approach regarding student retention are fairly similar in terms of direction and size (see Table 7.2). Looking at the effects on student graduation, we observe that the effects of the matching technique are fairly high compared with the effects found using the meta-analysis. The directions are, however, maintained. We observe that the effect sizes of the matching approach range between .06 and .21 of a standard deviation for retention. For graduation, we find effect sizes which range between .10 and .17 of a standard deviation. The effect size of the meta-analysis is only .05 of a standard deviation for both retention and graduation. There are two possible reasons for this. First, the educational context may play a role. Graduation rates in Italy are relatively low compared 
with the graduation rates of the other countries included in the meta-analysis. As a result, need-based grants may have a larger effect on graduation in Italy. Second, we observe that the studies which applied a matching technique generally find higher results. The effect sizes may be subject to upward bias (for more explanation, see Section 7.4 Study limitations).

In line with the earlier conclusion, we update the meta-analysis with our own findings. This allows us to combine the results of both chapters, and update the meta-analysis with new evidence. Table 7.2 shows the effect sizes of the matching technique and the results of the meta-analysis once these effect sizes are included. The average treatment effects of dropout and graduation increase owing to the inclusion of the effect sizes (see Table 7.2) and are positive and significant. These results indicate that need-based grants, on average, are a good option to stimulate student success as they, on average, increase retention and graduation. The previous results also showed that need-based grants increase enrollment, and that they target the most disadvantaged students. So need-based grants seem to increase access in higher education for low-income students.

In this dissertation, we also observed that the results are heterogeneous. The effects of Italian grants on sub-populations of students vary more within universities than across them. Although, in most cases, the direction of the baseline results is maintained, we observe different significance levels depending on the investigated subpopulation within each institution. We found a general positive effect for immigrant students, and a stronger effect of aid on students who decide to move from their home town for studying. The effect of aid in Italian universities also varies with the department.

This shows that the use of grants is effective for simulating success in higher education. However, this effectiveness differs between subgroups of low-income students and between universities. In some universities it seems effective to target a subpopulation 
Table 7.2: Input data for and results of extra meta-analyses

\begin{tabular}{|c|c|c|c|}
\hline \multirow[b]{2}{*}{ Variable } & \multirow{2}{*}{$\begin{array}{c}\text { Effect sizes (ES)from } \\
\text { Chapter } 5 \\
\text { ES }\end{array}$} & \multicolumn{2}{|c|}{$\begin{array}{c}\text { ES from meta-analyses (Chapter } \\
\text { 2) }\end{array}$} \\
\hline & & $\begin{array}{c}\text { Previous } \\
\text { Average } \\
\text { Treatment } \\
\text { Effect }\end{array}$ & $\begin{array}{c}\text { New Average } \\
\text { Treatment } \\
\text { Effect }\end{array}$ \\
\hline Student retention & $\begin{array}{l}\text { University A: .21 } \\
\text { University C: .06 } \\
\text { University D: } .06 \\
\text { University E: .13 }\end{array}$ & .05 & .052 \\
\hline $\begin{array}{l}\text { Student graduation within the } \\
\text { nominal time }\end{array}$ & $\begin{array}{l}\text { University A: } .10 \\
\text { University C: } .17 \\
\text { University D: } .17 \\
\text { University E: . } 15\end{array}$ & .05 & .089 \\
\hline
\end{tabular}

Note: The first column indicates the calculated ES from the results of Chapter 5. The second column shows the ATE from Chapter 2. The last column indicates the ATE if we include the ES of Chapter 5 in the meta-analysis.

of low income students (e.g. immigrant students), while in other universities a more general policy without focussing on a particular subgroup seems in order. This can be explained by the fact that some universities are more general while others are more specific, and that they target different student populations. Consequently, a national policy concerning need-based grants that targets specific subpopulations of low income students does not seem to be effective.

We have shown that the implementation of grants in the EU can lead to 70,000 extra students who enter an university and gain a degree. The average EU country has a direct yearly expenditure for grants of $€ 1,000$ per student. If the average student graduates within 5 years, this implies that the implementation of the grants comes down to $€ 350$ million $^{51}$. However, the return on a Bachelor's degree is $€ 154,000$ or $€ 10,800$ million for 70,000 students (OECD, 2014). The return for society is $€ 6,300$ million. Thus, the total returns seem to outweigh the implementation costs. This is in line with the finding of Chapter 5 ,

${ }^{51}$ The calculations can be found in the corresponding chapters. 
which shows that the costs of the implementation of need-based grants in Italian universities are $€ 4.7$ million per year (i.e. a grant of $€ 3500$ for 1,345 students). Because of the grants, 355 extra students will earn a degree after 4 years. Italian Bachelor’s degree holders have a private return of $€ 111,000$ compared with high school graduates. The return for society is $€ 113,000$ per graduate. This comes down to a total return of 80 million. Again, we note that these numbers represent the maximum returns and need to be interpreted with caution. We should also take the indirect costs of implementing need-based grants into account. These can be, for example, increased administrative duties. We do not, however, have information concerning these expenditures.

\section{Differentiation through mergers contributes to retaining students in the first year.}

In Chapter 6 it was shown that higher vocational institutions in the Netherlands are in search of differentiation. Specialized and comprehensive campuses have merged with a partner that is different in terms of academic field. While comprehensive campuses have strived for a complementary partner located close by, specialized campuses did not take the distance to the merging partner into account. This indicates that the comprehensive campuses may want to combine different infrastructures and realize cost savings. The specialized campuses are interested in becoming more visible and in offering students more study choice. Medium-sized campuses did not strive for differentiation.

From our results it became clear that mergers lead to less student dropout. This can be explained by the fact that mergers often seek for differentiation in programs, and thus lead to more choice of study. This will prevent students who do not have a good match with their study program from switching between institutions. Mergers can also lead to better quality teaching and more student services. Surprisingly, no relationship between mergers and student graduation was found so we suppose that mergers have no long term impact on student outcomes. 


\section{Faculty mentoring has a major impact on student success.}

We have shown that organizational change in the form of student-faculty mentoring leads to less dropout and more student graduation. We have found that, if 100 students are being mentored, 7 extra students will be retained and 5 extra students will graduate compared with if they had received the control treatment. This is an important finding since student mentoring is one of the most often used interventions to stimulate student success.

It is, however, also one of the most expensive interventions to support students. The costs of student-faculty mentoring depend on the intensity and the type of mentoring. We are, however, able to calculate the benefits. Student-faculty mentoring may lead to an increase of 210,000 first-year EU Bachelor students. There is a return of $€ 153,975$ for each Bachelor degree holder and a return for society of €89,376 per graduated Bachelor student. So the total return for the EU countries will be $€ 51,100$ million ${ }^{52}$. In deciding to implement faculty mentoring, one also has to take the remuneration of the faculty mentors into account, the necessary facilities, the extra administrative support, etc. The calculations are thus again the maximum returns.

\subsection{Valorization of the research findings}

The findings of this dissertation provide some policy implications. Some of the conclusions can be translated into policy advice for national governments, while others are relevant for the higher education institutions.

In Italy, need-based grants appear to be an effective instrument to: (1) stimulate access in higher education; and (2) achieve the Europe 2020 goal of tertiary education for $40 \%$ of the relevant age group. Our results have shown that need-based grants increase enrollment

\footnotetext{
52 The calculations of the costs and benefits can be found in the corresponding chapters.
} 
for students from low socio-economic backgrounds. This will result in a more equal enrollment in higher education and a more diverse student population. We also found that student retention and graduation are increased by need-based grants. This, in turn, will lead to increased attainment levels. It can, therefore, be suggested to implement need-based grants on a larger scale. While this is costly to implement, it can be expected that the costbenefit analysis is favorable due to the pay-off in the long run ${ }^{53}$.

Italian policymakers need to keep in mind that there is a heterogeneous impact of needbased grants. While the grants are beneficial for a group of students in one Italian university, they may not have benefits for the same group of students in another Italian university. Italian policymakers could opt for a combination of two grant allocation mechanisms: (1) they could implement a general need-based policy that is open for all students who meet certain criteria (for example, family income); and (2) they could target specific subpopulations of students for extra financial aid. These subpopulations can differ per university depending on the group of students most in need of financial support (for example, immigrant students).

In the Netherlands the use of need-based grants has been insufficiently investigated. A study concerning the effects of need-based grants seems necessary because of the new student loan system in the Netherlands. Under the old system, students were entitled to a grant that became a gift if they graduated within 10 years. If a student does not graduate, the grant became a loan. The new system no longer grants money in the form of a gift. Students need to borrow all the necessary money. Since the national policymakers still offer grants to the students with the lowest incomes (i.e. an annual family income below $€ 46000$ ), one could opt to study the effectiveness of this grant. A pilot study could also be necessary to investigate whether need-based grants for students with an annual family

${ }^{53}$ This cost-benefit analysis assumes that more students access higher education, and that more students graduate. 
income which is only just above the threshold is effective. Indeed, there are some concerns with regard to access to higher education for this latter group of students.

In the past, governments have stimulated mergers between different higher education institutions to cope with social challenges. In particular, governments want to increase efficiency in higher education and deal with institutional fragmentation (i.e. the presence of many small specialized institutions). Specialized institutions, in particular, are in search of differentiation in order to extend their fields of study. From our results we can conclude that dealing with institutional fragmentation is neither necessary nor efficient

For EU national governments, it is helpful to know that student mentoring and academic probation are also effective tools to improve student success.

From this dissertation it has become apparent that, independent of the dropout level, higher levels of graduation can be achieved. Given the dropout level, not all institutions in the Netherlands are performing as efficiently as possible. Some institutions could obtain a higher quality-adjusted graduation rate, if they were able to work like the best performing institutions in the Netherlands. As some student characteristics (i.e. being male, a minority student, and satisfied) are related to an inefficient interaction between student dropout and quality-adjusted graduation rates, policymakers could develop interventions to help these subpopulations of students. We recommend a more local policy, whereby every institution or even each department can decide: (I) whether it is necessary to support these groups of students; and (II) how they want to support them. Male and ethnic minority students could, for example, be monitored more closely, and, if necessary, be given the opportunity to participate in special mentoring programs. New didactical techniques, such as flipping the classroom, could positively affect satisfaction. One could also increase the quality of the buildings and the quality of the lecture halls. 
In order to increase the quality adjusted graduation rate, institutions could also opt to implement an academic dismissal mechanism. However, this intervention has to go hand in hand with another intervention to increase the satisfaction of the students. As previously shown, academic dismissal has a negative influence on the satisfaction level, which, in turn, has a unfavorable influence on the quality-adjusted graduation rates.

$\mathrm{AD}$ policies in the Netherlands lead to more graduates in the institutions that implement them. It can therefore be recommended that $\mathrm{AD}$ policies should be implemented on a larger scale and in institutions that suffer from low student success rates. Nevertheless, we showed that this measure comes at the cost of decreased student satisfaction. A second issue with the implementation of AD policy results from the increased student dropout in the first year. Students who do not have a good match with the study program (e.g. due to low engagement) and make unsatisfactory progress need to leave the program and even the institution. The fact that an $\mathrm{AD}$ policy leads to more dropouts shows that the matching procedure before students enter higher education is not flawless.

We have observed that mergers do not result in lower student outcomes in the long run is relevant. When a merger is in order, institutions should be aware that the type of merging partner is of importance. A merger partner which is located close by may lead to cost savings by eliminating duplicate resources. A horizontal merger (i.e. a merger with a comparable partner) may also provide the opportunity to eliminate duplicate resources, while a vertical merger (i.e. a merger with diversified partners) may optimize the scale of operations by extending the area of expertise. 


\subsection{Study limitations}

Although each chapter of this dissertation has already highlighted the limitations of each area of research and the scope for further research, there are still some general limitations that need to be mentioned.

First, it is always difficult to know the external validity of the results as the findings from this dissertation are not universal. The results from Chapters 3, 4, and 6 are based on data from the Netherlands, while the results from Chapter 5 are based on Italian data. Student success in higher education depends on many aspects of the educational context. Examples are: the quality of the primary and secondary school; the teaching methods in higher education; and the age of enrollment in higher education. These elements can differ by country. Despite these differences, the organization of higher education in the European Union has many similar characteristics (e.g. Bama-structure, comparable tuition costs, and the open educational system). Therefore the results of the evaluated interventions can still be of interest for other countries. However, one needs to be careful when interpreting the results.

Second, we used propensity score matching (PSM) to evaluate the effect of grants. Currently, there is a debate about whether propensity score matching produces causal results (e.g. King \& Nielsen, 2015). If we had had information concerning the family income of enrolled students, we could have run a regression discontinuity analysis as a robustness check. Based on the meta-analysis, we observed that studies which use a methodology other than PSM find lower effect sizes than our results. Hence, there is the possibility that our results have overestimated the real effect of need-based grants.

Third, a difference-in-differences estimation yields causal results. However, this empirical strategy is based on the assumption that the control and the intervention group before treatment are subject to the same time trend. While we tried to show that this time trend is equal for both groups, there is no possibility to prove this condition irrefutably. 
Furthermore, the data are analysed at the study program level. It would, however, have been better to have data at the individual level.

Fourth, some of the methodologies used in this dissertation do not allow for a causal interpretation. For example, the efficiency and spatial lag-analysis only provide correlational results. However, these results can still be valuable, as Stanovich (2007) points out. First, while correlation does not imply causality, the reverse is true. So, while a correlational study cannot prove a causal hypothesis, it can rule one out. Next, some variables cannot be manipulated for ethical reasons, and other variables, such as birth and sex, are fixed. Correlational designs could be an option here. On the basis of correlational studies, predictions can be made, and can lead to testing under controlled experimental conditions or to the use of quasi-experimental designs. It should also be noted that the analyses of Chapter 5 were based on only a limited number of cases. Finally, the studies included in this dissertation focus on only a limited number of countries. Hence, we cannot prove the external validity of some of the interventions.

Next, the efficiency analysis provide correlational results. Indeed, we did not account for possible endogeneity. There is, therefore, the possibility that the input (i.e. the dropout rate) is related to the outputs (i.e. the graduation rate and the quality rating). This can be the case in the context of our study, since universities with higher quality and graduation rates may attract better students. Since the education level of the students determines the dropout level, we observe a correlation between the input levels and efficiency. In order to overcome this issue, we should have applied the instrumental variable (IV) approach. The efficiency analysis would then only include the exogenous part of the endogenous input. We have, however, no access to an appropriate instrument.

Finally, while the difference-in-differences analysis in Chapter 6 provided causal results, we have to be aware of the shortcomings of this study. Indeed, we have a limited 
number of observations and only few institutions merged during the analysed period. Therefore, the results of this chapter have to be interpreted with caution.

\subsection{Further research}

This thesis provides various topics for further research. By using a mixed-methods design, future studies could investigate the mechanisms behind the interventions. Once these mechanisms are clear, one could then investigate the effect of these interventions in other countries. At the moment, there are some remaining questions concerning the $\mathrm{AD}$ policy (i.e. the optimal threshold and the implementation of an AD policy after the first year). One could extend this research line by investigating what AD policy threshold would be optimal. The Erasmus University of Rotterdam, for example, even applies an AD policy of 60 ECTS. This means that students need to pass all courses in order to enrol in the second year. Further research could explore whether a credit threshold of 60 ECTS is effective in terms of student success. In the Netherlands, the idea is being mooted that the academic dismissal policy should be extended to the second year of study. With the use of a randomized experiment on the study program level, the effectiveness of this intervention could be studied. As the effect of mergers on student outcomes is a neglected area, future research should focus more on this. At the moment, it is not clear whether the finding that mergers do not lead to worse student outcomes is also true for mergers in other countries. Because of the implementation of the new loan system in the Netherlands, the use of needbase grants in the Netherlands to improve access to higher education is also a topic for further research.

According to the report of Kolster et al. (2015), there are some best practices which could be implemented to improve student success. However, many of these practices have not been evaluated in the Netherlands or only in a limited number of cases. The use of an early alert system seems interesting. The University of New England (UNE) has installed 
an alert system to monitor its students. This system used multiple databases to identify students with a higher likelihood of dropping out. These students will be contacted by student guidance counsellors. The use of such a system should be explored in the higher education context in the Netherlands. 
References

\section{References}

Abadie, A. (2005). Semiparametric difference-in-differences estimators. The Review of Economic Studies, 72(1), 1-19. doi: 10.1111/0034-6527.00321

Abbott, M., \& Doucouliagos, C. (2003). The efficiency of Australian universities: a data envelopment analysis. Economics of Education review, 22(1), 89-97. doi: :10.1016/S0272-7757(01)00068-1

Adelman, C. (1991). Women at Thirty something: Paradoxes of Attainment. Washington, DC: Office of Educational Research and Improvement.

Adelman, C. (2006). The Toolbox Revisited: Paths to Degree Completion From High School Through College. Washington, DC: US Department of Education.

Agasisti, T. (2009). Market forces and competition in university systems: theoretical reflections and empirical evidence from Italy. International Review of applied economics, 23(4), 463-483. doi: 10.1080/02692170902954783

Agasisti, T. (2011). Performances and spending efficiency in higher education: a European comparison through non-parametric approaches. Education Economics, 19(2), 199224. doi: 10.1080/09645290903094174

Agasisti, T., \& Dal Bianco, A. (2006). Data envelopment analysis to the Italian university system: theoretical issues and policy implications. International Journal of Business Performance Management, 8(4), 344-367. doi: 10.1504/IJBPM.2006.009613 
References

Agasisti, T., \& Murtinu, S. (2014). Grants in Italian university: a look at the heterogeneity of their impact on students' performances. Studies in Higher Education, 1-27. doi: $10.1080 / 03075079.2014 .966670$

Alexander, F. K. (2000). The changing face of accountability: Monitoring and assessing institutional performance in higher education. Journal of Higher Education, 71(4), 411-431. Retrieved from http://www.jstor.org/stable/2649146

Alon, S. (2011). Who Benefits Most from Financial Aid? The Heterogeneous Effect of Need-Based Grants on Students' College Persistence. Social Science Quarterly, 92(3), 807-829. doi: 10.1111/j.1540-6237.2011.00793.x

Albouy, D. (2004). Program evaluation and the difference in difference estimator. $\begin{array}{lll}\text { Retrieved } \quad \text { 07/02, } & \text { 2013, }\end{array}$ http://emlab.berkeley.edu/users/webfac/saez/e131_s04/diff.pdf

Anselin, L., Bera, A. K., Florax, R., and Yoon, M. J. (1996). Simple diagnostic tests for spatial dependence. Regional science and urban economics, 26 (1), 77-104. doi: 10.1016/0166-0462(95)02111-6

Appleton-Knapp, S. L., \& Krentler, K. A. (2006). Measuring student expectations and their effects on satisfaction: The importance of managing student expectations. Journal of marketing education, 28(3), 254-264. doi: 10.1177/0273475306293359

Andrews, L., Aungles, P., Baker, S. and Sarris, A. (1998). Characteristics and Performance of Higher Education Institutions. Canberra, Australia: Department of Employment, Education, Training and Youth Affairs.

Andrews, J., Higson, H., Green, P. \& Jones, C. (2012). How do you encourage student engagement in placement in placement learning? Conference proceedings 2012, 050.

Angrist, J., Lang, D., \& Oreopoulos, P. (2009). Incentives and services for college achievement: Evidence from a randomized trial. American Economic Journal: Applied Economics, 1(1), 136-163. doi: 10.1257/app.1.1.136 
Archibald, R. B., \& Feldman, D. H. (2008). Graduation rates and accountability: Regressions versus production frontiers. Research in Higher Education, 49(1), 80100. doi:10.1007/s11162-007-9063-6

Arendt, J. N. (2013). The effect of public financial aid on dropout from and completion of university education: evidence from a student grant reform. Empirical Economics, 44(3), 1545-1562. doi: 10.1007/s00181-012-0638-5

Arnold, I. J. (2015). The effectiveness of academic dismissal policies in Dutch university education: an empirical investigation. Studies in Higher Education, 40(6), 10681084.doi: 10.1080/03075079.2013.858684

Arnold, I., \& Van den Brink, W. (2010). Naar een effectiever bindend studieadvies [ Towards a more effective binding study advice]. Tijdschrift voor Hoger Onderwijs en Management, 5(10), 10-13.

Astin, A. W. (1985). Achieving Educational Excellence. San Francsico: Joseey-Bass.

Astin, A. W. (1993). What matters in college?; Four critical years revisited. San Francisco: Jossey-Bass.

Astin, A. W., Green, K. C., \& Korn, W. S. (1987). The American freshman: Twenty year trends, 1966-1985. Los Angeles: Higher Education Research Institute.

Astin, A. W., \& Solmon, L. C. (1981). Are reputational ratings needed to measure quality? Change: The Magazine of Higher Learning, 13(7), 14-19. Retrieved from https://www.jstor.org/stable/pdf/40163746.pdf

Astin, A. W., \& Scherrei, R. (1980). Maximizing Leadership Effectiveness. San Francisco: Jossey-Bass

Austin, M., \& Hatt, S. (2005). The Messengers are the Message: A study of the effects of employing Higher Education Student Ambassadors to work with school students. Widening Participation and Lifelong Learning, 7(1), 1-8. Retrieved from http://www.ingentaconnect.com/content/openu/jwpll/2005/00000007/00000001/ar $\underline{\mathrm{t} 00007}$ 
References

Autor, H.D., \& Dorn, D. (2013). The growth of low-skill service jobs and the polarization of the US labor market. The American Economic Review, 103(5), 1553-1597. doi: 10.1257/aer.103.5.1553

Autor, H.D. \& Handel, M. J. (2013). Putting tasks to the test: Human capital, job tasks, and wages. Journal of Labor Economics, 31(2 Pt. 2), 59-96. doi: 10.1086/669332

Avdic, D. \& Gartell, M. (2015). Working while studying? Student aid design and socioeconomic achievement disparities in higher education. Labour Economics, 33, 26-40. doi: 10.1016/j.labeco.2015.01.002

Avkiran, N. K. (2001). Investigating technical and scale efficiencies of Australian universities through data envelopment analysis. Socio-Economic Planning Sciences, 35(1), 57-80. doi: 10.1016/S0038-0121(00)00010-0

Avkiran, N. K., \& Rowlands, T. (2008). How to better identify the true managerial performance: state of the art using DEA. Omega,36(2), 317-324. doi: 10.1016/j.omega.2006.01.002

Bailey, T., Calcagno, J. C., Jenkins, D., Leinbach, T., \& Kienzl, G. (2006). Is student-rightto-know all you should know? An analysis of community college graduation rates. Research in Higher Education, 47(5), 491-519.

Barnes, R. A., \& Piland, W. E. (2010). Impact of learning communities in developmental English on community college student retention and persistence. Journal of College Student Retention: Research, Theory \& Practice, 12(1), 7-24. doi: 10.2190/CS.12.1.b

Baum, S., Ma, J., \& Payea, K. (2013). Education pays 2013: The Benefits of Higher Education for Individuals and Society. New York: The College Board.

Bean, J. P., \& Bradley, R. K. (1986). Untangling the satisfaction-performance relationship for college students. The Journal of Higher Education, 393-412. doi: $10.2307 / 1980994$ 
Bean, J. P., and Eaton, S. (2000). A Psychological Model of College Student Retention. In Reworking the Departure Puzzle: New Theory and Research on College Student Retention, edited by J. M. Braxton, 73-89. Nashville, TN: University of Vanderbilt Press.

Bean, J. P. (1983). The application of a model of turnover in work organizations to the student attrition process. The Review of Higher Education, 6(2), 129. Retrieved from http://files.eric.ed.gov/fulltext/ED205151.pdf

Bean, J. P. (1990). Why students leave: Insights from research. In D. Hossler (Ed.), New Direction for Higher Education (Vol. 53, pp. 147-169). San Francisco, CA: JosseyBass.

Beecher, M., \& Fischer, L. (1999). High School Courses and Scores as Predictors of College Success. Journal of College Admission, 163, 4-9. Retrieved from http://eric.ed.gov/?id=EJ592749

Beller, M. (2001). Admission to higher education in Israel and the role of the Psychometric Entrance Test: Educational and political dilemmas. Assessment in Education: Principles, Policy \& Practice, 8(3), 315-337. doi: 10.1080/09695940120089125

Belot, M., Canton, E. \& Webbink, D., (2007). Does reducing student support affect scholastic performance? Evidence from a Dutch reform. Empirical Economics, 32(1), 261-275. doi: 10.1007/s00181-006-0094-1

Bénabou, R., \& Tirole, J. (2003). Intrinsic and extrinsic motivation. The Review of Economic Studies, 70(3), 489-520. doi: 10.1111/1467-937X.00253

Benneworth, P., De Boer, H., Cremonini, L., Jongbloed, b., Leisyte, L., Vossensteyn, H., \& De Weert, E. (2011). Quality-related funding, performance agreements and profiling in higher education. Enschede: Center for Higher Education Policy Studies.

Berger, J. B., \& Braxton, J. M. (1998). Revising Tinto's interactionalist theory of student departure through theory elaboration: Examining the role of organizational 
References

attributes in the persistence process. Research in Higher education, 39(2), 103-119. doi:10.1023/A:1018760513769

Berger, J. B. (2001). Understanding the organizational nature of student persistence: Empirically-based recommendations for practice. Journal of College Student Retention: Research, Theory \& Practice, 3(1), 3-21. doi: 10.2190/3K6A-2RECGJU5-8280

Berger, J. B., \& Milem, J. F (2000). Organizational behavior in higher education and student outcomes. In J. C. Smart (Ed.), Higher education: Handbook of theory and research (Vol. XV, pp. 268-338). New York: Agathon.

Bettinger, E. (2004). How financial aid affects persistence. In College choices: The economics of where to go, when to go, and how to pay for it (pp. 207-238). University of Chicago Press.

Bettinger, E. (2015). Need-based aid and college persistence the effects of the ohio college opportunity grant. Educational Evaluation and Policy Analysis, 37(1 suppl), 102119. doi: $10.3102 / 0162373715576072$

Bettinger, E., \& Baker, R. (2011). The effects of student coaching in college: An evaluation of a randomized experiment in student mentoring. Cambridge, England: National Bureau of Economic Research.

Bettinger, E., \& Baker, R. (2014). The effects of student coaching: An evaluation of randomized experiment in student advising. Education Evaluation and Policy Analysis, 36(1), 3--19. doi: 10.3386/w16881

Bitner, M. J., \& Hubbert, A. R. (1994). Encounter satisfaction versus overall satisfaction versus quality: the customer's voice. In R. T. Rust \& R. L. Oliver (Eds.), Service quality: New directions in theory and practice (pp. 72-94). Thousand Oaks, CA: Sage.

Blau, P. (1973). The Organization of Academic Work. John Wiley \& Sons, New York. 
Blundell, R., \& Dias, M. C. (2009). Alternative approaches to evaluation in empirical microeconomics. Journal of Human Resources, 44(3), 565-640. doi: 10.3368/jhr.44.3.565

Borenstein, M., Hedges, L. V., \& Rothstein, H. (2007). Introduction to meta-analysis. Chichester, England: Wiley.

Bonaccorsi, A., \& Daraio, C. (2008). The differentiation of the strategic profile of higher education institutions. New positioning indicators based on microdata. Scientometrics, 74(1), 15-37. doi: 10.1007/s11192-008-0101-8

Bonaccorsi, A., Daraio, C., \& Simar, L. (2007). Efficiency and productivity in European universities: exploring trade-offs in the strategic profile. In Bonaccorsi, A. and C. Daraio (Eds.) Universities and Strategic Knowledge Creation: Specialization and Performance In Europe. Specialization and Performance in Europe. Edward Elgar PRIME collection.

Boruch, R. F. (1997). Randomized experiments for planning and evaluation: A practical guide. Thousand Oaks, CA: Corwin

Bound, J., Lovenheim, M. F., \& Turner, S. (2010). Why have college completion rates declined? An analysis of changing student preparation and collegiate resources. American economic journal. Applied economics, 2(3), 129. doi: 10.1257/app.2.3.129

Boyd, V., Hattauer, E., Brandel, I. W., \& Buckles, N. (2003). Accreditation standards for university and college counseling centers. Journal of Counseling and Development: JCD, 81(2), 168. doi: 10.1002/j.1556-6678.2003.tb00238.x

Bradley, S., J. Johnes and A. Little (2010). The measurement and determinants of efficiency and productivity in the further education sector in England. Bulletin of Economic Research, 62(1), 1-30. doi: 10.1111/j.1467-8586.2009.00309.x 
References

Bratti M., Checchi D., \& de Blasio G. (2008). Does the Expansion of Higher Education Increase the Equality of Educational Opportunities? Evidence from Italy. Labour 22 (Special Issue), 53-88. doi: 10.1111/j.1467-9914.2008.00411.x

Braxton, J. M. (2003). Student Success. In Student Services: A Handbook for the Profession, 4th ed., edited by S. R. Komives and D. B. Woodard, Jr., 317-338. San Francisco: Jossey-Bass

Braxton, J. M. (2006). Faculty professional choices in teaching that foster student success.Washington: National Postsecondary Education Cooperative.

Brock, T., \& Richburg-Hayes, L. (2006). Paying for Persistence. Early Results of a Louisiana Scholarship Program for Low-Income Parents Attending Community College. $M D R C, 43$.

Broek, A. van den, Kurver, B., \& Hampsink, S. (2012). NSE 2011: Onderzoeksverantwoording. ResearchNed Nijmegen. Retrieved 16-08, from http://www.studiekeuzeinformatie.nl/wpcontent/uploads/2012/05/Onderzoeksverantwoording-NSE-2011.pdf

Bruckmeier, K. \& Wigger, B. U. (2014). The effects of tuition fees on transition from high school to university in Germany. Economics of Education Review, 41,14-23. doi: 10.1016/j.econedurev.2014.03.009

Bruinsma, M. (2004). Motivation, cognitive processing and achievement in higher education. Learning and instruction, 14(6), 549-568. doi: 10.1016/j.learninstruc.2004.09.001

Bryant, J. L. (2006). Assessing expectations and perceptions of the campus experience: The Noel-Levitz Student Satisfaction Inventory. New Directions for Community Colleges, 2006(134), 25-35. doi: 10.1002/cc,234

Calcagno, J. C., Bailey, T., Jenkins, D., Kienzl, G., \& Leinbach, T. (2008). Community college student success: What institutional characteristics make a difference? 
Economics of Education Review, 27(6), 632-645. doi: 10.1016/j.econedurev.2007.07.003

Calcagno, J. C., Crosta, P., Bailey, T., \& Jenkins, D. (2007). Stepping stones to a degree: The impact of enrollment pathways and milestones on community college student outcomes. Research in Higher Education, 48(7), 775-801. doi: 10.1016/j.econedurev.2007.07.003

Caliendo, M. \& Kopeinig, S. (2008). Some practical guidance for the implementation of propensity schore matching. Journal of Economic Surveys, 22(1), 31-72. doi: 10.1111/j.1467-6419.2007.00527.x

Cave, M., Hanney, S., Kogan, M., \& Trevett, G. (1991). The Use of Performance Indicators in Higher Education: a critical analysis of developing practice. Jessica Kingsley, London

Campbell, T. A., \& Campbell, D. E. (1997). Faculty/student mentor program: Effects on academic performance and retention. Research in Higher Education, 38(6), 727742. doi: 10.1023/A:1024911904627

Campbell, T. A., \& Campbell, D. E. (2007). Outcomes of mentoring at-risk college students: gender and ethnic matching effects. Mentoring \& Tutoring, 15(2), 135148. doi: 10.1080/13611260601086287

Capuccinello, R. I., \& Bradley, S. (2014). The effect of college mergers on student dropout behavior (No. 64907218). Lancaster University Management School, Economics Department.

Capuccinello, R. I. (2014). Education mergers and students'dropout decision. University of Pavia, Department of Political and Social Sciences.

Casey, M., Cline, J., Ost, B., \& Qureshi, J. (2015). Academic Probation, Student Performance and Strategic Behavior (working paper). Retrieved at 07-04-2016, from:

https://aefpweb.org/sites/default/files/webform/aefp40/Academic_Probation.pdf 
References

Castleman, B.J., Long, B.T., (2012). Looking beyond enrolment: the causal effect of needbased grants on college access, persistence, and graduation. paper presented at the Annual Conference of the Association for Education Finance and Policy: Boston.

Catalano, G. \& Figà Talamanca, A. (2002). Eurostudent: le condizioni di vita e di studio degli studenti universitari italiani [Eurostudent: Living and Studying Conditions of Italian University Students]. Bologna, Italy: Il Mulino.

Cazals, C., Florens, J.-P., \& Simar, L. (2002). Nonparametric frontier estimation: a robust approach. Journal of Econometrics, 106(1), 1-25. Retrieved from http://dx.doi.org/10.1016/S0304-4076(01)00080-X

Cingano, F. \& Cipollone, A. (2007). University Drop-out - The Case of Italy. Bank of Italy, Working Paper, No. 626

Chapman, B. \& Ryan, C. (2005). The access implications of income-contingent charges for higher education: lessons from Australia. Economics of Education Review, 24(5), 491-512. doi: 10.1016/j.econedurev.2004.08.009

Checchi, D., Fiorio, C.V. \& Leonardi, M. (2013). Intergenerational persistence of educational attainment in Italy. Economics Letters, 118(1), 229-232. doi: 10.1016/j.econlet.2012.10.033

Chi, O. L., \& Dow, A.W. (2014). Improving Balance in Regression Discontinuity Design by Matching: Estimating the Effect of Academic Probation After the First Year of College. Paper presented at SREE 2014 Improving Education Science and Practice:The Role of Replication, Cambridge, Harvard University

Chickering, A. W., \& Reisser, L. (1993). Education and Identity. San Francisco, CA: Jossey-Bass

Clark, B., Heist, D., McConnell, M., Trow, M., \& Yonge, G. (1972). Students and colleges: Interaction and change. Berkeley, Calif.: Center for Research and Development in Higher Education. 
Coelli, T., \& Perelman, S. (2000). Technical efficiency of European railways: a distance function approach. Applied Economics, 32(15), 1967-1976. doi: $10.1080 / 00036840050155896$

Cohen, J. (1988). Statistical power analysis for the behavioral sciences ( $2^{\text {nd }}$ ed.). Hillsdale, NJ: Erlbaum.

Cox, P., Schmitt, E., Bobrowski, P., \& Graham, G. (2005). Enhancing the first-year experience for business students: Student retention and academic success. Journal of Behavioral and Applied Management, 7(1), 40-68.

Dehejia, R. H., \& Wahba, S. (2002). Propensity score-matching methods for nonexperimental causal studies. Review of Economics and statistics, 84(1), 151161. Retrieved from http://www.jstor.org/stable/3211745

Daraio, C., \& Simar, L. (2005). Introducing control variables in nonparametric frontier models: a probabilistic approach. Journal of Productivity Analysis, 24(1), 93-121. $\begin{array}{ll}\text { Retrieved } & \text { from }\end{array}$ http://web.b.ebscohost.com/ehost/pdfviewer/pdfviewer?sid=509059f7-ab36-409a86d9-e8c6cfd7ba6e\%40sessionmgr107\&vid=0\&hid=125

Daraio, C., \& Simar, L. (2007). Advanced robust and nonparametric methods in efficiency analysis: methodology and applications. Series: Studies in Productivity and Efficiency, Springer.

Davies, S. (2002). Marketing in higher education: Matching promises and reality to expectations. Responding to Student Expectations. Paris, France: OECD Publications.

Deil-Amen, R., \& Rosenbaum, J. E. (2003). The social prerequisites of success: Can college structure reduce the need for social know-how?. The Annals of the American Academy of Political and Social Science, 586(1), 120-143. doi: $10.1177 / 0002716202250216$ 
De Corte, E. (2014). Evaluation of Universities in Western Europe: From Quality Assessment to Accreditation. Belgium, Leuven: KU Leuven. Retrieved at 13-04, 2015, from: $\quad$ http://vo.hse.ru/data/2015/01/14/1106361466/2014-

\section{4_DeCorte_En.pdf}

De Koning, B. B., Loyens, S. M. M., Rikers, R. M. J. P., Smeets, G., \& van der Molen, H. T. (2014). Impact of binding study advice on study behavior and pre-university education qualification factors in a problem-based psychology Bachelor program. Studies in Higher Education,39(5), 1-13. doi: 10.1080/03075079.2012.754857

De Paola, M. (2009). Does teacher quality affect student performance? evidence from an Italian university. Bulletin of Economic Research, 61(4), 353-377. doi: 10.1111/j.1467-8586.2008.00299.x

De Paola, M., Scoppa, V. \& Nisticó, R. (2012). Monetary Incentives and Student Achievement in a Depressed Labor Market: Results from a Randomized Experiment. Journal of Human Capital, 6 (1), 56-85. doi: 10.1086/664795

De Witte, K. and Hudrlikova, L. (2013). What about excellence in teaching? A benevolent ranking of universities. Scientometrics 96 (1), 337-364.

De Witte K and Kortelainen M (2013). What explains performance of students in a heterogeneous environment? Conditional efficiency estimation with continuous and discrete control variables. Applied Economics, 45(17): 2401-2412. doi: 10.1080/00036846.2012.665602

De Witte, K., Rogge, N., Cherchye, L. and Van Puyenbroeck, T. (2013a). Accounting for economies of scope in performance evaluations of university professors. Journal of the Operational Research Society 64, 1595-1606. doi: 10.1057/jors.2012.115

De Witte, K., Rogge, N., Cherchye, L. and Van Puyenbroeck, T. (2013b). Economies of scope in research and teaching: a non-parametric investigation. Omega International Journal of Operational Research 41, 305-314. Retrieved from http://dx.doi.org/10.1016/j.omega.2012.04.002 
Dill, D. D. (2001). The regulation of academic quality: critical issues in problem diagnosis and policy design. Paper presented at the Norwegian Institute for Studies in Research and Higher Education Oslo.

Drennan, L. T., \& Beck, M. (2001). Teaching quality performance indicators-key influences on the UK universities' scores. Quality Assurance in Education, 9(2), 92-102. doi:10.1108/09684880110389663

Duijndam, F. J., \& Scheepers, A. W. A. (2009). Bindend studieadvies [Academic dismissal policy]. Hoger Onderwijs Management, 5, 17-19. Retrieved from http://www.schoolmanagementtotaal.nl/archief-ho-

management/doc/tijdschriftartikelen/2009/nr05-september/bindendstudieadies.html

Duncan-Hewitt, W. C. (1996). Designing admissions criteria: A framework. American Journal of Pharmaceutical Education, 60(2), 109-121. doi: aj6002109.pdf

DUO (2015). Hoger Onderwijs. Retrieved at 15-07-2016 from https://www.duo.nl/open onderwijsdata/databestanden/ho/

Duval, S., \& Tweedie, R. (2000). Trim and fill: a simple funnel-plot--based method of testing and adjusting for publication bias in meta-analysis. Biometrics, 56(2), 455463. doi: 10.1111/j.0006-341X.2000.00455.x

Dynarski, S. M. (2003). Does Aid Matter? Measuring the Effect of Student Aid on College Attendance and Completion. American Economic Review 93(1), 279-88. doi: 10.3386/w7422

Dynarski, S. (2008). Building the Stock of College-Educated Labor. Journal of Human Resources, 43(3), 576-610. Retrieved from http://www.jstor.org/stable/40057360

Dynarski, S. \& Scott-Clayton, J., (2013). Financial aid policy: lessons from research, NBER Working Paper n. 18710: Cambridge (MA; USA).

Education Inspectorate (2009). Uitval en rendement in het hoger onderwijs: achtergrondrapport bij werken aan een beter rendement. Retrieved at 24-10, 2013, 
References

from

http://www.onderwijsinspectie.nl/binaries/content/assets/Actueel_publicaties/200

9/Werken+aan+een+beter+rendement+-+achtergrondrapport.pdf

Egger, M., Smith, G. D., Schneider, M., \& Minder, C. (1997). Bias in meta-analysis detected by a simple, graphical test. Bmj, 315(7109), 629-634. doi: 10.1136/bmj.315.7109.629

Elliott, K. M. (2002). Key determinants of student satisfaction. Journal of College Student Retention: Research, Theory and Practice, 4(3), 271-279. doi: 10.2190/B2V7R91M-6WXR-KCCR

Elliott, K. M., \& Shin, D. (2002). Student satisfaction: An alternative approach to assessing this important concept. Journal of Higher Education Policy and Management, 24(2), 197-209. doi: 10.1080/1360080022000013518

EQUNET (2010). Evolving Diversity. An Overview of Equitable Access to HE in Europe, Technical Report, Working for Equitable Access to HE in Europe, Lifelong Learning Program of the European Commission.

European Commission (2015). Targets. Retrieved at 01-05-2015, from: http://ec.europa.eu/europe2020/europe-2020-in-a-nutshell/priorities/index_en.htm European Commission (2016) Europe 2020 Target: Tertiary education attainment. $\begin{array}{lll}\text { Retrieved } \quad \text { at } & \text { 30-08-2016, from: }\end{array}$ http://ec.europa.eu/europe2020/pdf/themes/28_tertiary_education.pdf

Eurostat (2016a). Distribution of pupils/student by level. Retrieved from http://ec.europa.eu/eurostat/en/web/products-datasets/-_EDUC_ILEV

Eurostat (2016b). Expenditures on education in current prices. Retrieved from http://appsso.eurostat.ec.europa.eu/nui/submitViewTableAction.do

Eurostat (2016c). Annual expenditure on public and private education institutions per pupil/student. Retrieved from 
http://ec.europa.eu/eurostat/tgm/refreshTableAction.do?tab=table\&plugin=1\&pco $\underline{\text { de}}=$ tps00067\&language $=$ en

Eurostat (2016d). Tertiary educational attainment by sex, age group 30-34. Retrieved from http://ec.europa.eu/eurostat/tgm/table.do?tab=table\&init=1\&language=en\&pcode =t2020_41\&plugin=1

Fack, G., \& Grenet, J. (2013). Improving college access and success for low-income students: Evidence from a large need-based grant program (working paper). retrieved at 15-03-2016, from: http://pubs.aeaweb.org/doi/pdfplus/10.1257/app.20130423

Felsö, F., van Leeuwen, M., \& Zijl, M. (2000).Verkenning van stimulansen voor het keuzegedrag van leerlingen en studenten. Ministerie van Onderwijs, Cultuur en Wetenschappen. $\quad$ Retrieved from: http://www.seo.nl/uploads/media/545_Verkenning_van_stimulansen_voor_het_ke uzegedrag_van_leerlingen_en_studenten.pdf

Fike, D. S., \& Fike, R. (2008). Predictors of first-year student retention in the community college. Community College Review, 36(2), 68-88. doi: $10.1177 / 0091552108320222$

Fielden, J. and Markham, L. (1997). Learning Lessons from Mergers in Higher Education, CHEMS Paper 17. London: Commonwealth Higher Education Management Service (CHEMS).

Fletcher, J. M., \& Tokmouline, M. (2010). The Effects of Academic Probation on College Success: Lending Students a Hand or Kicking Them While They Are Down? (Working paper). Retrieved at 04-07-2016, from:

http://citeseerx.ist.psu.edu/viewdoc/download?doi=10.1.1.600.115\&rep=rep1\&ty pe=pdf 
References

Forrest, A. (1982). Increasing Student Competence \& Persistence. Iowa City: Iowa: ACT National Center for the Advancement of Educational Practices.

Frenette, M., Upward, R., \& Wright, P. W. (2011). The Long-term Earnings Impact of Postsecondary Education Following Job Loss (No. 334). Statistics Canada. Retrieved from http://twitmails3.s3-website-eu-west1.amazonaws.com/users/14808835/20/attachment/20110406-\%20LongTerm\%20Earnings\%20Impact\%20of\%20PostSecondary\%20Education\%20Follo wing\%20Job\%20Loss.pdf

Frölich, N. (2008). The politics of steering by numbers: Debating Performance-based funding in Europe. NIFU STEP Rapport 3/2008.

Frølich, N., Kalpazidou Schmidt, E., \& Rosa, M. J. (2010). Funding systems for higher education and their impacts on institutional strategies and academia: A comparative perspective. International Journal of Educational Management, 24(1), 7-21.

Garibaldi, P., Giavazzi, F., Ichino, A. \& Rettore, E. (2012). College Cost and Time to Complete a Degree: Evidence from Tuition Discontinuities. Review of Economics and Statistics, 94 (3), 699-711. doi: 10.1162/REST_a_00195

Geys, B. (2006). Looking across borders: A test of spatial policy interdependence using local government efficiency ratings. Journal of urban economics, 60 (3), 443-462. doi: 10.1016/j.jue.2006.04.002

Gijbels, D., Van der Rijt, J., \& Van de Watering, G. (2004). Het bindend studieadvies in het hoger wetenschappelijk onderwijs: worden de juiste studenten geselecteerd? [The binding study advice in higher scientific education: Are the right students selected?]. Tijdschrift voor Hoger Onderwijs, 22(2), 62-72.

Glass, G., McGaw, B., \& Smith, M. L. (1981). Meta-analysis in social re- search. Beverly Hills, CA: Sage

Glocker, D. (2011). The effect of student aid on the duration of study. Economics of Education Review, 30(1), 177-190. doi: 10.1016/j.econedurev.2010.08.005 
Goedegebuure, L. (2012). Mergers and More: the Changing Tertiary Landscape in the 21th Century. working Paper Series, HEIK, Faculty of Educational Sciences, University of Oslo

Goedegebuure, L. C., and Meek, V. L. (1991). Restructuring Higher Education. A Comparative Analysis between Australia and The Netherlands. Comparative Education, 27 (1), 7-22. Retrieved from http://www.jstor.org/stable/3099353

Goldin, C., Katz, L. F., \& Kuziemko, I. (2006). The homecoming of American college women: The reversal of the college gender gap. The Journal of Economic Perspectives, 20(4), $\quad$ 133-133. $\quad$ Retrieved from http://www.jstor.org/stable/30033687

Goldrick-Rab, S. (2010). Challenges and opportunities for improving community college student success. Review of Educational Research, 80(3), 437-469. doi: $10.3102 / 0034654310370163$

Goldrick-Rab, S., Douglas N.H., Kelchen, R., and Benson, J. (2012). Need-Based Financial Aid and College Persistence: Experimental Evidence from Wisconsin. Madison, WI: Institute for Research on Poverty.

Goos, M., Salomons, A., \& Vandeweyer, M. (2013). Job Polarization During the Great Recession and Beyond. Euroforum KU Leuven Policy Paper Series, Leuven.

Goos, M., \& Manning, A. (2007). Lousy and lovely jobs: The rising polarization of work in Britain. The review of economics and statistics, 89(1), 118-133. doi: 10.1162/rest.89.1.118

Graziosi, G. (2014). The Role of Merit-based and Need-based financial aid: Evidence from Trieste Univesity’s Grant Programs. Rivista Italiana degli Economisti [Italian Economic Journal], XIX(1), 103-126. doi: 10.1427/76116

Greenwald, R., Hedges, L. V., \& Laine, R. D. (1996). The effect of school resources on student achievement. Review of educational research,66(3), 361-396. doi: $10.3102 / 00346543066003361$ 
References

Habley, W. R., and R. McClanahan. 2004. What works in student retention: All survey colleges. Iowa City, IA: American College Testing (ACT).

Häkkinen, I \& Uusitalo, R (2003). The effect of a student aid reform on graduation: a duration analysis. Working paper 2003:8. Uppsala University, Uppsala

Hagedorn, L. S. \& Nora, A. (1996). Rethinking admissions criteria in graduate and professional programs. New Directions for Institutional Research, 1996(92), 31-44. doi: 10.1002/ir.37019969205

Hall, M. (1999). Why students take more than four years to graduate. Paper presented at the Association for Institutional Research Forum, Seattle, WA

Harman, G., and Harman, K. (2003). Institutional mergers in higher education: Lessons from international experience. Tertiary Education and Management, 9(1), 29-44. doi: 10.1023/A:1022261409801

Harman, G., and Harman, K. (2008). Strategic mergers of strong institutions to enhance competitive advantage. Higher Education Policy, 21(1), 99.121. doi: 10.1057/palgrave.hep.8300172

Harman, G., Beswick, D. \& Schofield, H. (1985). The Amalgamation of Colleges of Advanced Education at Ballarat and Bendigo. Parkville: Centre for the Study of Higher Education, University of Melbourne.

Hattie, J. (2015). The applicability of Visible Learning to higher education.Scholarship of Teaching and Learning in Psychology, 1(1), 79. doi: 10.1037/stl0000021

Heckman, J. J., \& Vytlacil, E. J. (2007). Econometric evaluation of social programs, part I: Causal models, structural models and econometric policy evaluation. Handbook of econometrics, 6, 4779-4874. doi: 10.1016/S1573-4412(07)06070-9

HEFCE (n.d.). Percentage who either 'mostly agree' or 'definitely agree'. Retrieved from: http://www.hefce.ac.uk/analysis/nsstrend/line/ 
Higgins, J. P. (2008). Commentary: Heterogeneity in meta-analysis should be expected and appropriately quantified. International journal of epidemiology,37(5), 1158-1160. doi: 10.1093/ije/dyn204

Huisman, J. (2000). Higher education institutions: as different as chalk and cheese?. Higher Education Policy,13 (1),41-53. doi: 10.1057/palgrave.hep.8390138

Huisman, J. (2008). Shifting boundaries in higher education: Dutch hogescholen on the move. In Taylor J., J. B. Ferreira, M. De Lourdes Machado \& R. Santiago (eds.) Non-university higher education in Europe. Milton Keynes: Springer, 147-167.

Huisman, J., \& Currie, J. (2004). Accountability in higher education: Bridge over troubled water? Higher Education, 48(4), 529-551. Retrieved from https://www.jstor.org/stable/pdf/4151570.pdf

Hoffer, S. B. (2010). A Formal Mentoring Program and its Relationship to Academic Success and Retention Rates of First-Time Freshman College Students at Walla Walla University (Doctoral dissertation). Retrieved from http://digitalcommons.andrews.edu/cgi/viewcontent.cgi?article=1442\&context=di ssertations

Holland, P.W. (1986). Statistics and causal inference (with discussion). Journal of the American Statistical Association, 81, 945-970. Retrieved from http://www.jstor.org/stable/2289064 doi:1

Hollon, C. J, \& Chesser, R. J (1976). The relationship of personal influence dissonance to job tension, satisfaction and involvement. The Academy of Management Journal, 19(2), 308-314. Retrieved from http://www.jstor.org/stable/255780

Holmes, C. (2013). Has the expansion of higher education led to greater economic growth?. National Institute Economic Review, 224(1), 29-47. doi: $10.1177 / 002795011322400103$ 
References

Hosch, B. J. (2008). Institutional and Student Characteristics that Predict Graduation and Retention Rates. Paper presented at the North East Association for Institutional Research Annual Meeting.

Inspectie van het Onderwijs. (2010). Bindend Studieadvies: een landelijk beeld. Bijlage bij het rapport "Met beide benen op de grond. Onderzoek naar de uitvoeringspraktijk van het bindend studieadvies in het hoger onderwijs”. Utrecht, The Netherlands: Inspectie van het Onderwijs.

Johnes, J. (1996). Performance assessment in higher education in Britain. European Journal of Operational Research, 89(1), 18-33. doi: 10.1016/S0377-2217(96)90048-X

Johnes, J. (2006). Measuring teaching efficiency in higher education: An application of data envelopment analysis to economics graduates from UK Universities 1993. European Journal of Operational Research, 174(1), 443-456. doi: :10.1016/j.ejor.2005.02.044

Johnes, J. (2012). Measuring efficiency and input substitutability: Evidence from the English higher education sector over a period of expansion. Paper presented at the Beijing Forum, Beijing.

Johnes, J., \& Taylor, J. (1990). Performance Indicators in Higher Education: UK Universities. Open University Press and the Society for Research into Higher Education, Milton Keynes.

Johnstone, D. B. (2004). The economics and politics of cost sharing in higher education: comparative perspectives. Economics of education review, 23(2004), 403-410. doi: 10.1016/j.econedurev.2003.09.004

Jongbloed, B. (2001). Performance-Based Funding in Higher Education: an International Survey. Centre for the Economics of Education and Training, Monash University, Australia, Working Paper n.35 
Jongbloed, B. (2003). Marketisation in higher education, Clark's triangle and the essential ingredients of markets. Higher Education Quarterly, 57(2), 110-135. doi: $10.1111 / 1468-2273.00238$

Jongbloed, B. W. A., Koelman, J. B. J., Goudriaan, R., de Groot, H., Haring, H. M. M., \& van Ingen, D. C. (1994). Kosten en doelmatigheid van het hoger onderwijs in Nederland, Duitsland en Groot-Brittannië. Beleidsgerichte studies Hoger Onderwijs en Wetenschappelijk onderzoek 57, Ministerie van Onderwijs, Cultuur en Wetenschappen. SDU, Den Haag.

Jongbloed, B., Salerno, C., Kaiser, F., (2003). Kosten per Student. Methodologie Schattingen en een Internationale Vergelijking. CHEPS, Enschede.

Jongbloed, B., \& Vossensteyn, H. (2001). Keeping up performances: an international survey of performance-based funding in higher education. Journal of Higher Education Policy and Management, 23(2), 127-145. doi: $10.1080 / 13600800120088625$

Kalnins, A. (2003). Hamburger prices and spatial econometrics. Journal of Economics \& Management Strategy, 12 (4), 591-616. doi: 10.1111/j.1430-9134.2003.00591.x

Kamens, D. H. (1971). The college" charter" and college size: Effects on occupational choice and college attrition. Sociology of education, 270-296. doi: $10.2307 / 2111994$

Kane, T. J., \& Rouse, C. E. (1995). Labor-market returns to two-and four-year college. The American Economic Review, 85(3), 600-614. Retrieved from http://www.jstor.org/stable/2111994

Kane, T. J. (2003). A quasi-experimental estimate of the impact of financial aid on collegegoing (No. w9703). National Bureau of Economic Research.

King, G. \& Nielsen, R. (2015). Why Propensity Scores Should Not Be Used for Matching. Retrieved from http://www.polmeth.wustl.edu/files/polmeth/psnot4.pdf 
References

Kumbhakar, S. C., \& Lovell, C. K. (2003). Stochastic frontier analysis. Cambridge University Press

Kokkelenberg, E. C., Sinha, E., Porter, J. D., \& Blose, G. L. (2008). The efficiency of private universities as measured by graduation rates. Cornell Higher Education Research Institute Working paper, 113

Kolster, R., de Boer, H., Jongbloed, B., Cremonini, L., Lemmens-Krug, K., Benneworth, P., ..., Westerheijden, D. (2015) International good practices onderwijskwaliteit en studiesuccess. Den haag, Ministerie van Onderwijs, Cultuur en Wetenschap. Retrieved from https://www.rijksoverheid.nl/binaries/rijksoverheid/documenten/rapporten/2015/0 4/01/internationale-good-practices-onderwijskwaliteit-en-studie/internationalegood-practices-onderwijskwaliteit-en-studie.pdf.

Kot, F. C. (2014). The impact of centralized advising on first-year academic performance and second-year enrollment behavior. Research in higher education, 55(6), 527563. doi: 10.1007/s11162-013-9325-4

Kotler, P., \& Fox, K. F. (1995). Strategic marketing for educational institutions. Englewood Cliffs, NJ: Prentice Hall.

Kuh, G. D., Kinzie, J., Schuh, J. H., and Whitt, E. J. (2005). Student Success in College: Creating Conditions That Matter. San Francisco: Jossey-Bass

Kuh, G. D., Kinzie, J., Buckley, J. A., Bridges, B. K., \& Hayek, J. C. (2006). What matters to student success: A review of the literature commissioned report for the national symposium on postsecondary student success: Spearheading a dialog on student success. Washington DC: National Postsecondary Education Cooperative

Kuh, G. D., Kinzie, J., Buckley, J. A., Bridges, B. K., \& Hayek, J. C. (2007). Piecing Together the Student Success Puzzle: Research, Propositions, and Recommendations (ASHE Higher Education Report 32, No. 5). San Francisco: Wiley Periodicals. 
Kuh, G. D., Cruce, T. M., Shoup, R., Kinzie, J., \& Gonyea, R. M. (2008). Unmasking the effects of student engagement on first-year college grades and persistence. The Journal of Higher Education, 79(5), 540-563. doi: 10.1353/jhe.0.0019

Krohn, G. A., \& O'Connor, C. M. (2005). Student effort and performance over the semester. The Journal of Economic Education, 36(1), 3-28. doi: 10.3200/JECE.36.1.3-28

Kyvik, S. (2002). The merger of non-university colleges in Norway. Higher Education, 44 (1), 53-72. doi: 10.1023/A:1015561027230

Kyvik, S., \& Olsen, T. (2008). Does the aging of tenured academic faculty affect the research performance of universities?. Scientometrics, 76(3), 439-455. doi: 10.1007/s11192-007-1767-z

Larsen, M. R., Sommersel, H. B., \& Larsen, M. S. (2013). Evidence on Dropout Phenomena at Universities. Danish Clearinghouse for educational research.

Lau, L. K. (2003). Institutional factors affecting student retention. Education, 124(1), 126136. Retrieved from http://www.uccs.edu/Documents/retention/2003\%20Institutional\%20Factors\%20 Affecting\%20Student\%20Retention.pdf

Lang, D.W. (2003). A Comparative Study of Mergers as Instruments of Reform in Higher Education. Presented to the Reform of Higher Education in Six Countries International Workshop, Centre for Policy Studies in Higher and Training, University of British Columbia, August 14-15, 2003, Vancouver, British Columbia

Lee, C., \& Buckthorpe, S. (2008). Robust performance indicators for non-completion in higher education. Quality in higher Education, 14(1), 67-77. doi: $10.1080 / 13538320802028163$

Lenning, Q. T. \& Ebbers, L. H. (1999). The powerful potential of learning communities: Improving education for the future. ASHE-ERIC Higher Education Report 26(6). Washington, D.C.: The George Washington University, Graduate School of Education and Human Development 
References

Leverett-Main, S. (2004). Program directors' perceptions of admission screening measures and indicators of student success. Counselor Education and Supervision, 43(3), 207-219. doi: 10.1002/j.1556-6978.2004.tb01843.x

Levitz, R. S., Noel, L., \& Richter, B. J. (1999). Strategic moves for retention success. In G. H. Gaither (Ed.), New directions for higher education: promising practices in recruitment, remediation , and retention (Vol. 1999, pp. 31-49). San Francisco, CA: Jossey-Bass.

Lindo, J. M., Sanders, N. J., \& Oreopoulos, P. (2010). Ability, Gender, and Performance Standards: Evidence from Academic Probation. American economic journal: Applied economics, 2(2), 95-117. doi: 10.1257/app.2.2.95

Lovell, C. K., Travers, P., Richardson, S., \& Wood, L. (1994). Resources and functionings: a new view of inequality in Australia. In W. Eichhorn (Ed.), Models and measurement of welfare and inequality (pp. 787-807). Berlin: Springer-Verlag.

Mao, Y.-q., Du, Y., and Liu, J.-j. (2009). The effects of university mergers in China since 1990s: From the perspective of knowledge production. International journal of educational management, 23 (1), 19-33. doi: 10.1108/09513540910926402

Marcotte, D. E., Bailey, T., Borkoski, C., \& Kienzl, G. S. (2005). The returns of a community college education: Evidence from the National Education Longitudinal Survey. Educational Evaluation and Policy Analysis, 27(2), 157-175. Retrieved from http://www.jstor.org/stable/3699524

Mattern, K., and Wyatt, J. N. (2009). Student Choice of College: How Far Do Students Go for an Education?. Journal of College Admission, 203, 18-29. retrieved from http://files.eric.ed.gov/fulltext/EJ838811.pdf

McCracken, J. D., \& Barcinas, J. D. T. (1991). Differences between rural and urban schools, student characteristics, and student aspirations in Ohio. Journal of Research in Rural Education, 7(2), 29-40. Retrieved from http://jrre.vmhost.psu.edu/wpcontent/uploads/2014/02/7-2_3.pdf 
McMillan, M. L., \& Datta, D. (1998). The relative efficiency of Canadian universities: a DEA perspective. Canadian Public Policy, 24(4), 485-511. Retrieved at: http://www.jstor.org/stable/3552021

McNabb, R., Pal, S., \& Sloane, P. (2002). Gender differences in educational attainment: The case of university students in England and Wales. Economica, 69(275), 481503. Retrieved from http://www.jstor.org/stable/pdf/3549136.pdf

Mealli, F. \& Rampichini, C. (2012). Evaluating the effects of university grants by using regression discontinuity designs. Journal of the Royal Statistical Society A, 175(3), 775-798. doi: 10.1111/j.1467-985X.2011.01022.x

Meek, V.L. (2000). The Uses of Higher Education Policy Research. Inaugural lecture. University of New England, Armidale.

Mellanby, J., Martin, M., \& O'Doherty, J. (2000). The 'gender gap’ in final examination results at Oxford University. British Journal of Psychology, 91(3), 377-390. Retrieved from http://onlinelibrary.wiley.com/doi/10.1348/000712600161880/pdf Mennen, J. (2013). Laid-back of up-tempo? De voorspellende Kwaliteit van het Eerste jaar voor de Studievoortgang in een Conservatorium. Thesis, Open Universiteit. $\begin{array}{llll}\text { Retrieved } \quad \text { at } & \text { 06-04, } & \text { from }\end{array}$ http://dspace.ou.nl/bitstream/1820/4803/1/OWJMennen-02012013.pdf

Miles, R. H. (1976). A Comparison of the Relative Impacts of Role Perceptions of Ambiguity and Conflict by Role. Academy of Management Journal, 19(1), 25-35. Retrieved from https://www.jstor.org/stable/pdf/255445.pdf

Miller, R. (2003). Student satisfaction and institutional success. Paper presented at the 43rd annual AIR forum, Tampa, FL, May, 2003.

Moretti, E. (2004). Estimating the social return to higher education: evidence from longitudinal and repeated cross-sectional data. Journal of econometrics,121(1), 175-212. doi: 10.3386/w9108 
References

Moore, C., Offenstein, J., \& Shulock, N. (2009). Steps to success: Analyzing milestone achievement to improve community college student outcomes. Sacramento: California State University, Institute for Higher Education Leadership \& Policy.

Morris, J. G. (1999). The value and role of the interview in the student admissions process: a review. Medical Teacher,21(5), 473-481.doi: 10.1080/01421599979149

Neumann, R. (2001). Disciplinary differences and university teaching. Studies in Higher Education, 26(2), 135-146. doi: 10.1080/03075070120052071

NSE (2016). Alle landelijke resultaten NSE 2016 op een rij. Retrieved from: https://www.studiekeuze123.nl/alle-landelijke-resultaten-nse-2016-op-een-rij

NSSE (2009). Assessment for improvement: Tracking student engagement over timeAnnual results 2009. Bloomington, IN: Indiana University Center for Postsecondary Research.

NSSE (2013). A Fresh Look at Student Engagement-Annual Results 2013. Bloomington, IN: Indiana University Center for Postsecondary Research.

NVAO (n.d.) NVAO: Nederlands-Vlaamse accreditatieorganisatie. Retrieved 14-02, 2013, from http://www.nvao.net/over_nvao

OCW (2011). Hoofdlijnenakkoord OCW-VSNU. Retrieved at 24-10, 2013, from http://www.vsnu.nl/files/documenten/Domeinen/Accountability/HLA/Hoofdlijnen akkoord_universiteiten_DEF_20111208.pdf

OECD (2012). Education indicators in focus. Retrieved from http://www.oecd.org/education/skills-beyond-school/49471658.pdf

OECD (2013). Education at a Glance 2013. Retrieved from https://www.oecd.org/edu/eag2013\%20(eng)-FINAL\%2020\%20June\%202013.pdf

OECD (2015). Education at a Glance 2015. Retrieved from http://download.eiie.org/Docs/WebDepot/EaG2015_EN.pdf 
Okun, M. A., \& Finch, J. F. (1998). The big five personality dimensions and the process of institutional departure. Contemporary Educational Psychology,23(3), 233-256. doi: 10.1006/ceps.1996.0974

Onderwijs Evaluatie Rapport (2007). Bindend studieadvies. Een onderzoek naar de meningen en ervaringen van eerstejaars Bachelorstudenten aan de Universiteit Utrecht. Retrieved at 25-07, 2014, from: http://stichting-oer.nl/wordpress/wpcontent/uploads/2010/10/0607-bsa.pdf

Onderwijsraad. (2008). Een succesvolle start in het hoger onderwijs. Den Haag: Onderwijsraad.

Özsoy, C. (2008) The Contribution of Higher Education to Economic Development. 8th Global Conference on Business and Economics, October 18- 19, 2008, Florence, Italy

Pascarella, E. T., and Terenzini, P. T. (1991). How College Affects Students: Findings and Insights From Twenty-Years of Research (1st ed.). San Francisco: Jossey-Bass Publishers.

Pascarella, E .T., and Terenzini, P. T. (2005). How College Affects Students: A Third Decade of Research. San Francisco: Jossey-Bass.

Pantages, T. J., \& Creedon, C. F. (1978). Studies of college attrition: 1950-1975. Review of $\begin{array}{lll}\text { educational } & \text { research, } & \text { Retrieved }\end{array}$ from http://www.jstor.org/stable/1169909

L. Payne (2008). The evidence base on college size and mergers in the Further Education sector. Technical Report 19, Department for Innovation, Universities and Skills.

Peduzzi, P., Concato, J., Kemper, E., Holford, T. R., \& Feinstein, A. R. (1996). A simulation study of the number of events per variable in logistic regression analysis. Journal of Clinical Epidemiology, 49, 1373-1379. doi: 10.1016/S08954356(96)00236-3 
References

Peikes, D. N., Moreno, L., \& Orzol, S. M. (2008). Propensity Score Matching. The American Statistician, 62(3), 222-231. doi: 10.1198/000313008X332016

Peltier, G. L., Laden, R., \& Matranga, M. (1999). Student persistence in college: A review of research. Journal of College Student Retention, 1(4), 357-375. doi: 10.2190/L4F7-4EF5-G2F1-Y8R3

Peterson, M., Wagner, J. A., \& Lamb, C. W. (2001). The Role of Advising in NonReturning Students' Perceptions of Their University. Journal of Marketing for Higher Education, 10(3), 45-59. doi: 10.1300/J050v10n03_03

Porter, S. R. (2000). The robustness of the "'graduation rate performance”' indicator used in the

U.S. News and World Report college ranking. International Journal of Educational $\begin{array}{llll}\text { Advancement } & 1(2), & \text { 10-30. } & \text { Retrieved }\end{array}$ http://files.eric.ed.gov/fulltext/ED432176.pdf

Porter, S. R., and Toutkoushian, R. K. (2002). Institutional research productivity and the connection to average student quality and overall reputation. Paper presented at the 2002 annual meetings of the Western Economic Association, Seattle, WA.

PriceWaterhouseCoopers (2010). In the eye of the storm. Moving from collaboration to consolidation. Retrieved at 23-07, 2013, from: https://www.pwc.com/en_GX/gx/psrc/pdf/in_the_eye_of_the_storm.pdf.

Psacharopoulos, G., \& Patrinos, H. A. (2004). Returns to investment in education: a further update. Education economics, 12(2), 111-134. doi: 10.1596/1813-9450-2881

PThU. (2015). Jaarstukken 2015. Retrieved from https://www.pthu.nl/Over PThU/Over ons/Publiciteit/Jaarverslag/.

Rosenbaum, P. R., \& Rubin, D. B. (1983). The central role of the propensity score in observational studies for causal effects. Biometrika, 70(1), 41-55. doi: 10.1093/biomet/70.1.41 
Reason, R. D. (2003). Using an ACT-based merit-index to predict between-year retention. Journal of College Student Retention: Research, Theory and Practice, 5(1), 71-87. doi: 10.2190/FK5Q-WR6Q-9MK0-84JY

Reason, R. D. (2009). Student Variables that Predict Retention: Recent Research and New Developments. Naspa Journal, 40(4), 172-191. doi: 10.2202/1949-6605.5022

Rienzi, B. M., Allen, M. J., Sarmiento, Y. Q., \& McMillin, J. D. (1993). Alumni perception of the impact of gender on their university experience. Journal of College Student Development, $\quad 34(2), \quad$ 154-157. $\quad$ Retrieved from http://psycnet.apa.org/psycinfo/1993-35416-001

Rijksoverheid. (n.d.) Wat is het binded studieadvies (BSA) in het hoger onderwijs (ho)? Retrieved 8-03, 2013, from http://www.rijksoverheid.nl/onderwerpen/hogeronderwijs/vraag-en-antwoord/wat-is-het-bindend-studieadvies-bsa-in-het-hogeronderwijs-ho.html

Ripoll-Soler, C., and de-Miguel-Molina, M. (2013). Are mergers a win-win strategic model? A content analysis of inter-institutional collaboration between higher education institutions. Tertiary Education en Management, ahead of print. doi: 10.1080/13583883.2013.860187

Robison, H., \& Christophersen, K. (2003a). The socioeconomics generated by Hillsborough Community College. Volume 2. Retrieved from https://archive.org/details/ERIC_ED482182

Robison, H., \& Christophersen, K. (2003b). The socioeconomics generated by New Jersey's 19 community colleges. Trenton: New Jersey State Department of Higher Education

Robst, J. (2001). Cost efficiency in public higher education institutions. Journal of Higher Education, 72(6), 730-750. doi: 10.2307/2672901 
References

Rubin, D.B. (1974). Estimating causal effects of treatments in randomized and nonrandomized studies. Journal of Educational Psychology, 66(5), 688-701. doi: $10.1037 / \mathrm{h} 0037350$

Rubin, D. B. (1980). Randomization Analysis of Experimental Data: The Fisher Randomization Test Comment. Journal of the American Statistical Association,75 (371), 591-593. Retrieved from http://www.jstor.org/stable/2287648

Rumberger, R. W. (1995). Dropping out of middle school: A multilevel analysis of students and schools. American educational Research journal,32(3), 583-625. doi: $10.3102 / 00028312032003583$

Rumberger, R., \& Thomas, S. (2000). The Distribution of Dropout and Turnover Rates among Urban and Suburban High Schools. Sociology of Education, 73(1), 39-67. doi: $10.2307 / 2673198$

Sadler, D. R. (2005). Interpretations of criteria-based assessment and grading in higher education. Assessment \& Evaluation in Higher Education, 30(2), 175-194. doi: $10.1080 / 0260293042000264262$

Salerno, C. (2003). What we know about the efficiency of higher education institutions: The best evidence. CHEPS, Universiteit Twente.

Salinitri, G. (2005). The effects of formal mentoring on the retention rates for first-year, low achieving students. Canadian Journal of Education/Revue canadienne de l'education, 853-873. doi: 10.2307/4126458

Salvatori, P. (2001). Reliability and validity of admissions tools used to select students for the health professions. Advances in Health Sciences Education, 6(2), 159-175. doi: 10.1023/A:1011489618208

Sandner, M. (2015). The effects of high-quality student mentoring. Economics Letters, 136, 227-232. doi: 10.1016/j.econlet.2015.09.043 
Schertzer, C. B., \& Schertzer, S. M. (2004). Student satisfaction and retention: A conceptual model. Journal of Marketing for Higher Education, 14(1), 79-91. doi: 10.1300/J050v14n01_05

Schnell, C., Louis, K., \& Doetkott, C. (2003). The first-year seminar as a means of improving college graduation rates. Journal of The First-Year Experience \& Students in Transition, 15(1), 53-76. Retrieved from http://eric.ed.gov/?id=EJ668241

Schudde, L. \& Scott Clayton, J. (2014). Pell grants as performance-based aid? An examination of satisfactory academic progress requirements in the nation's largest need-based aid program (Working Paper). Columbia University Academic Commons. Retrieved at 05-05-2016, from: http://dx.doi.org/10.7916/D89K491C.

Schwarz, S., \& Westerheijden, D. F. (2004). Accreditation and evaluation in the European higher education area. Springer Science \& Business Media.

Scott, M., Bailey, T., \& Kienzl, G. (2006). Relative success? Determinants of college graduation rates in public and private colleges in the US. Research in Higher Education, 47(3), 249-279. doi: 10.1007/s11162-005-9388-y

Scott, G., Shah, M., Grebennikov, L., \& Singh, H. (2008). Improving student retention: A University of Western Sydney case study. Journal of Institutional Research, 14(1), 9-23. Retrieved from http://files.eric.ed.gov/fulltext/EJ1055597.pdf

Scott-Clayton, J. (2012). On money and motivation. A quasi-experimental analysis of financial incentives for college achievement. Journal of Human Resources, 46(3), 614-646. doi: 10.3368/jhr.46.3.614

Scrivener, S., \& Au, J. (2007). Enhancing student services at Lorain county community college: Early results from the opening doors demonstration in Ohio. New York, NY: MDRC

Seidman, A. (1991). The evaluation of pre/post admissions/counseling process at a suburban community college: Impact on student satisfaction with the faculty and 
References

the institution, retention, and academic performance. College and University, 66, 223-232. retrieved from http://eric.ed.gov/?id=EJ430187

Sianesi, B. (2004). An Evaluation of the Active Labour Market Programmes in Sweden. The Review of Economics and Statistics, 86(1), 133-155. doi: $10.1162 / 003465304323023723$

Skodvin, O.-J. (1999). Mergers in higher education .Success or failure? Tertiary Education and Management, 5(1), 65-80. doi: 10.1023/A:1018749021147

Smith, J. P., \& Naylor, R. A. (2001). Dropping out of university: a statistical analysis of the probability of withdrawal for UK university students. Journal of the Royal Statistical Society: Series A (Statistics in Society), 164(2), 389-405. doi: 10.1111/1467-985X.00209

Stanovich, K. (2007). How to Think Straight About Psychology. Boston, MA: Pearson.

Steenkamp, F., Timmers, T., \& van Schilt, J. (2008a). Jaarrapport Nationale Studentenenquête 2007. Leiden, The Netherlands: Centrum Hoger Onderwijs Informatie voor Consument en Expert.

Steenkamp, F., Timmers, T., van Schilt, J., Heim, M., \& de Goede, M. (2008b). Tien jaar patronen en trends in" student satisfaction" in Nederland: een analyse van oordelen uit de Keuzegidsenquête en de Nationale Studenten Enquête, 1996-2005. Leiden, the Netherlands: Centrum Hoger Onderwijs Informatie voor Consument en Expert.

Stegers-Jager, K. M., Cohen-Schotanus, J., Splinter, T. A. W., \& Themmen, A. P. N. (2011). Academic dismissal policy for medical students: effect on study progress and help-seeking behaviour. Medical education, 45(10), 987-994. doi: 10.1111/j.1365-2923.2011.04004.x.

Stensaker, B., \& Harvey, L. (2006). Old wine in new bottles? A comparison of public and private accreditation schemes in higher education. Higher Education Policy, 19(1), 65-85. doi: 10.1057/palgrave.hep.8300110 
Stevens, P. A. (2001). The determinants of economic efficiency in English and Welsh universities. National Institute of Economic and Social Research, London.

Studyportals. (2016). International Student Satisfaction in Europe 2016. Retrieved from: http://www.studyportals.com/intelligence/international-student$\underline{\text { satisfaction/international-student-satisfaction-awards-2016/ }}$

Strauss, L. C., \& Volkwein, J. F. (2002). Comparing student performance and growth in 2and 4-year institutions. Research in Higher Education,43(2), 133-161. doi: 10.1023/A:1014495823183

Stratil, M., Schreiner, L.A., \& Noel, P. (Eds). (2001). Retention management system: Advisor's guide - Form B. National Center for Student Retention. Iowa City, IA: USA Group Noel-Levitz.

Studiekeuze123. (2012). Routeboek voor de Nationale Studentenenquête 2012. Retrieved 04/10, 2012, $\quad$ from $\quad$ http://www.studiekeuzeinformatie.nl/wpcontent/uploads/2012/04/NSE_ROUTEBOEK_2012_COMPLEET_DEF.pdf

Swanson, J.E. (2006). Success in the First Year: Impact of Alternative advising on students of a liberal arts college (Unpublished Dissertation). Westerm Michigan University, Michigan.

Sweitzer, K., \& Volkwein, J. F. (2009). The Correlates of Prestige across Graduate and Professional Schools. Research in Higher Education, 50, 129-148. doi: 10.1007/s11162-009-9140-0

Tan, K. C., \& Kek, S. W. (2004). Service quality in higher education using an enhanced SERVQUAL approach. Quality in Higher Education, 10(1), 17-24. doi: $10.1080 / 1353832242000195032$

Timms, M. (2015). Big data in education: a guide for educators, Centre for Strategic Education, Occasional Paper \#139.

Tinto, V. (1975). Dropout from higher education: A theoretical synthesis of recent research. Review of Educational Research, 45, 89-125. doi: 10.3102/00346543045001089 
References

Tinto, V. (1987). Leaving College: Rethinking the Causes and Cures of Student Attrition. Chicago: University of Chicago Press.

Tinto, V. (1993). Leaving College: Rethinking the Causes and Cures of Student Attrition. (2nd ed.). Chicago: University of Chicago Press.

Tinto, V. (2002). Promoting student retention: Lessons learned from the United States. Paper presented at the 11th Annual Conference of the European Access Network, Prato, Italy.

Tinto, V. (2006). Research and practice of student retention: what next?. Journal of College Student Retention: Research, Theory \& Practice, 8(1), 1-19. doi: 10.2190/4YNU4TMB-22DJ-AN4W

Titus, M. A. (2004). An examination of the influence of institutional context on student persistence at 4-year colleges and universities: A multilevel approach. Research in Higher Education, 45(7), 673-699. doi: 10.1023/B:RIHE.0000044227.17161.fa

Tricker, T. (2005). Student expectations—how do we measure up. In F. MCMahon \& T. Cleas (Eds.), Probing the boundaries of higher education (pp. 111-114). Oxford, UK: Inter-Disciplinary Press.

Triventi, M. \& Trivellato, P. (2009). Participation, performance and inequality in Italian higher education in the 20th century. Higher Education, 57(6), 681-702. doi: $10.1007 / \mathrm{s} 10734-008-9170-0$

Turner, A. L., \& Berry, T. R. (2000). Counseling center contributions to student retention and graduation: A longitudinal assessment. Journal of College Student Development. retrieved from http://psycnet.apa.org/psycinfo/2000-12548-004

Umbach, P. D., \& Porter, S. R. (2002). How do academic departments impact student satisfaction? Understanding the contextual effects of departments. Research in Higher Education, 43(2), 209-234. doi: 10.1023/A:1014471708162 
Van Damme, D. (2000). Internationalization and quality assurance: towards worldwide accreditation? European Journal for Education Law and Policy, 4(1), 1-20. doi: 10.1.1.199.5877

Van den Broek, A., Kurver, B., \& Hampsink, S. (2012). NSE 2011: Onderzoeksverantwoording. ResearchNed Nijmegen. Retrieved 16-08, from http://www.studiekeuzeinformatie.nl/wpcontent/uploads/2012/05/Onderzoeksverantwoording-NSE-2011.pdf

Van der Klaauw, W. (2002). Estimating the effect of financial aid offers on college enrollment: A Regression--Discontinuity Approach. International Economic Review, 43(4), 1249-1287. doi: 10.1111/1468-2354.t01-1-00055

Van Heerden, A. (2013). Dropout and study progress in Higher Education. Hogeschool van Amsterdam - TIER, mimeo.

Van Klaveren, C. P. B. J., de Wolf, I. F., \& de Witte, K. (2015). Systematic Reviews in Education Research; when do effect studies provide evidence?.Contemporary economic perspectives in Education, 11-34. Retrieved from https://www.researchgate.net/profile/Chris_Klaveren/publication/280717607_Con temporary_Economic_Perspectives_in_Education/links/55d2dd7f08aec1b0429efb $\underline{\text { 9a.pdf }}$

Van Vught, F. A., \& Westerheijden, D. F. (1994). Towards a general model of quality assessment in higher education. Higher Education, 28(3), 355-371. Retrieved from: http://www.jstor.org/stable/pdf/3447776.pdf

Visher, M., Butcher, K. F., \& Cerna, O. S. (2011). Guiding Math Students to Campus Services: An Impact Evaluation of the Beacon Program at South Texas College. Society for Research on Educational Effectiveness.

VSNU (2012). Prestaties in perspectief: Trendrapportage universiteiten 2000-2020. Retrieved at 13-11, 2013, from: http://www.vsnu.nl/files/documenten/Publicaties/Trendrapportage_DEF.pdf. 
References

Vught, F. van (2012). International rankings, institutional maps and the need to discuss the structure of Dutch higher education. Opening lecture Dies Natalis Maastricht University. September 3, 2012.

Wan, Y., and Peterson, M. W. (2007). A case study of a merger in Chinese higher education: The motives, processes, and outcomes. International Journal of Educational Development, 27 (6), 683-696. doi: 10.1016/j.ijedudev.2006.07.007

Ward, D.M, and Gleditisch, K.S. (2007). An introduction to Spatial Regression Models in the Social Sciences. Retrieved at 30-01, 2015, from: https://web.duke.edu/methods/pdfs/SRMbook.pdf

Watts, J., \& Robertson, N. (2011). Burnout in university teaching faculty: a systematic literature review. Educational Research, 53(1), 33-50. doi: $10.1080 / 00131881.2011 .552235$

Wiers-Jenssen, J., Stensaker, B., \& GrØgaard, J. B. (2002). Student satisfaction: towards an empirical deconstruction of the concept. Quality in Higher Education, 8(2), 183195. doi: $10.1080 / 1353832022000004377$

Williamson, J. S. (2002). Assessing student strengths: Academic performance and persistence of first-time college students at a private church-affiliated $\begin{array}{lll}\text { college (Doctoral } & \text { dissertation). } & \text { Retrieved }\end{array}$ http://digitalcommons.olivet.edu/cgi/viewcontent.cgi?article=1000\&context=facp SgCS

Winship, C., \& Morgan, S. (1999). The Estimation of Causal Effects from Observational. Data.Annual Review of Sociology, 25, 659-706. Retrieved from http://www.jstor.org/stable/223520

Woelders, L., Visser, W., \& Rijksbaron, S. (2013). Bindend studieadvies in relatie tot studieresultaat. [Binding study advice in relation to study results]. OnderwijsInnovatie, 26-27.Retrieved from 
References

https://www.ou.nl/documents/10815/36320/OI_2013_2_Onderzoek_studieadvies. pdf

Yorke, M., \& Longden, B. (2004). Retention \& Student Success in Higher Education. Maidenhead: Open University Press. 


\section{Appendix A}

\begin{tabular}{|c|c|c|c|c|c|c|c|c|c|}
\hline \hline Author & Year & Country & $\begin{array}{c}\text { Level of } \\
\text { education }\end{array}$ & Method & Outcome & $\begin{array}{c}\text { ES method } \\
\text { used }\end{array}$ & $\begin{array}{c}\text { Treatment } \\
\text { analysis N }\end{array}$ & $\begin{array}{c}\text { Control } \\
\text { analysis N }\end{array}$ & Notes \\
\hline $\begin{array}{c}\text { Agasisti \& } \\
\text { Martinu }\end{array}$ & 2013 & Italy & University & Matching & Retention & $\begin{array}{c}\text { Mean } \\
\text { difference/ } \\
\text { Pooled standard } \\
\text { deviation }\end{array}$ & 354 & 869 & $\begin{array}{c}\text { The effect size is recalculated in order to } \\
\text { show the effect of a grant of } € 1000\end{array}$ \\
\hline & & & & $\begin{array}{c}\text { Graduation } \\
\text { within the } \\
\text { nominal } \\
\text { study time } \\
\text { difference/ } \\
\text { Pooled standard } \\
\text { deviation }\end{array}$ & 166 & 670 & See above. \\
\hline & & & $\begin{array}{c}\text { Graduation } \\
\text { within 6 } \\
\text { years }\end{array}$ & $\begin{array}{c}\text { Mean } \\
\text { difference/ }\end{array}$ & 166 & 670 & See above. \\
\hline
\end{tabular}




\begin{tabular}{|c|c|c|c|c|c|c|c|c|c|}
\hline & & & & & & $\begin{array}{l}\text { Pooled standard } \\
\text { deviation }\end{array}$ & & & \\
\hline \multirow[t]{2}{*}{ Alon } & 2011 & VS & Retention & IV & Retention & $\begin{array}{l}\text { Unstandardized } \\
\text { regression } \\
\text { Coefficient }\end{array}$ & 4,037 & 3,711 & $\begin{array}{l}\text { The unstandardized regression coefficient is } \\
\text { recalculated in order to show the effect of a } \\
\text { grant of } € 1000\end{array}$ \\
\hline & & & & & Completion & $\begin{array}{l}\text { Unstandardized } \\
\text { regression } \\
\text { Coefficient }\end{array}$ & 3,711 & 4,029 & See above. \\
\hline Arendt & 2013 & DK & University & $\begin{array}{c}\text { Natural } \\
\text { experiment }\end{array}$ & Graduation & $\begin{array}{c}\text { Logit } \\
\text { coefficient }\end{array}$ & 618 & 557 & $\begin{array}{l}\text { Assume } .526 / .474 \text { split. Based on summary } \\
\text { statistics. We also assumed an average } \\
\text { increase of } € 2170 \text { to transform the logit } \\
\text { coefficient so it represented the effect of an } \\
€ 1000 \text { increase in grant. }\end{array}$ \\
\hline \multirow[t]{2}{*}{ Arnold } & 2015 & NL & University & $\begin{array}{l}\text { Cohort } \\
\text { analysis }\end{array}$ & Retention & $\begin{array}{l}\text { Unstandardized } \\
\text { regression } \\
\text { Coefficient }\end{array}$ & 528 & 1,923 & \\
\hline & & & & & $\begin{array}{c}\text { Graduation } \\
\text { within the } \\
\text { nominal } \\
\text { study time }\end{array}$ & $\begin{array}{l}\text { Unstandardized } \\
\text { regression } \\
\text { coefficient }\end{array}$ & 525 & 1,911 & \\
\hline $\begin{array}{l}\text { Baumgartner \& } \\
\text { Steiner }\end{array}$ & 2006 & $\mathrm{DE}$ & $\begin{array}{l}\text { College and } \\
\text { universities }\end{array}$ & DiD & Enrollment & $\begin{array}{l}\text { Unstandardized } \\
\text { regression } \\
\text { coefficient }\end{array}$ & 347 & 451 & \\
\hline Bettinger & 2015 & VS & University & DiD & Retention & $\begin{array}{l}\text { Unstandardized } \\
\text { regression } \\
\text { coefficient }\end{array}$ & 41,062 & 42,197 & $\begin{array}{l}\text { Averaged the coefficient of the subsample } \\
\text { of winners and losers. The unstandardized }\end{array}$ \\
\hline
\end{tabular}




\begin{tabular}{|c|c|c|c|c|c|c|c|c|c|}
\hline & & & & & & & & & $\begin{array}{l}\text { regression coefficient is recalculated in } \\
\text { order to show the effect of a grant of } € 1000\end{array}$ \\
\hline \multirow[t]{2}{*}{$\begin{array}{l}\text { Bettinger \& } \\
\text { Baker }\end{array}$} & 2014 & VS & University & RCT & Retention & $\begin{array}{c}\text { Unstandardized } \\
\text { regression } \\
\text { coefficient }\end{array}$ & 8,049 & 5,506 & $\begin{array}{c}\text { Assume } .59 / .41 \text { split. Based on summary } \\
\text { statistics. }\end{array}$ \\
\hline & & & & & Graduation & $\begin{array}{l}\text { Unstandardized } \\
\text { regression } \\
\text { coefficient }\end{array}$ & 799 & 546 & See above. \\
\hline $\begin{array}{c}\text { Brock \& } \\
\text { Richburg- } \\
\text { Hayes }\end{array}$ & 2006 & VS & College & RCT & Enrollment & $\begin{array}{c}\text { Frequencies } \\
\text { [PROBIT] }\end{array}$ & $197 / 67$ & $191 / 82$ & \\
\hline \multirow[t]{2}{*}{$\begin{array}{l}\text { Campbell \& } \\
\text { Campbell }\end{array}$} & 2007 & VS & University & Matching & Retention & $\begin{array}{l}\text { Frequencies } \\
\text { [PROBIT }\end{array}$ & $290 / 49$ & $250 / 89$ & \\
\hline & & & & & Graduation & $\begin{array}{c}\text { Frequencies } \\
\text { [PROBIT] }\end{array}$ & $198 / 141$ & $177 / 162$ & \\
\hline \multirow[t]{2}{*}{ Casey et al. } & 2015 & VS & University & RDD & Retention & $\begin{array}{l}\text { Unstandardized } \\
\text { regression } \\
\text { coefficient }\end{array}$ & 1,928 & 12,906 & $\begin{array}{c}\text { Assume } .13 / .87 \text { split. Based on summary } \\
\text { statistics. }\end{array}$ \\
\hline & & & & & $\begin{array}{l}\text { Graduation } \\
\text { within the } \\
\text { nominal } \\
\text { study time }\end{array}$ & $\begin{array}{l}\text { Unstandardized } \\
\text { regression } \\
\text { coefficient }\end{array}$ & 1,125 & 7,526 & See above. \\
\hline
\end{tabular}




\begin{tabular}{|c|c|c|c|c|c|c|c|c|c|}
\hline & & & & & $\begin{array}{l}\text { Graduation } \\
\text { within } 6 \\
\text { years }\end{array}$ & $\begin{array}{l}\text { Unstandardized } \\
\text { regression } \\
\text { coefficient }\end{array}$ & 744 & 4,979 & See above. \\
\hline \multirow[t]{4}{*}{$\begin{array}{l}\text { Castleman \& } \\
\quad \text { Long }\end{array}$} & 2013 & VS & $\begin{array}{l}\text { University } \\
\text { and college }\end{array}$ & RDD & Enrollment & $\begin{array}{l}\text { Unstandardized } \\
\text { regression } \\
\text { coefficient }\end{array}$ & 3,628 & 3,289 & $\begin{array}{l}\text { Assume } .53 / .61 \text { split. Based on summary } \\
\text { statistics. The unstandardized regression } \\
\text { coefficient is recalculated in order to show } \\
\text { the effect of a grant of } € 1000\end{array}$ \\
\hline & & & & & Retention & $\begin{array}{l}\text { Unstandardized } \\
\text { regression } \\
\text { coefficient }\end{array}$ & 3,591 & 3,962 & See above. \\
\hline & & & & & $\begin{array}{l}\text { Graduation } \\
\text { within the } \\
\text { nominal } \\
\text { study time }\end{array}$ & $\begin{array}{l}\text { Unstandardized } \\
\text { regression } \\
\text { coefficient }\end{array}$ & 4,280 & 3,881 & See above. \\
\hline & & & & & $\begin{array}{l}\text { Graduation } \\
\text { within } 6 \\
\text { years }\end{array}$ & $\begin{array}{l}\text { Unstandardized } \\
\text { regression } \\
\text { coefficient }\end{array}$ & 3,628 & 3,289 & See above. \\
\hline \multirow[t]{2}{*}{ Chi \& Down } & 2014 & Canada & University & $\begin{array}{l}\text { RDD with } \\
\text { matched } \\
\text { data }\end{array}$ & Retention & $\begin{array}{l}\text { Unstandardized } \\
\text { regression } \\
\text { coefficient }\end{array}$ & 2,538 & 3,969 & $\begin{array}{c}\text { Assume .39/.61 split. Based on summary } \\
\text { statistics. }\end{array}$ \\
\hline & & & & & $\begin{array}{l}\text { Graduation } \\
\text { within the } \\
\text { nominal } \\
\text { study time }\end{array}$ & $\begin{array}{l}\text { Unstandardized } \\
\text { regression } \\
\text { coefficient }\end{array}$ & 1,860 & 2,909 & See above. \\
\hline
\end{tabular}




\begin{tabular}{|c|c|c|c|c|c|c|c|c|c|}
\hline & & & & & $\begin{array}{l}\text { Graduation } \\
\text { within } 6 \\
\text { years }\end{array}$ & $\begin{array}{l}\text { Unstandardized } \\
\text { regression } \\
\text { coefficient }\end{array}$ & 1,288 & 2,015 & See above. \\
\hline Eijsvogels et al. & 2015 & NL & University & $\begin{array}{c}\text { Cohort } \\
\text { analysis }\end{array}$ & Retention & $\begin{array}{c}\text { Frequencies } \\
\text { [PROBIT] }\end{array}$ & $835 / 151$ & $607 / 48$ & \\
\hline \multirow[t]{3}{*}{ Fack \& Grenet } & 2015 & FR & University & RDD & Enrollment & $\begin{array}{l}\text { Unstandardized } \\
\text { regression } \\
\text { coefficient }\end{array}$ & 11,527 & 4,940 & $\begin{array}{l}\text { Assume } .70 / .30 \text { split. Based on summary } \\
\text { statistics. The unstandardized regression } \\
\text { coefficient is recalculated in order to show } \\
\text { the effect of a grant of } € 1000 \text {. }\end{array}$ \\
\hline & & & & & Retention & $\begin{array}{l}\text { Unstandardized } \\
\text { regression } \\
\text { coefficient }\end{array}$ & 10,487 & 4,495 & See above. \\
\hline & & & & & Graduation & $\begin{array}{l}\text { Unstandardized } \\
\text { regression } \\
\text { coefficient }\end{array}$ & 7,666 & 3,285 & See above. \\
\hline $\begin{array}{l}\text { Fletcher \& } \\
\text { Tokmouline }\end{array}$ & 2010 & VS & University & RDD & Retention & $\begin{array}{l}\text { Unstandardized } \\
\text { regression } \\
\text { coefficient }\end{array}$ & $\begin{array}{c}\text { University } \\
\text { A: 5,182 } \\
\text { University } \\
\text { B:6,317 } \\
\text { University } \\
\text { C: 2,089 } \\
\text { University } \\
\text { D: } 3,621\end{array}$ & $\begin{array}{c}\text { University } \\
\text { A: } 11,533 \\
\text { University } \\
\text { B: } 15,025 \\
\text { University } \\
\text { C: } 5,648 \\
\text { University } \\
\text { D: } 4,780\end{array}$ & $\begin{array}{l}\text { Split of } \\
\text { University A: .31/.69 } \\
\text { University B: .29/.71 } \\
\text { University C: .27/.73 } \\
\text { University D: .43/.57 }\end{array}$ \\
\hline
\end{tabular}




\begin{tabular}{|c|c|c|c|c|c|c|c|c|c|}
\hline & & & & & $\begin{array}{l}\text { Graduation } \\
\text { within the } \\
\text { nominal } \\
\text { study time }\end{array}$ & $\begin{array}{l}\text { Unstandardized } \\
\text { regression } \\
\text { coefficient }\end{array}$ & $\begin{array}{l}\text { University } \\
\text { A: 4,315 } \\
\text { University } \\
\text { B: 6,135 } \\
\text { University } \\
\text { C: } 1,470 \\
\text { University } \\
\text { D: } 2,377\end{array}$ & $\begin{array}{c}\text { University } \\
\text { A: } 9,604 \\
\\
\text { University } \\
\text { B: } 15,021 \\
\text { University } \\
\text { C: } 3,676 \\
\text { University } \\
\text { D: 3,150 }\end{array}$ & See above. \\
\hline & & & & & $\begin{array}{c}\text { Graduation } \\
\text { within } 6 \\
\text { years }\end{array}$ & $\begin{array}{l}\text { Unstandardized } \\
\text { regression } \\
\text { coefficient }\end{array}$ & $\begin{array}{c}\text { University } \\
\text { A: } 3,610 \\
\text { University } \\
\text { B: } \\
5,126 \\
\text { University } \\
\text { C: } 1,128 \\
\text { University } \\
\text { D: } 1,842\end{array}$ & $\begin{array}{c}\text { University } \\
\text { A: } 8,034 \\
\text { University } \\
\text { B: } \\
\text { 12,533 } \\
\text { University } \\
\text { C: } 3,049 \\
\text { University } \\
\text { D: } 2,442\end{array}$ & See above. \\
\hline \multirow[t]{2}{*}{$\begin{array}{l}\text { Goldrick-Rab et } \\
\text { al. }\end{array}$} & 2012 & VS & University & RCT & Enrollment & $\begin{array}{c}\text { Frequencies } \\
\text { [PROBIT] }\end{array}$ & $590 / 10$ & $880 / 20$ & $\begin{array}{l}\text { The effect size is recalculated in order to } \\
\text { show the effect of a grant of } € 1000 \text {. }\end{array}$ \\
\hline & & & & & Retention & $\begin{array}{c}\text { Frequencies } \\
\text { [PROBIT] }\end{array}$ & $526 / 74$ & $778 / 122$ & See above. \\
\hline
\end{tabular}




\begin{tabular}{|c|c|c|c|c|c|c|c|c|c|}
\hline Kot & 2014 & VS & University & Matching & retention & Odds Ratio & 1,238 & 1,143 & \\
\hline Hoffer & 2010 & VS & University & RCT & Retention & T-test & 76 & 73 & \\
\hline & & & & & $\begin{array}{l}\text { Graduation } \\
\text { within the } \\
\text { nominal } \\
\text { study time }\end{array}$ & $\begin{array}{l}\text { Unstandardized } \\
\text { regression } \\
\text { coefficient }\end{array}$ & 3,087 & 5,734 & See above. \\
\hline & & & & & $\begin{array}{l}\text { Graduation } \\
\text { within } 6 \\
\text { years }\end{array}$ & $\begin{array}{l}\text { Unstandardized } \\
\text { regression } \\
\text { coefficient }\end{array}$ & 2,102 & 3,903 & See above. \\
\hline Nielsen et al. & 2008 & $\mathrm{DE}$ & $\begin{array}{c}\text { College and } \\
\text { University }\end{array}$ & DiD & Enrollment & $\begin{array}{l}\text { Unstandardized } \\
\text { regression } \\
\text { coefficient }\end{array}$ & 40,173 & 41,408 & $\begin{array}{l}\text { The unstandardized regression coefficient is } \\
\text { recalculated in order to show the effect of a } \\
\text { grant of } € 1000\end{array}$ \\
\hline Scheepers & 2004 & NL & University & $\begin{array}{c}\text { Cohort } \\
\text { Analysis }\end{array}$ & Retention & $\begin{array}{c}\text { Frequencies } \\
\text { [PROBIT] }\end{array}$ & $1,542 / 758$ & $1,261 / 368$ & \\
\hline $\begin{array}{l}\text { Scheepers \& } \\
\text { Duijndam }\end{array}$ & 2009 & NL & University & $\begin{array}{l}\text { Cohort } \\
\text { Analysis }\end{array}$ & Retention & $\begin{array}{c}\text { Frequencies } \\
\text { [PROBIT] }\end{array}$ & $\begin{array}{c}6,324 / 3,25 \\
8\end{array}$ & $\begin{array}{c}7,854 / 2,34 \\
6\end{array}$ & \\
\hline Seftor \& Turner & 2002 & VS & College & DiD & Enrollment & $\begin{array}{l}\text { Unstandardized } \\
\text { regression } \\
\text { coefficient }\end{array}$ & 57,911 & 51,901 & $\begin{array}{l}\text { Average effect of two subsamples. The } \\
\text { unstandardized regression coefficient is } \\
\text { recalculated in order to show the effect of a } \\
\text { grant of } € 1000\end{array}$ \\
\hline Swanson & 2006 & VS & University & RCT & Retention & $\begin{array}{c}\text { Chi-Square } 3 \times 2 \\
\text { design }\end{array}$ & $46 / 5$ & $47 / 17$ & \\
\hline Visher et al. & 2011 & VS & University & RCT & Retention & Proportions & 1,067 & 1,098 & \\
\hline
\end{tabular}


Appendix B

\section{Appendix B}

Table: Calculations of the costs and benefits

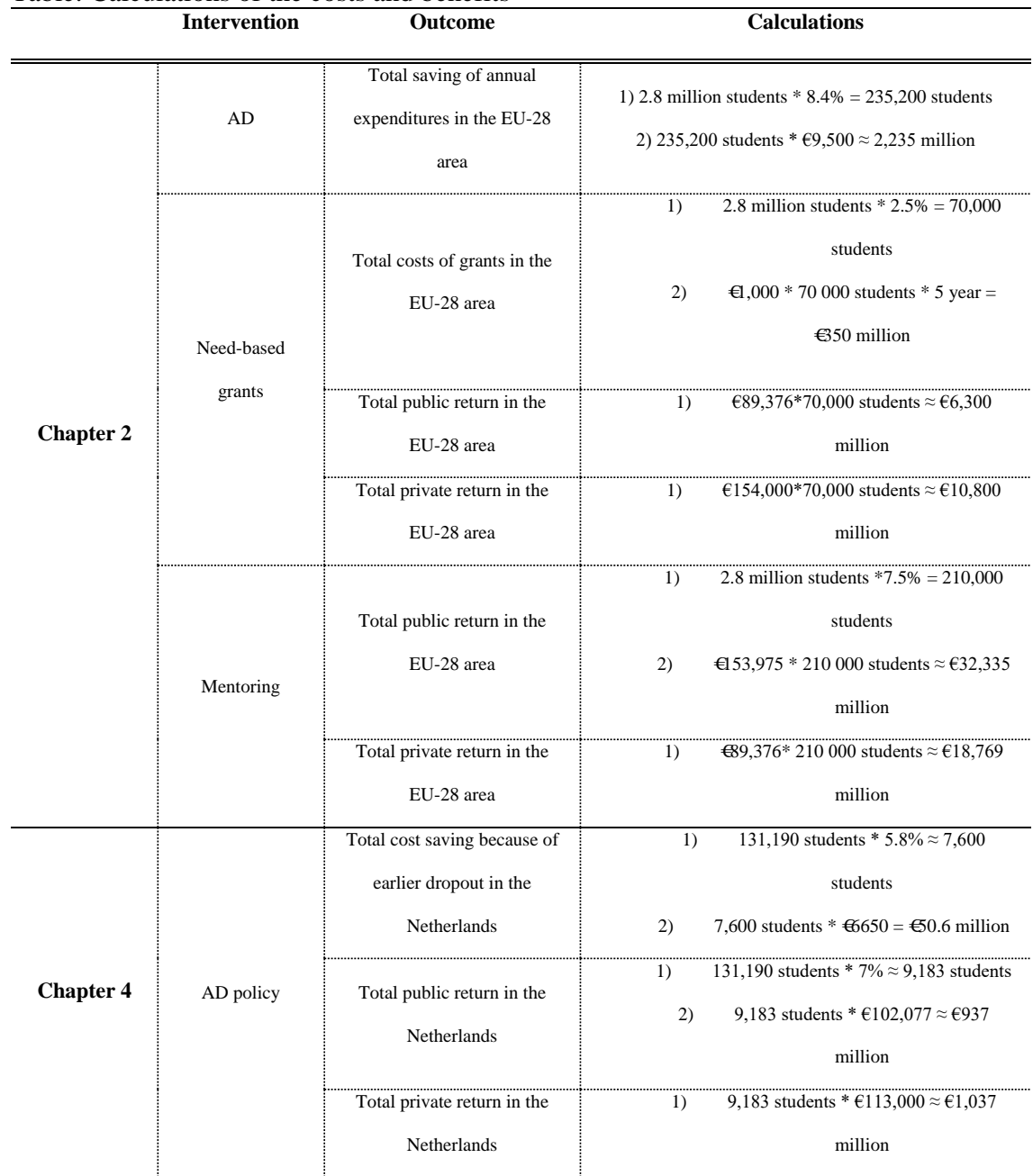


Appendix B

Chapter 5

Need-based

grants
Total public return in the

four investigated Italian

universities

Total private return in the

four investigated Italian

universities
1) $€ 113,000 * 355$ students $=€ 40.115$

million

1)

$€ 111,000 * 355$ students $=€ 39.405$

million 


\section{Appendix C}

Table: The inclusion of the different costs and benefits in the calculation of the return of a Bachelor degree in comparison to a upper secondary or a post-secondary non-tertiary degree. This is represented for private and public return

\begin{tabular}{|c|c|c|}
\hline & Total costs & Total benefits \\
\hline Public & $\begin{array}{l}\text { Direct costs } \\
\text { Expenditures per student taking into account } \\
\text { the duration of studies } \\
\text { Foregone taxes on earnings } \\
\text { Lost tax recipients during the years of } \\
\text { schooling } \\
\text { Grant effect } \\
\text { Public subsidies to households for } \\
\text { scholarships and already existing grants } \\
\text { during years of schooling }\end{array}$ & $\begin{array}{l}\text { Income tax effect } \\
\text { Additional tax revenues associated with } \\
\text { higher earnings } \\
\text { Social contribution effect } \\
\text { Additional social contributions associated } \\
\text { with higher earnings } \\
\text { Transfer effect } \\
\text { Social transfers (e.g. housing benefits) that do } \\
\text { not have to be paid because of higher earnings } \\
\text { Unemployment effect } \\
\text { Unemployment compensations that do not } \\
\text { have to be paid because of higher earnings }\end{array}$ \\
\hline Private & $\begin{array}{l}\text { Direct costs } \\
\text { Tuition fees during the duration of studies } \\
\text { Foregone earnings } \\
\text { Lost earning during the years of schooling } \\
\text { Income tax effect } \\
\text { Additional taxes that have to be paid because } \\
\text { of higher earnings } \\
\text { Social contribution effect } \\
\text { Additional social contributions that have to } \\
\text { be paid because of higher earnings }\end{array}$ & $\begin{array}{l}\text { Gross earnings benefits } \\
\text { Higher earnings associated with a Bachelor } \\
\text { degree } \\
\frac{\text { Unemployment effect }}{\text { probability of }} \\
\text { finding work, expressed in monetary terms } \\
\text { Grant effects } \\
\text { Public subsidies to households for } \\
\text { scholarships and already existing grants } \\
\text { during years of schooling }\end{array}$ \\
\hline
\end{tabular}


Appendix C

\begin{tabular}{|c|c|c|}
\hline & Transfer effect & \\
Social transfers (e.g. housing benefits) that & \\
are not received because of higher earnings & \\
& & \\
\hline
\end{tabular}




\section{Summary}

Higher education provides benefits for governments, students and society. Students benefit from entering and graduating from higher education by means of more job opportunities, higher wages, and better health. Governments and society at large benefit because a flexible and highly educated workforce helps to maintain economic growth. The European Commission acknowledges that student success has become important for many stakeholders, and has targeted student success as an important aspect of the European 2020 strategy. This strategy aims at delivering smart, inclusive, and sustainable growth. The EU Member States have agreed to reach a tertiary education attainment of $40 \%$ of the $30-34$ year olds by 2020. To reach this goal, the European Commission proposes three types of measures to increase attainment levels: (I) remove financial barriers to broaden participation; (II) improve guidance and counseling and help students choose an appropriate course; and (III) develop skills profiles relevant to the world of work.

Student success is a complex concept and is related to students' academic achievement and psychological experience. It can be measured by quantifiable student attainment indicators such as the enrolment rate, course credits obtained, time to degree, and graduation. Students' impressions of institutional quality, their willingness to attend the institution again, and their overall satisfaction with the institution are all precursors of the psychological dimension of student success. Other measurable indicators of success in higher education are employment opportunities and income. The interventions proposed by 
Summary

the European Commission are fairly general, and it is unclear how the EU Member States can implement them in practice. While there has been some research concerning these interventions, cultural differences can cause effects to differ between countries. Furthermore, the effect of the initiatives on the social dimension of student success is a neglected area.

This dissertation contributes to the existing research by investigating the impact of different interventions on student success. With the use of a meta-analysis, the overall effect of need-based grants, student-faculty mentoring, and academic dismissal policies are made clear. In line with the recommendations of the European Commission, we evaluate these three interventions. In particular, we examine the efficiency of higher education programs by their dropout and graduation rate, and student's quality ratings of programs. Moreover, we assess the impact of academic dismissal policies and mergers on student success in the Netherlands. We also look at the influence of need-based grants on student success in Italy.

\section{Answers to the research questions}

We formulate six research questions: (I) What is the effect of an academic dismissal policy, need-based grants, and student-faculty mentoring on student enrolment, dropout, and student graduation?; (II) Do study programs maximize their student graduation rates and quality ratings conditional on the first-year student dropout rates?; (III) What institutional and program characteristics explain the relative efficiency of study programs?; (IV) Does the introduction of an academic dismissal (AD) policy result in lower dropout levels, higher graduation rates and, lower student satisfaction?; (V) Is there a heterogeneous influence of need-based grants on the number of formative credits, dropout, and graduation between and within universities?; and (VI) Do mergers occur between diversified or comparable higher education institutions, does distance between these institutions play a role, and what is their influence on student dropout and student graduation? We summarize the results to provide answers to these research questions. 
(I) What is the effect of an academic dismissal policy, need-based grants, and student-faculty mentoring on student enrolment, dropout, and student graduation?

In Chapter 2, we apply a meta-analysis to investigate the effect of an academic dismissal (AD) policy, need-based grants, and student-faculty mentoring on student success. It becomes clear that two of these three interventions have a positive and statistically significant effect on student success. In particular, student-faculty mentoring has a positive and statistically significant effect on both retention and graduation. Needbased grants have a positive significant effect on enrolment, retention, and graduation. An AD policy, on the other hand, has a negative and statistically significant effect on student retention, and does not have an effect on student graduation.

(II) Do study programs maximize their student graduation rates and quality ratings conditional on the first-year student dropout rates?

The efficiency analysis in Chapter 3 indicates that study programs at universities in the Netherlands can increase their quality-adjusted graduation rates by approximately $37 \%$ if they operate as well as the best practices (i.e. those academic programs that obtain the highest student graduation rates and quality ratings for a given student dropout). There is, however, a significant variation in performance across academic programs. Once we control for various study program and institutional characteristics, the average study program can increase its quality-adjusted graduation rate by only .20\% for a given dropout level. Thus, the average academic program in the Netherlands performs rather well compared with the best performing programs. There are, however, large differences between the worstperforming programs and the best-performing programs. This indicates that not all 
Summary

academic programs are able to deal effectively with the first-year dropout in order to increase program quality and graduation.

(III)

\section{What institutional and program characteristics explain the relative efficiency of study programs?}

The efficiency analysis from Chapter 3 shows that study programs at universities in the Netherlands can improve the interaction between student dropout, student graduation and quality ratings by focusing on a number of student and program characteristics. Institutional characteristics, on the other hand, have a limited impact on the relationship between dropout, graduation and program quality ratings. We observe the following study program characteristics at universities in the Netherlands that contribute to higher graduation rates and high quality ratings: (i) high student program satisfaction; (ii) a high percentage of first-year female students; (iii) a low percentage of first-year ethnic minority students; (iv) the presence of an academic dismissal policy; and (v) a high percentage of faculty older than 50 . We also find that student success and program quality (for given dropout rates) differ between subjects (e.g. ICT, mathematics, economics).

(IV) Does the introduction of an academic dismissal (AD) policy result in lower dropout levels, higher graduation rates, higher program feasibility and, lower student satisfaction?

In Chapter 4 we come to the conclusion that the introduction of an $\mathrm{AD}$ policy results in higher dropout levels. Due to an AD policy, student dropout increases by 5.8\%. However, graduation rates significantly increases by $7 \%$ and program feasibility by .33 of a point (on a 10-point scale). The implementation of an AD policy has a small but significant negative influence on overall student satisfaction (i.e. -.35 of a point on a 10-point scale) and average NSE score (i.e. .26 of a point on a 10-point scale). 

universities?

We conclude in Chapter 5 that the effect of need-based grants is fairly homogeneous between universities in Italy, and that the impact of the Italian need-based grants is positive and relatively large for all performance indicators. For three of the five Italian universities we find a positive significant effect on the number of credits and student retention. For the other two a statistically insignificant effect is found. Considering in-time graduation and graduation by the end of the fourth year, we observe a positive and significant effect of the need-based grants for all Italian universities, except for one university where we find a positive but insignificant effect.

The effects of Italian need-based grants on sub-populations of students vary more within universities than across them. Although, in most cases, the direction of the baseline results is maintained, we observe different significance levels depending on the investigated subpopulation within each institution. We find a general positive effect for immigrant students, and a stronger effect of aid on students who decide to move from their home town for studying. The effect of aid in Italian universities also varies with the department.

(VI) Do mergers occur between diversified or comparable higher education institutions, does distance between these institutions play a role, and what is their influence on student dropout and student graduation?

In Chapter 6 it is shown that mergers between higher vocational institutions in the Netherlands differ depending on the type of partners and the distance between them. Specialized campuses merge with a diversified partner, but distance does not play a significant role. We suspect that these campuses aim for scale optimization by extending 
Summary

their areas of expertise. Medium-sized campuses, on the other hand, merge with campuses which are located close by. The degree of differentiation does not play a role. These campuses may strive for cost efficiencies by eliminating duplicate resources. Scale optimization by extending their fields of study or removing duplicate study programs is also an option, and depends on the type of merging partner. Comprehensive campuses merge with complementary partners which are located close by. These mergers may lead to scale optimization by covering larger areas of knowledge, and to cost efficiencies by removing duplicate resources.

Furthermore, we find that mergers between vocational institutions in the Netherlands during 2002-09 had an effect on student outcomes. We observe that mergers have a significant negative influence on student dropout. Students of merged campuses have a lower dropout rate. However, the positive results are not maintained in the long run, as the graduation rates are not affected by mergers. 


\section{Samenvatting}

Hoger onderwijs biedt voordelen voor overheden, studenten en de maatschappij in het algemeen. Een tertiair diploma leidt voor studenten tot, bijvoorbeeld, meer banen en hogere lonen. Regeringen en belastingbetalers hebben baat bij flexibele en hoogopgeleide arbeidskrachten om de economische groei te behouden. Ook hier leidt hoger onderwijs toe. Studentensucces is dus van belang voor verschillende partijen. De Europese Commissie erkent dit en heeft studentensucces vooropgesteld als een belangrijk onderdeel van de Europese 2020-strategie. Deze strategie is gericht op het leveren van slimme, inclusieve en duurzame groei. Meer bepaald dient $40 \%$ van de $30-34$ jarigen in de EU-lidstaten een diploma hoger onderwijs te hebben behaald tegen 2020. Om dit doel te bereiken, stelt de Europese Commissie drie soorten maatregelen voor: (I) het wegnemen van de financiële belemmeringen om zo deelname aan het hoger onderwijs te stimuleren; (II) de verbetering van studentenbegeleiding en het helpen van studenten bij het kiezen van een studierichting; en (III) de ontwikkeling van vaardigheidsprofielen die relevant zijn voor het werkveld.

Studentensucces is een complex concept en is gerelateerd aan de academische prestatie en psychologische ervaring van studenten. Het kan worden gemeten aan de hand van kwantificeerbare studentindicatoren zoals inschrijvingspercentages, studiepunten, studiejaren, en afstudeerpercentages. De impressie van studenten betreffende de kwaliteit van de instelling, hun bereidheid om zich opnieuw in te schrijven in de instelling, en de algemene tevredenheid met de instelling zijn allen kenmerken van de psychologische 
Samenvatting

dimensie van studentensucces. Andere meetbare indicatoren van succes in hoger onderwijs zijn tewerkstellingskansen en inkomen.

De interventies voorgesteld door de Europese Commissie zijn vrij algemeen, en het is onduidelijk hoe de EU-lidstaten ze kunnen toepassen in de praktijk. Hoewel er reeds onderzoek is betreffende bepaalde interventies, kunnen culturele verschillen leiden tot verschil in effect tussen landen. Bovendien is het effect van de initiatieven op de sociale dimensie van studentensucces ongekend. Dit proefschrift draagt bij aan het bestaande onderzoek door het onderzoeken van het effect van verschillende interventies op studentensucces. Met behulp van een meta-analyse wordt het algemene effect van behoeften gebaseerde subsidies, student-faculteit begeleiding en bindend studieadvies duidelijk. De evaluatie van deze drie interventies zijn in overeenstemming met de aanbevelingen van de Europese Commissie. De efficiëntie van het hoger onderwijs betreffende uitval, rendement en kwaliteitsoordelen wordt onderzocht in Nederland. Alsook het effect van bindend studieadvies en het effect van fusies op studentensucces in Nederland. Hiernaast kijken we naar de invloed van behoeften gebaseerde subsidies op studentensucces in Italië.

\section{Antwoorden op de onderzoeksvragen}

We hebben zes onderzoeksvragen in de algemene introductie geformuleerd: (I) Wat is het effect van bindend studieadvies, behoeften gebaseerde subsidies, en student-faculteit mentoring op de deelname aan het hoger onderwijs, uitval en rendement?; (II) Maximaliseren studieprogramma's hun rendement en kwaliteitsoordelen gegeven de eerstejaarsuitval?; (III) Welke institutionele en programma kenmerken bepalen deze relatieve efficiëntie?; (IV) Leidt de introductie van een bindend studieadvies tot minder uitval, een hoger rendement, een hogere haalbaarheid van het studieprogramma en een lagere studententevredenheid?; (V) Is er een heterogene invloed van behoeften gebaseerde subsidies op het aantal studiepunten, uitval en rendement binnen en tussen universiteiten?; 
en (VI) Komen fusies voor tussen gedifferentieerde of soortgelijke hoger onderwijsinstellingen, speelt afstand tussen de instellingen een rol en wat is de invloed op uitval en rendement? We vatten de resultaten samen om zo een antwoord te bieden op elke onderzoeksvraag.

(I) Wat is het effect van bindend studieadvies, behoeften gebaseerde subsidies, en student-faculteit mentoring op de deelname aan het hoger onderwijs, uitval en rendement?

In Hoofdstuk 2 hebben we gebruik gemaakt van een meta-analyse om het effect van bindend studieadvies, behoeften-gebaseerde subsidies en student-faculteit mentoring op studentensucces te onderzoeken. Het is duidelijk geworden dat twee van deze interventies een positief en significant effect hebben op studentensucces. Student-faculteit mentoring heeft meer bepaald een positief en statistisch significant effect op zowel het behoud van studenten als op het rendement. Behoeften gebaseerde subsidies hebben een positief significant effect op de inschrijving, het behoud en het afstuderen van studenten. Bindend studieadvies, aan de andere kant, heeft een negatief significant effect op studentenbehoud, en geen effect op rendement.

(II) Maximaliseren studieprogramma's hun rendement en kwaliteitsoordelen gegeven de eerstejaarsuitval?

De efficiëntie analyse in Hoofdstuk 3 geeft aan dat universitaire studieprogramma’s in Nederland hun rendement en kwaliteitsoordelen met ongeveer $37 \%$ kunnen verhogen wanneer ze op het niveau van de best presterende studieprogramma’s zouden werken. De resultaten geven ook aan dat er een grote variatie is betreffende de prestaties van studieprogramma's. Eenmaal we controleren voor covariaten kan het gemiddelde studieprogramma het rendement en de kwaliteitsoordelen slechts met $.20 \%$ verhoogt worden gegeven de uitval. We kunnen besluiten dat het gemiddelde studieprogramma in 
Samenvatting

Nederland goed presteert in vergelijking met de best presterende programma's. Er zijn echter wel grote verschillen tussen de best presenterende en de slechts presterende programma's. Dit geeft aan dat niet alle studieprogramma's in staat zijn om op een efficiënte manier om te gaan met uitval.

(III) Welke institutionele en programma kenmerken bepalen deze relatieve efficiëntie?

De efficiëntie analyse van Hoofdstuk 3 toont aan dat universitaire studieprogramma’s in Nederland de interactie tussen uitval, rendement en kwaliteitsoordelen kunnen verhogen door te focussen op een aantal kenmerken van het studieprogramma. Institutionele eigenschappen hebben slechts een beperkte impact op bovengenoemde relatie. We observeren dat de volgende karakteristieken bijdragen aan een hoger rendement en hogere kwaliteitsoordelen in universitaire studieprogramma's: (I) een hoge studententevredenheid, (II) een hoog percentage van vrouwelijke eerstejaars, (III) een laag percentage van allochtone eerstejaars, (IV) de aanwezigheid van een bindend studieadvies, en (V) een hoog percentage van personeel ouder dan 50. We vinden ook dat de richting van de studieprogramma’s een rol speelt (bv. IT, wiskunde en economie).

(IV) Leidt de introductie van een bindend studieadvies tot minder uitval, een hoger rendement, een hogere haalbaarheid van het studieprogramma en een lagere studententevredenheid?

We zijn in Hoofdstuk 4 tot de conclusie gekomen dat de introductie van een bindend studieadvies leidt tot een stijging van de uitval met 5,8\%. Tegelijk neemt het rendement toe met $7 \%$ en de haalbaarheid van het studieprogramma met ,33 van een punt (op een tienpuntenschaal). De introductie van een bindend studieadvies zorgt ook voor een kleine maar significant negatieve invloed op de algemene tevredenheid (nl. -,35 van een punt op 
een tienpuntenschaal) en de gemiddelde NSE score (nl. -,26 van een punt op een tienpuntenschaal).

(V) Is er een heterogene invloed van behoeften gebaseerde subsidies op het aantal studiepunten, uitval en rendement binnen en tussen universiteiten?

In Hoofstuk 5 zijn we tot het besluit gekomen dat het effect van behoeften gebaseerde subsidies vrij homogeen is tussen universiteiten in Italië. De impact van deze subsidies is positief en relatief groot voor alle prestatie indicatoren. Drie van de vijf Italiaanse universiteiten vinden een positief significant effect op het aantal verworven studiepunten en op studentenbehoud. Voor de andere twee indicatoren is een insignificant effect gevonden. We observeren een significant positief effect van behoeften gebaseerde subsidies op afstuderen binnen de nominale tijd en afstuderen tegen het einde van het vierde inschrijvingsjaar. Bij één universiteit vinden we een positief maar insignificant effect.

De invloed van behoeften gebaseerde subsidies op subpopulaties van studenten varieert meer binnen Italiaanse universiteiten dan tussen hen. Hoewel de richting van de effecten meestal gelijk blijft, observeren we verschillende significantielevels afhankelijk van de onderzochte subpopulatie. We vinden een algemeen positief effect voor allochtone studenten en voor studenten die verhuizen voor hun studies. Het effect van financiële hulp varieert bovendien per departement.

(VI) Komen fusies voor tussen gedifferentieerde of vergelijkbare hoger onderwijsinstellingen, speelt afstand tussen de instellingen een rol en wat is de invloed op uitval en rendement?

Hoofdstuk 6 toont dat fusies tussen Nederlandse hogescholen verschilt afhankelijk van het type partner en de afstand tussen hen. Gespecialiseerde campussen fusioneren met een gedifferentieerde partner en afstand speelt een significant rol. We vermoeden dat deze campussen mikken op schaalvoordelen door het uitbreiden van hun expertisegebieden. 
Samenvatting

Algemene campussen fusioneren met dichtbijgelegen campussen. Differentiatie speelt hier geen rol. Deze campussen streven mogelijk naar kostefficiënties via de eliminatie van overlappende diensten. Schaalvoordelen door het uitbreiden van studierichtingen of de verwijdering van overlappende studierichtingen is ook een optie. Brede campussen fusioneren met vergelijkbare en nabijgelegen partners. Deze fusies leiden mogelijk tot schaalvoordelen door een uitgebreid kennisgebied en tot kostefficiënties door de eliminatie van overlappende diensten.

Hiernaast zijn we tot de conclusie gekomen dat de fusie van hogescholen in Nederland tussen 2002 en 2009 heeft geleid tot een effect op studentenuitkomsten. We observeren dat fusies een significant negatief effect hebben op uitval. Studenten van gefusioneerde campussen hebben dus een lagere kans op uitval. De fusies leiden echter niet tot effecten op rendement waardoor de resultaten niet worden behouden op lange termijn. 


\section{Biography}

Eline Sneyers was born in Sint-Truiden, Belgium, on March 29, 1989. She completed a B.A. and a M.Sc. in business economics at the KU Leuven between 2007 and 2011. She graduated from the Specific Teacher Training in Economics at the KU Leuven in July 2012.

In September 2012, Eline joined the Top Institute for Evidence Based Education Research at Maastricht University as a PhD candidate. During her doctoral studies, she has been a visiting $\mathrm{PhD}$ student at the Politechnic institute of Milano, Italy. Her work has been published in international peer-reviewed journals as 'Studies in Higher Education', 'Educational Review’ and the 'Journal of Operational Research Society’.

Eline has presented parts of this dissertation at various international conferences and workshops, including the Annual Conference of the European Association of Labour Economists (2014, 2016), the European Economic Association Annual Congress (2014) and the Workshop on Education Economic (2015, 2016).

As of November 2016, Eline works as a lecturer at the PXL University College. She teaches economic courses and supervises students with their Bachelor thesis. 


\section{Top Institute for Evidence Based Education Research (TIER)}

The Top Institute for Evidence Based Education Research (TIER) is an inter-university institute that conducts research to develop evidence based education. The institute has three partners: the University of Amsterdam, Maastricht University and the University of Groningen and is located in Amsterdam, Maastricht and Groningen.

TIER contributes to the improvement of the quality of education in the Netherlands by promoting an evidence based approach as a guiding principle in education policy and practice. It accomplishes this by developing (cost) effective education interventions that are grounded in sound scientific research. TIER research is funded by the Ministry of Education, Culture and Science and the participating universities through the NWO and complies with the quality standards and evaluation procedures used by NWO.

The following books recently appeared in the TIER Research Series:

I. C. Haelermans (2012), On the productivity and efficiency of education. The role of innovations in Dutch secondary education

II. L. van Welie (2013), They Will Get There! Studies on Educational Performance of Immigrant Youth in the Netherlands

III. S. Cabus (2013), An Economic Perspective on School Dropout Prevention using Microeconometric Techniques

IV. I.Cornelisz (2013), School Choice, Competition and Achievement: Dutch Compulsory Education

V. M. Heers (2014), The Effectiveness of Community School: Evidence from the Netherlands

VI. N. Ruijs (2014) Empirical Studies in the Economics of education

VII. D. Bartelet (2015), Basic Mathematics Skills Development in Children: An Evaluative Study on Cognitive and educational factors 
VIII. I.Rud (2015), The Relationship between Youth Crime and Education

IX J. Coenen (2016) Teacher Characteristics and Student Performance

X D. Hidalgo Saá (2017) Essays in Economics of Education and Training

XI E. Sneyers (2017) What works to improve student success: The effects of academic dismissal policies, student grants and institutional mergers on student outcomes 